tstclark
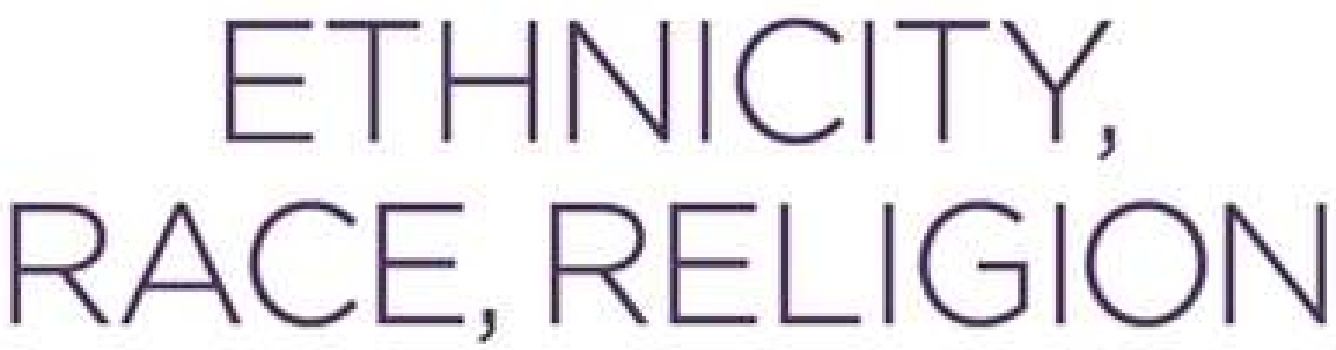

Identities and Ideologies in Early Jewish and Christian Texts, and in Modern Biblical Interpretation 

Ethnicity, Race, Religion 



\title{
Ethnicity, Race, Religion
}

\author{
Identities and Ideologies in Early \\ Jewish and Christian Texts, and in \\ Modern Biblical Interpretation
}

Edited by
Katherine M. Hockey and David G. Horrell 
T\&T CLARK

Bloomsbury Publishing Plc

50 Bedford Square, London, WC1B 3DP, UK

1385 Broadway, New York, NY 10018, USA

T\&T CLARK and the T\&T Clark logo are trademarks of Bloomsbury Publishing Plc

First published in Great Britain 2018

This paperback edition first published 2020

Copyright @ Katherine M. Hockey and David G. Horrell, 2018

Katherine M. Hockey and David G. Horrell have asserted their right under the Copyright, Designs and Patents Act, 1988, to be identified as Editors of this work.

\section{Cover image () urbancow/iStock}

All rights reserved. No part of this publication may be reproduced or transmitted in any form or by any means, electronic or mechanical, including photocopying, recording, or any information storage or retrieval system, without prior permission in writing from the publishers.

A catalogue record for this book is available from the British Library.

A catalog record for this book is available from the Library of Congress.

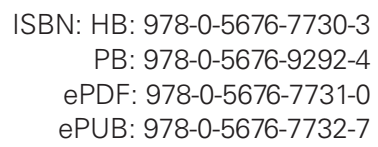

Typeset by Deanta Global Publishing Services, Chennai, India

To find out more about our authors and books visit www.bloomsbury.com and sign up for our newsletters. 


\section{Contents}

Contributors vii

Preface viii

Abbreviations $\quad x$

Introduction David G. Horrell 1

Part 1 Ethnicity, Religion, and Identity in Antiquity: Jews and Christians in the Hellenic World $\quad 21$

1 Society, Identity, and Ethnicity in the Hellenic World Teresa Morgan 23

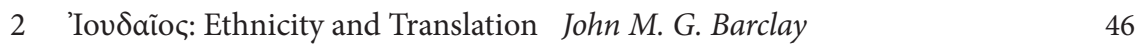

3 Identity Games in Early Christian Texts: The Letter to Diognetus

Judith M. Lieu

Part 2 Ethnicity, Race, and Religion in European Traditions of Biblical Scholarship

4 S. R. Driver and Higher Criticism: Mapping 'The Differences of Race' in Genesis Gregory L. Cuéllar 75

5 What's in a Name?: Ideologies of Volk, Rasse, and Reich in German New Testament Interpretation Past and Present Kathy Ehrensperger 92

6 From Ernest Renan to Anders Behring Breivik: Continuities in Racial Stereotypes of Muslims and Jews Halvor Moxnes 113

7 Other Problems from a British Perspective: 'Jewishness', Jesus, and the New Perspective on Paul James G. Crossley

Part 3 Challenging White, Western Traditions of Interpretation: Critique and Alternatives

8 Anachronistic Whiteness and the Ethics of Interpretation

Denise Kimber Buell 
9 The Bible in the Bush: The First 'Literate' Batswana Bible Readers Musa W. Dube

10 Exploring the (In)Visibility of the Christ-believers' 'Trans-ethnicity':

A Lowland Filipina Catholic's Perspective Ma. Marilou S. Ibita

11 Double Vision for Revolutionary Religion: Race Relations, Moral

Analogies, and African-American Biblical Interpretation Love L. Sechrest

12 Re-examining the Master's Tools: Considerations on Biblical Studies'

Race Problem Wei Hsien Wan

Index of Ancient Sources

Index of Subjects 


\section{Contributors}

John M. G. Barclay (PhD, University of Cambridge) is Lightfoot Professor of Divinity at Durham University, UK.

Denise Kimber Buell (PhD, Harvard University) is Cluett Professor of Religion at Williams College, United States.

James G. Crossley (PhD, University of Nottingham) is Professor of Bible, Society, and Politics at St Mary's University, Twickenham, London, UK.

Gregory L. Cuéllar (PhD, Brite Divinity School) is Associate Professor of Old Testament at Austin Presbyterian Theological Seminary, United States.

Musa W. Dube (PhD, Vanderbilt University) is Professor of New Testament at the University of Botswana, Botswana.

Kathy Ehrensperger ( $\mathrm{PhD}$, University of Wales) is Research Professor of New Testament in Jewish Perspective at Abraham Geiger College, University of Potsdam, Germany.

David G. Horrell ( $\mathrm{PhD}$, University of Cambridge) is Professor of New Testament Studies and Director of the Centre for Biblical Studies at the University of Exeter, UK.

Ma. Marilou S. Ibita (PhD, Katholieke Universiteit Leuven) is Postdoctoral Researcher at the Faculty of Theology and Religious Studies, Katholieke Universiteit Leuven, Belgium.

Judith M. Lieu (PhD, University of Birmingham) is Lady Margaret's Professor of Divinity at the University of Cambridge, and Fellow of Robinson College, Cambridge, UK, and a Fellow of the British Academy.

Teresa Morgan (PhD, University of Cambridge) is Professor of Graeco-Roman History at Oxford University and Fellow and Tutor in Ancient History at Oriel College, Oxford, UK.

Halvor Moxnes (Dr theol., University of Oslo) is Professor Emeritus in the Faculty of Theology at the University of Oslo, Norway.

Love L. Sechrest (PhD, Duke University) is Associate Professor of New Testament at Fuller Theological Seminary, California, United States.

Wei Hsien Wan (PhD, University of Exeter) is an independent scholar who resides in Klang, Malaysia. 


\section{Preface}

It is not difficult to make the case that issues concerning ethnicity, race, and religion - and the points at which they intersect and overlap - are hugely important in the contemporary world and are directly implicated in some of the most difficult challenges to humanity's peaceful coexistence. One need not listen to the news for long before hearing reports in which these dimensions of human identity are prominent. Perhaps the contemporary importance of these topics helps to explain why there has also been considerable scholarly interest in ethnicity or race in antiquity, not least in the discussion of Jewish and early Christian identities: Historical scholarship is always driven, to some extent at least, by the preoccupations and anxieties of the present. Moreover, the historical interpretation of ancient Judaism and earliest Christianity has long been bound up with modern ideologies and convictions regarding ethnicity, race and religion, sometimes with terrible consequences.

These issues begin to indicate something of the aims and scope of this volume. When contributors were initially invited to participate, they were given an outline of the agenda that the volume seeks to address, as well as a broad indication of their specific topic or area; they were not given any particular steer with regard to the methodology they should adopt or the arguments they might propose. Indeed, while certain themes and overlapping arguments emerge, as discussed in the introduction, it will also become clear to readers of these essays that there is considerable diversity both of approach and argument.

The essays presented here were (with one exception) presented and discussed at either one of two workshops or an international conference, all held at the University of Exeter during 2016 as part of a project funded by the Arts and Humanities Research Council (AHRC) of the UK entitled 'Ethnicity, Race, and Religion in Early Christian and Jewish Identities: A Critical Examination of Ancient Sources and Modern Scholarship' (Grant Ref. AH/M009149/1). Our first (and pleasant) duty, then, is to express our gratitude to the AHRC for their support of this project. The funding was awarded to David Horrell in the form of a fellowship and also provided for the appointment of Katherine Hockey as postdoctoral research associate. We have therefore worked closely together on this volume, from the initial invitations to the events through to the various stages of editing the essays. This particular history is relevant not only to acknowledge the source of our funding, but also to make clear that while one of us (David Horrell) takes responsibility for the topic of the volume, and its intellectual orientation, scope, and organization, the other (Katherine Hockey) has undertaken much of the work of organizing the events, communicating with the contributors, and preparing their essays for publication - and done a great deal else with outstanding care and great efficiency, for which David would like here to record his sincere thanks and appreciation. 
It goes without saying - but should always be said - that we are indebted to all our contributors, and extremely grateful for their willingness to prepare papers for discussion and publication. We would also like to thank all those, too many to list, who participated in the two workshops and the conference; their questions and contributions have helped in the shaping of this volume of essays. We would particularly like to thank three scholars - Denise Kimber Buell, Musa Dube, and Love Sechrest - who accepted the invitation to come to Exeter and spend a little longer engaging with the work of the project and with colleagues in the Department of Theology and Religion, offering insight and advice, though they are, of course, not to be blamed for any weaknesses or omissions in the final outputs.

One final point about the volume should be stressed. As the list of contributors will indicate, those who have written for this volume come from a variety of contexts and perspectives. Yet this is not a volume of 'minority voices' or any similarly specific designation, nor have we sought to identify any of our contributors in this way. This is, rather, simply a volume of essays by scholars all of whom are working in the field of biblical studies (and, in one case, contributing to it from the discipline of ancient history), albeit in diverse and sometimes conflicting ways. As is explained towards the end of the introduction, this kind of equalization of the value of the diverse range of scholarship represented here seems to us an important step towards the emergence of biblical studies from its Eurocentric origins into a truly global discipline.

The Editors

Exeter

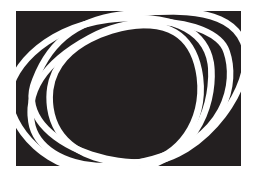

Arts \& Humanities Research Council 


\section{Abbreviations}

Other than the following, all abbreviations are taken from The SBL Handbook of Style. 2nd edn. Atlanta: SBL Press, 2014.

BICS Bulletin of the Institute of Classical Studies

D.S. Diodorus Siculus, Library of History (Loeb Classical Library 279)

JAJ Journal of Ancient Judaism

JSHJ Journal for the Study of the Historical Jesus

$P$ Teb The Tebtunis Papyri (1902-76)

ZNThG/JHMTh Zeitschrift für Neuere Theologiegeschichte / Journal for the History of Modern Theology 


\title{
Introduction
}

\author{
David G. Horrell
}

Ethnicity, race, religion: these are not merely prominent categories of human identity and affiliation; they also signal some of the most complex, contested, and controversial aspects of human social relationships. Indeed, among the most pressing challenges to peaceful coexistence in the contemporary world are those that are depicted and perceived in terms that lie precisely at the fuzzy points of intersection between these categories. Some of the points of conflict, both historical and contemporary, might be seen primarily as issues of race - such as the exploitation of black Africans by white Europeans during the late-nineteenth- and early-twentieth-century 'scramble for Africa, ${ }^{1}$ or the contemporary Black Lives Matter Movement, provoked by the killing of black Americans by police. Other conflicts might seem to be predominantly conflicts of religion - such as the sixteenth- and seventeenth-century European 'wars of religion', or the increasing harassment of religious minorities in many countries in the contemporary world. ${ }^{2}$ But in many cases, though by no means uniformly or necessarily, religion and ethnicity or race are somehow bound together in forms of categorization and causes of conflict. One can hardly understand anti-Semitism in Nazi Germany, for example, without considering how Jewish identity was racialized within a broader ideology of racial types and racial superiority. In Northern Ireland, Catholic and Protestant serve as one marker of ethnic identity - though, as Claire Mitchell has shown, these religious identities should not be seen as merely markers of ethnicity, but rather as substantively contributing to people's constructed sense of identification, group-categorizations and boundaries. ${ }^{3}$ Contemporary Islamophobia, like anti-Semitism, cannot properly be understood as an issue purely of religion - nor, on the other hand, purely one of ethnicity or race. Rather, these are issues in which perception and construction of identity - of self and other, in-group and out-group - frequently blend together aspects of religion, physical appearance (especially skin

1 See, for example, M. E. Chamberlain, The Scramble for Africa, 3rd edn (Seminar Studies in History; Abingdon and New York: Routledge, 2013).

2 For example, a Pew Research Center report ('Religious Hostilities Reach Six-Year High', 14 January 2014) documents markedly increased levels of hostility and abuse towards religious minorities around the world: 'Incidents of abuse targeting religious minorities were reported in $47 \%$ of countries in 2012, up from $38 \%$ in 2011 and $24 \%$ in the baseline year of the study' (2007). Available online: http://www.pewforum.org/2014/01/14/religious-hostilities-reach-six-year-high/ (accessed 23 June 2017).

3 Claire Mitchell, 'Behind the Ethnic Marker: Religion and Social Identification in Northern Ireland', Sociology of Religion 66, no. 1 (2005): 3-21; eadem, 'The Religious Content of Ethnic Identities', Sociology 40, no. 6 (2006): 1135-52. 
colour), culture, language, dress, and so on. Indeed, contributors to a recent special issue of Ethnic and Racial Studies, ${ }^{4}$ edited by Nasar Meer, argue for the need to integrate much more closely the study of race and racism, on the one hand, and antiSemitism and Islamophobia, on the other. ${ }^{5}$ To take a different example to illustrate the connections, a recent Pew Research Center survey revealed that in some of the predominantly Christian countries surveyed, being Christian was felt by a significant proportion of the population to be 'very important' in order truly to share the national identity - Greek, Polish, American, and so on. ${ }^{6}$

Such intersections are, in one sense, unsurprising, since religion - along with culture, language, and so on - is among the commonly recognized facets of ethnic identity (often closely related to perceptions of national identity) and is indeed often constitutive, in part, of such an identity. Race perhaps evokes different associations, linked as it has long been with phenotypical characteristics, particularly skin colour. But all of these terms - 'ethnicity', 'race', 'religion' - are contested. None of them should be taken to capture some essential, ubiquitous, or clearly definable feature of human identity - as if it were simply a fact, as it were, that humans can all be categorized in, say, ethnic terms. Rather, as we shall see in more detail below, and in the essays that follow, these concepts are themselves social constructions, with their own particular histories and associations, which people invoke, in varied ways, to identify themselves, sometimes over against others, to create or maintain a sense of group, and to organize the social world in ways that are meaningful - if sometimes destructively so.

\section{Ethnicity, race, religion: Concepts and theories}

Any moderately attentive reader will already have noticed that I have used the terms 'ethnicity' and 'race' somewhat interchangeably, as if they were more or less equivalents. Yet that is one of the first areas of controversy we must consider. Up until the 1940s, 'race' - which (in this sense) came into the English language only in the sixteenth century - was the standard term to refer to the various divisions

4 Nasar Meer, ed., Racialization and Religion, special issue of Ethnic and Racial Studies 36, no. 3 (2013), 385-515. Also published as an edited book: Nasar Meer, ed., Racialization and Religion: Race, Culture and Difference in the Study of Antisemitism and Islamophobia (Ethnic and Racial Studies; London and New York: Routledge, 2013).

5 See, esp., Meer's introductory essay: Nasar Meer, 'Racialization and Religion: Race, Culture and Difference in the Study of Antisemitism and Islamophobia, Ethnic and Racial Studies 36, no. 3 (2013): 385-98.

6 Fifty-four per cent of Greeks, 34 per cent of Poles, and 32 per cent of Americans interviewed agreed that 'being a Christian is very important for being truly (survey country nationality)'; the figure rose to 57 per cent for white, evangelical Protestants in the United States. Other countries - such as Spain ( 9 per cent), the Netherlands ( 8 per cent), and Sweden (7 per cent) - exhibited much lower levels of conviction on this point. See Pew Research Center, 'What It Takes to Truly Be "One of Us"', 1 February 2017, 21-22. Available online: http://www.pewglobal.org/2017/02/01/what-ittakes-to-truly-be-one-of-us/ (accessed 23 June 2017). For a more micro-scale ethnographic analysis of these intersections in a northern English town, see Ingrid Storm, "Christianity Is Not Just About Religion”: Religious and National Identities in a Northern English town', Secularism and Nonreligion 2 (2013): 21-38. 
of the human race, which had been classified in what turned out to be pseudoscientific and Eurocentric terms, concurrently (and not merely coincidentally) with the era of European colonialism. ${ }^{7}$ Some of the essays that follow- particularly those by Gregory Cuéllar, Kathy Ehrensperger, Halvor Moxnes, Denise Kimber Buell, and Wei Hsien Wan - explore in more detail the implications of this for the emergent shape of modern critical biblical studies, which developed in Europe during the same historical period.

The term 'ethnicity' appears to have first been used in 1941 (though previous discussion in the 1930s had begun to talk of 'ethnic groups') ${ }^{8}$ and became established in modern English-language usage during the 1940s and 1950s, in part as a deliberate alternative to the language of race at a time when the latter was perceived to have become 'deeply compromised by "racism". " For example, in the 1950 UNESCO statement on 'the race question', one key reason 'ethnicity' is preferred to 'race' is what the report describes as 'the injustices and crimes which give such tragic overtones to the word "race"': 'It would be better when speaking of human races to drop the term "race" altogether and speak of ethnic groups. ${ }^{10}$ It is unsurprising, then, that the term 'race' (and, even more so, its German equivalent Rasse - for reasons Ehrensperger details in her essay in this volume (Chapter 5$))^{11}$ has been replaced by ethnicity in much academic discussion in the humanities and social sciences.

However, this remains a contested area, and one in which - as the following essays illustrate - different (national and linguistic) contexts profoundly shape a sense of the implications of particular terms: Rasse remains a highly problematic term in the German context, but 'race' is a standard term in American discussion, without which the crucial bifurcation of white and black would seem hard to grasp. While some contemporary social scientists do not see any meaningful distinctions between the concepts of ethnicity and race, ${ }^{12}$ or seem to use the two terms more or

7 On these historical developments, see, for example, Ivan Hannaford, Race: The History of an Idea in the West (Washington, DC/Baltimore: Woodrow Wilson Center/Johns Hopkins University Press, 1996); Colin Kidd, The Forging of Races: Race and Scripture in the Protestant Atlantic World, 1600 2000 (Cambridge: Cambridge University Press, 2006).

8 See David M. Miller, 'Ethnicity Comes of Age: An Overview of Twentieth-Century Terms for Ioudaios', Currents in Biblical Research 10 (2012): 293-311, at 296.

9 Werner Sollors, 'Foreword: Theories of American Ethnicity', in Theories of Ethnicity: A Classical Reader, ed. Werner Sollors (New York: New York University Press, 1996), x-xliv, at xxix; and see p. x on the origin of 'ethnicity' in the United States in 1941-2.

10 UNESCO, 'The Race Question. Text of the Statement Issued 18 July 1950', 1 and 6 respectively (italics original). Available online: http://unesdoc.unesco.org/images/0012/001282/128291eo.pdf (accessed 16 December 2015). See also Hannaford, Race, 386.

11 Although it is a crude indication, a Google Ngram survey of the use of Rasse in German literature between 1700 and 2008 clearly shows this trend: frequency of the word's appearance rises from around 1840, most rapidly after 1929, reaching a peak in 1940, then declines very sharply between 1941 and 1951, remaining low in frequency thereafter. Tool available online: https://books.google. com/ngrams/ (accessed 10 November 2015).

12 Cf. Thomas H. Eriksen, 'Ethnicity, Race, Class and Nation', in Ethnicity, ed. John Hutchinson and Anthony D. Smith (Oxford Readers; Oxford: Oxford University Press, 1996), 28-31. 
less interchangeably, ${ }^{13}$ others offer distinct but related definitions of each. ${ }^{14}$ When it comes to the study of antiquity in general, and biblical texts in particular, there is widespread agreement that the pseudo-biological racial definitions of postEnlightenment Europe should not be retrojected onto ancient understandings of people-groups, but disagreement about whether the term 'race' can legitimately or valuably be employed. One of the reasons given for not using the term is that it unhelpfully invokes the later pseudo-biological theories and their ideological framework, lending cogency to a concept that is both anachronistic and pernicious. ${ }^{15}$ On the other hand, those who argue for retaining the language of race do so partly on the basis that other concepts (gender, ethnicity, religion, etc.) are also modern constructions and that avoiding the language of race may allow interpreters simply to evade, rather than confront, issues of racism. ${ }^{16}$ Handling these intersections between the ancient world of the texts and the modern contexts of interpretation is an issue discussed in a number of the essays that follow.

But whether one uses the language of race or of ethnicity, the direction of discussion in recent decades may be summarized as a move away from the idea that race or ethnicity refers to innate or biologically determined human groups towards an increasingly widespread acceptance that such identities are instead social constructions, 'generated by ... people's beliefs and practices. ${ }^{17}$ Even the latest advances in genetics, and the widely available DNA-based ancestry tests, lend no support to the notion that humanity can be divided up into genetically defined racial groups. As geneticist Steve Jones bluntly insists, 'The genes do show that there are no separate

13 For example, Rogers Brubaker, Grounds for Difference (Cambridge, MA: Harvard University Press, 2015); idem, Trans: Gender and Race in an Age of Unsettled Identities (Princeton, NJ, and Oxford: Princeton University Press, 2016).

${ }^{14}$ See Stephen Cornell and Douglas Hartmann, Ethnicity and Race: Making Identities in a Changing World (Sociology for a New Century; Thousand Oaks, CA: Pine Forge, 2007), 15-40. See their summary table of 'definitional distinctions' between ethnicity and race on 36.

15 See, for example, Calvin J. Roetzel, 'No "Race of Israel” in Paul', in Putting Body and Soul Together: Essays in Honor of Robin Scroggs, ed. Virginia Wiles, Alexandra Brown and Graydon F. Snyder (Valley Forge, PA: Trinity Press International, 1997), 230-44; Philip F. Esler, Conflict and Identity in Romans: The Social Setting of Paul's Letter (Minneapolis: Fortress, 2003), 40, 55; Kathy Ehrensperger, 'Paulus, sein Volk und die Rasseterminologie: Kritische Anfragen an den "Race"-Diskurs in neuerer englischsprachiger Paulus-Forschung, Kirche und Israel 27 (2012): 119-33 (and see further the discussion in her essay).

16 Denise Kimber Buell, Why This New Race: Ethnic Reasoning in Early Christianity (New York: Columbia University Press, 2005), 13-21. Cf., similarly, Sara Ahmed, 'Declarations of Whiteness: The Non-performativity of Anti-Racism', borderlands 3, no. 2 (2004): 'We cannot do away with race, unless racism is "done away" ... . Thinking beyond race in a world that is deeply racist is a [sic] best a form of utopianism, at worse [sic] a form of neo-liberalism' (para. 48). Also insisting on the relevance of 'race' language to the study of antiquity is Denise Eileen McCoskey, Race: Antiquity and its Legacy (Ancients and Moderns; London and New York: I. B. Tauris, 2012).

17 Brubaker, Grounds for Difference, 48; cf. idem, Ethnicity without Groups (Cambridge, MA and London: Harvard University Press, 2004), 17: 'Ethnicity, race, and nationhood are fundamentally ways of perceiving, interpreting, and representing the social world. They are not things in the world, but perspectives on the world.' See also Mark G. Brett, 'Interpreting Ethnicity: Method, Hermeneutics, Ethics', in Ethnicity and the Bible, ed. Mark G. Brett (Biblical Interpretation; Leiden: Brill, 1996), 3-22: 'Although ethnie can be exceptionally durable once formed, they are also symbolic constructions which have to be maintained by reiterated practices and transactions' (10). 
groups within humanity' and that 'the idea of pure races is a myth. ${ }^{18}$ Indeed, the kind of ancestral profiling offered through DNA analysis might more plausibly be taken to demonstrate what Rogers Brubaker refers to as 'universal mixedness' - that we are all, one might say, multiracial. ${ }^{19}$

The recognition that ethnic or racial identities are matters of social construction or, as Max Weber classically put it, based on belief ${ }^{20}$ - has led to attempts to identify what characteristics typically form the basis for a sense of shared ethnic identity. Richard Schermerhorn, for example, offers a concise and influential definition: An ethnic group is 'a collectivity within a larger society having real or putative common ancestry, memories of a shared historical past, and a cultural focus on one or more symbolic elements defined as the epitome of their peoplehood. ${ }^{21}$ Schermerhorn's definition is adapted and extended in Anthony D. Smith's influential list of the characteristics of ethnic identity, first laid out in his 1986 work on the ethnic origins of nations, and later summarized in a collaborative work with John Hutchinson as follows:

1. a common proper name, to identify and express the 'essence' of the community;

2. a myth of common ancestry, a myth rather than a fact, a myth that includes the idea of a common origin in time and place and that gives an ethnie a sense of fictive kinship, what Horowitz terms a 'super-family'...;

3. shared historical memories, or better, shared memories of a common past or pasts, including heroes, events, and their commemoration;

4. one or more elements of common culture, which need not be specified but normally include religion, customs, or language;

5. a link with a homeland, not necessarily its physical occupation by the ethnie, only its symbolic attachment to the ancestral land, as with diaspora peoples;

6. a sense of solidarity on the part of at least some sections of the ethnie's population. ${ }^{22}$

${ }^{18}$ Steve Jones, The Language of the Genes: Biology, History and the Evolutionary Future, rev. edn (London: Flamingo HarperCollins, 2000), 255, 266.

19 Cf. Brubaker, Grounds for Difference, 73: 'Autosomal tests ... reveal that virtually everyone derives genetic ancestry from a variety of ancestral populations. This emphasis on universal mixedness undermines typological forms of racial thinking.' See further $48-84$ for Brubaker's overview of the findings of recent biology and, in light of these findings, a reiteration of the case for a constructionist view of race/ethnicity.

${ }^{20}$ Weber defines ethnic groups as those 'which cherish a belief in their common origins of such a kind that it provides a basis for the creation of a community'; Max Weber, 'Race Relations' [1922], in Max Weber: Selections in Translation, ed. W. G. Runciman (Cambridge: Cambridge University Press, 1978), 359-69, at 364 .

${ }^{21}$ Richard A. Schermerhorn, Comparative Ethnic Relations: A Framework for Theory and Research ([1970] Chicago and London: University of Chicago Press, 1978), 12. Schermerhorn's definition is adopted, for example, by Cornell and Hartmann, Ethnicity and Race, 19-20.

22 John Hutchinson and Anthony D. Smith, 'Introduction', in Ethnicity, ed. Hutchinson and Smith, 3-14, at 6-7, summarizing the more extended discussion of the 'foundations of ethnic community' in Anthony D. Smith, The Ethnic Origins of Nations (Oxford: Blackwell, 1986), 22-31, for whom the roots of modern nations are to be found in a model of ethnic community (x). Love L. Sechrest, $A$ Former Jew: Paul and the Dialectics of Race (LNTS 410; London and New York: T\&T Clark, 2009), $48-50$, also presents this definition of an ethnic group, drawing on Smith's work. 
Also significant is a broader criterion noted by Schermerhorn: that there must be 'consciousness of kind among members of the group', that is, some shared sense of being a 'people.'23

More recent work, notably by Rogers Brubaker, has pressed the case for a subjectivist and constructionist perspective still further: Lists of characteristics such as Smith's should not be taken to imply that ethnic groups exist as a clearly defined and consistent category of human groups. ${ }^{24}$ For a start, Brubaker is critical of what he terms 'groupism', that is, 'the tendency to take bounded groups as fundamental units of analysis. ${ }^{25}$ Instead, he insists, the focus of study should be on how various kinds of potential basis for 'groupness' are invoked and claimed in different circumstances. Rather than see the identification of a certain group as 'ethnic' as having achieved any kind of explanation, Brubaker therefore argues that 'ethnic common sense - the tendency to partition the social world into putatively deeply constituted, quasi-natural intrinsic kinds ... - is a key part of what we want to explain, not what we want to explain things with. ${ }^{26}$ Rather than ask 'what is race?' or 'what is an ethnic group?', Brubaker suggests that we should instead 'ask how, when, and why people interpret social experience in racial, ethnic, or national terms. ${ }^{27}$

A second point Brubaker stresses is that ethnic or racial groupings are enormously diverse, such that it is much more important to investigate the specific forms and practices through which a group identity is constructed than to invoke a standard model to classify groups as 'ethnic' or not. ${ }^{28}$ This helps us to see why any one of the features Anthony Smith lists - including religion, and other features of cultural practice and way of life - may be more or less significant in sustaining a sense of identity as a people. Indeed, features such as religion or language, as well as notions of shared descent, history, and territory, cannot be separated off from the study of ethnicity, for it would then be hard to see what residual substance might be left to constitute the notion of ethnic identity. ${ }^{29}$

Another issue of conceptual and definitional controversy is indeed religion itself. It is now widely accepted that 'religion', at least in the modern sense of the word, is an anachronistic concept for the ancient world. There is no word in Greek or Latin that corresponds exactly to the modern notion of religion - though there are various words that overlap in some way with this broad domain ( $\varepsilon \dot{v} \sigma \varepsilon \dot{\varepsilon} \beta \varepsilon$, $\delta \varepsilon ı \sigma \delta \alpha \iota \mu \nu i \alpha, \theta \rho \eta \sigma \kappa \varepsilon i \alpha$, religio, pietas, supplicatio, etc.). What we might identify as religion (religio), it is often pointed out, had more to do with cultic practice and dutiful obligation than allegiance to a set of beliefs and doctrines, as the modern

23 Schermerhorn, Ethnic Relations, 12.

24 See, for example, Brubaker, Grounds for Difference, 48-84, esp. 48-49, 81-84.

25 Brubaker, Ethnicity without Groups, 2.

26 Brubaker, Ethnicity without Groups, 9.

27 Brubaker, Ethnicity without Groups, 87.

28 Cf. Brubaker, Ethnicity without Groups, 27: 'It may be that "ethnicity" is simply a convenient though in certain respects misleading - rubric under which to group phenomena that, on the one hand, are highly disparate, and, on the other, have a great deal in common with phenomena that are not ordinarily subsumed under the rubric of ethnicity.

29 Cf. Brubaker, Grounds for Difference, 88. 
notion might be taken to imply. ${ }^{30}$ Moreover, as Paula Fredriksen has stressed, in antiquity 'religious' practices and devotion are often intimately bound up with what we might call an ethnic sense of being a people: 'Gods also attached to particular peoples; "religion" ran in the blood ... ethnicity expressed "religion" (acknowledging the anachronism of both terms for our period), and religion expressed "ethnicity." 31 As Brent Nongbri has recently emphasized, the modern category of 'religion' has a particular history that reflects its historical and cultural context of production in the sixteenth and seventeenth centuries: 'The idea of religion is not as natural or universal as it is often assumed to be. Religion has a history. It was born out of a mix of Christian disputes about truth, European colonial exploits, and the formation of nation-states. ${ }^{32}$

It is also worth stressing that this is not only a difficulty that applies to antiquity. Wilfred Cantwell Smith's classic study from 1962, The Meaning and End of Religion, which spends a considerable number of pages arguing that the modern notion of religion is inappropriate and ill-suited to the ancient world, also has as one of its central arguments the claim that 'religion' as a (specifically modern, Western, Christian) concept is confusing and inappropriate in the modern world too: "The word "religion" has had many meanings; it ... would be better dropped. This is partly because of its distracting ambiguity, partly because most of its traditional meanings are, on scrutiny, illegitimate. ${ }^{33}$ Abandoning the term altogether may be too drastic a move, however, not least because we would probably need to invent some other (equally questionable, flexible) term to replace it in order to denote the particular aspects of human behaviour we wish to specify. As Jonathan Z. Smith notes, having surveyed the complex history and varied definitions, "Religion" is not a native term; it is a term created by scholars for their intellectual purposes and therefore is theirs to define' - but, as such, is crucial, he insists, in 'establishing a disciplinary horizon. ${ }^{34}$

These discussions of categories and terminology should alert us to the complexities of talking about ethnicity, race, and religion, and to the risk of pretending that any of these terms refers to a clear and well-defined category. On the contrary, these are overlapping, blurry, and contested categories, whose dominant definitions often reflect particular historical and cultural contexts, not least those of the modern Christian West.

30 See, for example, Wilfred Cantwell Smith, The Meaning and End of Religion ([1962] Minneapolis: Fortress, 1991), 20-1.

31 Paula Fredriksen, 'What "Parting of the Ways"? Jews, Gentiles, and the Ancient Mediterranean City', in The Ways that Never Parted: Jews and Christians in Late Antiquity and the Early Middle Ages, ed. Adam H. Becker and Annette Yoshiko Reed (TSAJ 95; Tübingen: Mohr Siebeck, 2003), 35-63, at 39. Cf. also eadem, 'Judaizing the Nations: The Ritual Demands of Paul's Gospel', NTS 56 (2010): 232-52, at 234-40; eadem, 'Mandatory Retirement: Ideas in the Study of Christian Origins Whose Time Has Come to Go', Studies in Religion/Sciences Religieuses 35 (2006): 231-46, at 232; Larry W. Hurtado, Destroyer of the Gods: Early Christian Distinctiveness in the Roman World (Waco, TX: Baylor University Press, 2016), 78-9.

32 Brent Nongbri, Before Religion: A History of a Modern Concept (New Haven and London: Yale University Press, 2013), 154. See also the overview of the term's history and complexities in Jonathan Z. Smith, 'Religion, Religions, Religious', in Critical Terms for Religious Studies, ed. Mark C. Taylor (Chicago and London: University of Chicago Press, 1998), 269-84.

33 Smith, Meaning and End, 194. On the point that 'religion' is not an ancient category, but a modern, Christian one, see 15-50.

34 Smith, 'Religion, Religions, Religious', 281. 


\section{Aims of the volume and summary of the essays}

This brief outline of conceptual complexity and the influence of particular historical contexts should help to indicate why this volume takes its particular aims. The overall goal of the essays is to explore and illuminate how ideas and ideologies of ethnicity, race, and religion contribute to the construction and interpretation of Jewish and Christian identities in biblical and early Christian texts and in the traditions of scholarship dealing with those texts. There are three more specific aims, which correspond to the three groups of essays that follow, though these are overlapping and closely related aims, linking together to form a logical progression. The first such aim is to explore the ways in which, around the time of Christian origins, notions of, or appeals to, ethnicity/race and religion may be understood to feature in the construction of 'Jewish' and 'Christian' identities - set in the context of ethnic identities in the ancient Greek world. The second aim is critically to explore the ways in which scholarly (and popular) perceptions of these identities - and the use of the terminology of ethnicity, race, and religion in these perceptions - reflect particular historical, religious, and ideological contexts. The third aim is both critical and constructive: to show how dominant traditions of biblical interpretation continue to be enmeshed in the racial and religious assumptions of the white, Christian West, and to offer possibilities for alternatives, and for moving beyond this long-established situation.

\subsection{Ethnicity, religion, and identity in antiquity: Jews and Christians in the Hellenic world}

The first section of the book therefore focuses on the intersections of ethnicity and religion in ancient constructions of identity - though the contemporary implications of interpretative decisions are also at issue, particularly in relation to the translation of the term 'Iov反aĩoc. In the opening chapter, Teresa Morgan provides a broad historical context for the discussion of ethnicity in relation to Jewish and early Christian identities, by examining how ethnic identifiers were assigned, claimed, and deployed in the early Greek and Hellenistic periods. Her essay offers both an overview of recent scholarship on the subject - with ample bibliographical information - and plentiful illustrations from the primary sources to exemplify her observations. One thing that emerges prominently is the complexity and fluidity of notions of ethnicity, and the ways in which identities were deliberately claimed or acquired, such that, as Morgan puts it with regard to classical cities such as Athens, 'shared descent, history and territory were never sufficient arbiters of identity' (p. 28). Alexander the Great likewise illustrates how multiple identities may be invoked and presented, in different times and contexts (p. 29). In the Hellenistic period, the malleability and flexibility of identity continues to be evident. For example, ethnicity, Morgan shows, was often an assigned identity, related to tax or legal status, or to citizenship or occupation. Moreover, the evidence indicates that individuals could acquire a new (ethnic) identity, without losing their old identity, in a process Morgan refers to as accretive; they could thus retain multiple identities, between which they could switch, as circumstance or context required. Morgan invokes the notion of 'code-switching' (p. 34) to illuminate this phenomenon. 
She summarizes the complexity of ancient ethnicity by referring to it as 'the "queer" of its day: A set of labels designed to define, differentiate, and discriminate, which are taken over by those to whom they apply, and then resisted, subverted, reworked, embraced, abandoned and celebrated in a conversation that ranges far beyond what states or dominant social groups control' (p. 38). This flexibility also means, as Morgan illustrates in her final section (Section 2.4), that culture, philosophy, religion, and magic are all relevant to our consideration of what ethnicity means in the ancient world, even if the boundaries of any such categorization are inevitably fluid. For example, Stoic cosmopolitanism may be viewed as a certain kind of alternative ethnicity, and one that might be relevant to understanding 'how early Christians might think of themselves in ethnic terms' (p. 39). Most of all, Morgan's essay powerfully shows how ethnicity in the Greek and Hellenistic world was a fluid and flexible field of identity-making, one in which multiple identities could be assigned or claimed, displayed or invoked, and negotiated through modes of code-switching. This fluidity and flexibility - of both the term or category of ethnicity, and of the identities to which it relates - is a crucial theme which connects other essays in the volume, and on which I shall comment further below.

Addressing an issue that is currently the subject of significant debate, John Barclay

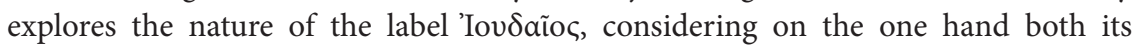
ancient context and the ways in which 'ethnicity' and 'religion' might be related to this identity-designation, and also, on the other hand, the modern scholarly debates about appropriate translation, which in part reflect precisely the issues of distinguishing ethnic and religious identities. Beginning with Josephus' use of ethnic labels, Barclay highlights the complexity and ambiguity of ancient 'ethnic' terminology, arguing that ethnicity must be seen as a polythetic concept, 'inherently malleable' (p. 56), in which various characteristics may feature, none of them essential. To explore and illustrate these proposals Barclay turns to examine in some detail Josephus' account of the 'conversion' of the royal house of Adiabene (Ant. 20.17-96). Crucial is the claim, concerning Izates' 'conversion', that 'it makes little sense to describe this change as "religious" as opposed to "ethnic" (p. 51). The narrative also illustrates the polythetic nature of Josephus' understanding of what it meant to be 'Iovdaĩoc: while ancestry could feature in claims to Jewish/Judean ethnic identity, the Izates story shows that it need not do so, and need not be essential to one's identity as 'Iov反aĩoc. As Barclay remarks, 'Judean ethnicity was a cluster-formed polythetic category that did not depend on shared ancestry' (p. 53). These historical findings lead to reflections on the contested question about the translation of 'Iov反aĩoc. Given the preceding arguments it is no surprise that Barclay insists that both of the main options, 'Jew' and 'Judean' which are in any case 'terms with partly overlapping meanings' that need 'to be spelt out carefully in each case' (p. 56) - may need to be used 'together and interchangeably' (p. 56). Not only is ethnicity such a diverse and malleable phenomenon, but religion is complexly woven into it, not least in the case of ancient Judaism.

In an essay that explores one particular example of the ways in which early Christian texts deploy both 'ethnic' and 'religious' language in their discursive strategies of identity-making, Judith Lieu returns to the Letter to Diognetus, the text that provided her initial entry into what became an extensive consideration of the making of early 
Christian identity. In particular, the question posed at the opening of the letter, concerning the 'genos or practice' that has entered 'as new' (so Lieu), has invited reflection on the categorization of Christian identity that is implied and invoked in this text. Through a detailed reading of the early chapters of the letter, Lieu shows how the author's depiction of the Christian way of life, juxtaposed with that of Jews and Greeks, both does and does not construct 'Christian' identity in comparable terms: In some sense, this is an exercise in what Denise Kimber Buell has called 'ethnic reasoning' (p. 69), yet the author's deployment of terminology, Lieu suggests, 'neither affirm[s] nor denie[s] the categories of "race and way of life" but transfigures and defers such categories (p. 71). In such a discourse, it makes little sense to try to make either/or decisions as to whether Christian identity is constructed in ethnic or in religious terms, or in local or universal categories; but it is equally clear that the discourse plays with - evokes and invokes - many of the established facets of the discourse of ethnic identity, while leaving tantalizingly unclear how the Christian's (new) identity was to be performed.

\subsection{Ethnicity, race, and religion in European traditions of biblical scholarship}

The second group of essays focuses on various European traditions of biblical scholarship, since it was in post-Enlightenment Western Europe that the modern critical discipline of biblical studies developed (on this, see also Wan's essay in Part 3). Taking specific examples located in specific national and linguistic contexts, these essays illustrate some of the particular ways in which ideologies of race and religion shaped approaches to biblical interpretation and how such interpretative endeavour is thus more closely bound up with these contemporary ideologies than is often recognized.

In the first of these essays, Gregory Cuéllar turns to the late nineteenth century and the sometimes fierce debates in the Church of England about the use of 'Higher Criticism' in biblical studies. Beginning with a report of the arguments made during a Church Congress meeting held at Exeter in 1894, Cuéllar focuses in particular on the work of Samuel Rolles Driver, renowned and still influential scholar of Hebrew language and the Hebrew Bible/Old Testament. Cuéllar shows how the Higher Criticism espoused and defended by Driver had, woven into it, Orientalist assumptions about the superiority of Western European culture, race, and intellectual achievement. These assumptions, along with contemporary theories concerning human races and languages, Cuéllar goes on to show, then came to be embedded in Driver's interpretation of Genesis (particularly of chapters 10-11). Without in any way denying the enduring value or quality of Driver's work as a whole, Cuéllar's research shows how the assumptions of the racial science of Driver's era are replicated in his work, and in that sense indicate something of Driver's own racialized location as a scholar. Cuéllar concludes by calling for critical interrogation both of such critics' racialized identities and also of the ways in which their scholarship perpetuates - even if unknowingly or unintentionally - forms of racial oppression.

Taking as her starting point the recent interest in the language of ethnicity and race to explore the identity of the earliest Christians, Kathy Ehrensperger offers a critical 
perspective on this development by tracing some of the main contours of Germanlanguage discussion, from the nineteenth century to the present day. She turns first to Johann Gottfried Herder's notion of the Volk, which, she suggests, was not itself initially or necessarily racist, but was later linked with racist ideologies - before and not only in the era of German National Socialism. Her focus then turns to Adolf von Harnack, and specifically his discussion of Christians as das dritte Geschlecht - the third entity. As Ehrensperger shows, despite the tendency to translate this phrase into the language of race ('the third race'), Harnack himself avoided this terminology, even though it was clearly available to him. Finally, Ehrensperger considers the most recent German-language discussion, where interest in the concept of ethnicity in relation to early Christian-identity is much less evident than in English-language scholarship. German scholarship avoids entirely the application of the language of race (Rasse) to early Christian identity, for reasons to do with both the associations of that language in modern German history and the sense that such a term would be inappropriate and anachronistic for the ancient world: The idea of referring to the early Christians as a 'race' (Rasse) would be virtually unthinkable and certainly objectionable. The notion of ethnicity is more readily discussed in relation to ancient Judaism and formative Christianity, particularly in terms of the integration of different ethnic groups into the early Christ-communities; but the idea that the early Christian groups might themselves be seen as ethnic in character is either not considered or explicitly rejected. Both the history of German-language scholarship and the most recent discussion thus raise critical questions about the use of 'race' language in English-language discussion and highlight the crucial considerations bound up in the choice of terminology to describe the earliest Christ-following groups. Ehrensperger's essay also helps to illustrate the broader point that terms such as ethnicity and race (and their equivalents in other languages) have particular histories and ideological associations that unavoidably shape their resonances in contemporary discussion.

In an essay that traverses different national contexts, time periods, and both scholarly and popular perspectives, Halvor Moxnes examines the 'continuities in racial stereotypes of Muslims and Jews' (p. 113) in the work of the nineteenth-century French philologist and historian Ernest Renan and the twenty-first-century Norwegian terrorist Anders Breivik. His study thus examines how such stereotypes are reproduced not only across significant periods of time but also across the divide between academic scholarship and popular views. With regard to Renan, Moxnes stresses how his (negative) views of ancient Jews were shaped not only by his historical and philological work but also by his encounters with Arab Muslims in his own time, during his travels in Syria and in Jerusalem. Renan contrasted what he saw as Arab/Muslim rejection of science, rationality, and progress with the European ideal, with its desire for human freedom. This stereotypical contrast between Arab/Muslim and European also underlies Breivik's manifesto, which continues to reproduce similar oppositions, dependent on an essentialized view of both Islamic and European (specifically Norwegian) identities. Moreover, while Breivik's views are extreme, they form part of a continuum of negative attitudes towards Muslims that may be traced among both politicians and the wider public in Norway (as well as elsewhere). In a concluding postscript, which addresses the problems that arise from such essentializing views, Moxnes notes how the images 
of Jesus established in historical scholarship have shifted over time, not least under the pressure of contemporary events - such as the emphasis on Jesus' Jewishness that emerged in the wake of the Second World War and the Holocaust. Moxnes suggests that we need a new image of Jesus that does more justice to the 'cultural complexity' of his ancient setting and, at the same time, to our own need to grapple with and appreciate the 'complexities and hybridities of societies' (p. 128). Such an image may help us to break with the damaging stereotypes reproduced by figures as different and distant as Renan and Breivik.

Turning to the British context, James Crossley offers a critical analysis of the constructions of Judaism and Jewishness in more recent New Testament scholarship on Jesus and Paul, focusing in particular on the work of the British scholar N. T. Wright. Crossley sets his critical analysis in the wider context of the shifts in perspective on Jesus and Paul that took place in the wake of E. P. Sanders' groundbreaking work in the 1970s and 1980s, notably in the New Perspective on Paul developed by James Dunn, along with Wright and others. Crossley also, crucially, sets these scholarly perspectives into the wider sociopolitical context of neoliberalism and contemporary ideologies of race, arguing that despite the apparent shift of scholarly perspective on Judaism, there remains an 'essentializing' tendency that, particularly in Wright's work, presents a monolithic and static Judaism as a backdrop to the positive achievements of Jesus and Paul. Thus, despite the changes in tone, and even 'anti-racist' intentions, such academic discourse can continue to perpetuate 'unconscious and implicit racializing distinctions' (p. 136). More broadly, this kind of discourse, and the categories it uses, can, Crossley argues, 'be used in malign ways ... for monitoring and surveillance of minority groups by the liberal capitalist state ... thereby perpetuating difference and the potential for discrimination' not least in 'racial' or 'racist' ways (p. 143).

\subsection{Challenging white, Western traditions of interpretation: Critique and alternatives}

Having considered some of the ways in which ethnicity and religion could feature in constructions of identity in early Christian and Jewish texts, and the ways in which some of the established traditions of biblical scholarship reflect the historical contexts and racial ideologies of Western Europe, the task for the third and final group of essays is both to develop a critique of these traditions and to illustrate possible alternatives.

In the first of these essays, drawing on the work of Sara Ahmed in particular, Denise Kimber Buell explores the notion of 'whiteness' and its relevance to a critical engagement with New Testament and early Christian studies. She does this via three particular 'nodes'. First, Buell considers the 'white' orientation of contemporary New Testament and early Christian studies, not primarily in terms of the statistical dominance of those of European descent - evident though that is - but more in regard to the orientation of the field, its perspectives and approaches, and the ways in which students are trained. Secondly, Buell explores briefly how, from its origins in Germany and its developments in Europe and North America, scholarship on Christian origins is enmeshed with contemporary concerns about race, and with the relationship between the dominant 'white' (and Christian) people(s) and the 'others' 
whom they encounter. Thirdly, and most distinctively, Buell illustrates how the lens of whiteness might be applied to an ancient Christian text, presenting two examples focused on Clement of Alexandria's writing. In the first case, Buell compares Clement's concern with the habituation of Christian bodily action with the kind of habituated bodily practices Ahmed associates with whiteness. In the second case, she considers the construction of Christian boundaries over and against that which is deemed to be heretical or untrue, suggesting that this is both an intrinsic feature of the earliest Christian writings and also a problematic legacy that requires ongoing critical probing. Finally, in drawing together her conclusions, Buell briefly indicates, referring to policy at her own institution, what a 'reorienting away from whiteness in New Testament and Early Christian studies' (p. 164) might require in practice. This kind of consideration finds echoes in the essays that follow in this section.

Musa Dube's essay begins by revisiting anthropologist Laura Bohannan's classic account of her sharing the story of Hamlet with the Tiv of Nigeria. Just as the Tiv engaged actively in the process of interpreting, retelling, and reshaping the story, so Dube examines the ways in which the first Batswana readers responded to the Setswana Bible, first translated between 1840 and 1857 by Scottish missionary Robert Moffat. Published letters enable us to see Batswana objections to various aspects of the ways in which their language was adapted for the biblical translation, in ways that rendered it a kind of 'English-Setswana', imposing infantilizing errors and misunderstanding upon its users. The archival material also makes clear that the missionaries' concerns were given more weight in responding to such objections than those of the people for whom the language was their mother-tongue. Yet as well as these written objections, there is also evidence of other modes of resistance to the missionary translation: In the oral forms it was read aloud, which subverted and avoided some of the difficulties of the official printed translation. Another example of the ideological implications of the translation process is the decision to render 'demons' with the word badimo, meaning ancestors. This is both exposed as a form of cultural colonialism and also seen as another site for resisting readings. Finally, Dube highlights the importance of studies of biblical translation - and their striking neglect in programmes of biblical studies - as an archival site for the understanding of cultural and racial encounter and emerging forms of decolonial community resistance. This appeal for more focus on critical analysis of biblical translations within academic departments where biblical studies is taught constitutes one proposal for reshaping and extending the focus of the discipline.

Writing explicitly from her perspective as a lowland Filipina Catholic scholar, Ma. Marilou S. Ibita explores the relations and tensions between the notion of a 'transethnic' Christian identity that is promoted both by Catholicism and in biblical studies on the one hand, and the specific ethnic identities and locations of its members, on the other. She notes, with particular reference to the context of the Philippines, various ways in which a trans-ethnic (Catholic) identity is fostered, and how this contributes to the invisibility of ethnic identities and specificities. She also observes how the ethnic identities referred to in the biblical texts - including that of Jesus and other Jews of his time - are often obscured or invisible to contemporary Filipino Christians. Particularly problematic is the depiction of 'the Jews' in the Pasyon - a narration of 
Jesus' life and passion that remains popular in the Philippines to this day - which depicts Jews resolutely as the enemies of Jesus, effectively transposing the opposition between Spanish colonizers and the indigenous colonized in the Philippines onto the depiction of the Jews and Jesus. Nonetheless, levels of anti-Semitism in the Philippines are comparatively low. Ibita then turns to issues affecting the discipline of biblical interpretation, which indicate how, despite its promotion of a 'trans-ethnic' perspective, it is shaped by Western identity and values. These issues range from the pragmatic matters of languages, timings of conferences, journal policies, and so on, to the more ideological issues of Western bias and questions about whether Western scholars are as ready to learn from their non-Western colleagues as is the expectation vice versa. Finally, Ibita turns to the dialogical approach advocated by the Federation of Asian Bishops Conference and by the Filipino biblical scholar and theologian Carlos Abesamis, along with the 'Dialogue School' pedagogy developed for Catholic schools in Belgium and Australia at the Catholic University of Leuven, as a potential way to hold together the solidarity of a shared (trans-ethnic, and religious) identity alongside recognizing and treasuring specific ethnic identities. She also proposes 'that historically-informed and inculturated ways of doing narrative criticism' (p. 196) might be especially fruitful for both exegetes and the wider ecclesial communities, resonating with 'the Asian and Filipino's preference for storytelling' (p. 196). Rather than reject the existing tools in biblical studies, Ibita sees fruitful potential in a weaving together of old and new, integrating diverse perspectives.

Setting her study within the field of African-American biblical interpretation, and specifically highlighting the use of analogy as a hermeneutical resource, Love Sechrest examines the use of the Bible in one of Martin Luther King Jr's speeches, showing the various ways in which King draws analogies between the characters in Luke's parable of the rich man ('Dives') and Lazarus and the situation of his own time both within the United States and internationally. One of the features Sechrest identifies is the way in which King used this analogy to address both intra-racial and interracial challenges, national and international relations. Sechrest then presents her own African-American reading of the parable of the Good Samaritan, finding in it similar resources for considering both intra-racial and interracial relationships. This is because, unlike many interpreters, she argues that part of Jesus' point in the parable is that the Samaritan is an Israelite, an 'insider', who rightly acted as such, embodying 'intra-racial' concern. This, she suggests, may be placed alongside (not to replace) the more established focus on interracial dynamics. As in King's speech, her reading of the parable draws analogies to enable its fruitful appropriation in the contemporary context, for example, in relation to the tendency among Americans to treat people of colour as 'forever foreign' or as a challenge to some within the middle-class black community 'to eschew the respectability politics that inhibits many of them from direct ministry to the black casualties of the prison-industrial complex' (p. 215). Her interpretation of the parable and the attempts to find fruitful analogies at various levels of scale are thus, fundamentally, an attempt to continue to develop African-American readings of scripture 'in the tradition of Martin Luther King Jr'. (p. 217).

Wei Hsien Wan begins his essay, which helpfully resonates with a number of the preceding contributions, by revisiting Audre Lorde's influential speech in which she 
made her now-famous remark that 'the master's tools will never dismantle the master's house. This provides a way of entry into a discussion about the dominant tools in the discipline of biblical studies, which clearly - based on such evidence as a recent SBL survey - has a 'race problem', disproportionately dominated as it is by those of white, European descent. Wan examines briefly the early origins of the discipline in Reformation Europe, thereby showing how its central methods and concerns were defined both by the religious conflicts of Europe and also by Europe's colonial expansion into the wider world. Wan proposes that these defining characteristics continue to shape the discipline today, illustrating this claim with two examples. First, there is the assumed canon of scripture that dominates biblical studies, with its primarily Protestant focus, and its corresponding lack of attention to texts included in the Armenian, Ethopian, Syriac, or Coptic canons. Second, there is the goal of objectivity. Despite recognition that this cannot be fully claimed or attained, Wan suggests that the goal of much biblical studies continues to embody an epistemology rooted in a particular subject-object conception and an implicit claim that the knowledge acquired is not fatally compromised by, or constrained within, the context of the researcher. What is required as a first step, Wan argues, is a due recognition of the extent to which the discipline remains Eurocentric in its ideologies, outlooks, and practices. Only then might we proceed to consider a solution to biblical studies' race problem, a solution that might, drawing again from Lorde, entail a radical embracing of difference, a recognition of interdependence, as essential for escaping the current forms of mastery.

\section{Emerging themes}

It would be neither appropriate nor accurate to pretend that these essays, varied as they are in both topic and perspective, combine to produce a single coherent argument, or even a clear programme for the future of biblical studies. However, there do seem to be some themes that emerge across the collection, and that are significant for our ongoing reflection.

The first such theme is that of fluidity - the fluidity of identities in general, of ethnic identities in particular, and of the place of 'religion' in such identities. Whether we think of Teresa Morgan's depiction of the multiple, flexible, and accretive deployment of ethnic identifiers in the Hellenic world, Judith Lieu's examination of the use of ethnic and religious language in Diognetus, or John Barclay's argument that ancient Jewish ethnicity was polythetic, with no one essential criterion, and inextricably bound up with what we call religion, there is clear fluidity in the category of ethnicity, and the diverse ways in which identity can be claimed, presented, contested, and changed. While this theme thus emerges in those essays whose focus is primarily on the reading of ancient texts, it is also important to point out how it is, in a sense, also a product of and an emphasis in - the modern context of interpretation (a context that is explicitly

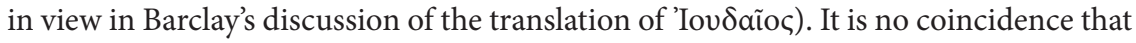
it is now that we are discovering the fluidity of (ethnic) identity in antiquity, precisely at a time when we are increasingly conscious of the fluidity and flexibility of our own 
identity categories - a time, as Halvor Moxnes points out, of cultural complexity. Such fluidity, while it may be celebrated and affirmed in some circles, can, however, be potentially disturbing to our sense of who we are in the world. Indeed, as Moxnes' essay highlights, attempts to insist on the preservation and protection of notions of essentialized identity, fictional though these are, carry popular appeal in such an age of flexible and unsettled identities. Moreover, this flexibility is policed in all sorts of ways, official and unofficial, that contain and conceal it. ${ }^{35}$ Yet it seems hard to avoid the conclusion that, however much it is depicted or perceived as stable and fixed, identity in general, and ethnic or racial identity in particular, is fluid and malleable, socially constructed with definitions and lines that are the product of specific sociopolitical (and religious) contexts.

A second theme, closely connected with the idea that ethnic or racial identity is socially defined and constructed, is the importance of specific histories and contexts. For example, as already noted above, Kathy Ehrensperger's essay illuminates aspects of the history of German scholarship which help to show why the word Rasse ('race') has such a negatively loaded resonance in that context. By contrast, Love Sechrest's essay on African-American biblical interpretation is one in which the language of race plays a central part, rooted as it is in the context of the United States, where the black/white binary has exerted, and continues to exert, such social force. Observing that such language has different roots and resonances in different national or social contexts does not mean that we cannot debate appropriate terminology for the earliest Christians or for contemporary interpretative contexts. But it does at least help us to appreciate the contexts which shape our perceptions of the terminology we use, and our convictions as to what its importance and force might be. Indeed, several of the essays in the volume show how deeply the language and perceptions of ethnicity, race, and religion that shape biblical interpretation are the products of particular socio-historical contexts, even if the influence of that context is unacknowledged and potentially hidden beneath the aspirations of ('objective', 'scientific') historical exegesis, whether this be the early scholarship of the nineteenth century or much more recent work. It is often easier to see how scholarship of the past was enmeshed in the racial and religious ideologies of its time than it is to appreciate how far our own present work continues to be shaped by such ideologies. But the attempt to cast the same kind of critical spotlight onto the present, difficult and controversial though it may be, is an important part of the ongoing task of critical reflection on scholarship itself, as James Crossley's essay shows. Moreover, while it may be uncomfortable - at least for those of us who are raced as white - to reflect critically on how 'whiteness' shapes the perceptions and practices of biblical scholarship, such critical probing is, as Denise Kimber Buell demonstrates, essential if we are to grapple with the ongoing impact of race and racism in our discipline (and beyond).

35 See, for example, Brubaker, Trans, who uses the notion of 'trans' to think through issues relating to gender and race, seeking, among other things, 'to explain why changing sex or gender is understood as more legitimate than changing race or ethnicity, even though biological differences between the sexes are deeper and more socially consequential than the superficial biological differences between socially defined racial and ethnic groups' (11). 
A third and final theme that connects a number of the essays, particularly in the third part of the volume, is that of the developments that might be necessary to help move biblical studies beyond its traditional Eurocentrism, beyond whiteness, as it were, and further towards being a truly global discipline. As a number of the essays in this volume detail, biblical studies as a modern critical discipline is bound up with the religious history and racial ideologies of Western Europe. This raises difficult questions, as Marilou Ibita discusses, about how students and scholars from other cultures and contexts, of other racial and ethnic identities, should enter the discipline, without simply absorbing - or being expected to replicate - the established training, methods, and underlying ideological biases of that discipline, with its historical location and its specific contextual roots. ${ }^{36}$ Ibita also mentions (as do Buell and Wan) some of the more practical and institutional barriers that continue to constrain the participation of scholars not from the traditionally dominant centres of the discipline. But the essays in Part 3 also contain various constructive proposals, whether implicitly or explicitly: Musa Dube's argument for more focus on issues of biblical translation (and their production in contexts of colonial occupation), and of the languages into which the Bible was translated; Buell's indications as to the thoroughgoing changes of process and perspective that are needed to break the hold of whiteness; Ibita's promotion of a dialogical approach as one way to weave together old and new methods in biblical studies, for example. In this connection, one significant observation, noted by Buell and Wan, among others, is that these newer approaches - particularly from 'minority' scholars - are often labelled in ways that mark their specificity, whereas traditional historical-critical exegesis remains unmarked as simply 'biblical studies', despite its particular origins and methods and, as Buell and Wan note, its predominantly white practitioners ${ }^{37}$ Doing more to acknowledge the particularity of that approach might be one move that would help to equalize the status and value of the range of perspectives currently brought to the task of biblical interpretation, including the African-American perspective presented by Love Sechrest - also the product of a particular history, and acknowledged as such. ${ }^{38}$ Indeed, the kind of use of analogy that Sechrest discusses as a significant aspect of that particular hermeneutic might perhaps be interestingly juxtaposed with the kinds of analogy that operate - but often implicitly rather than explicitly - in much traditional historical exegesis. All this brings us to the point with which Wan concludes his essay, and the volume as a whole, referring to Audre Lorde and her appeal for a true appreciation and celebration of difference. This would mean, it seems to me, not simply welcoming a diversity of approaches into the field of

${ }^{36}$ On this issue, see also, Musa W. Dube, 'Introduction. The Scramble for Africa as the Biblical Scramble for Africa: Postcolonial Perspectives', in Postcolonial Perspectives in African Biblical Interpretations, ed. Musa W. Dube, Andrew M. Mbuvi, and Dora R. Mbuwayesango (Atlanta: Society of Biblical Literature, 2012), 1-26, at 17-20, on 'Unthinking Eurocentrism'.

37 Cf. the comment of Richard Dyer, White (London and New York: Routledge, 1997), 4: 'It has become common for those marginalised by culture to acknowledge the situation from which they speak, but those who occupy positions of cultural hegemony blithely carry on as if what they say is neutral and unsituated - human but not raced ... there is something especially white in this non-located and disembodied position of knowledge, and thus it seems especially important to try to break the hold of whiteness by locating and embodying it in a particular experience of being white.'

38 See, for example, Emerson B. Powery and Rodney S. Sadler Jr., The Genesis of Liberation: Biblical Interpretation in the Antebellum Narratives of the Enslaved (Louisville, KY: WJK, 2016), for the early slave narratives as the early forms of African-American biblical hermeneutics. 
biblical studies, and arranging these as 'minority voices' around a stable and unlabelled core, but rather recognizing the particularity of our epistemological locations - products of our particular bodily locations, with all the various facets of our identity (ethnic/racial, religious, etc.) - and therefore recognizing too that a diversity of perspective and insight, representing the range of embodied locations, is necessary for rich, full, and relevant insight. Yet that would also mean addressing the dynamics and differentials of power that continue to structure the field, without which celebration of difference remains a patronizing gesture on the part of the gatekeepers of our discipline. If, as well as a range of historical insights into texts and interpretation, this volume can contribute something to the ongoing critical conversation through which such restructuring of the discipline can continue, then it will have served a valuable purpose.

\section{References}

Ahmed, Sara. 'Declarations of Whiteness: The Non-Performativity of Anti-Racism'. borderlands 3, no. 2 (2004): (n.p.). Available online: http://www.borderlands.net.au/ vol3no2_2004/ahmed_declarations.htm (accessed 30 August 2017).

Brett, Mark G. 'Interpreting Ethnicity: Method, Hermeneutics, Ethics'. In Ethnicity and the Bible, edited by Mark G. Brett, 3-22. Biblical Interpretation. Leiden: Brill, 1996.

Brubaker, Rogers. Ethnicity without Groups. Cambridge, MA and London: Harvard University Press, 2004.

Brubaker, Rogers. Grounds for Difference. Cambridge, MA: Harvard University Press, 2015.

Brubaker, Rogers. Trans: Gender and Race in an Age of Unsettled Identities. Princeton, NJ, and Oxford: Princeton University Press, 2016.

Buell, Denise Kimber. Why This New Race: Ethnic Reasoning in Early Christianity. New York: Columbia University Press, 2005.

Chamberlain, M. E. The Scramble for Africa. 3rd edn. Seminar Studies in History. Abingdon and New York: Routledge, 2013.

Cornell, Stephen and Douglas Hartmann. Ethnicity and Race: Making Identities in a Changing World. Sociology for a New Century. Thousand Oaks, CA: Pine Forge, 2007.

Dube, Musa W. 'Introduction. The Scramble for Africa as the Biblical Scramble for Africa: Postcolonial Perspectives. In Postcolonial Perspectives in African Biblical Interpretations, edited by Musa W. Dube, Andrew M. Mbuvi, and Dora R. Mbuwayesango, 1-26. Atlanta: Society of Biblical Literature, 2012.

Dyer, Richard. White. London and New York: Routledge, 1997.

Ehrensperger, Kathy. 'Paulus, sein Volk und die Rasseterminologie: Kritische Anfragen an den „Race“-Diskurs in neuerer englischsprachiger Paulus-Forschung. Kirche und Israel 27 (2012): 119-33.

Eriksen, Thomas H. 'Ethnicity, Race, Class and Nation'. In Ethnicity, edited by John Hutchinson and Anthony D. Smith, 28-31. Oxford Readers. Oxford: Oxford University Press, 1996.

Esler, Philip F. Conflict and Identity in Romans: The Social Setting of Paul's Letter. Minneapolis: Fortress, 2003.

Fredriksen, Paula. 'What "Parting of the Ways"? Jews, Gentiles, and the Ancient Mediterranean City'. In The Ways that Never Parted: Jews and Christians in Late Antiquity and the Early Middle Ages, edited by Adam H. Becker and Annette Yoshiko Reed, 35-63. TSAJ 95. Tübingen: Mohr Siebeck, 2003. 
Fredriksen, Paula. 'Mandatory Retirement: Ideas in the Study of Christian Origins Whose Time Has Come to Go', Studies in Religion/Sciences Religieuses 35 (2006): 231-46.

Fredriksen, Paula. 'Judaizing the Nations: The Ritual Demands of Paul's Gospel'. NTS 56 (2010): 232-52.

Hannaford, Ivan. Race: The History of an Idea in the West. Washington, DC/Baltimore: Woodrow Wilson Center/Johns Hopkins University Press, 1996.

Hurtado, Larry W. Destroyer of the Gods: Early Christian Distinctiveness in the Roman World. Waco, TX: Baylor University Press, 2016.

Hutchinson, John and Anthony D. Smith. 'Introduction'. In Ethnicity, edited by John Hutchinson and Anthony D. Smith, 3-14. Oxford Readers. Oxford: Oxford University Press, 1996.

Jones, Steve. The Language of the Genes: Biology, History and the Evolutionary Future. Revised edn. London: Flamingo HarperCollins, 2000.

Kidd, Colin. The Forging of Races: Race and Scripture in the Protestant Atlantic World, 1600-2000. Cambridge: Cambridge University Press, 2006.

McCoskey, Denise Eileen. Race: Antiquity and its Legacy. Ancients and Moderns. London and New York: I. B. Tauris, 2012.

Meer, Nasar. 'Racialization and Religion: Race, Culture and Difference in the Study of Antisemitism and Islamophobia'. Ethnic and Racial Studies 36, no. 3 (2013): 385-98.

Meer, Nasar, ed. Racialization and Religion, special issue of Ethnic and Racial Studies 36, no. 3 (2013): 385-515. Also published as an edited book: Nasar Meer, ed. Racialization and Religion: Race, Culture and Difference in the Study of Antisemitism and Islamophobia. Ethnic and Racial Studies. London and New York: Routledge, 2013.

Miller, David M. 'Ethnicity Comes of Age: An Overview of Twentieth-Century Terms for Ioudaios'. Currents in Biblical Research 10 (2012): 293-311.

Mitchell, Claire. 'Behind the Ethnic Marker: Religion and Social Identification in Northern Ireland'. Sociology of Religion 66, no. 1 (2005): 3-21.

Mitchell, Claire. 'The Religious Content of Ethnic Identities'. Sociology 40, no. 6 (2006): 1135-52.

Nongbri, Brent. Before Religion: A History of a Modern Concept. New Haven and London: Yale University Press, 2013.

Pew Research Center. 'Religious Hostilities Reach Six-Year High'. 14 January 2014. Available online: http://www.pewforum.org/2014/01/14/religious-hostilities-reach-sixyear-high/ (accessed 23 June 2017).

Pew Research Center. 'What It Takes to Truly Be "One of Us"'. 1 February 2017. Available online: http://www.pewglobal.org/2017/02/01/what-it-takes-to-truly-be-one-of-us/ (accessed 23 June 2017).

Powery, Emerson B. and Rodney S. Sadler Jr. The Genesis of Liberation: Biblical Interpretation in the Antebellum Narratives of the Enslaved. Louisville, KY: WJK, 2016.

Roetzel, Calvin J. 'No "Race of Israel" in Paul'. In Putting Body and Soul Together: Essays in Honor of Robin Scroggs, edited by Virginia Wiles, Alexandra Brown and Graydon F. Snyder, 230-44. Valley Forge, PA: Trinity Press International, 1997.

Schermerhorn, Richard A. Comparative Ethnic Relations: A Framework for Theory and Research. [1970] Chicago and London: University of Chicago Press, 1978.

Sechrest, Love L. A Former Jew: Paul and the Dialectics of Race. LNTS 410. London and New York: T\&T Clark, 2009.

Smith, Anthony D. The Ethnic Origins of Nations. Oxford: Blackwell, 1986.

Smith, Jonathan Z. 'Religion, Religions, Religious'. In Critical Terms for Religious Studies, edited by Mark C. Taylor, 269-84. Chicago and London: University of Chicago Press, 1998. 
Smith, Wilfred Cantwell. The Meaning and End of Religion. [1962] Minneapolis: Fortress, 1991.

Sollors, Werner. 'Foreword: Theories of American Ethnicity'. In Theories of Ethnicity: A Classical Reader, edited by Werner Sollors, $\mathrm{x}$-xliv. New York: New York University Press, 1996.

Storm, Ingrid. "'Christianity is not just about religion”: Religious and National Identities in a Northern English town'. Secularism and Nonreligion 2 (2013): 21-38.

UNESCO. 'The Race Question. Text of the Statement Issued 18 July 1950'. Available online: http://unesdoc.unesco.org/images/0012/001282/128291eo.pdf (accessed 16 December 2015).

Weber, Max. 'Race Relations' [1922]. In Max Weber: Selections in Translation, edited by W. G. Runciman, 359-69. Cambridge: Cambridge University Press, 1978. 


\section{Part One}

Ethnicity, Religion, and Identity in Antiquity: Jews and Christians in the Hellenic World 



\title{
Society, Identity, and Ethnicity in the Hellenic World
}

\author{
Teresa Morgan
}

In the past thirty years, representations of ethnicity in the Greek and Roman worlds and their relationship with other ideas about identity have become a major field of research. The cultivation of the field owes much to two disciplines which arose separately but have increasingly interacted: the study of ethnic identifiers in documentary inscriptions and papyri, and the reading of Greek and Latin literature in a framework informed by theoretical writing on ethnicity in the social and physical sciences. ${ }^{1}$ Between them, these disciplines have transformed our understanding of ancient assumptions and assignations, evaluations, and manipulations of ethnicity: of their complexity and their significance.

On the literary side, the ground was broken in the mid-to-late 1980s by a series of studies in Greek culture by Edith Hall, Catherine Morgan, Paul Cartledge, and Jonathan Hall. ${ }^{2}$ Their work draws on thinking about ethnicity and race in biology and sociology, while paying close attention to the cultural specificity of ancient discourses and languages of identity. Jonathan Hall, perhaps the most influential of the group, developed a six-part definition of Greek ethnicity which has been adopted by both Greek and Roman historians (and also by scholars of ancient Judaism and early Christianity). Ethnic groups are 'self-ascribing and self-nominating' social entities which self-differentiate from other groups. Biological features may be invoked but do not ultimately define them; they are defined above all by shared myths of common descent, shared territory, and a sense of shared history. They are not static, and through time both assimilate with other groups and differentiate from them. Individuals have multiple social identities, so ethnic identity is not always the most important aspect of

1 The literary/documentary distinction has never been watertight, of course; studies on both sides refer to sources on the other.

2 Edith Hall, Inventing the Barbarian (Oxford: Oxford University Press, 1989); Catherine Morgan, Athletes and Oracles (Cambridge: Cambridge University Press, 1990); Paul Cartledge, The Greeks: A Portrait of Self and Others (Oxford: Oxford University Press, 1993); Jonathan M. Hall, Ethnic Identity in Greek Antiquity (Cambridge: Cambridge University Press, 1998). 
identity in a given context. Finally, ethnicity often emerges in the context of migration or conquest. ${ }^{3}$

Hall's list hints at another criterion which never becomes explicit but is often taken for granted by ancient historians: What he identifies as 'ethnics' (at least down to the level of the city ${ }^{4}$ ) tend to be terms for groups which, at some point in their history, were politically autonomous. ${ }^{5}$ This submerged, but significant, criterion helps to explain why historians include in studies of ethnicity groups very varied in shape and size, some of which at times identify closely with one another and share myths of descent, history, and even territory. Despite their obvious differences, for example, 'Athenian' (referring to a citizen of a city) may be counted an ethnic, and so may 'Boeotian' (typically referring to a citizen of one of a regional group of cities), 'Greek' (encompassing citizens of many cities and regions), 'Macedonian' (referring to a subject of the kingdom), 'Egyptian', 'Jewish', and 'Roman' (a highly complex concept which this essay will not attempt to map). This criterion also helps to explain why certain groups are excluded from studies of ethnicity. For example, ancient historians do not typically count 'Christian' as an

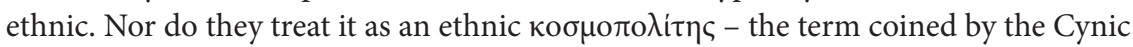
Diogenes to identify himself as a 'citizen of the world' and used by Stoics to identify with an abstract and universal community of the good - though it shares most of Hall's

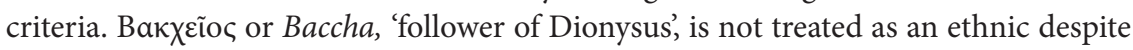
the fact that Livy, for instance, can attribute to the consuls at Rome in 186 BCE the conviction that followers of Dionysus constitute a sociopolitical entity whose existence is a political threat to the Roman state (Livy, 39.8-18). ${ }^{6}$

In thinking about ethnicity, are we justified in privileging groups which at some period enjoy political autonomy? Up to a point. What scholars recognize as ethnics are also terms used as identifiers in legal documents and public inscriptions, so modern scholarship often follows ancient political and social authorities. We should be aware, however, that ancient agents self-identify with a much wider range of what, on modern criteria, are identifiable as ethnicities than either ancient or modern authorities acknowledge: a point of relevance to students of early Christianity.

We will return to this issue, but most of this essay will discuss what most modern scholars treat as ethnic identifiers to see how their treatment by individuals and groups evolves in the half-millennium or so before the Common Era. First, however, it is worth noting that the Greek and Latin terms which we associate with ethnicity

3 Jonathan M. Hall, Hellenicity: Between Ethnicity and Culture (Chicago: University of Chicago Press, 2002), 9-10. The approach of Hall et al. now informs studies of ethnicity throughout the ancient Mediterranean and Near East: notably Greg Woolf, Becoming Roman: The Origins of Provincial Civilization in Gaul (Cambridge: Cambridge University Press, 1997); Nathanael Andrade, Syrian Identity in the Graeco-Roman World (Cambridge: Cambridge University Press, 2013); Alex Mullen, Southern Gaul and the Mediterranean: Multilingualism and Multiple Identities in the Iron Age and Roman Periods (Cambridge: Cambridge University Press, 2013); Kostas Vlassopoulos, Greeks and Barbarians (Cambridge: Cambridge University Press, 2013); Andrew Gardner, Edward Herring, and Kathryn Lomas, eds, Creating Ethnicities and Identities in the Roman World (London: Institute of Classical Studies, 2013).

4 " $\mathrm{E} \theta v \mathrm{oc}$ is also used of various 'tribal' groups within cities.

5 One exception are ethnics of non-autonomous cities within kingdoms; see P. M. Fraser, Greek Ethnic Terminology (Oxford: Oxford University Press, 2009).

6 Teresa Morgan, Roman Faith and Christian Faith (Oxford: Oxford University Press, 2015), 485-6. 
refer to far more than groups which at some point held political or military power. "E $\theta$ voc can refer to almost any kind of group, human or animal.7 Гévo kinship groups (small or large) but can also refer, among other things, to a sex, class, or any 'type' of person or thing. Genus is used of everything from the human race to an individual family member via all kinds of species, political groupings, professional classes, social orders, groups, sexes, or characters of plant, animal, or person."E $\theta v o \varsigma$, $\gamma \varepsilon \dot{v}$ o , and genus can refer to political groupings of many sizes and kinds, from a family network to a city-state, a collection of states, the people of a region, or a kingdom. Herodotus, for example, whose interest in identity makes him a rich, if sometimes idiosyncratic, source for the study of identity in the fifth century BCE, can use $\gamma \varepsilon$ ćvo to refer to a group within an $\varepsilon \dot{\varepsilon} \theta$ o $(1.56,1.101)$, عُ $\theta$ vo of a group within a $\gamma \dot{\varepsilon} v o \varsigma(1.143)$, and the two as synonyms. ${ }^{8}$ Meanwhile, the Greek term which most straightforwardly means 'kinship' or a grouping based on shared descent is $\sigma v \gamma \gamma \dot{\varepsilon} v \varepsilon\llcorner a$, which usually refers to relatively close family and is rarely used of groups with wider sociopolitical or cultural identities. When Greek or Latin writers refer to an $\varepsilon$ $\theta \nu \circ \varsigma, \gamma \varepsilon \dot{\varepsilon} \nu \varsigma$, or genus, they may therefore be talking about almost any kind of group, for which any aspect of the term may be important, marginal, or irrelevant. We must accordingly always treat the language of ethnicity or identity, including early Christian identity, with caution. Its terminology is so multivalent that its meaning is likely to be highly specific to the context in which it is used.

If terms such as $\gamma \dot{\varepsilon} v o \varsigma$ and $\varepsilon \theta v o \varsigma$ are complex and multivalent, 'Greek', 'Ionian', or 'Egyptian' are equally slippery, referring to different groups of people in different contexts or the same groups differently defined. Some scholars have responded by expanding their definition of ethnic identity to include a number of other markers which are invoked by ancient writers as identifying groups: above all shared language, customs, and/or cult. ${ }^{9}$ If these can also be arbiters of ethnicity, then Herodotus may have been articulating a widely shared view when he put into the mouths of the Athenians,

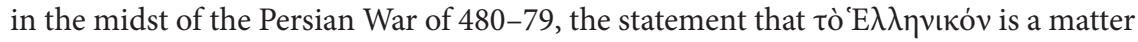
of shared blood, language, temples, rituals, and ways of life (8.144). Modern historians would refine Herodotus mainly by emphasizing what Herodotus often illustrates, that not every dimension is in play in every context, and that identity is not always defined by opposition. On the contrary, as Hall argues, though identity is always differential for 'Greeks', its articulation is by no means always intended adversarially. ${ }^{10}$

In recent years, studies of ethnicity in literary texts have interacted increasingly with documentary papyrology and epigraphy to generate richer historical accounts of ethnicity and more theoretically informed studies of documentary texts. P. M. Fraser's Greek Ethnic Terminology, for example, brings a theoretically sophisticated approach to the study of individual and group identity in Greek inscriptions. Fraser shows how, in their native city, individuals in the classical Greek world tend to be identified by name, patronymic, and/or deme (official 'home' village or region), rather than by city.

Fraser, Terminology, 1-35.

8 1.56.2, cf. 1.57.3, 5.91.1. Later historians follow Herodotus' example.

9 For example, David Konstan, 'Defining Ancient Greek Ethnicity', Diaspora 6 (1997): 97-110; Gardner et al., Creating Ethnicities, 2-3.

10 Jonathan M. Hall, 'Ancient Greek Ethnicities: Towards a Reassessment', BICS 58, no. 2 (2015): 15-29. 
Non-locals from nearby city-states tend to be identified by the name of their city ('Plataean', 'Epidauran'), though certain groups (such as 'Boeotian' and 'Thessalian' mercenaries), for uncertain reasons, are often identified by region rather than city. In some cases, non-locals are identified by both city and a larger grouping ('from Helikē, Achaean'). ${ }^{11}$ Non-locals from further away are more likely to be identified by terms for larger regions ('Thracian', 'Ionian') or simply as 'foreigner' ( $\xi \dot{\varepsilon} v o \varsigma) .{ }^{12}$ Fraser's work illustrates vividly how Greek 'ethnic' identities are not a set of fixed or objective categories, but vary according to context and the perspective of users. Under the Roman Empire, the use of ethnics in the Greek-speaking world in general dies out: perhaps, Fraser suggests, because it ceases to be strongly correlated with citizenship of politically autonomous cities. ${ }^{13}$ Fraser also observes that early Christians very rarely use 'ethnics': whether because most belonged to non-citizen populations of cities or because they lived in the countryside where such things seem to have been of less interest - or, one might add, because they identified with the kingdom of God rather than with any earthly group - we cannot currently tell. ${ }^{14}$

Some of the most striking findings about identity in the Greek and Roman worlds have emerged from the study of documentary papyri from Ptolemaic and Roman Egypt, to which we will return. ${ }^{15}$ Relatively rich evidence, mostly epigraphic rather than papyrological, also survives from the Hellenistic Seleucid kingdom and the Roman province of Syria. Richard Fowler has explored representations of identity under the Seleucids in 'Ethnicity and Power: Studies on Royal Ideology in the Hellenistic Fertile Crescent, ${ }^{\prime}{ }^{16}$ while Nathanael Andrade has treated the nature of 'Syrian-ness' in Syrian Identity in the Greco-Roman World. ${ }^{17}$ Fowler and Andrade focus particularly on the area around Babylon, one of two regions from which most of our best evidence for thinking about ethnicity in the Graeco-Roman Near East derives. The other is Israel. The study of Jewish understandings of identity and conflicts over identity in the Hellenistic world is a sizeable field in its own right which lies beyond the scope of this essay. Most recent studies, however, share with studies of Greek and Roman identity a nuanced account

11 Perhaps because the city belongs to a federation which self-identifies as an ethnic group.

12 See Fraser, Terminology, 76 (locals in home cities), 79 (mercenaries), 112 (foreigners in Athens), and 119-20 (identifications by city and regional ethnic).

13 Alternatively, other markers of Greekness may become more important. Cf. R. J. van der Spek, 'Multi-ethnicity and Ethnic Segregation in Hellenistic Babylon', in Ethnic Constructions in Antiquity: The Role of Power and Tradition, ed. Ton Derks and Nico Roymans (Amsterdam: Amsterdam University Press, 2009), 101-16.

14 Fraser, Terminology, 232.

15 Fundamental studies include Dorothy J. Thompson, Kerkeosiris: An Egyptian Village in the Ptolemaic Period (Cambridge: Cambridge University Press, 1971); eadem, Memphis Under the Ptolemies, 2nd edn (Princeton, NJ: Princeton University Press, 2012); Naphtali Lewis, Greeks in Ptolemaic Egypt (Oxford: Oxford University Press, 1986); Koen Goudriaan, Ethnicity in Ptolemaic Egypt (Amsterdam: J. C. Gieben, 1988); Per Bilde, Troels Engberg-Pedersen, Lise Hannestad, and Jan Zahle, eds, Ethnicity in Hellenistic Egypt (Aarhus: Aarhus University Press, 1992); Csaba La'da, Foreign Ethnics in Hellenistic Egypt (Leuven: Peeters, 2002); Gregor Weber, ed., Kulturgeschichte des Hellenismus: von Alexander dem Grossen bis Kleopatra (Stuttgart: Klett-Cota, 2007); Jean Bingen, Hellenistic Egypt: Monarchy, Society, Economy, Culture (Edinburgh: Edinburgh University Press, 2007); Sandra Coussement, 'Because I am Greek': Polyonymy as an Expression of Ethnicity in Ptolemaic Egypt (Leuven: Peeters, 2016).

16 DPhil. thesis, University of Oxford, 1999.

17 See note 3. 
of ethnicity informed by modern theory and close attention to ancient evidence. They recognize that while ethnicity is invoked regularly as a marker of Jewish identity and a form of differentiation, its content is variable, negotiable, and contestable.

A number of the ideas touched on here are now widely shared by scholars of ancient Mediterranean and Near Eastern ethnicity. Ethnicity (like identity in general) is always a construct. Representations may invoke (among other things) stories of shared descent, shared territory and history, language, culture, and/or cult. The content and significance of claims about ethnicity are closely tied to the contexts in which they occur and the perspectives of those who invoke them and, in any one context, some aspects of the concept will be privileged above others. Ethnicity is always open to renegotiation and challenge. It is differential, but not necessarily bipolar or adversarial. The rest of this essay will seek to draw out the significance of some of these propositions in the Greek, especially the Hellenistic, world. The final section will reflect briefly on their implications for thinking about ethnicity among early Christians.

\section{Early Greek views}

If there was a time and a region in the Graeco-Roman world in which the idea of ethnicity based on shared descent, history, and territory had particular currency, it has been suggested that it was the archaic and classical Greek world. Between the eighth and fourth centuries BCE, groups such as Dorians and Ionians can be found tracing themselves back to a single eponymous ancestor. ${ }^{18}$ Arcadians sometimes identify as descendants of aboriginal Pelasgians, Athenians as descendants of the autochthonous Erechtheus or Erichthonius. ${ }^{19}$ In the same period, however, some of the same groups tell stories of the migration of their ancestors across the Mediterranean to conquer the lands where they now live and intermarry with earlier inhabitants. ${ }^{20}$ Others trace their name back to that of a mythical king (Macedon, Cyzicus, Taras) without claiming that all their members are descended from him. Meanwhile, the most famous story of human origins composed in this period, Hesiod's 'ages of man' at the beginning of Works and Days (196-76), does not rely on the idea of shared descent, history, or territory at all. Identity based on these factors is at most one idea among several in play.

The context in which late archaic and classical Greek cities take the most practical interest in shared descent, history, and territory is in their citizenship laws. To count as Athenian, for instance, for political and legal purposes, in the early sixth century BCE, one had to live and work in Attica. After Cleisthenes' political reforms of 508/7, one's father had to be Athenian; under Pericles' citizenship law of 451, both parents. The citizen elite of Sparta, Spartiates, had two Spartiate parents. Even in classical Athens, however, grants of citizenship were made to individuals and groups who did

${ }_{18}$ Heraclides Criticus fr. 3.2 in Friedrich Pfister, Der Reisebilder des Herakleides (Vienna: R. M. Rohrer, 1951); Conon 26, FGH 1.27.

19 Euripides, Phoen, 638-75; Pherecydes 3 FGH 22 (Thebans); Herodotus 2.171.3 (Arcadians); Herodotus 1.57.3; 2.51.1-2 (Athenians).

${ }^{20}$ For example, Herodotus 2.51 (Pelasgians); Herodotus 1.171.2 and Thucydides 1.4 (Carians); see Hall, Ethnic Identity, 30-6. 
not qualify by birth, while in Sparta, entry to the group of adult male Spartiates was not only by birth but also by contribution to the common mess, and those who lacked funds to contribute were excluded. Even when cities most valued endogamy, shared descent, history, and territory were never sufficient arbiters of identity.

Hall has argued that the concept of 'Greekness' emerged largely as a result of Greek colonial expansion in the early Iron Ages and, moreover, that it emerged first in the new overseas settlements. It is when people leave home, he suggests, and come into contact with unfamiliar groups, that they first begin to think about and define identity. ${ }^{21}$ This attractive theory may also (at least partly) explain why some of the most creative and sustained thinking about identity in the Hellenistic and Roman worlds takes place among displaced Greeks, diaspora Jews, and early Christians.

Herodotus, however, shows how labile even apparently straightforward identifiers of colonial ethnicity are in his day and shortly before. At 1.146 he comments on the weakness of the Greek $\gamma \varepsilon$ v $v$ os in general in the mid-sixth century, and in particular that of the Ionian $\varepsilon \theta v o \varsigma$ (which he treats, in principle, as a descent group). Most of those, he says, whom outsiders called Ionians disliked the name and refused to use it. The exceptions were twelve cities, which built the Panionium cult centre to establish their shared identity. Inhabitants of these cities, however, were and are mostly not Ionians: They belong to other tribes which intermarried with locals. Herodotus, tellingly, invokes the idea of Ionian ethnicity here only to complicate and undermine it. ${ }^{22}$

Occasionally Herodotus goes further and shows not just complexity but the deliberate acquisition of aspects of others' identities as, paradoxically, an indication that aroup has a particularly strong, distinctive, and successful identity of its own. Equally paradoxically, the two groups that share this characteristic in his work are the two which, above all, are cast as ethnic opposites and enemies at its climax: Persians and Greeks. Persians and Greeks, says Herodotus, are both exceptionally syncretistic, constantly adopting and adapting the best features of other groups with which they come into contact (1.135). The Persians, for example, have adopted Median dress, Egyptian armour, and Greek sexual habits (7.62). The Greeks learnt about armour from the Carians (1.171), religion and geometry from the Egyptians (2.49-50, 2.109), and Athena's aegis from the Libyans (4.189). The paradox that cultural porosity and acquisitiveness may be markers of a strong and dominant identity is not widely acknowledged in studies of ethnicity, but we encounter it repeatedly in Hellenistic and Roman, and also in Jewish and Christian contexts.

The Persian wars of 480-79 (in which the forces of Xerxes were defeated by an alliance of cities whom their leader, the Spartan general Pausanias, contentiously described on the commemorative column he had inscribed at Delphi as 'the Greeks') inaugurated a period in which Greeks, especially Athenians, created some of the most ethnically and culturally adversarial texts and images that survive from the ancient

${ }^{21}$ Hall, Hellenicity, chs 4-5, though there was no period when Mediterranean peoples did not come into contact with one another through trade.

22 Herodotus also talks of 'Ionia' as a region (5.37) or a group of cities (6.1). Lydian and Persian rulers of Asia Minor, meanwhile, used Yauna or similar transcriptions of 'Ionian' to refer to Greeks of all origins in their territories (Robert Rollinger, 'New Observations on "Greeks" in the Achaemenid Empire According to Cuneiform Texts from Babylonia and Persepolis', in Organisation des pouvoirs et contacts culturels dans les pays de l'empire Achéménide, ed. P. Briant and M. Chauveau (Paris: Éditions de Boccard, 2009), 331-51). I am grateful to Alexander Wilson for this observation. 
world. These differentiate 'Greeks', especially Athenians, radically from others, especially 'barbarians' and above all 'Persians. ${ }^{23}$ Even in this period, though, there are signs that Greek, and especially Athenian, identity is not just complex but porous. In his funeral speech, delivered over the Athenian dead of the first year of the Peloponnesian War in 431/0, the Athenian general Pericles, according to Thucydides (2.39), claims that Athens is more hospitable to incomers than any other city. On this and other grounds, he boasts that Athens provides a $\pi \alpha i \delta \varepsilon v \sigma ı \varsigma$ - a common education or culture - for Greece (2.41). A generation later, in about 380, the Athenian orator and teacher Isocrates published a panegyric to Athens which echoes Thucydides, speaking of Athens' unique openness to strangers (41) and her gift of philosophy to the world (47):

The result is that the name of the Hellenes no longer seems to indicate an ethnic

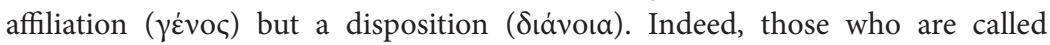
'Hellenes' are those who share our culture ( $\pi$ ai $\delta \varepsilon v \sigma \varsigma \varsigma)$ rather than a common nature $(\varphi v \dot{\sigma \iota \varsigma)})^{24}$

We do not know how the Panegyricus was received by its first audience but Isocrates was not unique in the fourth century in his views: Hall traces similar themes in the work of Xenophon, Plato, and Aristotle. ${ }^{25}$ We should not be surprised, therefore, to find Alexander the Great, Aristotle's pupil, in the late fourth century experimenting with his own culture and identity and that of his courtiers and subjects. It is no longer fashionable to suggest that Alexander aimed to abolish ethnic distinctions and achieve the 'unity of mankind', but he certainly invoked non-Macedonian identities in his public self-representation and that of his close associates. He represented himself as the son of Graeco-Egyptian Zeus-Ammon, adopted forms of Persian dress and behaviour, intermarried with his subjects and compelled other Macedonians to do the same, mixed Macedonians, Greeks, and Asians at court, and probably demanded that his courtiers treat him in some respects as a Persian king. ${ }^{26}$ Some of these behaviours were bitterly resented as un-Macedonian or un-Greek, but all attest to Alexander's conviction that identity may be at once porous, accretive, and distinctive.

Persia, Athens, and Macedon were all at different times aggressive, expansionist, successful states. For them all - and, one might argue, for the Hellenistic kingdoms and Rome ${ }^{27}$ - openness to acquiring aspects of other peoples' identities and sharing their own was part of their strong sense of identity, individuality, and power. They offer food for thought not least for those who study understandings of ethnicity and identity among Jews and Christians.

${ }^{23}$ Other members of the Achemenid Empire may stand for Persians, as does the bending Scythian on the Athenian 'Eurymedon vase'.

24 Trans. Hall, Hellenicity, 209, modified. In Panathenaeicus, Isocrates praises the Athenians as fit successors to Agamemnon, 'the general of the whole of Greece' (76).

25 Hall, Hellenicity, 210-20.

26 A. B. Bosworth, Conquest and Empire: The Reign of Alexander the Great (Cambridge: Cambridge University Press, 1988); idem, Alexander and the East: The Tragedy of Triumph (Oxford: Oxford University Press, 1996).

27 Cf. Emma Dench, Romulus' Asylum: Roman Identities from the Age of Alexander to the Age of Hadrian (Oxford: Oxford University Press, 2005). 


\section{The Hellenistic world}

The thought worlds of archaic and classical Greek cities continued powerfully to influence the imaginations of those who identified in some sense as 'Greek', as well as many whose primary identification was not Greek, long after what modern historians treat as the end of the classical Greek world. The next three centuries, however, also see developments in thought and practice which are extensions of past practice or new responses to the new contexts of the 'Hellenistic' kingdoms.

The definition of 'Hellenistic' is a moveable feast. It is widely used of a period of time (usually from the death of Alexander in $323 \mathrm{BCE}$ to the Battle of Actium in 31 BCE) and/or a geographical area under Macedonian rule (roughly from northern India to the eastern Mediterranean), but both definitions are fluid (in recent years, for instance, the concept of the 'Hellenistic west' has gained currency $\left.{ }^{28}\right)$. In the study of literature and art, 'Hellenistic' can mean 'post-classical-Greek', 'sub-classical-Greek', or 'classical-Greek-plus'. I shall take 'Hellenistic' to mean the post-Alexandrine, Greekinfluenced, political, social, and cultural world which in some aspects extends into the western Mediterranean and the period of Roman rule in both west and east. Traditional definitions have always included the history of Greek-speaking Jews and Jews under Greek-speaking rulers; my definition also includes the world of early Christians.

However defined, the Hellenistic world is a fascinating one in which to study ethnicity. Like the archaic Greek world, it is a time and place of exploration: of the conquest of new territories, building of new settlements, forging of new relationships and creation of new political, social, and cultural entities. It enables and enforces new ideas and practices of identity. Those who travel to new regions, settle new cities, serve new dynasties, write new texts, or create new artefacts look simultaneously backwards and inwards to their inherited identities and forwards and outwards to new ones.

\subsection{Shared descent, history, and territory}

We noted above the role that shared descent, history, and territory played in ethnic identification in the archaic and classical periods. All these remain sufficiently important in the Hellenistic world to be fabricated regularly by both individuals and groups. ${ }^{29}$ When, for example, new members joining the gymnasium or the ephebate in Seleucid Syria proudly advertised their Greek ancestry, onomastic evidence often suggests that they had made it up. ${ }^{30}$ Aristocratic families had long traced their ancestry back to gods or heroes. In this period individuals and, especially, cities continue to claim descent from a god or hero, often for the first time, and to invoke shared descent as a basis for new relationships and alliances. In the first century BCE, for instance, the Euboean city of Carystus sought an alliance with the Carian city of Alabanda in Anatolia (long under Macedonian rule, but usually recognized as non-Greek in origin)

28 J. R. W. Prag and Josephine Crawley Quinn, eds, The Hellenistic West: Rethinking the Ancient Mediterranean (Cambridge: Cambridge University Press, 2013).

29 An ancient pastime: cf. Herodotus 5.49; Nick Fisher and Hans van Wees, eds, 'Aristocracy' in Antiquity: Redefining Greek and Roman Elites (Swansea: Classical Press of Wales, 2015), 3-10.

30 Andrade, Syrian Identity, 44. 
on the novel grounds that both were descended from the teacher of Achilles, Chiron the centaur. ${ }^{31}$

Eftychia Stavrianopoulou has recently discussed an inscription from Sidon, erected around $200 \mathrm{BCE}$, which testifies to the importance of genealogy in a Hellenistic city but also hints at its malleability and celebrates its complexity. The inscription honours Diotimos, chief magistrate of the city and winner of the four-horse chariot race in the Nemean Games:

When all drove [their swift horses] from their chariots [in the] Argive [valley], [rivals in the competition,] to you, O Diotimos, [the people] of Phoronis [gave] noble fame, and you received the eternally memorable wreath. For, first of the citizens, the glory of an equestrian (victory) from Hellas have you brought to the home of the noble sons of Agenor. Thebes, sacred city of Kadmos, also boasts, seeing her mother-city glorious with victories. As for your father Dionysios, fulfilled was [his vow concerning the] context when Hellas shouted this clear [message]: 'Not only for its ships [is Sidon] extolled [above others], but now also for prize-winning [chariot-teams]. ${ }^{32}$

Sidon is a Phoenician city under Seleucid rule, which here links itself with Greek Argos (whose colony it claims to be) and Thebes (whose mother city it claims to be). The language and references are Greek, but there are hints that Greekness is not Diotimos' only affiliation. ${ }^{33}$ It is as a Phoenician, not a Greek, city that Sidon is famous for its ships. Stavrianopoulou argues, moreover, that in calling Dionysios

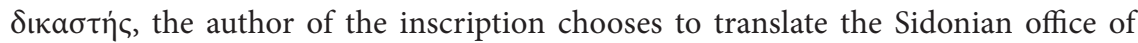
shofut with a Greek term which describes its role, rather than with the more common but less specific term for a Greek magistrate, ä $\rho \chi \omega v$. By this means, she suggests, the Sidonians advertise not only their own and Diotimos' Greekness but also their continuing Phoenicianism. ${ }^{34}$

As classical Greek cities took different approaches to maintaining citizen descent groups, so Macedonian royal dynasties took different approaches to maintaining their identity. The Ptolemies tended to marry within the family or with other Macedonian royal families. The Antigonid kings married Macedonian, Greek, and Epirote women, but not Asians. One of the wives of Lysimachus, king of Macedon and Thrace was the Persian princess Amastris, niece of Darius III. The Seleucids too married outside Macedonian or Greek families: Seleucus I (r. 305-281) and Demetrius I (r. 161-50) both seem to have married Sogdian princesses called Apama. There is no sign that any of these families regarded themselves as less Macedonian by the first century BCE than

31 IG XII 9.4; O. Curty, Les parentés légendaires entre cites grecques: catalogue raisonné des inscriptions contentant le terme SUNGENEIA et analyse critique (Geneva: Librarie Droz, 1995).

32 See Eftychia Stavrianopoulou, 'Hellenistic World(s) and the Elusive Concept of "Greekness", in Shifting Social Imaginaries in the Hellenistic Period: Narrations, Practices, and Images, ed. Eftychia Stavrianopoulou (Leiden: Brill, 2013), 177-205.

33 Stavrianopoulou, 'Hellenistic World(s)', 178.

34 Corinne Bonnet, Les enfants de Cadmos: le paysage religieux de la Phénicie hellénistique (Paris: Boccard, 2015), 260-5, offers a different interpretation which also captures Diotimos' ethnic complexity. 
in the third. Political advantage was undoubtedly a factor in all royal marriages, but we may also detect in them different attitudes to the transmission of ethnicity. ${ }^{35}$

Outside royal families we must assume that intermarriage was common, even the norm, between Macedonians, Greeks, and other inhabitants of the Hellenistic kingdoms. The earliest Macedonian and Greek settlers were soldiers and traders, most of whom, if not all, were male. In later generations it was probably still far more common for men than women to move around the Mediterranean. Even when we have information about family groups from tax or census documents, it rarely covers more than two or three generations, so we cannot trace lines of descent far (this is true even of relatively strongly self-defining groups such as Jews ${ }^{36}$ ). But by the late third century $\mathrm{BCE}$, it is likely that most families in the Hellenistic kingdoms, however ethnically selfdefined, were, to an outsider eye, mixed.

\subsection{Assigned identities: Tax, legal, and professional status}

Ethnic markers continued to be performed, recorded, advertised, and celebrated throughout the Hellenistic kingdoms. In many cases, however, ethnicity clearly became an assigned rather than inherited identity. It was a legal and tax status; a consequence of holding a certain type of citizenship or job. A few examples must suffice from the great wealth of data now available.

Alexander the Great and his successors established dozens of new cities in their kingdoms, some of which became primary seats of Macedonian administrations. Simultaneously, existing cities (such as Tyre, Sidon, Memphis, and Babylon) acquired Greek polis status and institutions. These cities were established or endowed with many of the political and social institutions of classical Greek poleis, including councils (which undertook much of the cities' day-to-day administration), magistracies, gymnasia, and ephebates. New cities were settled

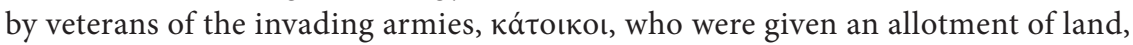
together with other Greek and Macedonian incomers and inhabitants of the area. Those eligible to serve in and enjoy the cities' elite sociopolitical institutions were their citizens, who were classed as Greeks. Some of these will have self-identified as Macedonian rather than Greek. Others, by background, were neither: they were Greeks by status.

Numerous inscriptions from later Hellenistic Seleucia honour individuals with Syrian names and Greek citizen rights. ${ }^{37}$ The citizens of the Greek polis of Tyriaion include individuals with Macedonian, Greek, Phrygian, and Galatian names. ${ }^{38}$ The Diary of the Messengers of the Citizens, a fragmentary astronomical diary from Babylon, refers (lines 3-7) to citizens in connection with the high priest of Esagila. Rolf Strootman has argued persuasively that this suggests that the Greek community

35 In other contexts, for different purposes, all these families could also represent themselves as belonging to other groups: see below, pp. 33-4.

${ }^{36}$ Gideon Bohak, 'Ethnic Continuity in the Jewish Diaspora in Antiquity', in Jews in the Hellenistic and Roman Cities, ed. John R. Bartlett (London: Routledge, 2002), 175-92.

37 See, for example, Fowler, 'Ethnicity', 179, 374; Andrade, Syrian Identity, 10, 42; cf. Pliny, Nat. 6.22.

38 Andrade, Syrian Identity, 43. 
in Babylon consisted in part of the upper echelons of earlier Babylonian society who were still worshipping their traditional gods. ${ }^{39}$ It has sometimes been argued that the aim of the reforms of Antiochus IV in Jerusalem was to establish a polis of which Hellenizing Jews would have become (some of) the citizens. Though few now think this was the case in this instance, there is nothing implausible about the idea in principle: The practice of enrolling non-Greeks as Greek citizens of a polis was widespread.

It was also possible to be classed as Greek without being a citizen of a city. This seems to have been the case for Alexandrian Jews, who were classed as Greeks for tax and legal purposes and had entry, for instance, to the gymnasium, but were not Alexandrian citizens. ${ }^{40}$ Dorothy Thompson and Willy Clarysse, in their study of Ptolemaic tax registers, have argued that the Ptolemies used tax status routinely as a means of social control and reward. Having acquired Egypt with a relatively small force of Macedonians and Greeks, they sought to enlist the support of the existing ruling classes (which included Persians, Egyptians, and probably Arabs) in government. ${ }^{41}$ These ruling classes, in cities, towns, and villages, were encouraged to learn Greek, adopt Greek customs, and serve the new administration; the reward of cooperation was to be redefined as Greek.

These 'tax Greeks', or 'new Greeks', ${ }^{42}$ included teachers of Greek letters, 'actors of Dionysus' who performed Greek drama, doctors, policemen, priests, soldiers, and temple workers (in both Greek and Egyptian temples). Some appear in documentary records writing in demotic, or writing Greek with a brush rather than a pen, revealing their training as Egyptian scribes. Many have non-Greek names (like the well-attested Petechonsis, scribe and an official of the tax-area of the Themistos Section between early 229 and mid-224 BCE) or belong to families of which all other members have Egyptian names. A few have double, Greek and Egyptian, tax status.

Occasionally we can trace the rise of an individual through the ethnic ranks. A famous case is that of Maron, also known as Nektsaphthis, son of Petosiris, of the Egyptian village of Kerkeosiris. Nektsaphthis first appears in the Kerkeosiris archives in a document dated to $119 / 8$ BCE. ${ }^{43}$ The following year, he appears as 'Maron son of Dionysios, formerly known as Nektsaphthis son of Petosiris'. A few years later he appears again as 'Maron son of Dionysius, Macedonian of the catoectic cavalry'. This is the elite military classification, carrying high social status, which originally belonged only to Macedonians by descent. Within about a decade, it seems, Nektsaphthis has risen from Egyptian to Macedonian status. ${ }^{44}$ (We may note that even if Nektsaphthis' tax

39 Rolf Strootman, 'Babylonian, Macedonian, King of the World: The Antiochus Cylinder from Borsippa and Seleukid Imperial Integration', in Social Imaginaries, ed. Stavrianopoulou, 67-98, esp. 84-5.

40 Avi Avidov, Not Reckoned Among the Nations: The Origins of the So-called 'Jewish Question' in Roman Antiquity (TSAJ 128; Tübingen: Mohr Siebeck, 2009), 172-8.

${ }^{41}$ Willy Clarysse and Dorothy J. Thompson, Counting the People in Hellenistic Egypt (2 vols; Cambridge: Cambridge University Press, 2006).

42 Clarysse and Thompson, Counting the People, 138.

${ }^{43} \mathrm{P}$ Teb. 1:546-7.

44 Jane Rowlandson, 'Dissing the Egyptians: Legal, Ethnic, and Cultural Identities in Roman Egypt', in Creating Ethnicities, ed. Gardner et al., 213-47, at 218. 
status has changed, he may not have left one identity behind when acquiring another; he may have kept them all in play in different contexts. ${ }^{45}$

Tax status did not always follow one's job. Those identified as 'Persian' or 'Arab' were, like Jews, classed as Greek for tax purposes, for reasons we do not know. The ethnic profile, in terms of descent, of these groups is particularly unclear. Many Persians have Egyptian names and some have both Egyptian and Greek names, suggesting that the Ptolemies may not have been the first imperialists to co-opt members of existing elites into the new ruling class. ${ }^{46}$ Some Arabs have names attested in the Arabian peninsula; others have Greek or Egyptian names. A significant number of Arabs are attested as shepherds or policemen, but the status of Arabs as tax Greeks seems to extend beyond particular occupations. ${ }^{47}$

It is common (though not universal) in Ptolemaic Egypt for individuals of very varied social status to have Greek names while the rest of their families have Egyptian names, or for the men of a family to have Greek names while the women have Egyptian names. In some cases this may indicate descent, but often it probably indicates that, for men engaged in public life, a Greek name was a reflection (or claim) of a certain status. Women, less engaged in public life, were less in need of acquiring such a name. It also suggests that there was no disgrace for a 'Greek' man in having an identifiably Egyptian family. The number of cases in which we know of both the Egyptian and the Greek name of an individual also indicates this, and further suggests that different names and identities were used in different contexts.

\subsection{Ethnicity and code-switching}

If it was appropriate for individuals to use different names and ethnic identifiers in different contexts, ethnic identity was not holistic or exclusive but could be a matter of code-switching. 'Code-switching' is a term borrowed from linguistics to refer (originally and most simply) to individuals who speak more than one language, using each as single-language speakers use it, rather than mixing the two on a linguistic or conceptual level. It has been widely applied in the study of cultures to people who are able to operate in more than one cultural context in a way appropriate to monocultural users of each. The most famous example of code-switching in the Hellenistic world is the self-representation of the Ptolemies. When they were crowned at the pre-Greek capital Memphis, in their observance of Egyptian cult, and in the temples they commissioned to Egyptian gods, the Ptolemies represented themselves in traditionally Egyptian style. At court, in Alexandrian statues and on coins, they represented themselves in Macedonian style. The Seleucid kings also practised code-switching, though apparently to a lesser degree. They participated in Babylonian cults, but they do not seem to have represented themselves iconographically as Persian or Assyrian kings. Hellenistic

45 The scribe in whose archive Maron appears is Menches son of Petesouchos, also known as Polemon, who seems to have used his Greek name in official and his Egyptian name in private life.

46 Coussement, 'Because I am Greek', 105.

47 Clarysse and Thompson, Counting the People, 157-60. 
kings could also code-switch by representing themselves differently at home and abroad. The first self-declared king of Cappadocia, Ariarathes III (r. 262/255-220), represented himself abroad as a Hellenistic king, to mark his status to other Hellenistic kings, but at home as a Persian, presumably to appeal to pre-Alexandrine local patriotism. ${ }^{48}$

If individuals, in life, often switched codes according to context, a remarkable group of tombstones from Apollinopolis Magna (modern Edfu) in the later second century BCE suggests that in death they were sometimes happy to set multiple identities side by side. The family of Ptolemaios, also known as Pashou, is commemorated by a series of paired tombstones: one of each pair wholly Greek, one wholly Egyptian in appearance. Some members of the family are army officers and Ptolemaios himself bears the title $\sigma v \gamma \gamma \varepsilon v \eta \dot{ }$, literally 'relative' of the king, marking him as a member of the Ptolemaic court. He may have been an Egyptian who had achieved Macedonian status. Alternatively, as J. Yoyotte suggests, he may have been a Macedonian who, like his king, represented himself as Egyptian when he thought it appropriate. ${ }^{49}$

The concept of code-switching highlights another aspect of ethnicity in this period: It is often - perhaps typically - accretive. People could acquire new ethnic designations in the course of their lives and make use of old and new identities in different, or even the same, contexts. ${ }^{50} \mathrm{~A}$ well-preserved cylindrical document from Seleucid Mesopotamia, dated to 268 BCE, offers an example of accretive royal identity. ${ }^{51}$ It begins: 'Antiochus the Great King ... king of the world, king of Babylon, king of countries ... foremost son of Seleucus, the king, the Macedonian ... am I'. Antiochus I here articulates his kingship simultaneously in Babylonian, Persian, and Macedonian terms. The language of the inscription is Akkadian, the old Babylonian language used throughout the Achaemenid Empire for official and cult purposes. The script is an archaizing form of Babylonian cuneiform which was also used in propaganda by the pre-Achaemenid kings of the Babylonian Empire. The cylinder proclaims both Antiochus' Macedonian identity and his regime's continuity with the region's previous two empires. ${ }^{52}$

That individuals owned and acknowledged, even advertised, multiple identities has a further implication: that identity was contextual. Being Jewish, or Egyptian, or Syrian might serve in one context, where being Greek or Roman was preferable, or necessary, in another. This could be true even in situations where one might expect ethnic identity to be most stable or directive, such as in law. Under the Ptolemies, individuals who claimed Greek identity, and therefore access to Ptolemaic law, might be expected to

48 Though he also implemented a polis constitution in the Cappadocian city of Hanisa, with a Macedonian calendar, Greek magistracies, and Greek temples (Christoph Michels, 'The Spread of Polis Institutions in Hellenistic Cappadocia and their Peer Polity Interaction Model', in Social Imaginaries, ed. Stavrianopoulou, 283-307, at 285-94).

49 J. Yoyotte, 'Bakhthis: religion égyptienne et culture grecque à Edfou', in Religions en Égypte Hellénistique et Romaine (Paris: Presses universitaires de France, 1969), 127-41.

50 Cf. J. Geiger, 'Language, Culture and Identity in Ancient Palestine', in Greek Romans and Roman Greeks, ed. E. N. Ostenfeld (Aarhus: Aarhus University Press, 2002), 233-46.

51 Strootman, 'Babylonian, Macedonian', 67-73.

52 On similar practices in Gaul see Mullen, Southern Gaul, 266-77; Ton Derks, Gods, Temples, and Religious Practices: The Transformation of Religious Ideas and Values in Roman Gaul (Amsterdam: Amsterdam University Press, 1998). 
have made contracts and conducted disputes under Greek law. In practice, they often seem to have used Greek, Egyptian, or Jewish law according to convenience. ${ }^{53}$

In a few cases we find individuals or groups explicitly marking, even celebrating, their multi-ethnicity and perhaps even their ethnic hybridity. In documents from Egypt and Syria it is common for individuals to give, for instance, both Greek and Egyptian, or Macedonian and Aramaic names. Double names appear especially in private contracts and religious or funerary texts, where individuals may have been particularly anxious that they should be clearly identified. ${ }^{54}$ We have already noted the bicultural funerary stelai of Pashou and his family. ${ }^{55}$ Michael Peppard takes this theme a stage further in an analysis of multi-ethnic nomenclature in the late antique (but still Hellenistic) Jewish cemetery at Beth Shearim. ${ }^{56}$ On the cemetery's 188 readable tombstones, names appear in Greek, Latin, Semitic languages including Hebrew and Palmyrene, and, in eight cases, in two different languages in various combinations (e.g. Ioulianos Kapitōn, Eisak Kurinos). Some of these double names, though not all, look like loose translations of each other. ${ }^{57}$ Peppard concludes that the individuals commemorated, and/or those who commemorated them, intended to celebrate their multiple identities and even their cultural hybridity.

In these examples, individuals and groups, over a long period of time and across a wide geographical area, appear to embrace, use, and celebrate ethnic identities that are often changeable and multiple. Over the same period, it has been suggested, paradoxically, that interest in ethnic identity is weakening. In the early Ptolemaic kingdom, for example, it is normal to find individuals with Greek names - especially if other family members also have Greek names - identifying themselves in documents as coming from a particular city, region, or island in the Greek world. In the late fourth or early third century, the time of highest immigration into Egypt, it is easy to imagine that these individuals originated in the places they name; through the third and second century it becomes more likely that the names remember (or invent) ancestral homelands. ${ }^{58}$ Through the Ptolemaic period self-identification by city, island, or region becomes less common, until under Roman rule it is normal for individuals with Greek names to identify themselves by the Egyptian city or town from which

${ }^{53}$ For example, CPJ 1.20 (228-221 BCE), CIJ 711 (Delphi, 119 CE). On syncretism in Hellenistic legal systems themselves, see Uri Yiftach-Firanko, 'Law in Graeco-Roman Egypt: Hellenization, Fusion, Romanization', in The Oxford Handbook of Papyrology, ed. Roger Bagnall (Oxford: Oxford University Press, 2011), 541-60; Robert A. Kugler, 'Dispelling an Illusion of Otherness? Juridical Practice in the Heracleopolis Papyri', in Negotiating Diaspora Jewish Strategies in the Roman Empire, ed. John Barclay (London: T\&T Clark, 2004), 457-70; cf. also Kimberley Czajkowski, Localized Law: The Babatha and Salome Komaise Archives (Oxford: Oxford University Press, 2017).

54 Coussement, 'Because I am Greek', 46.

55 Bingen, Hellenistic Egypt, 232, 276 and Koen Goudriaan, 'Ethnical Strategies in Graeco-Roman Egypt', in Ethnicity in Hellenistic Egypt, ed. Bilde et al., 74-99, at 75-9, discuss further examples.

56 Michael Peppard, 'Personal Names and Ethnic Hybridity in Late Ancient Galilee', in Religion, Ethnicity, and Identity in Ancient Galilee, ed. Jürgen Zangenberg, Harold W. Attridge, and Dale B. Martin (Tübingen: Mohr Siebeck, 2007), 99-113; cf. Coussement, 'Because I am Greek', 89, on translated names in papyri.

57 For example, Isthēr, a transcription of Esther, and Amthaitha, which derives from the verb 'to shine' and suggests that Esther was equated to the Greek å $\sigma \tau \eta \dot{\rho} \rho$, 'star'.

58 Individuals with Greek names whose families mostly or all have Egyptian names tend to identify themselves throughout the period simply as 'Greek'; La'da, Foreign Ethnics, 80-105. 
they come. ${ }^{59}$ (Gideon Bohak notes that this is also the case among those who identify as Ioudaios in documents of the third to the first century BCE. Whether this implies that many Jews are ceasing to think of themselves as a distinct group, or whether documents are decreasingly seen as an appropriate place to mark their distinctiveness, is unclear. ${ }^{60}$ )

The Roman Empire recognized only two tax and legal statuses: Roman and nonRoman. In the eyes of the Roman administration in Egypt, for instance, Greeks, Jews, Persians, Arabs, and Egyptians were all 'Egyptians' unless they were 'Romans'. It has been suggested that the absence of other ethnics in documents of the Roman period is due to their new legal irrelevance, but this does not explain their earlier decline. A better explanation of the trend, in light, for instance, of Fraser's work on classical Greece, is that in late Ptolemaic and Roman Egypt the names of Egyptian towns and cities are increasingly treated as ethnics. ${ }^{61}$ As migrants come to feel increasingly at home in their new locations, current location becomes more important than ancestral identity as an identifier. ${ }^{62}$

If ethnicity could be not only, or not at all, a matter of shared descent, history, or territory, nor even necessarily a matter of shared language, cult, or custom, but a tax status or the consequence of a certain job or a gift of citizenship; if it could be accretive, such that individuals and groups identified with and used multiple ethnicities; if one aspect of one's identity, such as tax status did not necessarily march in step with any other, such as background or culture; if one could switch between ethnicities as between codes, according to context, or celebrate multiple identities or hybrid identities - then the modern scholar might be forgiven for wondering whether the concept remains useful at all for thinking about Hellenistic society or identity. That, though, would be to underestimate the ability of individuals and groups in many cultures to acknowledge, celebrate, and make use of multiple languages and identities. ${ }^{63}$ It would also be an injustice to the evidence, which shows that what we think of as ethnic identifiers remains sufficiently important to individuals and groups to be articulated regularly in diverse contexts. Rather, the content of 'Greek', 'Syrian', 'Egyptian', 'Jewish', and so on, however, becomes more complex and flexible through this period, and so does the relationship of the concept to individual people and groups. At times ethnicity becomes less a concept with any fixed definition at all than a claim of relative status. In his study of the gymnasium and Greek identity in Ptolemaic and Roman Egypt, Mario Paganini notes that the Greeks of Alexandria viewed the Greeks of the $\chi \dot{\omega} \rho \alpha-$ the country beyond Egypt's three Greek cities - as no better than Egyptians or Jews, and certainly not their social or cultural equals. ${ }^{64}$ Tessa Rajak has observed that when Josephus talks of Greeks and Syrians in Palestine, he seems to use 'Greeks' to refer to non-Jews living in towns and cities, while non-Jews living in the countryside are

59 Bohak, 'Ethnic Continuity', 181.

60 Bohak, 'Ethnic Continuity', 186-7. Bohak argues that assumptions of high levels of Jewish endogamy are misleadingly based on evidence from the mediaeval diaspora.

61 See note 12 and discussion above.

62 Fowler, 'Ethnicity', 182, argues that the Seleucids were never much concerned with ethnicity.

63 Cf. Peter Burke, Cultural Hybridity (Cambridge: Cambridge University Press, 2007).

64 Mario Paganini, 'Gymnasia and Greek Identity in Ptolemaic Egypt' (DPhil. thesis, University of Oxford, 2011), 272. 
'Syrians'. Since country-dwellers are widely regarded by city-dwellers in the ancient world as lower class, poorer, less cultured, or of lesser account than themselves, what appear to be ethnic designations are probably, at times, expressions of social snobbery. ${ }^{65}$

What modern scholars call 'ethnic' terms in the Hellenistic world are highly complex. At once meaningful and vacant signs, absolute and relative categories, they are as definitive as a person's skin and as layered as their clothes. They are complex not least because they act simultaneously as outsider and insider terms: used by governments to classify and rank individuals and groups and by individuals and groups to switch identities, accrete them, perform multiple affiliations simultaneously, and in the process reinvent them. Ancient ethnicity, one might suggest, is the 'queer' of its day: A set of labels designed to define, differentiate, and discriminate, which are taken over by those to whom they apply, and then resisted, subverted, reworked, embraced, abandoned, and celebrated in a conversation that ranges far beyond what states or dominant social groups control. ${ }^{66}$

\subsection{Ethnicity in culture, philosophy, and religion}

So far, we have focused on ethnic identity mainly as a matter of (claimed) descent or as a formal, political, legal, or social status. Since, however, a long-standing topos of the study of the Hellenistic world is that 'Greekness' becomes more a matter of culture than anything else, it is worth turning briefly to some salient features of Hellenistic culture and their relationship with ethnicity.

It is a long-standing puzzle that Hellenistic Greek literature, philosophy, science, architecture, and art, all of which, since the early archaic period, had been highly receptive of external influences, became in this period almost impervious to them. All evolved significantly by their own internal dynamics, but - despite some ingenious efforts in recent years to identify examples - little convincing evidence has been found of borrowings from outside. ${ }^{67}$ Nor did self-identified Greeks seek to interpret their

65 Tessa Rajak, The Jewish Dialogue with Greece and Rome: Studies in Social and Cultural Interaction (Leiden: Brill, 2000), 140. Seth Schwartz, 'The Hellenization of Jerusalem and Shechem', in Jews in a Graeco-Roman World, ed. Martin Goodman (Oxford: Oxford University Press, 2004), 37-46, argues as a corollary that the Greekness of individuals or groups was variable and often very 'thin'.

${ }^{66}$ What, in this context, of the double name of Saul/Paul? The evidence above does not help us decide whether he held the names sequentially or simultaneously (though Acts 13.9 suggests the latter), but it raises the question why he chose to use a Roman name when writing to mixed communities of Jews and gentiles.

67 Despite claims of influence, notably by Jewish writers, for example, Erich Gruen, 'Jews and Greeks as Philosophers: A Challenge to Otherness', in Negotiating Diaspora, ed. Barclay, 402-22, and attempts to identify influences, for example, by Jacco Dielman and Ian S. Moyer, 'Egyptian Literature', in $A$ Companion to Hellenistic Literature, ed. James J. Clauss and Martin Cuypers (Chichester: WileyBlackwell, 2014), 429-47; Ian Rutherford, ed., Greco-Egyptian Interactions (Oxford: Oxford University Press, 2016); and (more successful than most) Rachel Wood, 'After the Achaemenids: Exchange, Transmission, and Transformation in the Visual Culture of Babylonia, Iran and Bactria c. 330- c. 100 BC' (DPhil. thesis, University of Oxford, 2012). Contra see, for example, Teresa Morgan, Literate Education in the Hellenistic and Roman Worlds (Cambridge: Cambridge University Press, 1998), chs 3-4; Richard Hunter, Theocritus, Encomium of Ptolemy Philadelphus (Berkeley: California University Press, 2003), 46-53; Kathryn Gutzwiller, A Guide to Hellenistic Literature (Oxford: Blackwell, 2007), 188-202. The influence of Greek on surrounding (notably Jewish) cultures is much better established. 
culture to others: No Greek equivalents survive of Josephus, Manetho (the Egyptian priest who wrote a History of Egypt in Greek under the patronage of Ptolemy I), or Berossus (the Babylonian astronomer who wrote a History of Babylonia in Greek under Antiochus I). The usual explanation for this is Greek chauvinism; a better explanation may be Macedonian admiration of the Greek. Alexander and his successors were keen consumers and patrons, especially of Homer and classical Athenian culture.

Philosophy, like other aspects of Greek culture, evolves, as far as we can see, solely by its own internal dynamics in this period. Philosophical schools, however, develop two new features which they share with ethnic groups. David Sedley has shown how they increasingly heroize their founder figures and link later practitioners, especially heads of schools, to their founders through complex genealogies. ${ }^{68}$ Malcolm Schofield has shown how Stoics develop Diogenes the Cynic's description of himself as a

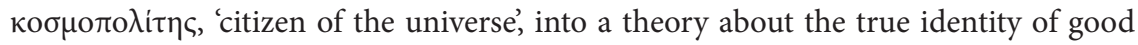
men. ${ }^{69}$ As Clement of Alexandria describes this theory:

The Stoics say that the universe is in the proper sense a city, but that those here on earth are not - they are called cities, but are not really. For a city or a people $(\delta \tilde{\eta} \mu \circ \varsigma)$ is something morally good, an organization or group of men administered by law which exhibits refinement. (Strom. 4.26$)^{70}$

Good men (Stoics do not recognize women as philosophers), together with the divine, constitute their own polity - no less real for having no geographical location - in which they live by practising virtue under the rule of cosmic law. ${ }^{71}$ Clement describes members of the community as a 'people', and conceptually he is surely right. To be a citizen of the universe and the community of the good amounts, in the terms we have been using throughout this essay, to an alternative ethnicity: one which transcends everyday affiliations without necessarily excluding them. As we have noted, cosmopolitanism is not an ethnicity recognized by modern scholars, but on their own criteria it has some claim to be. And recognizing the possibility that one could be a member of a people with no material location may help us to understand how early Christians might think of themselves in ethnic terms.

Religion and magic are usually treated, in (what are now rather old-fashioned) anthropological terms, as aspects of Graeco-Roman culture. This is misleading: Divine-human relations are as structural to ancient societies as intra-human relations, and good relations with gods are everywhere represented as indispensable to the good working of states. Places and processes of cultivation, consultation, affirmation of continuity, and the negotiation of change are as political and social when they take place between human beings and gods in temples, at altars and festivals, as when they occur between human beings in council houses, law courts, and marketplaces. Accordingly, as in other areas of Hellenistic politics, law, and social life, representations of gods and

68 David Sedley, 'Philosophical Allegiance in the Greco-Roman World', in Philosophia Togata, ed. Miriam Griffin and Jonathan Barnes (Oxford: Oxford University Press, 1989), 97-119.

69 Malcolm Schofield, The Stoic Idea of the City (Cambridge: Cambridge University Press, 2001).

70 Cited in Schofield, Stoic Idea, 61; cf. Morgan, Roman Faith, 489-92.

${ }^{71}$ Cicero, Nat. d. 2.154 . 
religious and magical practices interact and syncretize, while individuals and groups accrete religious identities, code-switch and parade their cultural complexity.

We have already encountered a number of examples; one or two more must suffice here from the wealth of evidence. ${ }^{72}$ Gymnasia often housed altars or shrines, and in Egypt they were seats of Ptolemaic dynastic cult, which took a fully GraecoMacedonian form. Gymnasial inscriptions honouring members, however, also refer sometimes to Egyptian myths of the afterlife. Paganini connects this with the readiness of self-identified Greeks to adopt Egyptian burial customs: Both suggest that Greeks found Egyptian ideas about the afterlife attractive and integrated them into their mythology. ${ }^{73}$ Alternatively, individuals with Egyptian backgrounds, having acquired Greek status, may have seen no paradox in displaying this aspect of their 'Egyptianness' in this most Hellenic context.

Egypt is the context for the most syncretistic cult of this period: that of Alexandrian Serapis. The cult of Serapis combines the mortuary aspect of the sacred Apis bull of Memphis with the cult of Osiris, and its cult building, the Serapeum at Memphis, dates back as least as far as the reign of Nectanebo II (r. 360-342). Ptolemy I (or possibly Ptolemy II or III) founded a new Serapeum in Alexandria in which the god is presented anthropomorphically in Greek style but with Egyptian trappings and surrounded by an eclectic iconography drawn from several other cults. $^{74}$ Greek writers identified Serapis variously with Dionysus, Hades, Demeter, Zeus, and Asclepius (D.S. 1.25); he became the tutelary god of Alexandria and was closely associated with the royal family. The syncretism of Serapis is unusual, but not unparalleled. Egyptian Isis was worshipped across the Greek world from at least the fourth century BCE, and Herodotus $(2.42,2.156)$ describes her as equivalent to Greek Demeter. During the Hellenistic period she begins to be identified with all Greek goddesses and is portrayed in Greek style. ${ }^{75}$ She retains titles and attributes from her Egyptian form, however, and can be described simultaneously as Egyptian and universal. ${ }^{76}$

Magic is increasingly, rightly, seen as continuous with ancient religion rather than as a separate phenomenon, and Hellenistic (including Jewish and early Christian) magic is famously culturally complex and syncretistic. The Graeco-Egyptian papyrus PGM IV 3125-71, to give just one of thousands of examples, gives instructions for casting a prosperity spell which involve making a statue out of Etruscan wax of a god with three (mainly) Egyptian heads: Horus, Hermanubis (a combination of Anubis and Greek Hermes), and Ibis. The accompanying incantation invokes a nameless angel, the Greek powers Tyche, 'Aion, ruler of hope', 'holy Agathos Daimon', and Selene. ${ }^{77}$

It is worth noting again that while the kingdoms of the Hellenistic world treat some ethnic identities as superior to others, tolerance of others' ethnicities and cultures,

72 On the distinctiveness of Hellenistic religion, see Angelos Chaniotis, 'Religion und Mythos', in Kulturgeschichte des Hellenismus, ed. Weber, 139-57.

73 Paganini, 'Gymnasia', 270-2.

74 Plutarch, Alex. 76; Arrian, Anab. 7.26.2.

75 For example, P.Oxy. 11.1380, 55.3239; Stobaeus, Ecl. 1.

76 For example, Diod. 1.11.4, 1.13.4-5, cf. 1.27.3-4.

77 H. D. Betz, The Greek Magical Papyri in Translation (Chicago: University of Chicago Press, 1986); on syncretism, see xliv-xlviii. 
code-switching, and even syncretism, may all be understood as signs of political and ethnic strength. ${ }^{78}$ The Achaemenids had signalled their power by boasting of the religious diversity of their empire; the Seleucids followed suit. Athens, most hospitable of cities to foreign cults, was also the most imperialist city of the classical period. Greg Woolf has shown how Rome, similarly, allowed the pre-Roman cults of Gaul to survive into the third century CE, as long as they did not take what were perceived as non-Roman (zoomorphic or aniconic) forms. ${ }^{79}$ Tolerance of pluralism with elements of syncretism, he argues, emphasized the strength and the magnanimity of Rome and did not challenge the hegemony of Roman identity. The same might well be said of Hellenistic Egypt. We could go further and understand syncretism as more than the combination of identities which continued to be recognized as separate. It creates a new identity in its own right: yet another new ethnicity in a world which over centuries is freely productive of new identities.

\section{Conclusion}

This brief survey has only begun to introduce the complexity of ideas about ethnicity and identity in the Greek and Hellenistic worlds. Much has been left out altogether: not least Jewish ideas about Jewish ethnicity and identity and that of gentiles. We have not explored the (rare, but not unknown) occasions when ethnicity is invoked by 'Jewish' or 'Egyptian' rebels as a reason to oppose oppressive 'Greek' rulers. Christians' use of the language of ethnicity and identity is for others in this volume to explore, but we may conclude with one or two observations.

On both ancient and modern definitions of ethnicity, early Christians have good claim to be discussed as a type of ethnic group, but we should also bear in mind that to find a group called an $\ddot{\varepsilon} \theta v o \varsigma, \gamma \varepsilon \dot{\varepsilon} v \varsigma$, or genus tells us little or nothing about its size or shape, the basis of its coherence or its function. Early Christians are normal in their world in taking an active interest in their identity. They may even be seen as sharing the particular interest in ethnicity which has been identified in colonial and diaspora groups. They are also normal in using ethnic terms to distinguish themselves from others (both outside what is usually understood as the group and sometimes within it). We should not be surprised to find such distinctions being used adversarially, but should not assume they are always adversarial.

Some ancient groups are more inclusive than others, and churches are typically very open to new members. This is compatible with the group's taking a high view of its potential for growth and power: It may even be symptomatic of it. Like Athenians,

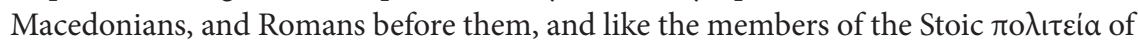
the good, Christians may mark their divinely sponsored confidence in the future by welcoming all comers into their community. (At least some) Christian groups, however, are unusual in seeking explicitly to hold all members of the group in equal respect.

We should not be surprised to find individual Christians identifying with multiple labels, accreting identities, code-switching, or even celebrating their hybridity. Nor

78 Or claims of strength: see, for example, Douglas R. Edwards, Religion and Power: Pagans, Jews and Christians in the Greek East (New York: Oxford University Press, 1996); Takashi Fujii, Imperial Cult and Imperial Representations in Roman Cyprus (Stuttgart: Franz Steiner, 2013), esp. 95-7.

79 Woolf, Becoming Roman, 206-7, 215. 
should we be surprised to find insider and outsider definitions of Christian identity in dialogue. We should be more surprised not to find evidence of any of these practices - which does not mean that we should take finding it for granted. The more nuanced our understanding of the operation of ethnicity in the world into which Christianity was born, however, the better our chance of recognizing what really is, and is not, distinctive about Christian identity.

\section{References}

Andrade, Nathanael. Syrian Identity in the Graeco-Roman World. Cambridge: Cambridge University Press, 2013.

Avidov, Avi. Not Reckoned Among the Nations: The Origins of the So-called 'Jewish Question' in Roman Antiquity. TSAJ 128. Tübingen: Mohr Siebeck, 2009.

Betz, Hans Dieter. The Greek Magical Papyri in Translation. Chicago: University of Chicago Press, 1986.

Bilde, Per, Troels Engberg-Pedersen, Lise Hannestad, and Jan Zahle, eds. Ethnicity in Hellenistic Egypt. Aarhus: Aarhus University Press, 1992.

Bingen, Jean. Hellenistic Egypt: Monarchy, Society, Economy, Culture. Edinburgh: Edinburgh University Press, 2007.

Bohak, Gideon. 'Ethnic Continuity in the Jewish Diaspora in Antiquity'. In Jews in the Hellenistic and Roman Cities, edited by John R. Bartlett, 175-92. London: Routledge, 2002.

Bonnet, Corinne. Les enfants de Cadmos: le paysage religieux de la Phénicie hellénistique. Paris: Boccard, 2015.

Bosworth, A. B. Conquest and Empire: The Reign of Alexander the Great. Cambridge: Cambridge University Press, 1988.

Bosworth, A. B. Alexander and the East: The Tragedy of Triumph. Oxford: Oxford University Press, 1996.

Burke, Peter. Cultural Hybridity. Cambridge: Cambridge University Press, 2007.

Cartledge, Paul. The Greeks: A Portrait of Self and Others. Oxford: Oxford University Press, 1993.

Chaniotis, Angelos. 'Religion und Mythos'. In Kulturgeschichte des Hellenismus von Alexander dem Grossen bis Kleopatra, edited by Gregor Weber, 139-57. Stuttgart: KlettCotta, 2007.

Clarysse, Willy, and Dorothy J. Thompson. Counting the People in Hellenistic Egypt. 2 volumes. Cambridge: Cambridge University Press, 2006.

Coussement, Sandra. 'Because I am Greek': Polyonymy as an Expression of Ethnicity in Ptolemaic Egypt. Leuven: Peeters, 2016.

Curty, Olivier. Les parentés légendaires entre cites grecques: catalogue raisonné des inscriptions contentant le terme SUNGENEIA et analyse critique. Geneva: Librarie Droz, 1995.

Czajkowski, Kimberley. Localized Law: The Babatha and Salome Komaise Archives. Oxford: Oxford University Press, 2017.

Dench, Emma. Romulus' Asylum: Roman Identities from the Age of Alexander to the Age of Hadrian. Oxford: Oxford University Press, 2005.

Derks, Ton. Gods, Temples, and Religious Practices: The Transformation of Religious Ideas and Values in Roman Gaul. Amsterdam: Amsterdam University Press, 1998. 
Dielman, Jacco and Ian S. Moyer. 'Egyptian Literature'. In A Companion to Hellenistic Literature, edited by James J. Clauss and Martin Cuypers, 429-47. Chichester: WileyBlackwell, 2014.

Edwards, Douglas R. Religion and Power: Pagans, Jews and Christians in the Greek East. New York: Oxford University Press, 1996.

Fisher, Nick and Hans van Wees, eds. 'Aristocracy' in Antiquity: Redefining Greek and Roman Elites. Swansea: Class Press of Wales, 2015.

Fowler, Richard. 'Ethnicity and Power: Studies on Royal Ideology in the Hellenistic Fertile Crescent'. DPhil. thesis, University of Oxford, 1999.

Fraser, Peter Marshall. Greek Ethnic Terminology. Oxford: Oxford University Press, 2009.

Fujii, Takashi. Imperial Cult and Imperial Representations in Roman Cyprus. Stuttgart: Franz Steiner, 2013.

Gardner, Andrew, Edward Herring, and Kathryn Lomas, eds. Creating Ethnicities and Identities in the Roman World. London: Institute of Classical Studies, 2013.

Geiger, J. 'Language, Culture and Identity in Ancient Palestine'. In Greek Romans and Roman Greeks, edited by Erik Nis Ostenfeld, 233-46. Aarhus: Aarhus University Press, 2002.

Goudriaan, Koen. Ethnicity in Ptolemaic Egypt. Amsterdam: J. C. Gieben, 1988.

Goudriaan, Koen. 'Ethnical Strategies in Graeco-Roman Egypt'. In Ethnicity in Hellenistic Egypt, edited by Per Bilde, Troels Engberg-Pedersen, Lise Hannestad, and Jan Zahle, 74-99. Aarhus: Aarhus University Press, 1992.

Gruen, Erich. 'Jews and Greeks as Philosophers: A Challenge to Otherness'. In Negotiating Diaspora: Jewish Strategies in the Roman Empire, edited by John Barclay, 402-22. London: T\&T Clark, 2004.

Gutzwiller, Kathryn. A Guide to Hellenistic Literature. Oxford: Blackwell, 2007.

Hall, Edith. Inventing the Barbarian. Oxford: Oxford University Press, 1989.

Hall, Jonathan M. Ethnic Identity in Greek Antiquity. Cambridge: Cambridge University Press, 1998.

Hall, Jonathan M. Hellenicity: Between Ethnicity and Culture. Chicago: University of Chicago Press, 2002.

Hall, Jonathan M. 'Ancient Greek Ethnicities: Towards a Reassessment'. Bulletin of the Institute of Classical Studies 58, no. 2 (2015): 15-29.

Hunter, Richard. Theocritus, Encomium of Ptolemy Philadelphus. Berkeley: California University Press, 2003.

Konstan, David. 'Defining Ancient Greek Ethnicity'. Diaspora 6 (1997): 97-110.

Kugler, Robert A. 'Dispelling an Illusion of Otherness? Juridical Practice in the Heracleopolis Papyri. In Negotiating Diaspora: Jewish Strategies in the Roman Empire, edited by John Barclay, 457-70. London: T\&T Clark, 2004.

La'da, Csaba. Foreign Ethnics in Hellenistic Egypt. Leuven: Peeters, 2002.

Lewis, Naphtali. Greeks in Ptolemaic Egypt: Case Studies in the Social History of the Hellenistic World. Oxford: Oxford University Press, 1986.

Michels, Christoph. 'The Spread of Polis Institutions in Hellenistic Cappadocia and Their Peer Polity Interaction Model'. In Shifting Social Imaginaries in the Hellenistic Period: Narrations, Practices, and Images, edited by Eftychia Stavrianopoulou, 283-307. Leiden: Brill, 2013.

Morgan, Catherine. Athletes and Oracles. Cambridge: Cambridge University Press, 1990. Morgan, Teresa. Literate Education in the Hellenistic and Roman Worlds. Cambridge: Cambridge University Press, 1998.

Morgan, Teresa. Roman Faith and Christian Faith. Oxford: Oxford University Press, 2015. 
Mullen, Alex. Southern Gaul and the Mediterranean: Multilingualism and Multiple Identities in the Iron Age and Roman Periods. Cambridge: Cambridge University Press, 2013.

Paganini, Mario. 'Gymnasia and Greek Identity in Ptolemaic Egypt'. DPhil. thesis, University of Oxford, 2011.

Peppard, Michael. 'Personal Names and Ethnic Hybridity in Late Ancient Galilee'. In Religion, Ethnicity, and Identity in Ancient Galilee, edited by Jürgen Zangenberg, Harold W. Attridge, and Dale B. Martin, 99-113. Tübingen: Mohr Siebeck, 2007.

Pfister, Friedrich. Der Reisebilder des Herakleides. Vienna: R. M. Rohrer, 1951.

Prag, J. R. W. and Josephine Crawley Quinn, eds. The Hellenistic West: Rethinking the Ancient Mediterranean. Cambridge: Cambridge University Press, 2013.

Rajak, Tessa. The Jewish Dialogue with Greece and Rome: Studies in Social and Cultural Interaction. Leiden: Brill, 2000.

Rollinger, Robert. 'New Observations on "Greeks" in the Achaemenid Empire According to Cuneiform Texts from Babylonia and Persepolis'. In Organisation des pouvoirs et contacts culturels dans les pays de l'empire Achéménide, edited by Pierre Briant and Michel Chauveau, 331-51. Paris: Éditions de Boccard, 2009.

Rowlandson, Jane. 'Dissing the Egyptians: Legal, Ethnic, and Cultural Identities in Roman Egypt'. In Creating Ethnicities and Identities in the Roman World, edited by Andrew Gardner, Edward Herring, and Kathryn Lomas, 213-47. London: Institute of Classical Studies, 2013.

Rutherford, Ian, ed. Greco-Egyptian Interactions. Oxford: Oxford University Press, 2016.

Schofield, Malcolm. The Stoic Idea of the City. Cambridge: Cambridge University Press, 2001.

Schwartz, Seth. 'The Hellenization of Jerusalem and Shechem'. In Jews in a Graeco-Roman World, edited by Martin Goodman, 37-46. Oxford: Oxford University Press, 2004.

Sedley, David. 'Philosophical Allegiance in the Greco-Roman World'. In Philosophia Togata, edited by Miriam Griffin and Jonathan Barnes, 97-119. Oxford: Oxford University Press, 1989.

Stavrianopoulou, Eftychia. 'Hellenistic World(s) and the Elusive Concept of "Greekness"'. In Shifting Social Imaginaries in the Hellenistic Period: Narrations, Practices, and Images, edited by Eftychia Stavrianopoulou, 177-205. Leiden: Brill, 2013.

Strootman, Rolf. 'Babylonian, Macedonian, King of the World: The Antiochus Cylinder from Borsippa and Seleukid Imperial Integration'. In Shifting Social Imaginaries in the Hellenistic Period: Narrations, Practices, and Images, edited by Eftychia Stavrianopoulou, 67-98. Leiden: Brill, 2013.

Thompson, Dorothy J. Kerkeosiris: An Egyptian Village in the Ptolemaic Period. Cambridge: Cambridge University Press, 1971.

Thompson, Dorothy J. Memphis Under the Ptolemies. 2nd edn. Princeton, NJ: Princeton University Press, 2012.

van der Spek, R. J. 'Multi-ethnicity and Ethnic Segregation in Hellenistic Babylon'. In Ethnic Constructions in Antiquity: The Role of Power and Tradition, edited by Ton Derks and Nico Roymans, 101-16. Amsterdam: Amsterdam University Press, 2009.

Vlassopoulos, Kostas. Greeks and Barbarians. Cambridge: Cambridge University Press, 2013.

Weber, Gregor, ed. Kulturgeschichte des Hellenismus: von Alexander dem Grossen bis Kleopatra. Stuttgart: Klett-Cota, 2007.

Wood, Rachel. 'After the Achaemenids: Exchange, Transmission, and Transformation in the Visual Culture of Babylonia, Iran and Bactria c. 330 - c. 100 BC'. DPhil. thesis, University of Oxford, 2012. 
Woolf, Greg. Becoming Roman: The Origins of Provincial Civilization in Gaul. Cambridge: Cambridge University Press, 1997.

Yiftach-Firanko, Uri. 'Law in Graeco-Roman Egypt: Hellenization, Fusion, Romanization'. In The Oxford Handbook of Papyrology, edited by Roger Bagnall, 541-60. Oxford: Oxford University Press, 2011.

Yoyotte, J. 'Bakhthis: religion égyptienne et culture grecque à Edfou'. In Religions en Égypte Hellénistique et Romaine, 127-41. Paris: Presses universitaires de France, 1969. 


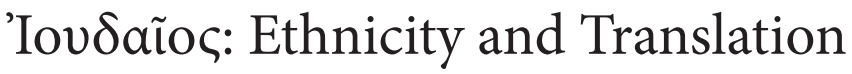

\author{
John M. G. Barclay
}

In the course of his heated literary debate with Apion, Josephus issues a statement that he presents as self-evident: 'Those who think highly of their own homelands are proud to be named after them, and censure those who improperly lay claim to

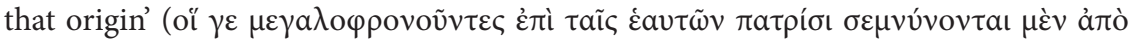

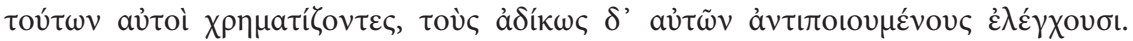
Apion 2.30; my translation). Such a declaration is rhetorically weighted. Josephus is here in the midst of claiming that Apion, because he was born in the depths of Egypt, should really call himself an 'Egyptian', but because he considered Egyptians 'utterly worthless' he 'deserted his own people' ( as an 'Alexandrian'. As this argument makes clear, ethnic identity can be contestable: People can lay claim to an identity others might dispute, or disown an identity others might attribute to them. In the Egyptian context of which Josephus is speaking, such matters were both exceedingly complex and extremely important. Who was classified as a 'Greek', an 'Alexandrian', or a 'Roman' mattered greatly for their political rights (e.g. citizenship) and for taxation. Josephus is aware of some of the complexities and of the possibility of multiple labels: In this context he claims that some Judeans/Jews ${ }^{1}$ have been labelled 'Macedonians' (2.37, probably a military title) and may be legitimately called 'Alexandrians' (2.38, in the sense of 'Alexandrian citizens'). In the bitter and sometimes violent Alexandrian disputes, many Judeans were considered, in fact, 'Egyptian' for taxation purposes, although they vigorously contested this classification. ${ }^{2}$

Thus Josephus' statement, for all its apparent simplicity, immerses us in a maelstrom of ancient complexity regarding the meaning of 'ethnic' labels. If we discuss what these labels 'meant' we have to ask immediately, 'meant to whom?' and 'as used by whom?' If some 'ethnic' labels were relatively unambiguous, others (including 'Greek', 'Roman', and 'Alexandrian') could have a range of senses, each open to contest. Informal usage was one thing; the precision required by law, and by the agents of taxation, was quite

1 As will become clear, I regard these two terms as partially overlapping and use them interchangeably; the translation question will be discussed at the end of this essay.

2 For translation and a commentary that explains the issues touched on here, see John M. G. Barclay, Flavius Josephus, Translation and Commentary, Vol. 10: Against Apion, ed. Steve Mason (Leiden: Brill, 2007). 
another. Rhetoric could play an important role, as the variable social and moral connotations of ethnic terms gave plenty of scope for self-promotion or polemical abuse. In many cases, such rhetorical 'play' could both produce and be produced by the ambiguity of the terms themselves.

But Josephus' statement also pitches us into another maelstrom, the contemporary scholarly dispute about the connotations of the term 'Iov\&aĩoc and its most appropriate translation into English. Josephus' presumption is that names relate to 'homelands', that (at least some) ethnic labels have geographical connotations. Earlier in this treatise he had cited a snippet of text from Clearchus, who himself cited an anecdote from Aristotle encountering a 'Judean' man in Asia Minor. According to Aristotle,

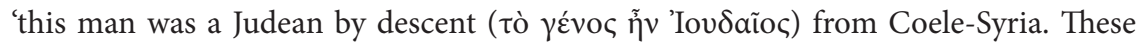
people are descendants of the philosophers in India. Among the Indians, they say, the philosophers are called Calanoi, and among the Syrians, Judeans, taking their name

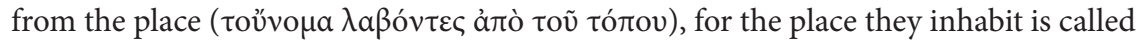
Judaea' (Apion 1.179). Even here different types of label are juxtaposed, and identity is made yet more complex when Aristotle describes this Judean as 'Greek, not only in his speech, but in his soul' (1.180). But the Clearchus/Aristotle comment makes

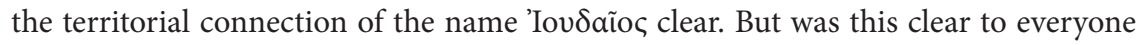
in antiquity, in all circumstances (e.g. even for long-term residents in the Diaspora)? Where a geographical connotation was salient, was it always equally strong? And what was understood by 'Judaea'? Would the label 'Iov反aĩoৎ apply to those nonJews by descent who, in Josephus' words, 'desire to live under the same laws as us' (Apion 2.210) or 'wish to share our customs' (2.261), and if so, what did it mean? Such questions are now compounded by recent disputes about translation into English, a question entangled with the politics of translation, and the (intended or unintended) effects of translation choices on contemporary perceptions of Jews and Judaism. ${ }^{3}$ For the purposes of this essay, I will focus initially on questions regarding 'ethnicity' and 'ethnic identity', keeping discussion of translation until the end.

\section{1 'Iov反aĩos as ethnikon - and as 'ethnic' label?}

The title of this section is meant to evoke both a thesis and a question. The thesis is that 'Iov反aĩoৎ is so commonly associated with a people, an ancestral tradition, communal customs, and a territory that it is proper to recognize it as an ethnikon - a label like one given to Egyptians, Syrians, Arabs, or Cretans ('Greek' is a far more complex phenomenon). The question is what we mean by 'ethnic' and 'ethnicity', and whether

3 For a survey of the issues and of scholarly positions, see the trio of articles by David M. Miller: 'The Meaning of Ioudaios and its Relationship to Other Group Labels in Ancient "Judaism", CBR 9 (2010): 98-126; 'Ethnicity Comes of Age: An Overview of Twentieth-Century Terms for Ioudaios', CBR 10 (2012): 293-311; 'Ethnicity, Religion and the Meaning of Ioudaios in Ancient "Judaism”, CBR 12 (2014): 216-65. Some of the heat in the entanglement of this debate with contemporary concerns can be gauged from the contributions to Timothy M. Law and Charles Halton, eds, Jew and Judean: A MARGINALIA Forum on Politics and Historiography in the Translation of Ancient Texts (Marginalia Review of Books; online publication, 2014). 
the use of these terms helps or hinders our understanding of what the ancients meant by an ' $ै \theta v o c$. Although it has become common to refer to 'ethnicity' in this matter, and to apply modern definitions of this phenomenon, herein lies a trap for the unwary: certain understandings of 'ethnicity' can skew our perception of the ancient evidence.

Anyone who approached the Sebasteion in Aphrodisias through its magnificent portico (built in the middle of the first century CE) would have had little doubt as to the category in which to put 'Iov反aĩol. In a display intended to represent the extent of Augustus' imperial successes, the portico contained fifty female statues representing peoples or places recently brought into the orbit of the empire (by conquest or clientela). Alongside statues identified as Cyprus, Crete, and Sicily, were many representing $\varepsilon \hat{\theta} \theta v \eta$

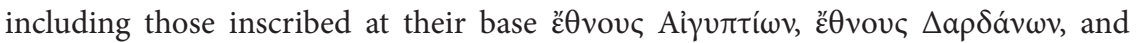

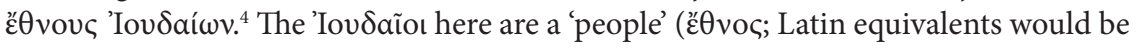
natio or gens) associated with a place.

What else might be implied by the name? Josephus' Contra Apionem allows us to compile quite a precise inventory of connotations. ${ }^{5}$ This includes (a) descent and shared ancestry: Josephus often uses the term $\gamma \varepsilon$ voc, refers to 'our ancestors' (e.g. 2.289), and emphasizes the significance of the family in the ancestral heritage; (b) territory: From the very first section Josephus speaks of the 'the land we now possess' (1.1), and refers to 'our own land', the 'ancestral land', as 'this land' $(1.60,103 ; 132,174,224 ; 2.289)$ and as $\pi$ átpıৎ $(1.210,212 ; 2.277)$, even though he writes self-consciously in the Diaspora; (c) language: Although he writes in Greek, Josephus figures the language of the Judeans as distinct from that of the Greeks (1.319; cf. 1.167; 2.27); (d) sacred texts: notably the Scriptures (1.6-56); (e) temple: Even though it was in ruins, Josephus puts the temple at the centre of the Jews' constitution (2.193-98); and (f) constitution: Josephus figures the customs and culture of Jews/Judeans in constitutional terms, putting special emphasis on its 'religious' components by coining the term 'theocracy' (2.165). ${ }^{6}$ All of these factors fit well within Greek and Roman ethnographic traditions, and an ancient reader would gain the impression of a nation associated with a place and endued with a strong sense of tradition and an especially pious culture. ${ }^{7}$

That, of course, is Josephus, writing with his own political and cultural agenda. Is he 'typical' and would this resonate with what other Jews, or outsiders, would

4 R. R. R. Smith, 'Simulacra Gentium: The Ethne from the Sebasteion at Aphrodisias', JRS 78 (1988): 50-77.

5 See Barclay, Flavius Josephus, lv-lxi. Cf. Philip F. Esler, 'Judean Ethnic Identity in Josephus' Against Apion', in A Wandering Galilean: Essays in Honour of Sean Freyne, ed. Zuleika Rodgers, Margaret Daly-Denton, and Anne Fitzpatrick McKinley (Leiden: Brill, 2009), 73-92.

6 The fact that Josephus continues to feature land and temple prominently in his definition of the Jewish people, in this his last work, puts in question the thesis of Daniel R. Schwartz that we can trace in Josephus' work a progression from a land-based (in his terms, 'Judean') identity to the identity of a non-land-based religion ('Jew'); see Daniel R. Schwartz, Judeans and Jews: Four Faces of Dichotomy in Ancient Jewish History (Toronto: University of Toronto Press, 2014), 48-61. On his distinction between 'Judean' and 'Jew', see the discussion in Section 2.

7 There is some overlap here with the six features of 'ethnicity' identified by John Hutchinson and Anthony Smith in their Ethnicity (Oxford: Oxford University Press, 1996), 6-7. They feature (i) a common proper name; (ii) a myth of common ancestry; (iii) a shared history; (iv) a common culture; (v) some link with a 'homeland'; and (vi) a sense of communal solidarity. There is a danger, of course, in retrojecting modern indices into the ancient world, and we should be alive to the dynamic and sometimes ambiguous ways that ancient texts themselves construct identity. 
associate with the name 'Iov反aĩot? To raise that (impossibly large) question invites awareness that, at the very least, different elements of this complex compound could be foregrounded or downplayed for social purposes. This is not simply the point (made by Fredrik Barth) that groups can retain their distinctive identities, including their labels, over time, even while the contents of those identities change. ${ }^{8}$ It also highlights the rhetorical work effected by ethnika, and the flexibility this gave to such labels. In fact, it is only possible to use the term 'ethnicity' for the ancient phenomena if we are clear that this is a polythetic, and not a monothetic, category. The difference is this: A monothetic category must have at least one element that is necessary for inclusion in the category, some common feature without which a phenomenon cannot be included. Polythetic, on the other hand, means 'relating to or sharing a number of characteristics which occur commonly in members of a group or class, but none of which is essential for membership of that group or class' (Oxford English Dictionary). ${ }^{9}$ One would expect clusters of characteristics, or 'family resemblances', but there is no single item which is the sine qua non of membership in that category, 'essential' either as necessary or as 'of the essence. ${ }^{10}$

Returning to Josephus' inventory, we might consider that a distinctive language is a non-necessary criterion of 'ethnicity', but what about ancestry or descent? The question here is not whether such descent is 'real' or 'fictive': in antiquity, as today, there were plenty of claims of fictive lines of ancestry, both by individuals and by nations. ${ }^{11}$ The question I am posing is whether any kind of claim to ancestry (real or imagined) is a necessary component of 'ethnicity'. Can we speak of shared 'ethnicity' even when there is no claim to shared ancestry, or is that a contradiction in terms? That is a definitional decision we have to make, and we must be clear that that is our decision.

An example of this problem is the impressively detailed philological and historical work of Shaye Cohen. ${ }^{12}$ Cohen's analysis works on the assumption that 'ethnic (or ethnic-geographic) identity is immutable; non-Judeans cannot become Judeans any more than non-Egyptians can become Egyptians, or non-Syrians can become Syrian' (109). Thus, 'ethnicity is closed, immutable, an ascribed characteristic based on birth' (136). Cohen then traces a trajectory by which the original ethnic identity of 'Iovdaĩo (defined in these terms) was altered during the late Hellenistic era (from the second century $\mathrm{BCE}$ ), under influence from Hellenism, such that people could become 'Iov反aĩo by political affiliation (e.g. the Idumaeans) or through 'religious' conversion (e.g. proselytes), acquiring identities that are mutable and therefore (in his terms) nonethnic. Thus when non-Judeans adopt the culture or 'religion' of the 'Iov反aĩol, they

8 Fredrik Barth, 'Introduction', in Ethnic Groups and Boundaries: The Social Organization of Cultural Difference, ed. Fredrik Barth (London: George Allen and Unwin, 1969), 9-38.

9 Available online: https://en.oxforddictionaries.com/definition/polythetic (accessed 6 February 2018).

10 For the application of this distinction to related matters, see Jonathan Z. Smith, 'Fences and Neighbours: Some Contours of Early Judaism', in idem, Imagining Religion: From Babylon to Jonestown (Chicago: University of Chicago Press, 1982), 1-18.

11 On the construction of Greek identity, see Jonathan M. Hall, Ethnic Identity in Greek Antiquity (Berkeley: University of California Press, 1997).

12 Shaye J. D. Cohen, The Beginnings: Boundaries, Varieties, Uncertainties (Berkeley: University of California Press, 1999). Numbers in brackets in what follows refer to page numbers in this book. 
do not change their ethnicity (that is, for Cohen, an impossibility); if they become 'Iov反aĩo that term changes from an 'ethnic' to a 'religious' label, ${ }^{13}$ that is, (for Cohen) from 'Judean' to 'Jew.' ${ }^{14}$

We will return to the translation issue below, but must maintain our focus here on the understanding of 'ethnicity'. If this is a monothetic category, in which shared ancestry (real or imagined) is essential, then we must grant Cohen's claim that conversion alters the meaning of the term 'Iov反aĩos, rending it fundamentally non-ethnic. On the same assumption, many have argued that 'Greek' ceases to be an ethnic term in the Hellenistic era. Following Isocrates' famous statement that Athens 'has made the

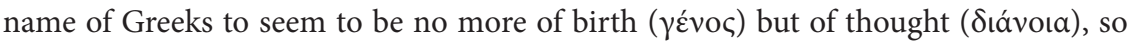
that those who share our education ( $\left.\pi \alpha \_\delta \varepsilon i ́ \alpha\right)$, more than those who share a common

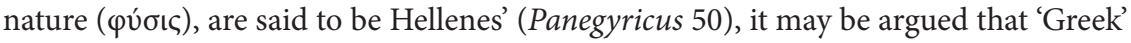
has lost an essential criterion of ethnicity. ${ }^{15}$ If people could claim to be 'Greek' without even far-fetched and fictive claims to Greek ancestry, then, on this argument, the term no longer denotes ethnicity. If, on the other hand, we determine that 'ethnicity' is a polythetic category, in which no one element, even ancestry, was essential, then one could claim that those who adopted Judean (or Greek) traditional customs - speaking, behaving, and (especially) worshipping the divine in distinctively Judean (or Greek) ways - had acquired Judean (or Greek) ethnicity, even though they had no claim, and made no claim, to Jewish (or Greek) ancestry, near or remote. ${ }^{16}$

That, of course, would be a decision we make about our definition of 'ethnicity'. To get a sense of how things might look in ancient terms, we can do no better than examine Josephus' account of the 'conversion' of the royal house of Adiabene (Ant. 20.17-96). ${ }^{17}$ Following the example of his mother, Helena, and his wives, and under the influence of the merchant Ananias, Izates, the king of Adiabene, was taught to worship

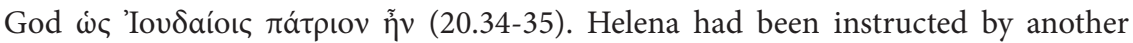

13 For Cohen, this means that Judaism becomes an 'ethno-religion', but the label as applied to converts can have only a religious, not an ethnic, sense (Beginnings, 109-39).

14 See Beginnings, 69-106, 29-39.

15 The issue is complex. See Irad Malkin, ed., Ancient Perceptions of Greek Ethnicity (Cambridge, MA: Harvard University Press, 2001); Simon Goldhill, ed., Being Greek under Rome: Cultural Identity, the Second Sophistic, and the Development of Empire (Cambridge: Cambridge University Press, 2001).

${ }_{16}$ Philip F. Esler similarly insists that 'no one feature can be determinative of, or a sine qua non for, ethnicity', Conflict and Identity in Romans: The Social Setting of Paul's Letter (Minneapolis: Fortress, 2003), 44. Something similar is argued (using different concepts) by Denise Kimber Buell, Why this New Race: Ethnic Reasoning in Early Christianity (New York: Columbia University Press, 2005). Speaking of 'fixed' and 'fluid' ends of a spectrum, she argues that 'if we do not suppose that ethnicity necessarily entails a privileging of the "fixed" end of the spectrum, we can say instead that the shift Cohen identifies entails a transformation in how ethnicity/race is defined, with a greater emphasis on its fluidity' (44). As will be clear below, rather than a narrative of 'transformation' (Cohen's or Buell's), I see in the evidence simply the clarification that these ancient ethnika were always polythetic, rather than monothetic, categories.

17 See also Steve Mason in his well-known article 'Jews, Judeans, Judaizing, Judaism: Problems of Categorization in Ancient History', republished in his Josephus, Judea and Christian Origins: Methods and Categories (Peabody: Hendrickson, 2009), 141-84, at 180-2. The precise terms Josephus uses in this story are given surprisingly little attention either by Shaye Cohen or by Daniel R. Schwartz, who

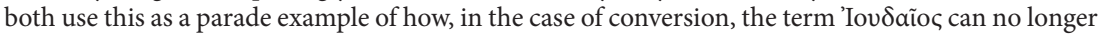
evoke ethnicity; see Daniel R. Schwartz, "Judean" or "Jew"? How Should We Translate ioudaios in Josephus?', in Jewish Identity in the Greco-Roman World, ed. Jörg Frey, Daniel R. Schwartz, and Stephanie Gripentrog (Leiden: Brill, 2007), 3-27, at 14. 


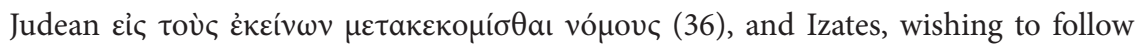

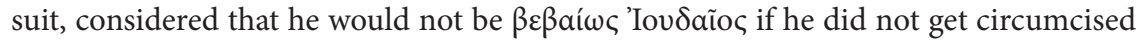
(38). This caused great alarm on political grounds. Despite her own attraction to Judean ways, Helena tried to dissuade him, 'for, she said, he was a king; and if his subjects should discover that he was devoted to rites that were strange and foreign to themselves, it would produce much disaffection and they would not tolerate the rule

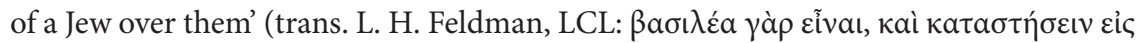

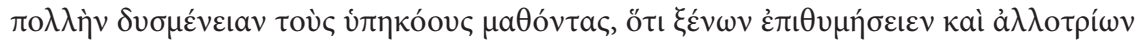

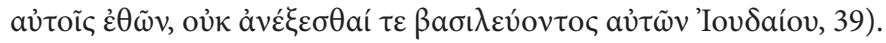

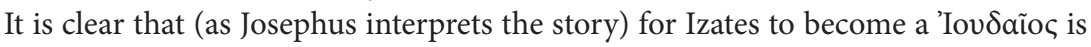
not a private or (in our terms) a merely 'religious' decision: it identifies him fully with a 'foreign' people, and therefore renders questionable his fitness to rule over the people of Adiabene. Nonetheless, Izates went ahead with circumcision and his mother and Ananias were petrified lest 'his subjects would not submit to government by a man

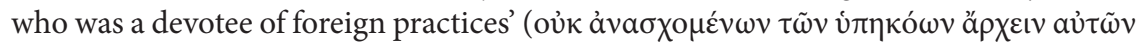

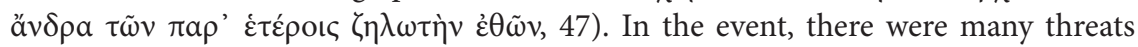
against Izates, but God (says Josephus) protected him from them all. When the cycle was repeated, and Izates' brother, Monobazus, and his kinsmen also 'became eager

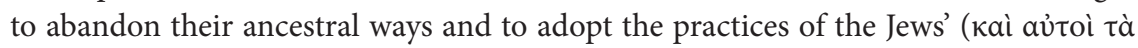

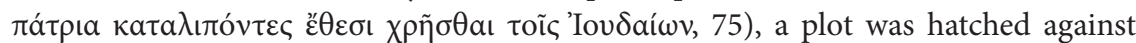
them, which God made sure did not succeed. The nobles of Adiabene then appealed to Parthia to intervene, 'for, they said, they had come to loathe their own king who had

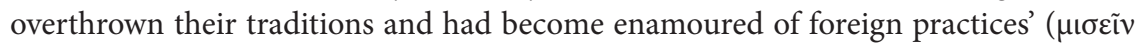

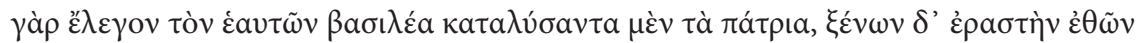
$\gamma \varepsilon v o ́ \mu \varepsilon v o v, 81-82)$. In answer to prayer, Izates was spared this threat also, and God protected his own.

The threefold repetition of the motif we have highlighted underlines an essential

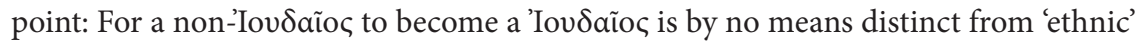
considerations. Izates' political prominence merely amplifies what is at stake: This is about abandoning the customs, traditions, and practices of one people and adopting those of another, 'foreign' nation. It makes little sense to describe this change as 'religious' as opposed to 'ethnic'. Apart from the problem of defining what we mean by 'religion', ${ }^{18}$ the change that Izates here undergoes concerns a package of social, cultural, and national traditions, which includes a special way of worshipping God (and of thinking about God), but only as part of a holistic shift in ethnic identity. ${ }^{19}$ Thus

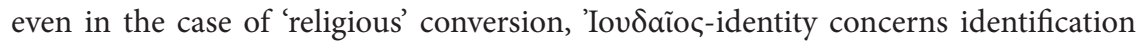
with an $\varepsilon \theta v o \varsigma$ to the extent that converts could be considered to have changed their national allegiance. This is impossible if ancestry is made an essential component of

18 The category is potentially problematic, as has been shown by Brent Nongbri, Before Religion: A History of a Modern Concept (New Haven: Yale University Press, 2013). But for an argument that it is not an inappropriate term in relation to ancient Judaism, see Daniel R. Schwartz, Judeans and Jews, 93-102.

19 Pace Seth Schwartz, I am not convinced that either the special intensity with which Jews/Judeans reflected on and practised their worship of God or their tight integration of its various dimensions constitutes the emergence of something that could be distinguished or 'disembedded' from its larger social context; see S. Schwartz, 'How Many Judaisms Were There?' JAJ 2 (2011): 208-38. 
'ethnicity', and if one cannot adopt an ethnicity to which one has no (either real or pretended) relation by birth. In Izates' case, when circumcised he could be considered 'securely a Jew/Judean': the objection was not that this was impossible, but that it was unacceptable. When he did so, he was obliged to adopt the ancestral traditions of others, while abandoning his own: In that sense, he gains a new ancestral tradition, without acquiring (through adoption) the accompanying ancestry. ${ }^{20}$ Thus in the case of the 'Iovdaĩol, the concept of 'ethnicity' must either be judged unhelpful (if defined monothetically) and best avoided, or it must be defined explicitly as a polythetic category, such that others could become ethnic Jews/Judeans even with no pretence of shared ancestry. ${ }^{21}$

The Izates story shows that 'Iov反aĩoc-ethnicity was not without its geographical connotations. After his conversion Izates was considered a 'foreigner' in Adiabene, and he sent five of his sons to Judaea 'to get a thorough knowledge of our native language

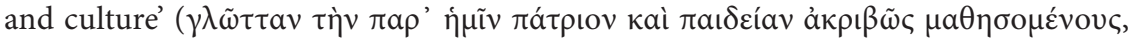
71). Helena, his mother, made an extended visit to Jerusalem 'to worship at the temple of God, which was famous throughout the world' (49), and while there gave famine relief to the people of Jerusalem by subsidizing imported grain (51-52); Izates also sent money to Jerusalem (53). Both of them, on death, were buried not in Adiabene, but in Jerusalem, in the three pyramids Helena had specially erected just outside Jerusalem (95). That is testimony to the extent of their identification with both nation and place. One senses that the geographical connotation of the name 'Iov $\delta$ aiol was not always equally strong, or even always present, but it was not uncommon. No doubt the Jerusalem temple, to which Jews famously made regular large payments, cemented and made visible their orientation to Judaea. The territorial connection

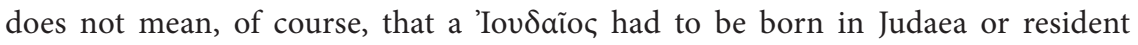
there: In an age when people were familiar with long-term migration and Diaspora communities, it simply meant a recognition of that land as (in a loose sense) their 'homeland'.22

No doubt that association could be played up or down for political and polemical purposes. In the bitter disputes between Jews/Judeans and Alexandrians in 37-41 CE, exactly how Judeans played their sense of 'belonging' was a very delicate matter, and

${ }^{20}$ It is possible that some proselytes were promised Abrahamic ancestry through circumcision, if that is what Paul's opponents in Galatia offered to his converts (that they become 'children of Abraham'). But the meaning of circumcision was itself open to dispute; see Matthew Thiessen, Contesting Conversion: Genealogy, Circumcision, and Identity in Ancient Judaism and Christianity (New York: Oxford University Press, 2011).

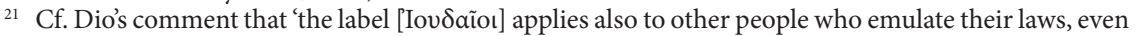

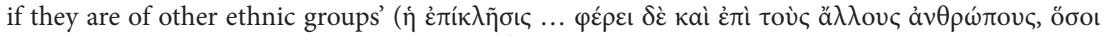

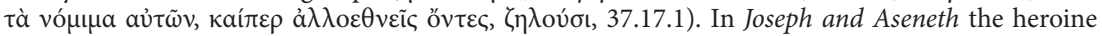
convert is never described as an 'Egyptian' (only as the daughter of the priest Pentephres), although she worshipped 'the gods of the Egyptians'. Instead, she is carefully introduced at the start as having 'nothing similar to the daughters of the Egyptians; she was in every respect similar to the daughters of the Hebrews; and she was as tall as Sarah and handsome as Rebecca and beautiful as Rachel' (1.5). This rhetorically assimilates Aseneth to Hebrew ancestry, without being able to erase her difference altogether.

22 Cf. Mason, 'Jews, Judeans', 183: 'The Judeans of the Greco-Roman world remained an $\varepsilon$ ' $\theta$ vo , a people associated with a place and its customs - no matter how far, or how long, they had been away from Judea.' 


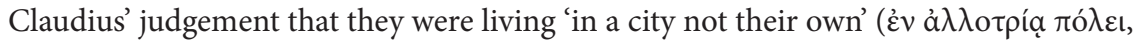
CPJ 153, line 95) was no doubt unwelcome to them. ${ }^{23}$ When, after the Judean War, the people of Antioch wanted to expel the Judeans from their midst, Titus did not accede to their request on the grounds that their homeland had just been destroyed (War 7.100-111). Although everyone knew that they were long-term residents in Antioch, and Titus wanted them to remain there, it was always possible, for positive or negative reasons, to associate them with another place, where they could be considered, in some sense, to 'belong. The exact connotations of the name 'Judaea' would matter to most people in the ancient world as little as it bothers most English speakers whether Holland is the whole country (properly called The Netherlands) or only one region within it. Since 'Judaea' contained Jerusalem and the temple, that was all that mattered. Finer distinctions between 'Judaea proper' and the 'Judaea in a wider sense' (including Idumaea and Galilee) were necessary only for close-grained descriptions of peoples and events in those small strips of land (of which we happen to have plenty in Josephus and the Gospels). ${ }^{24}$ But for most purposes all that mattered was that the name could be associated with a piece of territory known as 'Judaea.' 25

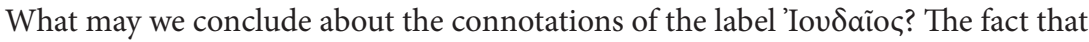
others of different descent could adopt this label (as the Izates story indicates) suggests that Judean ethnicity was a cluster-formed polythetic category that did not depend on shared ancestry. Only if we define 'ethnicity' as a monothetic category which requires shared ancestry (real or imagined) to mean anything at all does the phenomenon of conversion prove (as Cohen and others maintain) that 'Iov反aĩoৎ can cease to be an ethnic category, and can become something else. Within his definition of ethnicity, Cohen traced the origin of this change, as an 'ethnic definition' was supplemented, though not replaced, by a 'religious definition. ${ }^{26}$ But if we take the category to which 'Iovdaĩoc belongs as polythetic, we do not have to posit some point of change, simply the emergence of clarity that there is no one essential aspect of Judean/Jewish ethnicity even ancestry or birth. A polythetic category is, admittedly, imprecise, but imprecision is exactly what we find in many of our sources, even if certain elements of the mix, in certain contexts, gain privileged status. It was only rarely that one needed to be precise

23 On different kinds of belonging in the Diaspora, see Eric Gruen, Diaspora: Jews Amidst Greeks and

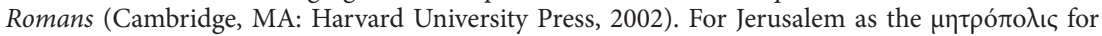
Philo (Flacc 45-6) and other indicators of Diaspora attachment to Jerusalem and the homeland, see John M. G. Barclay, Jews in the Mediterranean Diaspora from Alexander to Trajan (323 BCE - 117 CE) (Edinburgh: T\&T Clark, 1996), 418-23.

24 Josephus' own usage is notoriously inconsistent, 'Iov反aĩo meaning the residents sometimes of a part, and sometimes of the wider whole, of the geographical region. Where he needs to, Josephus

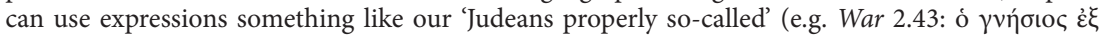

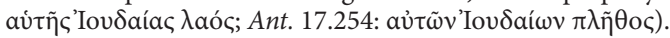

${ }_{25}$ Daniel R. Schwartz is right to point out that in some texts the link to the homeland is not particularly salient, but I doubt that this justifies a distinction in translation so that, in such cases, 'Jew' must be substituted for 'Judean' (Judeans and Jews, passim). By mapping these alternative translations onto his polarity between a land- and state-oriented identity (= 'Judean') and a Diasporan religious identity $(=$ 'Jew'), relatively small differences between texts, in the dimensions of ethnicity they make situationally salient, are elevated into categorical distinctions.

${ }^{26}$ Cohen, Beginnings, 137. For a similar narrative of change, see Daniel R. Schwartz, Studies in the Jewish Background of Christianity (Tübingen: Mohr Siebeck, 1992), 5-15. 
in such matters (for instance, in establishing liability to the fiscus Iudaicus). ${ }^{27}$ Thus, whether this category fits what we mean by 'ethnicity' depends on how we define that term, and what kind of category we take it to be; and the more self-conscious we are about that, the better.

\section{The question of translation}

The storm that has arisen over the preferred translation of 'Iovfaĩos (and Latin Judaeus) indicates not only the complexity of the problem but also its entanglement with properly sensitive concerns about the representation of Jews and Judaism both in scholarship and in the public domain. Translation, as interpretation, is never an entirely innocent matter. Some philosophies of translation favour 'formal correspondence' which will seek to reproduce, as closely as possible, 'what the ancients thought and felt. ${ }^{28}$ Others, concerned for 'dynamic equivalence' and with a different understanding of the purpose of translation, will pay more attention to the connotations of terms for the target audience, ${ }^{29}$ which means in this case special sensitivity to the ways that lexical choices might reduce or (inadvertently) increase the potential for anti-Judaism or anti-Semitism. The fact that the translation question first arose (in the 1970s) over the representation of 'Iov反aĩo in the gospel of John makes this latter consideration particularly powerful. ${ }^{30}$ The problem we face is that there are two possibilities for translation (for Aijú $\pi \tau ו o \varsigma$, and most other ancient ethnika there is only one), and that both are in some respects unsatisfactory as a translation.

Because there are two options, there is a natural tendency to draw a clear distinction between them, finding significantly different meanings in 'Judean' and 'Jew.' ${ }^{31}$ The most common distinction is that articulated by Cohen. In his view, "English Jew is primarily a "religious" term ... as opposed to a Catholic, Lutheran, Episcopalian, Hindu, Muslim, and so on. In some contexts the designation "Jew" may also have "ethnic" overtones, although it never has a geographic meaning, and, outside of the state of Israel, seldom a political one.' In contrast he takes 'Judean' to be an 'ethnic-geographic' term. Thus he hears in 'Judean' reference to 'birth' and 'geography', and in 'Jew' reference to 'culture' and 'religion.' ${ }^{32}$ Any differentiation such as this creates categorical distinctions which discourage entertaining the possibility of semantic overlap and multiple meanings. In other cases, this would be relatively unproblematic: We translate the Latin adjective Poenus as either

27 See Martin Goodman, 'Nerva, the Fiscus Judaicus and Jewish Identity', JRS 79 (1989): 40-4.

28 Mason, Josephus, 142; cf. 141: 'My interests are historical and philological: to engage the mindset, values, and category formations of the ancients.'

29 For the interests of ancient translations, see Sebastian Brock, 'Aspects of Translation Technique in Antiquity', GRBS 20 (1979): 69-87.

30 Malcolm F. Lowe, 'Who Were the IOY $\triangle$ AIOI?' NovT 18 (1976): 103-30. The debate continues: see Ruth Sheridan, 'Issues in the Translation of of 'Iov8aĩo in the Fourth Gospel', JBL 132 (2013): 671-95.

31 This is the stance taken by Daniel R. Schwartz, who insists that 'writers in English ... must decide which to use, and a decision to use "Judean," which is quite a rare term, amounts to a demonstrative statement that the other alternative, "Jew," is not appropriate' (Judeans and Jews, 7; cf. 84-5).

32 Cohen, Beginnings, 69-70. 
'Punic' or 'Carthaginian', but there is not much at stake in the choice between them. ${ }^{33}$ In our case, however, the alternative terms carry considerable freight. And because there are two options, the choice for one is readily heard as a choice against the other, and thus as a denial of the connotations that the other might evoke.

The translation 'Judean' maps onto 'Iovdaĩoৎ well (not only phonetically) in certain respects: It has the appearance of an ethnikon parallel to 'Egyptian',and so on, and it signals a geographical connection. It has the disadvantage of being unfamiliar to a nonacademic audience, and of seeming over-determined by its geographical connotations: Some hear this term as meaning only residents in, or emigrés from, Judaea (and thus as inapplicable to long-term Diaspora Jews) and many hear it as referring to the specific territory of 'Judaea proper', and thus as designating a sub-set of the people known as 'Jews'. It is perfectly possible for academics to introduce new technical terms (cf. the academic introduction of $\mathrm{CE}$ and $\mathrm{BCE}$ ), and they need not be overly concerned by dictionary definitions (which will change in time); but it will clearly take some time, and a lot of explanation, for the term 'Judean' to be heard with the set of resonances we

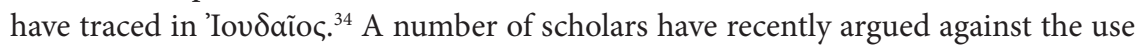
of this term on the grounds that it represents a denial that the people concerned were 'Jews', and thus suggests a break in continuity between 'Judeans' of the past and 'Jews' of the present (though the point of transition is uncertain).$^{35} \mathrm{In}$ fact, it is simple enough to explain that 'Judeans' is what Jews were called in the Graeco-Roman world (just as 'Israelites' is what Jews were called in earlier centuries). ${ }^{36}$ If we refuse to allow that a decision for 'Judean' is a decision against 'Jew', it might be possible to take some of the heat out of this discussion. The justification for 'Judean' would simply be that, although the two terms overlap, for scholarly purposes this usage is academically more precise.

The translation 'Jew' has the advantage of familiarity, in both popular and scholarly fields, but the disadvantage that it is under-determined in a number of ways that might

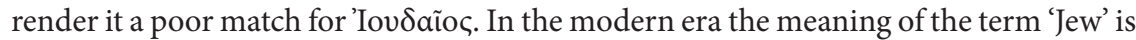
often ambiguous: Whether it designates birth/ancestry or 'religion', or both or neither, is often unclear and in some circumstances hotly contested. The deep connection in the ancient term 'Iov反aĩoৎ between religious practice and ancestral tradition (even for proselytes), and the ever-likely connection of both to a territory, is for some Jewish scholars, like Cohen, not implied by the term 'Jew', although for others it is. ${ }^{37}$ Thus, insofar as 'Jew' is understood to be an alternative to the ancestral-culturalgeographical cluster of connotations implicit in 'Judean', it seems a poor translation of 'Iovdaĩoc. (Whether the use of 'Jew' encourages or discourages 'anti-Semitism' is not

33 The former alludes to the connection with the Phoenicians, but we do not have an English substantive for the people 'the Punics', only an adjective ('the Punic War').

34 It is understandable that one should start from dictionary definitions of the two terms (Schwartz, Judeans and Jews, 3-6), but it not clear that scholars must be bound by them.

35 For example, Adele Reinhartz, 'The Vanishing Jews of Antiquity', in Jew and Judean, ed. Law and Halton, 5-10.

36 I cannot explore here the complex nuances of the terms 'Hebrew' and 'Israelite'; see Graham Harvey, The True Israel: Uses of the Names Jew, Hebrew and Israel in Ancient Jewish and Early Christian Literature (Leiden: Brill, 1996).

37 For Daniel R. Schwartz, the territorial association of 'Judean' makes the term equivalent to the modern 'Israeli' (Judeans and Jews, $\mathrm{x}, 87-9$ ), which complicates matters still more. 
altogether clear, and could be argued either way.) Of course, it is always possible for scholars to clarify that they mean by 'Jew' the ancient connotations of 'Iov反aĩos, but the fact that scholars on both sides of the debate have taken to interpreting 'Jew' as a purely 'religious' designation does not help to make this option easy. ${ }^{38}$

The issue of translation is largely a problem of the English language: Neither of the alternatives is ideal and both need explanation before they can map well onto the term 'Iov反aĩoc. I regard 'Judean' and 'Jew' not as stark alternatives, but as terms with partly overlapping meanings whose relation to 'Iov反aĩos is not self-evident and needs to be spelt out carefully in each case. Otherwise, we will need to leave the Greek and Latin terms untranslated or (my preferred option) use both terms together and interchangeably. ${ }^{39}$

For our purposes the problem of translation is interesting inasmuch as it sheds light on the complexities and ambiguities of what it means to be an $\varepsilon^{\prime} \theta v o \varsigma$, and the danger of mapping our definitions of 'ethnicity' onto ancient categories. Whatever the value of Hutchinson's and Smith's six-point list of the characteristics of 'ethnic identity', ${ }^{40}$ the crucial decision is whether ancestry (or any other single feature) is an essential element of a monothetic category, or whether we can allow the greater ambiguity of a polythetic phenomenon which allows some variation in the definition of ethnic groups. This variation concerns not just the rhetorical inventiveness that surrounds a constructed concept, but also the fuzziness of the concept itself. If we allow the latter, we may be less inclined to adopt narratives of change (from original integrity to later ambiguity or fragmentation), or to locate 'tipping points' when originally ethnic terms changed in meaning. On this reading of the evidence, such changes represent merely the reordering of features that never had any one 'anchor' or any definitive cluster-form but were always part of an inherently malleable phenomenon.

\section{References}

Barclay, John M. G. Jews in the Mediterranean Diaspora from Alexander to Trajan (323 BCE - 117 CE). Edinburgh: T\&T Clark, 1996.

Barclay, John M. G. Flavius Josephus, Translation and Commentary, Vol. 10 : Against Apion, edited by Steve Mason. Leiden: Brill, 2007.

Barth, Fredrik. 'Introduction'. In Ethnic Groups and Boundaries: The Social Organization of Cultural Difference, edited by Fredrik Barth, 9-38. London: George Allen and Unwin, 1969.

Brock, Sebastian. 'Aspects of Translation Technique in Antiquity'. GRBS 20 (1979): 69-87.

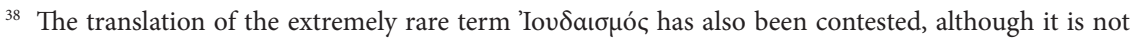

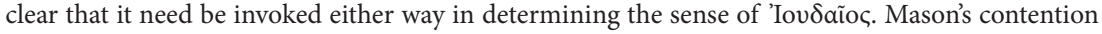
that the term meant originally not 'Judaism' but 'Judaization', a transitive noun, meaning inducing oneself or others towards the adoption of Jewish customs ('Jews, Judeans', 143-58), has been rightly contested by Daniel R. Schwartz (Judeans and Jews, 102-12), who shows that it means simply 'Judaism', at least in the key passages in 2 and 4 Maccabees.

39 The hybrid Jewdean might work in print, but is liable to please nobody!

40 See note 7. 
Buell, Denise Kimber. Why This New Race: Ethnic Reasoning in Early Christianity. New York: Columbia University Press, 2005.

Cohen, Shaye J. D. The Beginnings: Boundaries, Varieties, Uncertainties. Berkeley: University of California Press, 1999.

Esler, Philip F. Conflict and Identity in Romans: The Social Setting of Paul's Letter. Minneapolis: Fortress, 2003.

Esler, Philip F. 'Judean Ethnic Identity in Josephus' Against Apion'. In A Wandering Galilean: Essays in Honour of Sean Freyne, edited by Zuleika Rodgers, Margaret DalyDenton, and Anne Fitzpatrick McKinley, 73-92. Leiden: Brill, 2009.

Goldhill, Simon, ed. Being Greek under Rome: Cultural Identity, the Second Sophistic, and the Development of Empire. Cambridge: Cambridge University Press, 2001.

Goodman, Martin. 'Nerva, the Fiscus Judaicus and Jewish Identity'. JRS 79 (1989): 40-4.

Gruen, Eric. Diaspora: Jews Amidst Greeks and Romans. Cambridge, MA: Harvard University Press, 2002.

Hall, Jonathan M. Ethnic Identity in Greek Antiquity. Berkeley: University of California Press, 1997.

Harvey, Graham. The True Israel: Uses of the Names Jew, Hebrew and Israel in Ancient Jewish and Early Christian Literature. Leiden: Brill, 1996.

Hutchinson, John and Anthony Smith, eds. Ethnicity. Oxford: Oxford University Press, 1996.

Law, Timothy M. and Charles Halton, eds. Jew and Judean: A MARGINALIA Forum on Politics and Historiography in the Translation of Ancient Texts. Marginalia Review of Books; online publication, 2014.

Lowe, M. F. 'Who Were the IOY $\triangle$ AIOI?' NovT 18 (1976): 103-30.

Malkin, I., ed. Ancient Perceptions of Greek Ethnicity. Cambridge, MA; Harvard University Press, 2001.

Mason, S. 'Jews, Judeans, Judaizing, Judaism: Problems of Categorization in Ancient History'. In Josephus, Judea and Christian Origins: Methods and Categories, 141-84. Peabody: Hendrickson, 2009.

Miller, David M. 'The Meaning of Ioudaios and Its Relationship to Other Group Labels in Ancient "Judaism"'. CBR 9 (2010): 98-126.

Miller, David M. 'Ethnicity Comes of Age: An Overview of Twentieth-Century Terms for Ioudaios'. CBR 10 (2012): 293-311.

Miller, David M. 'Ethnicity, Religion and the Meaning of Ioudaios in Ancient "Judaism"'. CBR 12 (2014): 216-65.

Nongbri, Brent. Before Religion: A History of a Modern Concept. New Haven: Yale University Press, 2013.

Reinhartz, Adele. 'The Vanishing Jews of Antiquity'. In Jew and Judean: A MARGINALIA Forum on Politics and Historiography in the Translation of Ancient Texts, edited by Timothy M. Law and Charles Halton, 5-10. Marginalia Review of Books; online publication, 2014.

Schwartz, Daniel R. Studies in the Jewish Background of Christianity. Tübingen: Mohr Siebeck, 1992.

Schwartz, Daniel R. “Judean” or “Jew”? How Should We Translate Ioudaios in Josephus?' In Jewish Identity in the Greco-Roman World, edited by Jörg Frey, Daniel R. Schwartz, and Stephanie Gripentrog, 3-27. Leiden: Brill, 2007.

Schwartz, Daniel R. Judeans and Jews: Four Faces of Dichotomy in Ancient Jewish History. Toronto: University of Toronto Press, 2014.

Schwartz, Seth. 'How Many Judaisms Were There?' JAJ 2 (2011): 208-38. 
Sheridan, Ruth. 'Issues in the Translation of of 'Iov反aĩo in the Fourth Gospel'. JBL 132 (2013): 671-95.

Smith, Jonathan Z. 'Fences and Neighbours: Some Contours of Early Judaism'. In Imagining Religion: From Babylon to Jonestown, 1-18. Chicago: University of Chicago Press, 1982.

Smith, R. R. R. 'Simulacra Gentium: The Ethne from the Sebasteion at Aphrodisias' JRS 78 (1988): 50-77.

Thiessen, Matthew. Contesting Conversion: Genealogy, Circumcision, and Identity in Ancient Judaism and Christianity. New York: Oxford University Press, 2011. 


\title{
Identity Games in Early Christian Texts: The Letter to Diognetus
}

\author{
Judith M. Lieu
}

The explosion of interest in 'identity' as an organizing principle for the study of early Christianity and its literature has prompted new readings of familiar texts as well as bringing others out of obscurity. Among the latter is the anonymous writing, probably from the second century, known as the Letter to Diognetus. Not only does it include within its vocabulary many of the key terms and catch-phrases in the debate, but it also explicitly articulates the tension between separation and belonging that is a hallmark of any investigation into the social experience as well as the textual construction of the early Christian movement. Indeed, for this reason it has long served as a proof-text for systematic and pastoral theologians even before it grasped the critical analytical attention of those more attuned to the rhetorical strategies that accompanied the emergence of early Christianity. It was Diognetus that provided for the present author an entrée into the vigorous discussions of the constructed nature of ethnicity both in contemporary analysis and in studies of classical antiquity, and provoked a much more extensive attempt to map early Christian identity through a conversation between contemporary models and a close reading of the literature, Jewish and Greco-Roman as well as Christian, of the first two centuries. ${ }^{1}$

Over the twenty years since that first foray the analysis of identity has become ubiquitous even as it has also evolved, moving in new, sometimes conflicting, directions both in contemporary theory and application and in the analysis of antiquity, including Christian antiquity. The ubiquity can generate a degree of blandness, the restating of familiar observations in the truisms of a flattened theoretical base - appeals to boundaries and to the construction of 'the other' - both on the side of those who, unsurprisingly, find 'identity' everywhere and of those who deny its applicability either to the past in general or to early Christianity in particular. One of the consequences of this is that whereas the investigation of a textually constructed identity arose in part from the emphasis on the diversity of early Christianity that dominated the

1 Judith M. Lieu, 'The Forging of Christian Identity and the Letter to Diognetus', Mediterranean Archaeology 11 (1998): 71-82, reprinted in eadem, Neither Jew nor Greek? Constructing Early Christianity, 2nd edn ([2003] London: Bloomsbury T\&T Clark, 2016), 185-203; eadem, Christian Identity in the Jewish and Graeco-Roman World (Oxford: Oxford University Press, 2004). 
last quarter of the twentieth century, which was resistant to notions of a uniform orthodoxy, the Christianity-as-constructed that has emerged is in danger of assuming a certain homogeneity, reinforcing the gap between it and any attempt to recover lived experience. It is within this context that this essay returns to Diognetus to reflect on how it fares within the established world of identity scholarship and to bring it into dialogue with new questions as well as with old texts.

The value of Diognetus for questions of identity-formation is established by the question it purports to answer in the opening prologue: 'And why indeed as new has

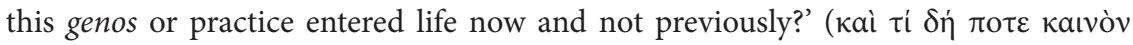

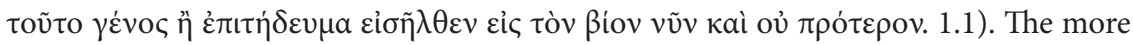
familiar translation, 'this new race', has proved to be a highly quotable point of appeal for discussions of the ethnic dimension of early Christianity. ${ }^{2}$ Yet equally quotable has been the later claim that 'Christians are not distinguished from other people in country, language or dress (or customs) ${ }^{3}$... every foreign place is their homeland, and every homeland foreign' $(5.1,5)$. Hence Diognetus can be understood as introducing an ethnic understanding of early Christianity (as $\gamma \dot{\varepsilon} v o \varsigma$ ) and at the same time as transcending one. This apparent contradiction might be understood simply as a consequence of what appears to be the composite character of a text whose original context and shape have been lost: Despite attempts to do so it is difficult to find a coherent structure or theology across all twelve chapters. Nonetheless, what follows will trace these tensions through a unitary reading of the early chapters of Diognetus and will seek to show how as a consequence it can be seen as engaging in a complex play with then contemporary appeals to forms of identity.

The prologue implies that the question and hence the language of $\gamma \varepsilon \dot{\varepsilon}$ o are posed by the addressee, Diognetus, who is assumed to be an interested 'outsider'; hence, this is presented primarily as an ascribed, or etic, identity. Supporting evidence for the external origin of the label has readily been found: Suetonius describes the Christians as 'a genus of people holding a new and mischievous superstitio' (Nero 16.2), which itself may draw on Livy's presentation of the Bacchic controversy of 168 BCE where, using a more politically loaded term, the threat posed is summarized by the emergence of 'almost a second (or 'alternative') people' (alterum populum: Hist. 39.13.14; cf. 16.10, 'superstitio'). ${ }^{4}$ In the same trajectory, Tertullian, a century later, describes the 'peoples of the nations' as crying out 'for how long the third race!' (usque quo genus tertium: Scorp. 10), although the meaning of this supposedly popular catcall is far from evident; elsewhere he subjects the epithet to characteristic ridicule, exploiting the ambiguity of genus which might be applied to either natio or superstitio and objecting that in neither case would the Christians count as third (Nat. 1.8). As shall be seen, the wide semantic range of

2 So Clayton N. Jefford, ed., The Epistle to Diognetus (with the Fragment of Quadratus): Introduction, Text, and Commentary (Oxford Apostolic Fathers; Oxford: Oxford University Press, 2013), 135; The Apostolic Fathers, trans. and ed. Bart D. Ehrman (LCL 25; Cambridge, MA: Harvard University Press, 2003), II:131; for its use, see Denise Kimber Buell, Why This New Race: Ethnic Reasoning in Early Christianity (New York: Columbia University Press, 2005).

3 The manuscript tradition is 'dress' ( $\varepsilon \sigma \theta \varepsilon \sigma \mathrm{l})$ although many editors/ translators follow the emendation 'customs' ('ย $\theta \varepsilon \sigma \mathrm{l})$.

4 On superstitio, see pp. 62-5. Pliny's account of the Christians, although possibly echoing Livy, uses the language of superstitio but not of genus/ populus (Ep. 10.96). 
genus/ $\gamma \varepsilon \dot{v}$ oc, and their fluidity even within a single author, is much discussed, and is only exacerbated by the mismatch with notions of 'race' in the modern period. Undoubtedly it can be used in polemical denigration of the characteristics of other 'peoples', as when Cato famously described the Greeks as 'the most wicked and uneducated genus' (apud Pliny, Nat. 29; cf. Vergil, Aen. 8.321), but perhaps in the case of Suetonius 'class' would be a more appropriate translation - although to deny any explicitly ethnic categories does not exclude the overtones of threat and possible subversion. Thus, at first reading Diognetus' question is potentially less innocent than it may sound.

On the other hand, it is not at all obvious that Diognetus presupposes an antagonistic relationship with its audience. The label 'letter' is probably not original; although to some extent it is supported by the singular address, it remains not entirely apposite, for the verbs used are of speaking and listening, not of writing $\left(1.2 ; 2.1\right.$, etc.). ${ }^{5}$ It has often been aligned with the apologetic writings of the second century, but it is not directly polemical, and while at times persecution appears to be the norm, there is nothing to give such references any precision in terms of time and context $(5.11-17 ; 6.5,9) .{ }^{6}$ Others have described it as a protreptic text, an introduction and invitation to an enquirer to engage in the philosophical life. Certainly the author describes himself as 'a teacher of the nations' (11.1), but the invitations with which the text closes are remarkably understated $(12.1,8)$. In any case, while the implied audience is external, the actual, and probably the intended, audience was internal. The opening move, therefore, must be read as a literary device, using models chosen by the author, and it needs to be examined alongside his other literary strategies. Its effect is sustained by the phrases 'I expect you are keen to hear ... I do not think you need to learn from me', which act as prompts to new stages in the argument $(3.1 ; 4.1)$. Putting the question with the specific label $\gamma \varepsilon$ ćvoৎ in the mouth of his addressee offers the author the possibility of interrogating and negotiating it without needing to justify its use.

The same purpose is served when Diognetus' interest is described as 'concerning the theosebeia of the Christians' (1.1). This term would support placing Diognetus amongst the apologists for whom it is a primary epithet. ${ }^{7}$ A recent edition translates $\theta \varepsilon$ co $\dot{\beta} \beta \varepsilon \alpha$ four different ways in six passages: religion (1.1), worship (3.[1], 3; 6.4), reverence (4.5), devotion (4.6); ${ }^{8}$ none quite fits and the problem illustrates the difficulty of applying the category of 'religion' to the ancient world. $\theta \varepsilon o \sigma \varepsilon \dot{\varepsilon} \beta$ เ $\alpha$ both parallels and, in many

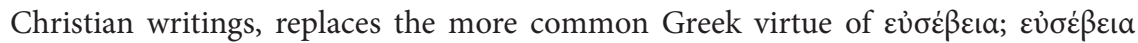
provided a koiné among all groups for claims to religious and civic or familial piety, and there is some evidence that Jewish apologetics similarly found in $\theta \varepsilon \sigma \sigma \varepsilon \dot{\varepsilon} \varepsilon$ เ some competitive advantage (4 Macc. 7.6, 22, etc.; Jos. Asen. 4.9; 8.5-8). Among the Christian apologists it is used in particular in competition with the claims of both Judaism and civic society, and in the later period it does become a preferred way of referring to the

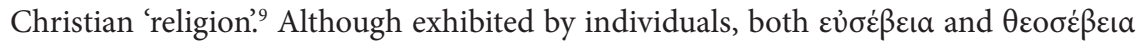

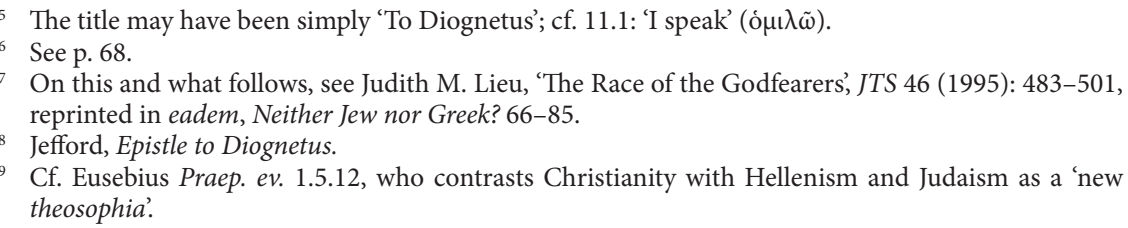

9 Cf. Eusebius Praep. ev. 1.5.12, who contrasts Christianity with Hellenism and Judaism as a 'new theosophia'. 
are corporate virtues, just as impiety, ả $\sigma \dot{\beta} \beta \varepsilon ı$ - which the author directs to the Jews (4.3) - matters not as a private position but for its social manifestations, as also does 'atheism'. Contemporaneous with Diognetus both the Martyrdom of Polycarp (3.2) and Melito's lost 'Apology' to Marcus Aurelius (apud Eusebius, Hist. eccl. 4.26.5) combine $\theta \varepsilon o \sigma \varepsilon \dot{\varepsilon} \varepsilon \varepsilon_{\alpha}$ with the language of $\gamma \dot{\varepsilon} v o c$ : the 'godfearing race' or 'race of godfearers'. Such language deliberately exploits the semantic breadth of $\gamma \dot{\varepsilon} v o c$, inasmuch as it mimics its ethnic characteristics at the same time as, by adopting a delimiting identifier that refers neither to place nor to ancestry, it undermines the strategies of differential labelling that belong to the latter.

Here that $\theta \varepsilon \circ \sigma \varepsilon \varepsilon \varepsilon \_$, about which Diognetus is so eager to learn, has three elements: (1) the identity of the God in whom the Christians trust, together with the manner of their worship; (2) the nature of their love for each other; and (3) the question discussed earlier, 'Why, indeed, this genos or epitēdeuma as new has entered life now and not previously?' The relationship between these questions is not clear; in part this is because the first question ( $\tau i v \imath \theta \varepsilon \tilde{\omega} \ldots \pi \tilde{\omega} \varsigma$ ) has been disrupted by an addition that grammatically now constitutes the main clause - namely, that they disdain the world and despise death, and neither recognize those considered gods by the Greeks nor observe the superstition of the Jews. ${ }^{10}$ The logic of the argument suggests that the first part of this expansion itself has been displaced and should properly accompany the love for one another. Diognetus would, therefore, be asking about the nature first of their God and worship (which contrasts with that of Greeks and Jews), and, second, of their mutual affection (which is matched by their disdain for the world and for death). For an insider these two might be seen as echoing the dual command of love for God and for neighbour or internal 'other' - although there are no explicit allusions even in the vocabulary used,

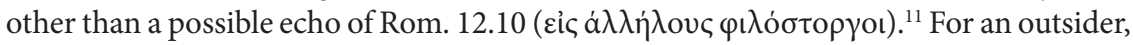
religious allegiance and corporate commitment would align the Christians with other cult groups or associations, even if the latter on occasion could be seen as politically dangerous. While the third element does add a new aspect - why now? - it also serves to summarize the first two as constituting $\gamma \dot{\varepsilon} v o \varsigma$ or $\dot{\varepsilon} \pi \imath \eta \dot{\delta} \delta \varepsilon \mu \alpha$.

\section{Which god and what manner of worship?}

The insertion into the more general question, 'which god and what sort of worship?' (Diogn. 1), of the contrast between 'Greeks' and 'Jews', together with the loaded

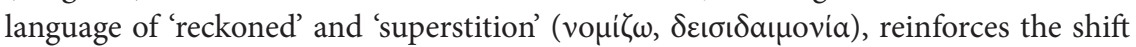
from an outsider to an insider discourse: 'Neither the gods reckoned by the Greeks nor the superstition of the Jews'. The alternative draws on Jewish antecedents, although there it usually takes the reverse order ('Jews and Greeks'), and it forms a conceptual opposition that should not be confused with debates as to whether 'Judaism' was 'hellenized'. Both are treated as unitary, and in the original formulation there is no

\footnotetext{
${ }^{10}$ Hence the questions are now followed by participles, leading translations to represent the main verbs within a result clause: 'In which god they trust ... so that they all ignore the world'.

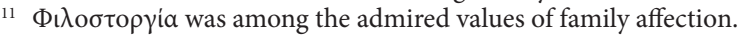


further or third option - it is a binary opposition that functions on both the universal and the local levels. In a Jewish framework the context is not normally 'religious': for example, Josephus distinguishes between Jewish and Greek authorities for his own apologetic and historical work, while he also identifies the conflict in Alexandria as between Jews and Greeks (Apion 1.72; War 1.17, 94; Ant. 18.257; cf. 2 Macc. 4.36). As an external observer, by contrast, Cassius Dio describes the Jews in Cyprus as killing Greeks and Romans (Hist. 68.32). However, the stereotyped pairing Jew/Greek is much more frequent in Christian sources, particularly in the context of the new alternative to both, and it occurs in this sense already in Paul (Rom. 1.16; 3.9; 1 Cor. 1.22; 12.13, etc.). ${ }^{12}$ There, however, it belongs to a world system shaped by the history of God's dealings with humankind, without the specifically political and cultural resonances. ${ }^{13}$

In what follows the author implicitly, but not explicitly, addresses Diognetus as belonging to the Greeks: 'Those considered by the Greeks as gods' becomes 'those you (pl.) consider gods' $(1.1 ; 2.1,7)$. Similarly, the singular 'you' ('Come now!') gives way to the plural, although this is in part qualified by the initial call, 'Purify yourself (sing.) from all the reasonings that constrain your understanding ... and become as it were a new human being' (2.1). Again, this may betray the incorporation of earlier material with a more directly polemical tone. ${ }^{14}$ Yet it also serves to reinforce the fact that the Jews consistently represent a separate third party, about whom the author assumes Diognetus knows as much as he does himself (3-4). Thus the Jews function as 'Other' both to the implied audience and to the implied author; in context, as shall be seen, this provides a cover for the harsh direct invective that sets Jews against Christians. Despite this, the author does not locate himself within the universe he is describing; even while the authorial first-person singular is sustained $(1.1-2 ; 3.1 ; 4.1,6 ; 7.1)$, the Christians are also consistently referred to in the third person, 'they.' ${ }^{15}$

The account of those whom 'you' consider as gods takes the form of a stereotypical denunciation of the worship of items of wood or metal, fashioned in much the same way as everyday utensils (2.5-6); parallels elsewhere in Jewish and Christian writings abound and there is little sense of immediacy. ${ }^{16}$ Besides a passing comment regarding 'your' hatred of Christians, this is seen as sufficient explanation of why Christians 'are not enslaved' to such gods $(2.6,10){ }^{17}$

The question as to why 'they' (Christians) do not practice their piety $(\theta \varepsilon 0 \sigma \varepsilon \beta \varepsilon \tilde{v} v)$ in a similar fashion to the Jews occupies rather more of the author's attention, and is clearly more pressing. The recurrence of the vocabulary of $\theta \varepsilon$ oos $\beta \varepsilon ı \alpha$, absent from the account of the Greeks, confirms that herein lies an urgent competition $(3.1,3 ; 4.5,6)$. Unlike the Greeks, the Jews might have some claim to $\theta \varepsilon o \sigma \varepsilon \dot{\beta} \varepsilon$ a, on the grounds that

12 Acts $14.1 ; 18.4 ; 19.10$ is closer to Josephus. See Clement of Alexandria, Protr. 11.112 for the threefold 'barbarian, Jew, Greek'.

${ }^{13}$ It may be that we should therefore be sceptical of Eusebius' account of the two apologists Apollinarius and Miltiades as addressing separately 'Jews' and 'Greeks' (Eusebius, Hist. eccl. 4.27; 5.17).

${ }_{14}$ However, the variation between singular and plural continues in 11.7-8; 12.1, 7.

15 The first-person plural in $8.11 ; 9.1,2$, etc., is generic, 'humankind'. The Apology of Aristides similarly uses the third person in its account of the Christians, but it also does so with reference to the Greeks.

${ }_{16}$ For other similar early Christian polemic, see Jefford, Epistle to Diognetus, 203-8.

17 The perfect passive should be retained rather than a more anodyne 'do not serve. There may be an echo of Gal. 4.9-10 here. 
they also revered, $\sigma \varepsilon \dot{\beta \varepsilon \iota v}$, one God, $\theta \varepsilon$ co $\varsigma$ (3.2) ${ }^{18}$ however, this claim is swiftly proved void. Even though they properly avoid the practices of the Greeks just described, and recognize one God - both potentially although not explicitly shared with the Christians - the worship ( $\theta \rho \eta \sigma \kappa \varepsilon i \alpha)$ of the Jews is reduced to the same level as that of the Greeks, simply by their participation in a sacrificial system which offers God that which God does not need (3.3-5). Despite the absence of scriptural quotations, in a post-70 context these are biblical Jews and most likely would be persuasive as such only to an internal audience. However, the following chapter adds a further characterization of the Jews that would probably have been more widely shared - their food laws, sabbath, circumcision, and fasting and new moon, and then their close attention to stars and moon in order to determine the seasons and liturgical cycle (4). These are condemned not only in philosophical terms for misunderstanding God's oversight as creator but more directly by a litany of derogatory nouns, 'superstition', 'pride', 'naivety', 'deceit', 'pretence, 'meddling', 'folly'. Far from being 'pious' (godfearing), they are exposed as impious (4.3).

There can be little doubt that the urgency of the author's polemic lies in the differentiation from the Jews, and that its rhetorical effectiveness is reinforced by implicit intertextual resonances. Some of these would be effective for insiders, recalling internal strategies of differentiation from practices associated with the (Jewish) law (Gal. 4.10; Col. 2.16); ${ }^{19}$ stronger associations probably lie elsewhere, in the long history of hostile comments on the Jews by both Greek and Roman authors.

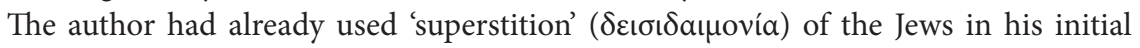
question (1.1), and its repetition here reinforces the rejection of any more positive label. 'Superstition' was a charge that was regularly levelled against the Jews, as it was against other foreign cults seen as dangerous to civic society; ${ }^{20}$ it had of course also been directed against the Christians, although at the most that is only indirectly being refuted here. ${ }^{21}$ The accusation of pride would echo the widespread denunciation of Jewish unsociability and hostility to everyone else; the mockery, in particular of their pride in 'mutilation of the flesh' as a sign of election and divine preference (4.4), partly recalls the polemical association of circumcision with Jewish self-separation, ${ }^{22}$ even if couched in language more familiar among Christian circles. 'Meddlesomeness' may have recalled complaints about their involvement in local civic disputes as well as their proselytism. ${ }^{23}$ On the other hand, there was already a Jewish apologetic tradition that refuted these negative charges and celebrated as marks of Jewish piety ( $\varepsilon \dot{\sigma \varepsilon \varepsilon} \beta \varepsilon \imath \alpha)$ the spread throughout the empire among non-Jews of those very practices that the author has identified for condemnation (Josephus, Apion 2.282-4). ${ }^{24}$ However, the author

18 If the emendation 'correctly' ( $\kappa \alpha \lambda \tilde{\omega} \varsigma$ ) is to be read here, then the author makes some grudging concession, only then to withdraw it.

19 For parallels, see Jefford, Epistle to Diognetus, 213-17.

20 For example, Cicero, Flac. 67 for whom Judaism is a barbara superstitio.

21 Tacitus, Ann. 15.44; Pliny, Ep. 10.96.

22 Tacitus, Hist. 5.5.2: 'They introduced circumcision of the genitals in order to be recognized by their difference.'

${ }^{23}$ See the full discussion of charges against the Jews in Benjamin Isaac, The Invention of Racism in Classical Antiquity (Princeton, NJ: Princeton University Press, 2004), 440-77.

24 Josephus here largely ignores circumcision. 
provides no hint that he is aware of this. Indeed, although it is hard to imagine that his audience, internal or external, would have had no knowledge of commonalities between Jews and Christians, for this author they simply do not exist, not even to be refuted. Indeed, neither here nor later in his account does the author give the slightest hint that Jewish history and experience had any role to play in the sending of the Son by God or in the Christian claims to a past or to an identity. ${ }^{25}$ Instead, he closes this part of the argument by reducing the Greek and Jewish alternatives to Christian concepts of the divine to a matter of somewhat anodyne moral qualities - the reverse side of their own $\theta \varepsilon o \sigma \varepsilon \dot{\beta} \varepsilon$ เ $\alpha$ is their avoidance of the general emptiness and deceit (perhaps of the Greeks), and meddling and pride of the Jews (4.6).

\section{The $\theta \varepsilon o \sigma \varepsilon \dot{\beta \varepsilon} \beta$ a of the Christians}

Thus far the argument seems to presume that Christians are 'the same sort of thing' as Greeks and Jews; the process of answering Diognetus' question has led the reader to expect a parallel account of how the Christians themselves understand God, and perhaps why they live as they do, although this has not been addressed directly with reference to Greeks or Jews. Instead the author gives up the rhetoric of differentiation, and moves to a new way of structuring reality, an undifferentiated one overlaid on a binary model structured around citizenship. The Jews now overtly disappear from his conceptual, cultural, and spatial world, although perhaps we may detect their shadowy presence. Instead, his claim that Christians live equally in 'Greek and barbarian' cities (5.4) does not refer to Greeks and Jews, as it might elsewhere, but to what was a familiar pairing within the Hellenistic and then the Roman empires, in particular in relation to the cities of Asia Minor with their different histories and structures. ${ }^{26}$

With this, in contrast to the formulaic opposition to and between the worship of the Greeks and Jews, the imagery assumes an urban context, not merely as a sociological reality but by evoking the city as the defining locus of communal and civilized living

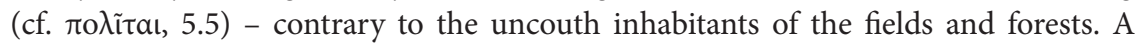
civic model would not of itself be incompatible with an ethnic one (cf. 2 Maccabees). Rather, by opening his account with a denial that Christians differ from all other people ${ }^{27}$ in 'land, tongue or dress (customs)' (5.1), ${ }^{28}$ the fundamental principles of ethnic reasoning are being evoked and simultaneously undermined; it was axiomatic that people do differ amongst themselves precisely in these ways, and that these differences have far-reaching consequences. Language, dialect, customs, and lifestyle are what make a Greek Greek, and equally a barbarian barbarian - and in other contexts, a Jew,

25 The references to being 'dishonoured by the people' and to 'the fathers ... the law ... and the prophets' in 11.3, 5-6 do not seriously change this.

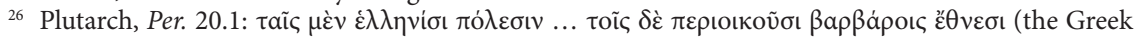
cities ... while to the neighbouring barbarian nations); cf. Luc. 26.1; Thucydides, Hist. 1.6.6; 7.80.3.

27 Contrast Cassius Dio who says of the Jews that they 'are separated from all other people ( $\tau \tilde{\omega} v \lambda$ oot $\pi \tilde{\omega} v$ à $v \theta \omega \dot{\omega} \pi \omega v)^{\prime}$ in all other matters of daily life and especially in their failure to honour any of the other gods. (Hist. 37.17)

28 See note 3. 
a Jew. For Strabo it is fundamental that the nation ( $(\varepsilon \vee v o \varsigma)$ of the Armenians, and those

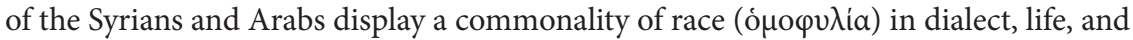
types (character) of body, and that all three belong in Mesopotamia (Geogr. 1.2.34). At the same time the potential malleability of 'language, customs and lifestyle' made it possible for the barbarian to become Greek, or even for the Greek to become Jew or barbarian, although this only underlines that such malleability is predicated on a prior differentiation: Apollonius of Tyana rejects the rights of the Ionians to retain the name 'Greeks' just on the grounds that they were a Greek colony, for Greekness also requires 'customs, laws, tongue and personal life' (Epist. 71). As the author further reduces such variation, even between Greek and barbarian, to being a matter of 'local customs' (Toĩ

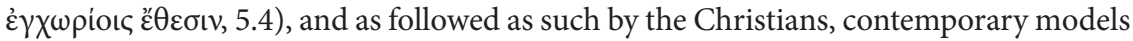
both of Greekness and of citizenship are being consciously decentred: 'Local' ( $\dot{\gamma} \gamma \chi \omega$ ' is routinely used in contrast both to a shared 'Greek' elite culture and to its civic

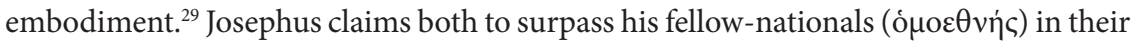

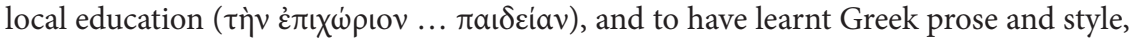

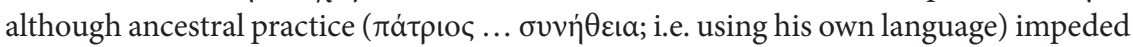
his pronunciation (Ant. 20.263).

Lucian, himself exemplary of the malleability of identity, provides a provocative dialogue partner for a reading of Diognetus, when he describes the visit of Anarchasis from Scythia to Athens, where he finds himself a 'foreigner and barbarian' ( $\xi \dot{\varepsilon} v o \varsigma$ кaì $\beta a \rho \beta a \dot{\rho} \rho \varsigma)$, not least because no one speaks his language and the Greeks mock his clothing. ${ }^{30}$ About to give up, he is prevented from so doing by a chance meeting with Toxaris, who himself was also originally from Scythia but moved to Athens out of love for Greece and the best ways of life ( $\dot{\pi} \iota \tau \eta \delta \varepsilon \dot{v} \mu \alpha \tau \alpha)$; while Toxaris recognizes Anarchasis by his dress, the latter had no way of knowing he was 'of the same people' (ó $\mu \varepsilon \theta v \eta \dot{\zeta}$ ) because of his Greek clothing, his shaven chin, his lack of belt or sword, and his fluent speech. Indeed, states Lucian, he was an aboriginal (av̉ tóxĐovoc) Attic, so changed by time (Scyth. 3). There is certainly more than a little irony here, for Lucian had already explained that Toxaris was worshipped as a 'hero' in Athens and thus demonstrated that the attribution of immortality to someone was not only

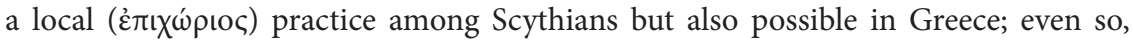
cult was paid to him as 'the Foreign Physician', and his shrine was decorated with the recognizable figure of a Scythian man.

Yet our author now takes a new tack as he acknowledges that Christians as individuals do have a native land or place of citizenship ( $\pi \alpha \tau \rho i \varsigma)$, but denies that these in any way determine who they are and where they belong (5.5). While this may seem to be an effort to distance Christians from the identity politics of the day, his strategy nonetheless continues to reflect the degree to which any predication of customs and lifestyle onto specific place increasingly required careful negotiation, as indeed was bound to happen in the wake of the spread of Greek colonies - as Apollonius' letter to the Ionians illustrates. Josephus, perhaps reflecting contemporary dilemmas, imagines

29 Thus it carries some of the nuances of the English, 'the locals', and is used of customs, gods, animals, etc., that are encountered as strange by a visitor or invader.

${ }^{30}$ Lucian, The Scythian. Lucian tells this story to explain his own experience as a Syrian seeking an entrée in Greek cities. 
the Midianite women, once they had persuaded the Hebrew youths to marry them, demanding that they worship their gods; if they refuse so to do 'they must seek some other land wherein to live alone according to their own laws' (Ant. 4.134-8). On the other hand, Cassius Dio, after expressing uncertainty as to why the land he knows as Palestine was called Judaea and its inhabitants Jews, goes on to explain that the label was transferred to other people, even of other nations, who adhered to their practices,

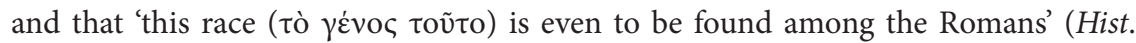
37.16-17). A recurring concern for the Jews of the diaspora, celebrated by Josephus in a long cache of letters, was their need for imperial support to follow their ancestral customs ( $\tau \grave{\alpha} \pi \alpha \dot{\tau} \tau \rho \alpha)$ and also to send money to Jerusalem, something Augustus granted because of the support the 'Jewish nation' gave him, namely by the leadership in Judea (Ant. 16.160-78).

It is within this trajectory that the apologist Athenagoras stands when he claimed that Roman permission to other peoples to follow their own customs and laws ought equally to apply to the Christians (Leg. 1). Diognetus adopts a very different tactic of negotiation - Christians are content to follow local practice in clothing, lifestyle, and other aspects of life; he would, presumably, plead not guilty to Celsus' accusation that the Christians transgress the fundamental principle that everyone should live according

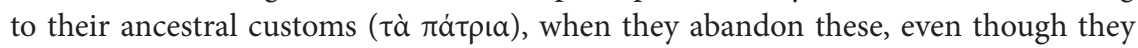
are not an ethnos like the Jews (see Origen, Cels. 5.35). But then, with a sudden twist, the author asserts that in so doing the Christians demonstrate the extraordinary and

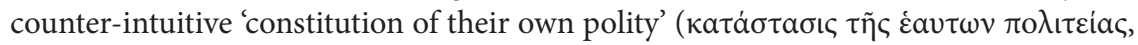
5.4 ) - although here too even while claiming difference he draws on the conventional terminology of analysis of different political systems or patterns of organization (cf. Plutarch Publ. 6.6; Cam. 1.2).

To illustrate that 'paradoxical' constitution, the author moves into an asyndetic litany founded on a set of antitheses: 'They happen to be in flesh, but they do not live according to the flesh' (5.6-15). Only the first part of this litany (5.6-10) directly addresses differentness, although subsumed under similarity ('like everyone else they marry'), and even here the examples are conventional: The avoidance of exposing their young and strict marital fidelity (5.6-7) in practice were shared with the Jews and perhaps more widely valued - something that is not conceded but would determine any apologetic effectiveness. Although it might be expected that they married and shared a table only among themselves, this is not stated - and it is difficult to ignore the fact that the Jewish separation of table and marriage bed was regarded with disgust and suspicion: 'Separated at meals, isolated in their beds, a race (gens) most prone to lust, they abstain from intercourse with foreign women, while among themselves nothing is prohibited' (Tacitus, Hist. 5.5.2). Nonetheless, it is striking that there are no hints of a set of distinctive communal practices among the Christians. The initial assertion of their love for one another is not illustrated, as in other apologetic writings, by any practical examples. ${ }^{31}$ Unlike many contemporary Christian writings, Diognetus does not introduce the language of family and kinship.

31 In chapter 10 not oppressing one's neighbours and supporting the needy is validated as being a form of imitation of God. 
In the second part of the litany a series of passive verbs, 'persecuted, condemned, put to death, dishonoured', begin to problematize the initial assertion of conformity (5.11-15). If, as is possible, this is traditional material, it is recontextualized by the return to the tripartite model at the close, although now expressed in the vocabulary of national or civic conflict and enmity (č $\chi \theta \rho \alpha)$ - 'they are warred on by the Jews as belonging to a foreign nation, ${ }^{32}$ pursued by the Greeks'. However, the main target is not the unjust suffering: In the following chapter the abuse and hatred Christians endure is as much in the nature of things as is the antipathy between body and soul (6.5-6). Instead, the primary focus is rather on how their identity is almost entirely defined in their antithetical response to the treatment meted out to them. Although the connection is not made explicit, this recalls the initial specification of their 'disdain for death' (1.1). This was a known characteristic of the Christians, perhaps deliberately mocked by Lucian in his account of Peregrinus (Peregr. 23; 33), but it was more positively valued in philosophical circles (Epictetus, Diatr. 4.1.70-71). It could therefore find a place in apologetic competition: Josephus celebrates the readiness to despise death in war as a God-given gift to the Jews, and through them to the world (Apion 2.293-4). Yet, in contradistinction to Jewish tradition, in Diognetus' account Christians have no ancestral practices of their own; neither do they die for them nor

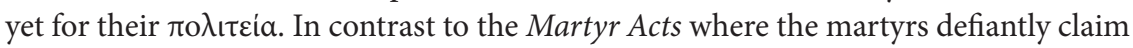
'Christian' as fulfilling every dimension of their ethnic identity, ${ }^{33}$ here the label has no added value.

This abnegation might be seen as a highly distinctive application of the theme of

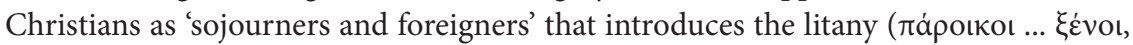
5.5). ${ }^{34}$ This much-studied topos hearkens back to a long tradition in Jewish thought, and is then adopted within Christian tradition, most notably as stimulated by 1 Peter (which also uses the language of $\gamma \varepsilon \dot{v}$ oc; 1 Pet. 1.1, 17; 2.9, 11). ${ }^{35}$ In Diognetus the alternation with the language of 'homeland' ( $\pi \alpha \tau \rho i \varsigma)$, and the qualifying 'as' ( $\dot{\omega} \varsigma)$, subvert the stability of the metaphor as one of either sustained alienation or relocation: They are, after all, 'citizens', perhaps unlike the 'migrants' ( $\pi \alpha \rho \varepsilon \pi i \delta \eta \mu \mathrm{o})$ of 1 Peter 1.1. The contrast between how they 'spend time on earth but exercise citizenship in heaven' similarly maintains rather than transcends the metaphors of space (5.9). ${ }^{36}$ In a new set of images chapter 6 compares Christians in the world to the soul in the body, and so develops further the dialectical relationship with the constraints of spatiality.

32 Not $\xi \dot{\varepsilon} v o$ as in 5.5 , but $\dot{\alpha} \lambda \lambda$ ó $\varphi v \lambda o$, the term used to translate the Philistines in the LXX and the opponents of the Maccabees, and more generally of non-Greek 'foreigners' by Josephus.

33 See Judith M. Lieu, "I am a Christian": Martyrdom and the Beginning of a "Christian Identity", in eadem, Neither Jew nor Greek? 223-43.

34 'They live in their own homelands, but as sojourners; they share in all things as citizens, and endure all things as foreigners; every foreign land is their homeland, and every homeland foreign'.

35 Besides commentaries and discussions of 1 Peter, see Benjamin H. Dunning, Aliens and Sojourners: Self as Other in Early Christianity (Philadelphia: University of Pennsylvania Press, 2009), especially 64-77 on Diognetus.

36 'Spend time', $\delta$ เ $\tau$ i $\beta \omega \omega$, is how Toxaris describes his long and permanent move to Athens (Lucian,

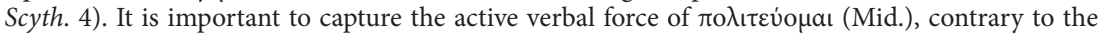
translation 'their citizenship is in heaven'; in 10.7 the same expression is used of God, although translators normally ascribe ideas of governing to the verb there. 
The moves that Diognetus makes have been readily aligned alongside other contemporary and competing claims to transcend the local - archetypically by Greekness, but then also by Romanness. ${ }^{37}$ These, too, however, are no less predicated on a deep consciousness of place: Other peoples may have fixed boundaries, but when it comes to Rome's space, city and world are one (Ovid, Fast. 2.683-4). Philo, perhaps courting political danger, sees Caligula's moves against Jerusalem as endangering the 'more universal politeia of the Jews', in contrast to their particular conflict in Alexandria (Legat. 194). By contrast, the philosophical aspiration of being a citizen of the world remained an aspiration predicated on specifically Hellenistic ideals; in particular it could provide a framework for dealing with the experience of exile and dislocation, thus recentring the locus of philosophical authority. ${ }^{38}$ Citizenship of heaven, however, is restricted to Jewish and then Christian sources. Philo, who can speak of a citizenship of the world (e.g. Vit. Mos. 2.51), pursues a characteristically idiosyncratic negotiation of this second concept: Interpreting Genesis 47 where Joseph's brothers settle in the despised Egypt, he imagines the response, 'we came to sojourn not to dwell' ( ou катоккеiv), explaining that for the soul of the wise man heaven is the homeland,

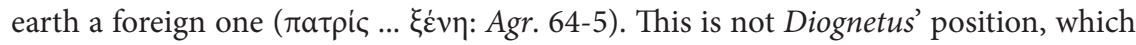
here is characteristically ambiguous, both disclaiming overt political claims and yet evoking them through the expectation of not just being reviled, but being warred upon.

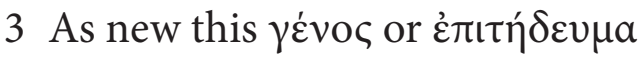

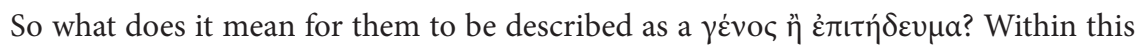
framework, here, as elsewhere, the use of $\gamma \varepsilon \dot{\varepsilon} v$ oc has provoked considerable debate: Is it best translated as 'race' or as 'kind/type'? The debates that lie behind this choice have often been rehearsed; it is not a matter of whether antiquity knew the concept of race as it has been developed in the modern period - few would make that claim although there might be more disagreement as to whether its antecedents may be found there. ${ }^{39}$ Rather it is a question of how the criteria for differentiation, and the rhetorical strategies that justify and reinforce this, are to be interpreted. Those who prefer 'kind/type' draw attention to the concern with religious practice, and to the theological debates over idolatry and/or law observance in the accounts of 'the Greeks' and 'the Jews'. Each of these, as has been seen, has its own historical and literary antecedents in contexts where ethnic/racial categories are not always determinative. Arguably implicit within this approach is the assumption that whatever term is used must presuppose some degree of articulation in social practice, whether confirmatory or contradictory.

Those who prefer to translate $\gamma \varepsilon$ 'vo as 'race' do so in terms of what Denise Buell has succinctly described as 'ethnic reasoning. ${ }^{40}$ The introduction by Diognetus of the

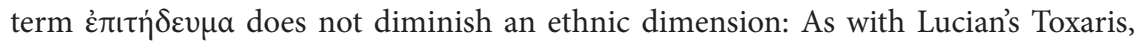

\footnotetext{
37 Lieu, Christian Identity, 212-15.

38 For example, Epictetus, Diatr. 2.10.3; Dionysius of Halicarnassus, Ant. rom. 11.16, 18.

39 Isaac, Invention.

40 Buell, This New Race, 30-3, 36.
} 
customs belong firmly to the aspects of an ethnic identity; similarly, Galen identifies his audience as including 'even those whom nature made barbarian by race but who

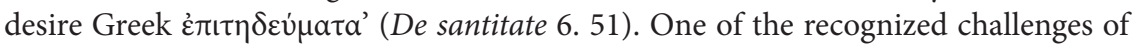
a concentration on rhetorical strategies is that the definitional boundaries between categories of race, ethnicity, and, in the modern context, nationhood, as well as even 'culture', become blurred. As has been seen, the particular association of identity with place and hence any clear distinction between 'ethnic' and 'cultural' identity were breaking down in the early Empire if not before. From this perspective the emphasis is on discourse and hence on rhetorical strategy more than on social practice. Certainly Diognetus' strategy of comparing the practices of the Greeks and the Jews with those of the Christians, and the static and formulaic terms in which these are described, could be seen as an exercise in ethnic reasoning: Difference is being constructed by ignoring anything that might be shared. There is no suggestion that there are Greeks or Jews who think differently, nor that some have moved naturally to join the Christians, or might do so. On the other hand, the negative account of 'the other' is not accompanied by a demonstration of the civilized self. Do we know how Christians do worship? ${ }^{41}$

The issue has not been helped by the tendency to read Diognetus in the light of the Apology of Aristides and of the Preaching of Peter. Aristides describes humankind as divided into three (in the Greek version) or four (Syriac) races ( $\gamma \varepsilon \dot{\varepsilon} v \varsigma$ ), largely defined in terms of their beliefs and practices concerning the gods; in the Syriac these are the barbarians, Greeks, Jews, and Christians; in the Greek they are 'worshippers of those called gods by you', later further subdivided as Chaldeans, Greeks, and Egyptians, and then the Jews and the Christians. Yet an important part of Aristides' scheme is the origins and 'genealogy' of each of these, something in which Diognetus has no interest. In the fragmentary Kerygma Petri the audience, purportedly those already taught by Peter, are urged 'not to worship ( $\sigma \dot{\varepsilon} \beta \varepsilon \sigma \theta \alpha$ ) according to the Greeks' nor 'according to

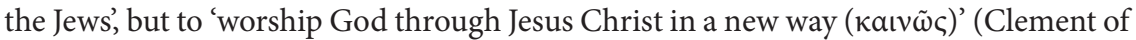
Alexandria, Strom. 6.5.39-42). The criticism of both Greek and Jewish worship follows closely that made by Diognetus, suggesting some literary links. These, and a further link with Aristides' Apology, might be strengthened if the Kerygma is the source for the immediately following appeal to Jeremiah's prophecy of a new covenant, and for the concluding words, 'For the things of the Greeks and the Jews are old, but we Christians

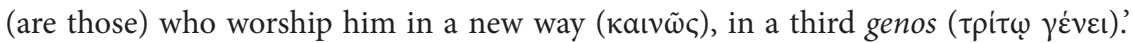
Here too there is considerable debate as to whether the phrase should be translated 'in a third style, 'as a third type', or 'as a third race. ${ }^{42}$ However, it is as likely that this final comment is not part of the Kerygma but is by Clement himself. ${ }^{43}$ Moreover, the differences from Diognetus, who apparently shows no interest in how Christians worship ( $\sigma \dot{\varepsilon} \beta \varepsilon \sigma \theta \alpha$ เ), are no less striking.

Here, however, lies the answer to Diognetus' initial question with its deliberate emphasis, 'Why new (Kaıvóv), now?' This question is not to be answered in terms

${ }^{41}$ The term used in Diognetus' question, 'how they worship him' $(\theta \rho \eta \sigma \kappa \varepsilon v \dot{\omega} \omega)$, is used of Greeks and Jews but not of the Christians $(1.1 ; 2.8 ; 3.2)$.

${ }^{42}$ See p. 60 on Tertullian.

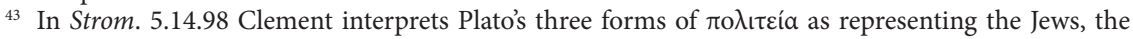
Greeks, and the Christians; cf. also 3.10.70. 
of prophecy or of a divine economy: What they have learnt owes nothing to 'the consideration or insight of meddlesome people, ${ }^{44}$ nor yet to human doctrines (5.3). Whereas other apologists answered the accusation of innovation by providing the Christians with a history reaching back to the origins of the world or of the scriptural past ${ }^{45}$ Diognetus is warned that he will never understand unless he becomes as

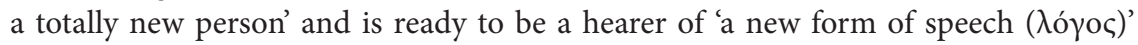
(2.1). The Christian $\theta \varepsilon o \sigma \varepsilon \dot{\beta} \varepsilon\llcorner\alpha$ is a mystery ( $\mu v \sigma \tau \eta \dot{\rho} \rho\llcorner o v, 4.6)$, just as it is also invisible (áópatoc, 6.4): these two assertions bracket the chapters we have been studying, and through them $\theta \varepsilon$ cós $\beta \varepsilon$ a becomes radically redefined, no longer an attribute of those who practice or display it, but determined by its source, the invisible God (7.1-2). Hence the author now drops the term and speaks instead of mystery $(7.1-2 ; 8.10 ; 10.7$; $11.2,5) .{ }^{46}$

The author of Diognetus has neither affirmed nor denied the categories of 'race and way of life', nor yet has he reinterpreted them within the categories of a transfigured citizenship. Indeed, all the categories that he does evoke have to undergo some degree of transfiguration, or, in more contemporary terms, of repeated deferral. On one level this expresses itself as a point-blank refusal to engage in the religio-ethnic competition that the terminology invites. Yet there have been hints that beneath what might be seen as a high level of abstraction from time and place a sophisticated (counter-)offensive is being prosecuted, if not against Judaism itself, then against the popular perception

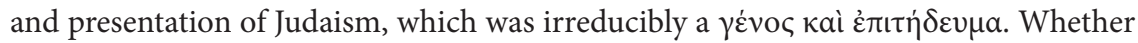
this was conscious, or, despite the author's best efforts, was in the nature of things is impossible to determine. No less impossible to determine must also be that aspect of identity that in the end matters - how, for the readers of the text, it was to be performed.

\section{References}

Buell, Denise Kimber. Why This New Race: Ethnic Reasoning in Early Christianity. New York: Columbia University Press, 2005.

Dunning, Benjamin H. Aliens and Sojourners: Self as Other in Early Christianity. Philadelphia: University of Pennsylvania Press, 2009.

Ehrman, Bart D., trans. and ed. The Apostolic Fathers. LCL 25. Cambridge, MA: Harvard University Press, 2003.

Isaac, Benjamin. The Invention of Racism in Classical Antiquity. Princeton, NJ: Princeton University Press, 2004.

Jefford, Clayton N., ed. The Epistle to Diognetus (with the Fragment of Quadratus): Introduction, Text, and Commentary. Oxford Apostolic Fathers. Oxford: Oxford University Press, 2013.

Lang, T. J. Mystery and the Making of a Christian Historical Consciousness: From Paul to the Second Century. BZNW 219. Berlin: de Gruyter, 2015.

${ }_{44}$ The term echoes the criticism of the Jews in 4.6.

${ }^{45}$ Lieu, Christian Identity, 84-6; but 11.4, 'who appeared new but was discovered old' slightly moderates this.

${ }^{46}$ On this, see T. J. Lang, Mystery and the Making of a Christian Historical Consciousness: From Paul to the Second Century (BZNW 219; Berlin: de Gruyter, 2015), 52-62. 
Lieu, Judith M. 'The Race of the Godfearers'. JTS 46 (1995): 483-501. Reprinted in eadem, Neither Jew nor Greek?, 66-85.

Lieu, Judith M. 'The Forging of Christian Identity and the Letter to Diognetus'.

Mediterranean Archaeology 11 (1998): 71-82. Reprinted in eadem, Neither Jew nor Greek?, 185-203.

Lieu, Judith M. Christian Identity in the Jewish and Graeco-Roman World. Oxford: Oxford University Press, 2004.

Lieu, Judith M. “I am a Christian": Martyrdom and the Beginning of a "Christian Identity". In eadem, Neither Jew nor Greek?, 223-43.

Lieu, Judith M. Neither Jew nor Greek? Constructing Early Christianity. 2nd edn. [2003] London: Bloomsbury T\&T Clark, 2016. 
Part Two

\section{Ethnicity, Race, and Religion in European Traditions of Biblical Scholarship}





\title{
S. R. Driver and Higher Criticism: Mapping 'The Differences of Race' in Genesis
}

\author{
Gregory L. Cuéllar
}

A full representative assembly of clergy and laity was present for the thirty-fourth meeting of the Church Congress held in the city of Exeter on 9 October 1894. As reported in The Church of England Pulpit and Ecclesiastical Review, 'the meetings have, perhaps, not been quite so lively as those at Birmingham, but that again was to be expected. The West Country folk are less demonstrative than the Midlanders.' ${ }^{\prime}$ Yet despite the region's tranquil demeanour, there was no lack of enthusiasm, with over 6,000 tickets taken during the four days of the Congress. ${ }^{2}$ Clearly, those organizing the official programme had no intention of shying away from religious and social controversies of the day. The occasion called for an ambitious agenda of topics like Biblical Criticism, the Mission of a Mother, Temperance Work and Legislation, the Catholic Church, the Care of the Poor, Secondary Education and Public Schools, the Ethics of Amusement, Church Reform and Discipline, Foreign Missions of the Church, Soldiers and Sailors, and the Doctrine and Dispensation of the Holy Spirit.

According to Rev. C. Dunkley, editor of the official proceedings, the audiences were generally well-mannered at all twenty-seven Congress meetings. In his words, 'This Congress was exceptionally favoured in having fewer peripatetic hearers than are customarily met with on these occasions. Members for the most part stuck to the subject of their choice, and sat out the discussion. ${ }^{3}$ Among the few exceptions was the meeting on Biblical Criticism between Rev. Joseph Leycester Lyne, also known as Father Ignatius of Llanthony Abbey, and Rev. Samuel Rolles Driver, Regius Professor of Hebrew and Canon of Christ Church at Oxford. Since the Birmingham Church Congress in 1893, Father Ignatius had solidified his reputation as a zealous opponent of Higher Criticism. During the Congress meeting on the Reunion of Christendom, he erupted with a vociferous protest against Rev. Charles Gore because of his 1889 essay entitled 'Holy

1 Anon., 'Church Notes', The Church of England Pulpit and Ecclesiastical Review 38, no. 967 (JulyDecember 1894): 188.

2 Herbert Edward Reynolds, A Short History of the Ancient Diocese of Exeter: From the Conquest to the Church Congress of 1894 (Cambridge: H. Besley \& Son, 1895), 451.

3 C. Dunkley, preface to The Official Report of the Church Congress Held at Exeter (London: Bemrose \& Sons, 1894), vi. 
Spirit and Inspiration' Using Higher Criticism, Gore had argued against the orthodox view that the Bible was infallible. ${ }^{4}$ Reports of Father Ignatius' outburst even appeared in the US press. The New York-based newspaper, Outlook, described the scene thus: 'When Mr. Gore attempted to speak, Father Ignatius, in full monkish garb, sprang to the front beneath the platform, and, with uplifted hand and vehement gesture, protested that "Charles Gore had no right to speak".5 As recorded in the official proceedings, Lord Bishop J. J. Stewart Perowne, Congress president and presiding chair, interjected with a call for order, but to no avail. Amid the widespread commotion, Father Ignatius lifted up a copy of the book Lux Mundi, which contained Gore's essay, and shouted again 'I protest in the name of Jesus Christ against Charles Gore being allowed to speak. ${ }^{6}$ Later in the meeting, he again hastened towards the platform and declared that he indeed had a right to address the meeting. ${ }^{7}$ Chairman Perowne sternly refused to grant him a hearing on the basis that his only objective was to attack a fellow Churchman. ${ }^{8}$ At another interval during the meeting, a section of the audience demanded a hearing from Father Ignatius and began shouting repeatedly 'Ignatius', which, in turn, was followed by counter-shouts of 'Chair.'. Chairman Perowne appealed to the audience, stating, 'I think we should not turn this hall into a House of Commons. ${ }^{\prime 10}$ The audience was in such an uproar that the Mayor of Birmingham intervened alongside Chairman Perowne to restore order. Father Ignatius, however, remained obstinate in his desire to speak to the point that he declared 'that he would be taken out by the police and no other party. ${ }^{11}$ Eventually, order was established and the meeting concluded without any further incident.

As for the meeting on Biblical Criticism at the Exeter Church Congress, a similar scene was anticipated from Father Ignatius. Prior to the event, the British press gave ample warning of his intentions to attend the Church Congress in Exeter for the sole purpose of uttering his protest against advocates of Higher Criticism, in particular Canon S. R. Driver. ${ }^{12}$ By this time, Driver not only was thoroughly familiar with German (Delitzsch, Dillmann, Wellhausen), North American (Briggs), and British (Robertson Smith, T. K. Cheyne) versions of Higher Criticism, but also had made significant contributions to this discourse in multiple articles and most notably in his 1891 book An Introduction to the Literature of the Old Testament. ${ }^{13}$ In fact, even before the Birmingham Church Congress, Father Ignatius had issued a letter of

4 Anon., 'The Religious World', The Outlook: A Family Paper 48, no. 19 (4 November 1893): 815-16, at 815.

5 Anon., 'The Religious World', 815.

6 C. Dunkley, ed., The Official Report of the Church Congress Held at Birmingham (London: Bemrose \& Sons, 1893), 320.

7 Dunkley, Official Report - Birmingham, 336.

8 Dunkley, Official Report - Exeter, 337.

9 Dunkley, Official Report - Exeter, 337

10 Dunkley, Official Report - Exeter, 337.

11 Dunkley, Official Report - Exeter, 337.

12 Anon., 'Father Ignatius in Cardiff', The Tablet 83 (11 August 1894): 15; Anon., 'Loigny, 1894', The Church of England Pulpit and Ecclesiastical Review 38, no. 967 (18 August 1894): 78; Beatrice de Bertouch, The Life of Father Ignatius O.S.B.: The Monk of Llanthony (London: Methuen \& Co., 1904), 579.

13 See S. R. Driver, 'The Critical Study of the Old Testament', Contemporary Review 57 (1890): 215-31; Anon., 'Professor Driver's Paper at Southwell', The Guardian, 28 November 1888, 1810; S. R. Driver, 'The Cosmogony of Genesis', The Expositor 3, no. 3 (January 1886): 23-45. 
caution to the event organizers against Rev. Driver's participation in the meetings claiming that he was a blasphemer of Christ for having identified himself with 'the false German Criticism.' ${ }^{14}$

Safeguarding the Church of England from Higher Criticism was not just the exclusive mission of Father Ignatius. Rev. Frederick Temple, Lord Bishop of London, and Rev. Edward H. Bickersteth, Lord Bishop of Exeter and president of the Congress, were some of the most prominent clergy at the Exeter Church Congress who also sought to mitigate Britain's acceptance of Higher Criticism. In his opening sermon at the Exeter Cathedral, Bishop Temple set the context for the Congress with these words: 'Ever since the tremendous crash of the great French Revolution, at the end of the last century, broke up men's belief in the permanence of ordinary institutions, there has been a spirit of questioning which seems to increase in strength as time goes on. ${ }^{15}$ For Bishop Temple this 'spirit of questioning' showed no restraint, asking, 'Is there, indeed, a God that made and that rules the world? Has He, indeed, made a revelation to mankind? Is there any reason for saying that the Book which Christians honour is such a revelation?'16 Shortly after, Bishop Bickersteth embraced a similar tone in his inaugural address as Congress president, which he delivered in the large Victoria Hall. In his view, the two pressing issues of the day were Church Reform and the Church's Mission to non-Christian lands. ${ }^{17}$ First and foremost among the subjects bearing on Church Reform was Biblical Criticism, stating that 'England's Church has never feared Biblical Criticism when serious and reverent .... Very much, however, of that which assumes the name of the Higher Criticism is not serious and faithful, but superficial and skeptical. ${ }^{18}$ Later in the afternoon, the meeting on Biblical Criticism took place in the Royal Public Rooms. In a telling opening statement as presiding Chair, Rev. Alfred Barry, Bishop of Sydney, hinted at the state of the discourse in late-nineteenth-century Victorian Britain, stating that 'the subject which we have to discuss to-day is one which are called "burning questions". ${ }^{19}$ Those appointed to speak represented a range of epistemological positions from scientific to orthodox. Rev. C. Waldergrave Sandford, Lord Bishop of Gibraltar, took the platform first and presented an apologetic paper on behalf of orthodox teaching entitled, 'The Grounds of Our Belief in the Divine Origin and Authority of the Holy Scriptures.2 ${ }^{20}$ Next was S. R. Driver, who contributed a paper entitled 'The Growth of the Old Testament'. Before I take up the content of Driver's paper and his broader contributions to Higher Criticism, it is important to note that, unlike the Birmingham incident, Father Ignatius was officially given ten minutes before the end of the meeting to address the audience, barring any personal controversy. The bulk of his response was scoldingly directed against Driver, from which the following words deserve mentioning:

${ }^{14}$ Anon., 'Summaries', The Church Eclectic: An Anglo-Catholic Magazine of Church Literature with Notes and Summaries 21, no. 7 (October 1893): 664.

${ }_{15}$ Dunkley, The Official Report - Exeter, 4.

16 Dunkley, The Official Report - Exeter, 6.

${ }_{17}$ Francis Keyes Aglionby, The Life of Edward Henry Bickersteth D.D., Bishop and Poet (London: Longmans, Green and Co., 1907), 86.

${ }_{18}$ Dunkley, The Official Report - Exeter, 14.

19 Dunkley, The Official Report - Exeter, 58.

${ }^{20}$ C. Waldergrave Sandford, 'The Grounds of Our Belief in the Divine Origin and Authority of the Holy Scriptures', in The Official Report of the Church Congress Held at Exeter, ed. C. Dunkley (London: Bemrose \& Sons, 1894), 59-64. 
I think that the paper which the learned professor and dignitary from Oxford has read, has placed us all in a very solemn position in regard to Christendom in general, and of the Church of England in particular .... I say that the paper to which I refer contradicts the teaching of Jesus Christ. It contradicts the unanimous consciousness of the Christian Church for eighteen centuries. I do not want at all to derogate from the majesty of criticism and science, but I do say that souls are not saved, and lives are not elevated, by criticism and science. ${ }^{21}$

As myopic as Father Ignatius' words may seem, his description of Driver's paper rightly pointed to both 'criticism and science' in defining his approach to the Bible. In terms of the science of Driver's Higher Criticism, it functioned in the modern Western European sense in that his analysis of scripture privileged logical positivism. ${ }^{22}$ Hence, Driver qualified sight and human reason as the master senses for generating truth-claims about the Bible's historic origin and literary development. Borrowing specifically from the natural sciences, he inspected the biblical version deemed 'original' by textual critics as an object bearing traces of predictable human activity, which by analogy remained constant for some populations across time. For instance, in his paper, he set out to show 'how the growth of the Old Testament is correlated with the development of religious truth, and how the historical character of revelation conditioned in many respects the form which it assumed, and developed in different directions the ideal of religious life. ${ }^{23}$ Here Driver situated the Old Testament within the time-bound realm of the natural and therefore susceptible to a series of observable processes like growth, development, and historical conditioning. As intrinsic as these natural processes were to the Old Testament's historical development, they were not exclusive to the human realm, but rather they pointed to a divine operation governing biblical revelation. As he stated,

Revelation might, so far as we can see, have consisted of a series of abstract propositions, of the nature of a creed or formulary of the faith, promulgated once for all at a particular moment of history. But the education of the race, as of the individual, is a gradual process; the mental and moral powers pass through successive stages of growth; and hence it cannot surprise us that the Author of nature should have adjusted His moral and spiritual providence to His natural providence, and have accommodated His teaching to the varying capacities of His children. ${ }^{24}$

Within the conceptual framework of Driver's Higher Criticism, as reflected both in his Exeter Church Congress paper and in his broader scholarship, we find the conflation of Darwinian evolution and Victorian notions of progress. ${ }^{25}$ While Driver affirmed

${ }^{21}$ Dunkley, The Official Report - Exeter, 87.

22 S. R. Driver, An Introduction to the Literature of the Old Testament (New York: C. Scribner's Sons, 1906), 3.

23 S. R. Driver, 'The Growth of the Old Testament', in The Official Report of the Church Congress Held at Exeter, ed. C. Dunkley (London: Bemrose \& Sons, 1894), 64.

${ }^{24}$ Driver, 'The Growth of the Old Testament', 64.

25 S. R. Driver, 'Evolution Compatible with Faith', in Sermons on Subjects Connected with the Old Testament (New York: Charles Scribner Son's, 1892), 13. 
Western scientific notions of historical linearity and civilizational progress, he also understood them as fixed organic processes that God providentially designed and used to reveal biblical truth. ${ }^{26}$ In his view, the nature of divine revelation bore its traces in the realm of human activity, which, in turn, was governed by upward moving stages of mental and moral development. Conversely, this implied that Driver stood on the other end of this natural trajectory of human advancement in which Western modernity and scientific discourse constituted higher stages of human intelligence. Ultimately, his scientifically grounded notions about the natural growth of the Old Testament not only mapped his analytical path back into the ancient world, but also they inversely pointed forward to Driver's privileged social position. In other words, the high degree to which Driver confided in the positive results of Higher Criticism corresponded to a broader Victorian certitude in Western modern advancements in particular, and the British Empire in general. This is not to deny the invigorating force of German critics like Julius Wellhausen and Franz Delitzsch on Driver's optimism for Higher Criticism but simply to render visible other ideals operating in what became his own English version of the discourse.

\section{Forging a middle position}

In forging a distinctive English version of Higher Criticism, Driver envisioned a middle position between Wellhausen and the reigning orthodoxy. As he expressed in a letter to Dr George Ridding, Bishop of Southwell, in 1892:

I think I had better dissociate myself from Wellhausen. It is true, I agree with him in some things, but not in others: and as he does not always express himself fully or clearly, his statements form an unsatisfactory basis to agree on. I have always felt that his positions were stated with exaggeration and that the truth probably be somewhere between his position and the traditional one: and I had hoped that I was finding my way towards this myself. ${ }^{27}$

On one side, Driver found a middle-ground position by not only offering an alternative dating scheme for biblical source materials like the 'Priests' Code' (a ceremonial section in Exodus-Numbers) but also championing the moral and devotional value of the Old Testament for the Christian Church. ${ }^{28}$ Yet even from this moderate position, Driver still faced harsh opposition from British clergy and orientalists alike. In coming to the defence of Higher Criticism in England, Driver certainly took a leading role - albeit

26 Driver, 'The Growth of the Old Testament', 65.

27 S. R. Driver, Letter to Dr. George Ridding, Bishop of Southwell, dated 10 October 1892, MS ENG LETT c.31, Bodleian Library, Oxford.

28 Wellhausen argued that the entire Priests' Code was from the exilic period; as for Driver, he posited that some of it was likely from the pre-exilic period. See S. R. Driver, 'The Critical Study of the Old Testament', Contemporary Review 57 (February 1890): 226-8; Driver, An Introduction to the Literature of the Old Testament, 142-3. As regards the moral value of the Old Testament, see S. R. Driver, 'The Moral and Devotional Value of the Old Testament', The Expository Times 4, no. 3 (December 1892): 110-13. 
mostly confined to the British periodical press. Important here are the ways in which the polemical exchanges between Driver and his British opponents opened a space for Driver to construct a uniquely English version of Higher Criticism. Inscribed in this process was less a general defence of the discourse than a modulated form of Higher Criticism from his specific social location.

Although not as vociferous an opponent as Father Ignatius, British Orientalist Archibald Henry Sayce issued a sharp critique against Higher Criticism in his 1894 book, The 'Higher Criticism' and the Verdict of the Monuments. In his opening chapter, for instance, he gives these excoriating words:

The arrogancy of tone adopted at times by the 'higher criticism' has been productive of nothing but mischief; it has aroused distrust even of its most certain results, and has betrayed the critic into a dogmatism as unwarranted as it is unscientific. ${ }^{29}$

Sayce's disdain for Higher Criticism was for him completely warranted given the pervasive indifference the discourse had showed towards 'oriental' archaeological discoveries. As he describes, 'the results of recent oriental discovery, so far as they bear upon this "higher criticism," are either not known at all, or else only in a vague and indefinite way. ${ }^{30}$ By this time, Driver had already responded to a similar critique by Sayce in his 1892 article for The Expository Times entitled, 'Professor Sayce and the "Higher Criticism". For our purpose, what is distinctive about their debate was how in Driver's defence of Higher Criticism we discover the contours of his conceptual framework and also his nationalistic commitments as an English higher critic. Indeed, these contours come into fuller view in his 1894 essay, 'Archaeology and the Old Testament', for The Contemporary Review, in which Driver issues a thorough yet unfriendly review of Sayce's book. Largely, Driver's defence of Higher Criticism was aimed at Sayce's critique of the discourse's indifference towards archaeological discoveries and its exaggerated historical scepticism. ${ }^{31}$ In addressing the latter charge, Driver argues that Sayce had confused Higher Criticism with what was clearly 'hyper' criticism. As he describes,

Professor Sayce uses the terms 'higher critic' and 'higher criticism' where he really means 'hyper-critic' and 'hyper-criticism'. The 'higher-critics' of whom he speaks so often with disparagement are not critics in general, but certain extreme critics, who accompany their literary criticism of the Old Testament by far-reaching and excessive historical scepticism. ${ }^{32}$

While Driver casts doubt on Sayce's core knowledge of higher-critical scholarship, he does so as a response to the severity of Sayce's charge of 'excessive historical scepticism', which ultimately was an affront to the discourse's essential claim to scientificity.

29 A. H. Sayce, The 'Higher Criticism' and the Verdict of the Monuments (London: Society for Promoting Christian Knowledge, 1910), 5.

30 Sayce, The 'Higher Criticism', 25.

31 Sayce, The 'Higher Criticism', 24.

32 S. R. Driver, 'Archeology and the Old Testament', The Contemporary Review 65 (January-June 1894): 410. 
As Sayce frames it, the excess of historical scepticism, or what he calls 'historical hair-splitting, ${ }^{33}$ was symptomatic of the higher critic's deficient mode of empirical verification. In his words, 'baseless assumptions have been placed on a level with ascertained facts, hasty conclusions have been put forward as principles of science. ${ }^{34}$ To constitute Higher Criticism as a scientific discourse, Sayce argues that one must engage a 'wider and more catholic survey of the facts. ${ }^{35}$ For this reason, the discursive tenor of Driver's rebuttal possesses a retaliatory force against Sayce's attacks on Higher Criticism's scientific prestige. For both Sayce and Driver, their polemical exchange dealt with a fundamental norm of scientific investigation, which had to do with the accurate verification of empirical evidence. As a result, their debate affected more than the scientific currency of Higher Criticism. Rather, as Pierre Bourdieu reminds us, concomitant with scientific prestige is social benefit, which in this case meant that Sayce's attack would have consequently undermined Driver's scholarly capital and ecclesial status. ${ }^{36}$

From the outset of his 1894 essay, Driver has in view Sayce's argument that higher critics lacked empirical depth, especially as it pertained to archaeology. As Driver describes,

From the general tenor of his [Sayce's] volume, the reader would imagine that the 'higher critic' was supremely indifferent to the facts of archaeology, and wrote with a lofty disdain of everything that was to be found in an ancient and contemporary document. Nothing could be further from the truth. ${ }^{37}$

Driver proceeds to list several scholarly works by premier German higher critics like Eberhard Schrader, Wellhausen, and Dillmann that were accessible examples of the discourse's use of archaeology. From here, he then moves to the English context of which he and T. K. Cheyne were also noteworthy examples, stating that 'in this country Professor Cheyne's writings overflow with historical and other illustrations derived from monuments; while I myself in my volume on Isaiah have quoted from Assyrian and Babylonian Inscriptions to whatever materials were available for my purpose. ${ }^{38}$ Like Sayce, Driver understood that his contact with disinterred artefacts was an essential practice by which higher critics were accredited scientifically. ${ }^{39}$ As evidenced in his 1888 book, Isaiah: His Life and Times and the Writings Which Bear His Name, his scientific gaze was not only on the literary strata of the biblical text's final form, but also on archaeological discoveries, in particular those held in the British Museum..$^{40}$ Given the widespread currency of 'oriental' archaeology within nineteenth-century Western

33 Sayce, The 'Higher Criticism', 15, 21.

34 Sayce, The 'Higher Criticism', 5.

5 Sayce, The 'Higher Criticism', 5.

36 Pierre Bourdieu, Homo Academicus, trans. Peter Collier (Stanford, CA: Stanford University Press, 1988), 16.

37 Driver, 'Archeology and the Old Testament', 410.

38 Driver, 'Archeology and the Old Testament', 411.

39 Bourdieu, Homo Academicus, 28.

40 S. R. Driver, Isaiah: His Life and Times and the Writings which Bear his Name (New York: Anson D.F. Randolph \& Company, 1888), 75. 
scientific discourse, his failure to uphold archaeology would have had a significant social impact and bearing on his scientific prestige as a burgeoning English higher critic. Fostering this currency was not determined solely by men of science but more significantly by imperial global networks, state museums, and university libraries. Hence to reject 'oriental' archaeological discoveries involved far-reaching social effects, which for Driver would have meant calling into question one's nationalistic loyalties.

\section{Driver's assurance in Western European prowess}

In defining his form of Higher Criticism, Driver emphasized the generative scholarship associated with his modern Western European context. Among the most notable advances he often referenced was the rapid progress of archaeological discoveries in the nineteenth century. The way he understood the role of disinterred artefacts, especially in relation to Higher Criticism, was very different from biblical literalism in the sense that inscriptions, monuments, and reliefs were not used to corroborate biblical chronology, but rather to shed light on the origin and literary character of biblical texts. ${ }^{41}$ Commensurate with Driver's confidence in the progress of archaeological discoveries was his assurance in Western European prowess. As Driver states in his 1899 essay entitled 'Hebrew Authority':

Babylonia and Assyria on the one side, Egypt on the other, - these are the countries which have yielded during the last half-century the most surprising archaeological results. In both, exploration has been actively carried on: Germany and France, England and America, have alternately vied with one another in their search for the treasures buried under the mounds of Babylonia and Assyria, or the sands of Egypt. And the texts obtained from both countries have engaged the attention of a series of scholars, in most cases men of marked ability and power, who have devoted their lives to analyzing more accurately the language, to studying the antiquities, and to piecing together the history of two great nations. ${ }^{42}$

Encoded in Driver's view of archaeological progress was a Western European male point of reference for 'piecing together the history' of ancient Western Asia and Northeastern Africa. Implicitly, this vantage point was positioned within an Orientalist notion that accurate historiography was intellectually out of reach for the native populations of these regions. In other words, by framing the progress of archaeology as a Western European enterprise, Driver also understood that their precise decipherment was solely under the purview of Western European men, who were of 'marked ability and power.43

Lauding the superiority of Western European archaeological achievements, Driver impressed upon his English readers an image of the extraordinary as it pertained to

${ }^{41}$ Driver, 'Archeology and the Old Testament', 410-12.

42 S. R. Driver, 'Hebrew Authority', in Authority and Archeology: Sacred and Profane, ed. David G. Hogarth (New York: Charles Scribner's Sons, 1899), 4-5.

43 Driver, 'Hebrew Authority', 5. 
Western scholarly production. As he declares, 'Much, it is certain, remains still to be discovered; but even now it may be said that the two last generations have seen exhumed and re-constructed two entire civilizations. ${ }^{34}$ His logic may be easily dismissed as enthusiastic optimism in Western European modernity. However, Edward Said reminds us that part of nineteenth-century Western biblical criticism was an Orientalist rationale which viewed the people of the East as incapable of constructing an accurate history of their own cultural heritage. ${ }^{45}$ Clearly, this rationale of Western scientific superiority persisted in Driver's higher-critical scholarship well into the early twentieth century, as demonstrated in his 1901 essay entitled 'The Old Testament in the Light of Today', where he makes the following statement within the context of modern Western progress:

The discovery and publication of inscriptions from Phoenicia, Syria, Moab, and Arabia, and the observations of travelers and explorers in the same regions, have in many important details augmented our former knowledge of the customs, and institutions, and habits of thought of Israel's neighbours, helping us thereby to realize more accurately the position taken by Israel amongst them, and the affinities mental not less than physical and material, subsisting between them. ${ }^{46}$

In the end, what qualified Driver's biblical criticism as 'higher' was not only that he dealt with 'more difficult class of problems' but also that as a Western European he viewed himself at the apex of intellectual development. ${ }^{47}$

\section{Driver's anthropology of race}

To avoid an oversimplification of Driver's sense of superiority as only finding support within the scientific currency of Western archaeological discoveries, I now turn to his discussions about the differences of race in his analysis of Genesis. Because Driver understood the accounts of the prehistoric age in Genesis as void of scientific value, he often appealed to the physical sciences and Victorian anthropologists of evolutionism in making empirical statements about the origins of the earth and humankind. In terms of the latter subject, it is in Driver's 1904 commentary on Genesis that we find a fuller version of his anthropology of race. From the outset of his commentary, Driver is clearly attuned to higher-critical concerns of Genesis' final form, such as demarcating and dating its different literary source material. As for his racial anthropology, our field of vision is limited to the interstices between the Genesis text and his highercritical analysis. For instance, under his introductory section entitled 'The Historical Value of the Book of Genesis', Driver shifts into an anthropological argument that the differences of language and race are true evidence for the antiquity of humankind. As he describes, 'the differences distinguishing languages entirely unrelated to each other

44 Driver, 'Hebrew Authority'.

45 Edward W. Said, Orientalism, 2nd edn (New York: Random House, 1994), 17, 289.

46 S. R. Driver, 'The Old-Testament in Light of To-Day', The Expositor, 6th ser., 3 (1875): 30.

47 Driver, An Introduction to the Literature of the Old Testament, 3. 
(as, for instance, Latin and Chinese), are dependent upon differences of race, which are not accounted for by the biblical narrative. ${ }^{48}$ Surprisingly, Driver relied here on Sayce's comparative philology of the world's languages, which according to his 1880 book, Introduction to the Science of Language, reflect five main morphological types: inflectional (W. Asia and Europe), agglutinative (Turkey, Central Asia, Pacific Islands, many parts of Africa), incorporating (Basque), isolating (E. Asia), and polysynthetic (America). ${ }^{49}$ In explaining these differences, Driver argues that 'different races do not think in the same way; and consequently the forms taken by the sentence in the languages spoken by them are not the same. ${ }^{50}$ For him, the differences of language not only presupposed differences of race but also the mental capacities associated with the different races. Implicit within his argument is a hierarchy of race in which grammar registered a group's inferior or superior intellect. For Sayce, the inflected languages of modern Europe stood at the apex of linguistic development, or as he states:

We have come to think that not only is the race to which we belong superior to all others, but that the languages we speak are equally superior. That the inflection is the supreme effort of linguistic energy, that it marks the highest stage in the development of speech, is regarded as a self-evident axiom. ${ }^{51}$

This held true in Driver's anthropology of race. For him, superior human intellect registered in the morphologies of different languages, which developed gradually at the same time that races were developed, out of some very primitive, inorganic type of speech. ${ }^{52}$

Although Driver's higher-critical aims restrained him from a more technical exposition of his anthropology of race, he was nevertheless compelled to do so in those areas of Genesis that showed a proximity to the subject of race, such as the origin of different nations in Genesis 10 and the dispersion of different languages in Genesis 11. As Driver indicates, 'differences of race, however, are not explained by the Biblical narrative; for though Gen $\mathrm{x}$. is ostensibly an explanation of the origin of different nations; and though Gen xi. 1-9 might conceivably be understood as such, ... no adequate explanation is thereby obtained of the racial differences exhibited by mankind. ${ }^{53}$ It is important to note that Driver's anthropology of race was premised on the scientific notion that racial differences were a natural product of human evolution and physically fixed after extensive periods of human migration. ${ }^{54}$ With racial differences as Driver's starting point, he thus makes sense of them not only along the lines of certain phenotypes but also according to their geographical placement. As to

48 S. R. Driver, The Book of Genesis (London: Methuen \& Co., 1904), xxxv.

49 A. H. Sayce, Introduction to the Science of Language (2 vols; London: C. Kegan Paul \& Co., 1880), 2:33-64.

50 Driver, Genesis, xxxv.

51 Sayce, Science of Language, 2:66.

52 Driver, Genesis, xxxv.

53 Driver, Genesis, xxxv.

54 Driver, Genesis, 134; also S. R. Driver, 'Confusion of Tongues', in A Dictionary of the Bible, Dealing with its Language, Literature, and Contents, Including the Biblical Theology, ed. James Hastings (New York: Charles Scribner's Sons, 1902), 4:790-1. 
the specific combination of phenotypes marking racial differences, Driver names the following: 'colour of the skin, the physical structure and arrangement of the hair, the stature and proportions of the body, the shape of the skull, the contour of the faces, the mental capabilities and character.55 Not original to Driver, this particular catalogue of physical characteristics reflected the work of Victorian evolutionists A. H. Keane and E. B. Tylor. Driver made considerable use of Tylor's book Anthropology, particularly chapter three, 'Races of Mankind', and Keane's book Ethnology, primarily the chapters dealing with the physical and mental criteria of race. ${ }^{56}$ Whether it was Tylor's skull comparisons or Keane's facial angle measurements, both evolutionists pointed to the modern European as the ultimate standard of measurement for superior intellectual capacities. ${ }^{57}$ To a certain extent, Driver insinuates this racial standard when he shifts into the first-person plural in listing those groups that are obvious physical examples of the differences of race, stating:

We are all familiar with the differences between the Chinaman, the Negro, and ourselves; and there are many other races which, though they may be less familiarly known, are not less markedly distinguished from each other - for instance, the chocolate coloured Australians, the light-brown Maoris, the reddish-brown native tribes of America, the yellow-hued Mongolians of Central Asia and China, the Patagonians, and the diminutive Bushmen of South Africa. ${ }^{58}$

Here, Driver's use of 'we' points to difference as the domain of the racialized Other rather than of his English readership. In this sense the English 'we' represents a norm from which racial comparisons are then what Paul Gilroy terms 'codified and calibrated..$^{59}$ For Driver, the result is a hierarchical arraignment of the 'most obvious division of mankind', which in his view consists of 'the white Caucasian, the yellow Mongol, the reddish-brown native American, and the black Negro races.60 This racialized grid had its roots in the ethnographic work of Keane, who categorized these racial groups according to four ideal types. In the corresponding footnote, Driver references Keane's book, Ethnology, and prompts his readers to see in detail chapter 10, 'The main divisions of the Hominidae' and chapters 11-14, which contain a careful survey of his four racial types. Apart from discovering the origins, migration journeys, languages, and phenotypes of each type, Keane also offers details on their respective innate temperament. As expected, the racial type most predisposed to achieve high levels of development in science, art, and letters is the white Caucasian. In contrast, Keane identifies the other three groups as either undeveloped or moderately developed in the areas of science, art, and letter. ${ }^{61}$

55 Driver, Genesis, xxxvi.

56 Driver, Genesis, xxxvi.

57 Edward Tylor, Anthropology: An Introduction to the Study of Man and Civilization (New York: D. Appleton and Company, 1889), 60; A. H. Keane, Ethnology (Cambridge: University Press, 1909), 181.

58 Driver, Genesis, xxxvi.

59 Paul Gilroy, 'The Crisis of "Race” and Raciology', in Against Race: Imagining Political Culture Beyond the Color Line (Cambridge, MA: Belknap Press, 2000), 36.

60 Driver, Genesis, xxxvi.

61 Keane, Ethnology, 227-8. 


\section{Geographical starting points for white humanity}

As mentioned above, Driver's anthropology of race functions more as an excursus in his Genesis commentary in large part because he saw differences of race as an undiscovered fact for the biblical writers. ${ }^{62}$ As he writes, 'the antiquity of man, and the wide distribution of man, with strongly marked racial differences, are two great outstanding facts, which the Biblical narrative, - whether here or elsewhere in Genesis, - not only fails to account for, but does not even leave room for. ${ }^{36}$ In calling his readers' attention to the absence of race in Genesis, Driver consequently reveals the subjective contours of his ostensibly objective hermeneutic. Race not only defined Driver's point of entry into the biblical text but rather it served as what he believed to be the necessary optic for understanding human origins. Yet, as factual as racial differences may have seemed to Driver and his English readers, linking Genesis to Western scientific racial discourse unfolded within a binary logic of Hebrew folklore versus scientific fact, or spiritual lesson versus empirical truth. At issue here is not that difference is absent from nature but that a fact of nature is a racial hierarchy of differences in which white humanity remains at the apex.

In his commentary on the Table of Nations in Genesis 10, Driver is preoccupied with the lack of racial specificity in the biblical text, so much so that he offers numerous scientific supplements to satisfy his readership's curiosity. Appealing to comparative philology, Orientalist archaeology, evolutionist racial anthropology, and the Aryan myth, Driver ascribes the Noachian genealogy to white humanity, stating that 'Gen $\mathrm{x}$ with the single exception of Cush (Jer. xiii. 23) and, possibly, of Magog (if by this are meant the Seythians) enumerates only tribes and nations belonging to the white race. ${ }^{64}$ As he explains, the distinctions between Noah's sons were different white racial types, which he identifies as Semites, Aryans, 'Hittites' or Mongolians, and Egyptians. He points out that the other black races of Africa, many nations of Europe, the Indian races, the Chinese, and the peoples of Australia, America, and the Pacific Isles were not mentioned because they were unknown to the ancient Hebrews. ${ }^{65}$ This was a clear departure from the classical tripartite division between the Hamite or 'Egyptian' race, the Semitic or 'Syro-Arabian' race, and the Japhetic or 'Aryan' race ${ }^{66}$ Driver's subtext draws upon concepts rooted in a scientific version of Western Europe's Aryan myth in which white Europeans located their origin within a Eurasian and Western Asian context first on linguistic grounds. ${ }^{67}$ By the end of the nineteenth century, the term 'Aryan' as an Indo-European language (i.e. Sanskrit) was also used to define the European race. ${ }^{68}$ For Driver's commentary, the term 'Aryan' functions more in the latter sense in that it represents a white racial type with first a particular physiognomy, which resulted

62 Driver, Genesis, 134.

63 Driver, Genesis, 134.

64 Driver, Genesis, 134.

65 Driver, Genesis, 113.

${ }^{66}$ Léon Poliakov, The Aryan Myth: A History of Racist and Nationalist Ideas in Europe, trans. Edmund Howard (New York: Basic Books, 1974), 211.

67 Poliakov, The Aryan Myth, 197.

68 Poliakov, The Aryan Myth, 213-14; Keane, Ethnology, 395-6. 
in the creation of a distinct language. In mapping the Noachian genealogy in Genesis 10, which he argues denoted primarily a geographical arrangement, Driver situates Japhet's descendants in the northern zone, Shem's descendants in the middle zone, and Ham's descendants in the southern zone. Combined, these three zones encompassed a vast geographical area from Armenia in the north to Ethiopia and Saudi Arabia in the south and from Elam in the east to Greece and the dimly known Tarshish in the west. ${ }^{69}$ Following closely Sayce's analysis of Genesis 10, Driver moves through each name in the genealogy, arranging them according to zone and when possible deciphering their particular white racial affiliation. For instance, Driver ascribes Japhet's son Madai to the Medes, who as he argues are 'often mentioned in the OT. From the $8^{\text {th }}$ century B.C. (2 K. xvii. 6, xviii. 11, Is. xxi. 2, xiii. 17 f., al); and in the Assyrian Inscriptions from the time of Rammân-nirâri (812-783 B.C.) onwards ... . The home of the Medes was in the mountainous country E. of Assyria, and SW. of the Caspian Sea. ${ }^{70}$ Here the Medes belonged to the Japhetic zone, which according to Sayce corresponded to 'the Aryan people who claimed relationship to the Aryans of Northern India and the Aryan populations of Europe, and one of the tribes belonging to them was that of the Persians, who had established themselves further south, on the eastern shores of the Persian Gulf'71 In Driver's assessment, the contrasts between the Mongolian, Aryan, and Semitic white racial types lie in their respective physiognomies and languages. In his description of Ham's grandson Heth, Driver is unclear as to whether this name referred to the great Hittite nation north of Palestine or offshoots of the Hittites. Yet with high certainty Driver offers a description of the Hittites' racial type using archaeological evidence. As he describes, 'the Hittites, as depicted on their monuments, have a striking physiognomy and dress: a retreating forehead and chin, full lips, large nose, high cheekbones, and the hair plaited behind in three pig tails, the type being that of the Mongol, very unlike either the Semitic or the Aryan type. ${ }^{32}$ I think it is important to reiterate how in this instance Driver used disinterred objects to support his argument about racial difference. Part of the science that legitimated the possession of ancient artefacts in the modern era was a racialized gaze for inspecting and codifying ancient material culture. Yet from a counter-reading, this mode of scientific inspection anachronistically reinscribed a Western scale of inferiority-superiority onto disinterred ancient objects. Hence these museum objects were in part valued based on their newly discovered racial currency, especially those objects that corroborated European superiority. ${ }^{73}$

Under the sons of Shem, Driver locates Elam in the middle zone; however, in terms of racial type he states that 'the Elamites were entirely distinct from the Semites, their language, for instance being agglutinative and belonging to a different family. ${ }^{34}$ As

69 Driver, Genesis, 113.

70 Driver, Genesis., 115; see also A. H. Sayce, The Races of the Old Testament (London: The Religious Tract Society, 1925), 45.

71 Sayce, Races of the Old Testament, 45-6.

72 Driver, Genesis, 125.

73 See Debbie Challis, The Archaeology of Race: The Eugenic Ideas of Francis Galton and Flinders Petrie (London: Bloomsbury, 2013); Neil Asher, 'Petrie's Head: Eugenic and Near Eastern Archaeology', in Assembling the Past: Studies in the Professionalization of Archaeology, ed. Alice B. Kehoe and Mary Beth Emmerichs (Albuquerque: University of New Mexico Press, 1999), 69-79.

74 Driver, Genesis, 128. 
for Elam's brother Asshur, Driver rightly assigned him to the Assyrians; yet in terms of their racial variety, he states, 'The Assyrians were a Semitic people, their language belonging obviously to the same family as Hebrew, Phoenician, Aramaic, Arabic, and Ethiopic. ${ }^{75}$ Deciphering racial differences in the history of human origins was also applied to the reading of ancient languages. This form of racial logic not only invigorated Western comparative philology but also accredited a racial currency to newly discovered inscriptions in much the same way as with reliefs and the racialized reading of physiognomies. In the end, the implied standard of measurement for varying physiognomies and resulting languages was the Aryan racial/linguistic type, which for Driver was the Europeans' ancestor. ${ }^{76}$

Proceeding to Genesis 11, Driver takes up again a racialized reading of the origin of different languages found in the Tower of Babel narrative (vv. 1-9). As with his reading of Genesis 10, his appeal to race comes from the narrative's disconnect with Western scientific explanations of the diversity of languages and the natural dispersion of humankind. In his words, 'The narrative, while explaining ostensibly the diversity of languages, offers no explanation of the diversity of races. ${ }^{77}$ In understanding the origin of different languages, Driver prompts his readers to move away from the biblical notion of a common linguistic origin for humanity to the more likely explanation of the differences of race. Here, Driver departs from Sayce's argument on the origin of different languages by privileging race and not society as the cause of the diversity of languages. ${ }^{78}$ As he argues, 'it is of course true that cases occur in which a people brought into contact with a people of another race have adopted their language; but, speaking generally, radically different languages are characteristic of different races. ${ }^{39}$ Thus, a language's attending grammar, structure, and roots point to the persistence of particular cognitive and vocal faculties that vary according to different racial physiognomies. ${ }^{80}$ Similar to Keane's arguments on the relationship between speech and race, Driver views the physical faculties for creating speech as fixed in the different races. ${ }^{81}$ As he explains, 'the great races into which mankind is divided must have migrated into their present homes, and had their existing character stamped upon them, at an age vastly earlier than that which the chronology of Genesis permits. ${ }^{82}$ Ultimately, Driver's anthropology of race brought more than scientific prestige to his form of Higher Criticism; it laid forth a racialized vision of human history and the biblical text that privileged a hermeneutic of difference from a fixed Western European position of superiority. Indicative of the ongoing acceptance of this vision is the long shelf life Driver's 1904 commentary on Genesis had during the twentieth century: its final (fifteenth) edition was published in 1948.

75 Driver, Genesis, 131.

76 S. R. Driver, 'The Ideals of the Prophet', in Sermons on Subjects Connected with the Old Testament (New York: Charles Scribner Son's, 1892), 53.

77 Driver, Genesis, 133.

78 Sayce, Science of Language, 1:75; 2:31, 333.

79 Driver, Genesis, 133.

80 Driver, Genesis, 133; Sayce, Science of Language, 2:23-74; Keane, Ethnology, 196-204.

81 Keane, Ethnology, 196-204.

82 Driver, Genesis, 134. 


\section{Conclusion}

In contextualizing S. R. Driver, I realize that he was a product of his time. I also do not take lightly nor completely reject his contributions to biblical criticism in general, like his definition of the nature of Hebrew prophecy or his attention to the human element behind the biblical text. Take, for instance, these words by Driver, 'The prophet speaks always, in the first instance, to his own contemporaries: the message which he brings is intimately related with the circumstances of his time', or these words, 'There is a human factor in the Bible, which, though quickened and sustained by the informing Spirit, is never wholly absorbed or neutralized by it. ${ }^{33}$ What I am concerned about, however, involves an ethics of interpretation and epistemological vigilance. In a world in which racism and white supremacy are on the rise, to what extent does modern biblical criticism have something to do with these realities? Does a racializing gaze or attention to race inevitably reinscribe oppressive racial notions of human bodies? Perhaps the first ethical step is to address critically the economic and ideological forces that allow for a modern racial logic to be recycled within contemporary biblical scholarship. Here, economies of professionalization and truth-making still point to the white European male as the default authority in contemporary biblical criticism. Indeed, addressing this trend begins at the educational level in which students of Bible learn not only how to exegete a text, but more importantly how to exegete the biblical critic. Guided in this way, students contextualize the biblical critic - indexing precisely the critic's social location. With a clear sense of social location, students can then move to a critical analysis of the critic's scholarly production. For this phase, students scrutinize the truth-claims of the biblical critic in order to register the political, racial, and ideological contours subtending his/her arguments. This is where the biblical critic's social location can be insightful to the extent that racializing 'truth-claims' about human beings are seen as part of a broader socialization process operating in and around the biblical critic. As the above analysis has shown, Driver's interpretation of racial differences in Genesis was invariably shaped by his social location and epistemological formation. On a meta-level, Driver's social location influenced him to view Europeans (in particular Aryans) as the superior race - citing as evidence their intellectual capacities, scientific innovations, language, and most certainly their colonial triumphs. Applying this racial logic to a culturally iconic text like Genesis allowed for its replication within religious domains and schools of higher learning. As such, Driver's scholarship proceeds as an authority within these domains of influence, allowing his notions of racial differences to go unchecked and eventually be rendered unseen in contemporary biblical criticism.

\section{References}

Aglionby, Francis Keyes. The Life of Edward Henry Bickersteth D.D.: Bishop and Poet. London: Longmans, Green and Co., 1907.

${ }^{83}$ Driver, An Introduction to the Literature of the Old Testament, 224-5. 
Anon. 'Church Notes'. The Church of England Pulpit, and Ecclesiastical Review 38, no. 967 (July-December 1894): 188-9.

Anon. 'Father Ignatius in Cardiff'. The Tablet 83 (11 August 1894): 15.

Anon. 'Loigny, 1894'. The Church of England Pulpit, and Ecclesiastical Review 38, no. 967

(18 August 1894): 78-9.

Anon. 'Professor Driver's Paper at Southwell'. The Guardian (28 November 1888): 1810.

Anon. 'The Religious World'. The Outlook: A Family Paper 48, no. 19 (4 November 1893): 815-16.

Anon. 'Summaries'. The Church Eclectic: An Anglo-Catholic Magazine of Church Literature with Notes and Summaries 21, no. 7 (October 1893): 663-72.

Bourdieu, Pierre. Homo Academicus, translated by Peter Collier. Stanford, CA: Stanford University Press, 1988.

de Bertouch, Beatrice. The Life of Father Ignatius O.S.B.: The Monk of Llanthony. London: Methuen \& Co., 1904.

Driver, Samuel Rolles. 'The Old-Testament in Light of To-Day'. The Expositor, 6th ser., 3 (1875): 27-49.

Driver, Samuel Rolles. 'The Cosmogony of Genesis'. The Expositor 3, no. 3 (January 1886): 23-45.

Driver, Samuel Rolles. Isaiah: His Life and Times and the Writings Which Bear His Name. New York: Anson D.F. Randolph \& Company, 1888.

Driver, Samuel Rolles. 'The Critical Study of the Old Testament'. Contemporary Review 57 (February 1890): 215-31.

Driver, Samuel Rolles. 'Evolution Compatible with Faith'. In Sermons on Subjects Connected with the Old Testament, 1-27. New York: Charles Scribner's Sons, 1892.

Driver, Samuel Rolles. 'The Ideals of the Prophet'. In Sermons on Subjects Connected with the Old Testament, 50-71. New York: Charles Scribner's Sons, 1892.

Driver, Samuel Rolles. Letter to Dr. George Ridding, Bishop of Southwell (dated 10 October 1892), MS ENG LETT c.31, Bodleian Library, Oxford.

Driver, Samuel Rolles. 'The Moral and Devotional Value of the Old Testament'. The Expository Times 4, no. 3 (December 1892): 110-13.

Driver, Samuel Rolles. 'Archeology and the Old Testament'. The Contemporary Review 65 (January-June 1894): 408-26.

Driver, Samuel Rolles. 'The Growth of the Old Testament'. In The Official Report of the Church Congress Held at Exeter, edited by C. Dunkley, 64-69. London: Bemrose \& Sons, 1894.

Driver, Samuel Rolles. 'Hebrew Authority'. In Authority and Archeology: Sacred and Profane, edited by David G. Hogarth, 1-52. New York: Charles Scribner's Sons, 1899.

Driver, Samuel Rolles. 'Confusion of Tongues'. In A Dictionary of the Bible, Dealing with its Language, Literature, and Contents, Including the Biblical Theology. Vol. IV: PleromaZuzim, edited by James Hastings, 790-93. New York: Charles Scribner’s Sons, 1902.

Driver, Samuel Rolles. The Book of Genesis. London: Methuen \& Co., 1904.

Driver, Samuel Rolles. An Introduction to the Literature of the Old Testament. New York: Charles Scribner's Sons, 1906.

Dunkley, Charles, ed. The Official Report of the Church Congress Held at Birmingham. London: Bemrose \& Sons, 1893.

Dunkley, Charles, ed. The Official Report of the Church Congress Held at Exeter. London: Bemrose \& Sons, 1894.

Gilroy, Paul. 'The Crisis of "Race” and Raciology'. In Against Race: Imagining Political Culture Beyond the Color Line, 11-53. Cambridge, MA: Belknap Press, 2000. 
Keane, Augustus Henry. Ethnology. Cambridge: University Press, 1909.

Poliakov, Léon. The Aryan Myth: A History of Racist and Nationalist Ideas in Europe, translated by Edmonds Howard. New York: Basic Books, 1974.

Reynolds, Herbert Edward. A Short History of the Ancient Diocese of Exeter: From the Conquest to the Church Congress of 1894. Cambridge: H. Besley \& Son, 1895.

Said, Edward W. Orientalism. 2nd edn. New York: Random House, 1994.

Sandford, C. Waldergrave. 'The Grounds of Our Belief in the Divine Origin and Authority of the Holy Scriptures'. In The Official Report of the Church Congress Held at Exeter, edited by C. Dunkley, 59-64. London: Bemrose \& Sons, 1894.

Sayce, Archibald Henry. Introduction to the Science of Language. 2 volumes. London: C. Kegan Paul \& Co., 1880.

Sayce, Archibald Henry. The 'Higher Criticism' and the Verdict of the Monuments. London: Society for Promoting Christian Knowledge, 1910.

Sayce, Archibald Henry. The Races of the Old Testament. London: The Religious Tract Society, 1925.

Tylor, Edward. Anthropology: An Introduction to the Study of Man and Civilization. New York: D. Appleton and Company, 1889. 


\title{
What's in a Name?: Ideologies of Volk, Rasse, and Reich in German New Testament Interpretation Past and Present
}

\author{
Kathy Ehrensperger
}

\begin{abstract}
Ammianus, a polytheistic historian of the late fourth century $\mathrm{CE}$, noted that it was unclear how one was to denote the strange groups that followed Christ (Xpıбтаavoí) and thereby indicated that according to a certain established system of categorization these people did not fit. There could be a number of reasons for this, not least the system of categorization known to, and favoured by, Ammianus, which for him was the system of categorization innate to the world (although in his context this was already contested). ${ }^{1}$ That Ammianus captured the phenomenon of these Christ-centred groups in the categories of his world is of course what one would expect: 'Categories structure and order the world for us. We use categories to parse the flow of experience into discriminable and interpretable objects, attributes and events.'2

Ammianus' question is highly contemporary when we look at the flow of publications which try to understand, define, describe, or analyse the groups which

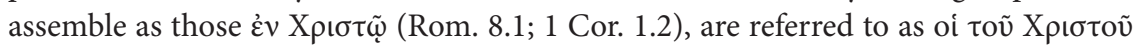
(1 Cor. 15.23; Gal. 5.24), are addressed by Paul as ä Rom. 1.7; 1 Cor. 1.2; 6.2; 10.32; 11.16, 22; 15.9; 2 Cor. 1.1; Gal. 1.13), and in 1 Peter are referred to as $\lambda a$ ó, $\varepsilon \ddot{\theta} \theta 0 \varsigma$, and $\gamma \dot{v} v \circ \varsigma$ (1 Pet. 2.9-10). The question of categorization seems intertwined with the question of identity; and the categories of ethnicity and race are only a few of those proposed recently, along or combined with associations
\end{abstract}

1 For example, Ammianus Marcellinus, Rerum Gestarum 21.16.18. Cf. Edwin A. Judge’s assessment of Ammianus' various comments on behaviour and practices of Christians in, 'On this Rock I will build my Ekklesia: Counter-cultic Springs of Multiculturalism', in idem, The First Christians in the Roman World (Tübingen: Mohr Siebeck, 2008), 619-68. He notes that although Ammianus attempts to describe these groups, he cannot find any one category known to him into which they would fit: 'They indicate his broad sense of a practice he cannot define and for which he has no word' (661). Ammianus' attitude towards Christianity is debated, wavering between positive openness and aggressive repudiation. The fact that he describes them and their practices as not fitting the 'normal' system may be a deliberate attempt at presenting them as odd outsiders. See also David Woods, 'Ammianus 22.4.6: An Unnoticed Anti-Christian Jibe', JTS 49 (1998): 145-48.

2 Roger Brubaker, Ethnicity without Groups (Cambridge, MA: Harvard University Press, 2004), 71. 


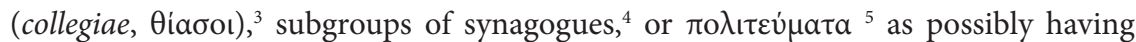
provided the template for the groups beginning to assemble in the name of someone referred to as the Christ.

Current events and events of the recent past have triggered questions of categorization, self-understanding, and identity in religious terms (in Western Europe religious affiliation/identities are being substantially questioned). It is particularly interesting that social-categorization terminology and respective concepts of ethnicity and race have emerged or re-emerged in current New Testament scholarship, given that such terminology was prominent in certain strands of biblical interpretation during the late nineteenth and early twentieth century, providing building blocks for biblical interpreters who had embraced the ideology of the Third Reich. ${ }^{6}$ The use of such categories is not self-evident since Christian self-understanding was not always formulated as a question of 'identity' and to an even lesser extent as a question which involved issues concerning 'ethnicity'. In the nineteenth century the question was predominantly formulated as a question concerning the essence or the core of Christianity rather than one concerning Christian identity. ${ }^{7}$ And although Judaism or the image of Judaism always played a role in the self-perception of Christianity, this relation was not necessarily formulated as a question of ethnicity but rather in terms of the question for truth, faith, ${ }^{8}$ the concept of religion, and notions of universalism and particularism. ${ }^{9}$ In current discussions, however, core questions are discussed in relation to identity and ethnicity which is due primarily to respective contemporary sociological and political debates. This is not to deny that there are trajectories in the sources which would render themselves open to interpretations which are informed by such contemporary concerns. In this discourse, an enduring question is the relation between universalism and particularity. Did the Christ-movement set out to overcome all distinctions between peoples and individuals as Pauline statements such as 'there is no distinction' (ov̉ үá (Gal. 3.28; cf. 5.6) seem to imply? And did it thus intend to create a universal identity above or beyond ethnic distinctions by overcoming or transcending them as a new creation' (cf. 2 Cor. 5.17; Gal. 6.15)? Or is the movement itself actually an ethnic entity, embarking on separating out a 'new race'?

3 Cf., for example, Richard Ascough, Paul's Macedonian Associations: The Social Context of Philippians and 1 Thessalonians (WUNT 2.161; Tübingen: Mohr Siebeck, 2003).

4 See, for example, Mark Nanos, The Mystery of Romans: The Jewish Context of Paul's Letter (Minneapolis: Fortress, 1996); idem, 'To the Churches within the Synagogues of Rome', in Reading Paul's Letter to the Romans, ed. Jerry L. Sumney (Atlanta: Scholars Press, 2012), 11-28.

5 Cf., for example, Dirk Schinkel, Die himmlische Bürgerschaft: Untersuchungen zu einem urschristlichen Sprachmotiv im Spannungsfeld von religiöser Integration und Abgrenzung im 1. und 2. Jahrhundert (Göttingen: Vandenhoeck \& Ruprecht, 2007).

6 Cf. Anders Gerdmar, Roots of Theological Antisemitism: German Biblical Interpretation and the Jews, from Herder and Semler to Kittel and Bultmann (Leiden: Brill, 2008).

7 Adolf von Harnack, Das Wesen des Christentums: Sechzehn Vorlesungen vor Studierenden aller Fakultäten im Wintersemester 1899/1900 am der Universität Berlin gehalten (Leipzig: Hinrich, 1901).

8 Cf. Walter Homolka, 'Adolf von Harnack und Leo Baeck: Zwei liberale Theologen, ein fiktiver Dialog', in Wende-Zeit im Verhältnis von Juden und Christen, ed. Siegfried von Kortzfleisch (Berlin: EB-Verlag, 2009), 189-217.

9 Brent Nongbri, Before Religion: A History of a Modern Concept (New Haven: Yale University Press, 2013). 
This recent discussion focuses almost entirely on the relation between Jewish and non-Jewish identities, with other differentiations, such as Greek and Roman, or Greek and Barbarian, or Galatian and Scythian, playing a marginal role, if any at all. ${ }^{10}$ Hence the discussion concerning the categorization is not about ethnicity, race, or nation, Volk, Rasse, or Ethnizität as such but about ethnic, or racial aspects as far as Jews and nonJews - in Pauline terminology $\varepsilon^{\prime} \theta \nu \eta /{ }^{\prime \prime} \mathrm{E} \lambda \lambda \eta \nu \varepsilon \varsigma$ - are concerned. It is - in the terminology of the nineteenth century - the Jewish Question, which lies behind the contemporary discussions (not the Roman or Italian, nor the Muslim question for that matter). ${ }^{11}$

The use of the term 'race' - or the compound adjective ethno-racial - as a designation for the identity of the Christ-following groups ${ }^{12}$ owes its current interest to concerns to move away from abstract theological terminology and perceptions. The hermeneutical presuppositions of my response to these attempts at tackling the issue of Christian identity in its earliest days are rooted in the tradition of German and Swiss scholarship; that is, they are contextual in terms of time and place. In light of these traditions, the use of the term and concepts of race in relation to first-century Christ-groups, and also more generally for antiquity, seems rather surprising. However, race/Rasse is not the only term and concept which comes under scrutiny from this perspective, but other terms such as Volk, völkisch, and Nation are considered with caution as well, given their recent history.

In January 1961 a group of German historians, lawyers, and journalists met in Bad Soden near Frankfurt a.M. for the sole purpose of answering the question, 'Was bedeuten uns heute Volk, Nation, Reich?'13 The meeting was guided by the conviction that it was time that 'the Germans began to rehabilitate terms that had been polluted or abused by Hitler and thus rendered suspect or unusable. ${ }^{14}$ The term that was remarkably absent in their list is the term Rasse (race). Of course, the Bad Soden meeting was conducted in the shadow of particular events and discourses in Germany, and hence the terms and concepts were discussed specifically in relation to their respective historical and conceptual context. The mere translation of these terms into other languages and contexts does not render them identical either in terms of linguistics or in terms of cultural encyclopaedias. The English terminology which translates these German terms is infused with, and carries the connotations of, its specific cultural and historical context. ${ }^{15}$ Thus a critical analysis of the terminology of one language should not be

10 Cf. Christopher D. Stanley, 'The Ethnic Context of Paul's Letters', in Christian Origins and Hellenistic Judaism: Social and Literary Contexts of the New Testament, ed. Stanley E. Porter and Andrew W. Pitts (Leiden: Brill, 2013), 177-202.

11 In the nineteenth century it surfaced with a new dimension in the context of the integration of Jews into nation states, which introduced into their legal systems the notion of the legal equality of all those living under its respective jurisdiction.

12 See Denise K. Buell, Why This New Race: Ethnic Reasoning in Early Christianity (New York: Columbia University Press, 2005); Love Sechrest, A Former Jew: Paul and the Dialectics of Race (London and New York: T\&T Clark, 2009); David G. Horrell, “Race", "Nation”, "People”: Ethnic Identity-Construction in 1 Peter 2.9', NTS 58, no. 1 (2012): 123-43.

13 'What is the meaning of people, nation, and empire for us today?'

14 Walter Erbe, 'Einleitung, in Was bedeuten uns heute Volk, Nation, Reich?, ed. Walter Erbe, et al. (Schriftenreihe der Friedrich Naumann-Stiftung zur Politik und Zeitgeschichte 3; Stuttgart: Deutsche Verlags-Anstalt, 1961), 3-11, at 3.

15 Hanna Arendt has brilliantly written about this in her Elemente und Ursprünge totaler Herrschaft: Antisemitismus, Imperialismus, totale Herrschaft (Munich: Piper, 1986 (German Translation of The Origins of Totalitarianism; New York: Harcourt Brace Jovanovich, 1951)), 292-300. 
directly applied to the terminology of another. The specific cultural encyclopaedias need to be taken into account in any comparative endeavour. Nevertheless, it is legitimate to draw analogies between the English and German terminology because there have been interactions, interchanges between, and mutual influences of English and German speaking scholars in intellectual as well as popular discourses on issues concerning collective identities since the early modern period. I thus wish to focus here on two terms: firstly, Volk (usually translated 'people'), which has a particular German history and connotation; and secondly, Rasse, the term omitted from the discussion at Bad Soden, and again one with a particular German history, although not confined to it. This leaves open the question of how far these discussions are also relevant in relation to British and American biblical scholarship. The terms are particularly relevant of course as translations of the Greek terms عُ $\theta$ vo and $\gamma \dot{\varepsilon} v o \zeta$ in New Testament interpretation.

In light of these preliminary observations, I will focus on some specific and necessarily eclectic aspects of ideological and terminological issues particularly in past and present German-language scholarship. In the first main section I will discuss Herder's use of the terms Volk and völkisch, and the racist interpretations of these in the period of the Third Reich. Next I will turn to Adolf von Harnack's discussion of the Christianoi as 'a third kind' in the context of late-nineteenth/early-twentieth-century debates in Germany. Finally, I will consider discussions of kollektive Identität and ethnicity in some current German-language New Testament interpretation.

\section{Herder and the 'Volk'}

The term and concept of 'Volk' was decisively shaped by Johann Gottfried Herder (1744-1803). ${ }^{16}$ It did not initially emerge as a nationalistic concept in the modern sense. Based on its etymological roots, which referred to 'Volk' in the vein of those who follow ('Gefolgschaft'), Volk was the term used to refer to people of the lower classes as distinct from the aristocracy. 'Volk' were those who followed and obeyed those who were born to be leaders. With Herder a conceptualization of the term was initiated, which - inspired by Enlightenment enthusiasm for education in the sense of holistic formation (in German, 'Bildung') - attributed the potential and capability of acquiring knowledge to all, including especially the lower classes, the 'Volk. Thus, Herder was of the view that the 'Volk' also had culture, that is, expressions and traditions worthy of being called culture in the sense of higher civilization. These traditions were seen as tied to the particular language of a 'Volk', and the specific characteristics of a 'Volk' - its 'Volksgeist' (spirit of the people) - were expressed most prominently through song (Volkslied), narratives (Märchen), and poetry (Volksdichtung). Through its language a 'Volk' expressed its essential characteristics (Wesen), its way of thinking and feeling. The diversity and distinctive characteristics of peoples/Völker were viewed as strongly intertwined with their respective language and, in Herder's perception, considered to be part of God's order of creation. Each and every 'Volk' had its location and task in the course of the world.

16 Herder was not the first to give significance to the term but had predecessors, such as Friedrich Carl von Moser who in 1765 published a pamphlet entitled Vom deutschen Nationalgeist. 
Significantly in Herder, there is as yet only the emphasis on a distinction between 'Völkern' but no hierarchical order as such nor a sequence of tasks assigned to them. With religion being part of the essence of a 'Volk' and intrinsically intertwined with it, the postulated equality between 'Völkern' in their diversity was nevertheless somewhat hampered. Herder considered Christianity to be the ideal religion, the goal of divine providence, thereby establishing an inherent hierarchy between 'christlichen Völkern' and all the others. ${ }^{17}$ It needs to be noted that Herder wrote his ideas and concepts as aspirations; they were republican and egalitarian and as such implicitly directed against the rule of German principalities. The idea of the 'Volk' served primarily an anti-aristocratic purpose and Herder sympathized with the revolutionary movement in France up until 1793. ${ }^{18}$

There was, however, no reality behind these ideas as yet. Lessing could state in 1768 that 'wir Deutschen noch keine Nation sind'19 which meant the concept of the German 'Volk' had not (yet) been translated into the political form of a state encompassing the German 'Volk'. The 'Volks-' idea was a discourse shared only by a small minority of intellectuals during Herder's lifetime, but it was politicized by Schleiermacher in the context of the German resistance against the Napoleonic invasion.

Herder's idea only really became relevant after the Heilige Römische Reich Deutscher Nation (Holy Roman Empire of the German Nation) collapsed under Napoleon in 1806. Before that, throughout the seventeenth and eighteenth centuries (particularly after the disastrous Thirty Years' War), the loose federation of principalities in its confessional and organizational diversity was an effective umbrella for otherwise disparate units under their princes. The Reich thus served a purpose and there was no need or urge to search for origins or a Volk, less still a race, to provide a unifying concept for this federation which had feudal ties to Savoy, Burgundy, the Lorraine, and Bohemia. The Reich was less a state than a loose commonwealth of princely states. The label 'Heiliges Römisches Reich Deutscher Nation' did not refer to nationality or peoplehood in the modern sense. 'Nation' at the time meant the aristocratic groups, in this case, those who elected the emperor, the prince electors of certain principalities (Kurfürsten) ${ }^{20}$

Eventually, Herder's ideas of a German 'Volk' as essentially constituted by a common language through which its spirit was expressed could easily be harnessed by the Prussian government in the campaign against Napoleon after 1813. Although what the unification aspired to was not achieved at that time, the goal was set and Herder's ideas were built upon by others (Hegel, Baur, et al.).

In parallel but distinct from these 'völkisch' ideas, we also see the emergence and rise of racist theories, initially in the wake of the scientific drive towards classification. It is noteworthy that Herder - against later dominating developments - clearly

17 Cf. also Gerdmar, Roots of Theological Antisemitism, 53.

18 From 1793 Herder became disgusted at the turn the revolution took with the execution of Louis XVI and his wife. Cf. Anne Löchte, Johann Gottfried Herder, Kulturtheorie und Humanitätsidee der Ideen, Humanitätbriefe und Adrastea (Würzburg: Königshausen \& Neumann, 2005), 94-5; Joachim Whaley, 'Reich, Nation, Volk. Early Modern Perspectives', The Modern Language Review 101, no. 2 (2006): 442-55, at 453 .

19 Gotthold Ephraim Lessing, 'Hamburger Dramaturgie', in Werke, Vol. 4 (Munich: Carl Hanser, 1973), 698.

20 Cf. Whaley, 'Reich, Nation, Volk', 447. 
distinguished his idea of 'Volk' from any notion of 'Rasse'. He even stated that the category of race/Rasse was not suitable to be applied to humans. Concerning emerging racial concepts he argued:

Some, for instance, have thought fit to employ the term races for four or five divisions, according to regions of origin or complexion. I see no reason for employing this term. Race refers to a difference of origin, which in this case either does not exist or which comprises in each of these regions or complexions the most diverse 'races. ${ }^{21}$

Similarly Goethe refused to apply his classification of colours to humans. And the first cultural historian, Gustav Klemm, who classified humans to some extent into categories (in his Allgemeine Kulturgeschichte der Menschheit, published 1843-52), assumes and respects a unified humanity, rather than one categorized into different races. ${ }^{22}$

But for the idea of one nation state, the notion of one 'Volk' was of course an important underpinning in the unification under Prussian military domination in 1870 and was harnessed ideologically in the build-up and consolidation of the Second German Reich.

As noted, the notion that 'Volk' and religion were intertwined constituted an inherent inconsistency in an ideology which intended to be egalitarian. It converged with claims that the German language was the highest possible development of any linguistic expression; hence, the German 'Volksgeist' - in conjunction with the highest form of religion, Christianity - was seen as the highest form of human civilization. This 'perfect' civilization obviously inherently created a problem for all those who were not or did not want to be part of this 'German Christian Volk', such as the Jews. It becomes evident that the concept and idea of 'Volk', although devised under different circumstances and for different purposes, served as the basis for the ideology of the Third Reich and biblical interpretation which associated itself with it. ${ }^{23}$

\subsection{Racializing biblical interpretation}

The idea of the intertwined aspect of 'Volk' and religion was taken up and further developed by theologians such as Ernst Moritz Arndt and Paul LaGarde, who maintained that Christendom developed to its highest form as Germanic religion, in

${ }^{21}$ Johann Gottfried Herder, 'Ideas for the Philosophy of the History of Mankind', in Herder on Social and Political Culture, trans. and ed. F. M. Barnard (Cambridge: Cambridge University Press, 1969), 255-326, at 284. Herder particularly rejected Kant's On the Different Races of Man (Von den verschiedenen Racen der Menschen, published 1775). Cf. also Arendt, Elemente und Ursprünge, 295; and Gerdmar, Roots of Theological Antisemitism, 58, who notes that 'Herder did not support national chauvinism or racial ideology in the same vein as later racial nationalism but his thoughts could be used as an important building block in such ideology'.

22 Arendt notes that the situation is different in Britain and the United States where the question concerns issues of practical life after the abolition of slavery rather than theories (Elemente und Ursprünge, 296-306).

${ }^{23}$ Cf. Cornelia Weber, Altes Testament und völkische Frage: Der biblische Volksbegriff in der alttestamentlichen Wissenschaft der nationalsozialistischen Zeit, dargestellt am Beispiel von Johannes Hempel (Tübingen: Mohr Siebeck, 2000). 
that only here was it finally purified of its distortion through Judaism and through Paul in particular. LaGarde advocated a 'völkisch gefärbte' religion as inherently necessary for the unified German Reich. He maintained that 'Germany is the totality of all German-feeling/sensing, German-thinking, German-willing Germans: each one of us is a traitor to the fatherland (Landesverräther), if he does not consider himself personally responsible for the existence, the wellbeing, and the future of the fatherland at each moment of his life, and each one is a hero and liberator if he acts accordingly.24 This implied that Jews either had to totally assimilate - that is cease being Jewish - or emigrate. There was no space for others in this political programme of the German Reich. It has been argued that LaGarde was not particularly influential during his lifetime. However, he was a protegé of the Prussian king (before the unification), was endowed with a chair in Göttingen, and was an important source for Houston Stewart Chamberlain, who has been described as the Kaiser's 'Evangelist of Racism. ${ }^{25}$ Of course, LaGarde's writings could be harnessed by the racism of National-Socialist ideology, even though this use and subsequent effect cannot be directly attributed to him. ${ }^{26} \mathrm{He}$ nevertheless provided further ideological underpinnings for the racialization of Christian theological discourses, which did not emerge with the National Socialists' rise to power but clearly came to flourish in the nineteenth century. Through so-called scientific and popular perceptions the concept of race was intertwined with theological notions. Aspects of Christian beliefs, from both Protestant and Roman Catholic traditions, were accommodated to racist convictions. The most important concept was a variation of Herder's idea of different 'Völker' in that, as Stanley Stowers in a recent analysis notes, it was postulated that

the God of Jesus Christ had created the world with distinct human races that each had its own God-given and essential species characteristics; and that the destiny of world history centred on the struggle of one superior race to protect itself from the depredations of another race and that this struggle had been dramatically enacted and prefigured by Jesus Christ's struggle against the Jews recorded in the New Testament. ${ }^{27}$

24 Paul LaGarde, 'Über die gegenwärtige Lage des Deutschen Reiches', in idem, Deutsche Schriften (Göttingen: Dietrichische Verlagsbuchhandlung, 1878), 98-167, at 167. When searching LaGarde on the internet I came across some hugely problematic internet sites - actively promoting racism, anti-Semitism, etc., in unbroken continuation of the ideology of the Third Reich.

25 See Wolfram Kinzig, ed., 'Der Kaiser und der „Evangelist des Rassismus.“ Houston Stewart Chamberlains Brief an Anne Guthrie über seine erste Begegnung mit Wilhelm II, mit einer Einleitung', ZNThG/JHMTh 11 (2004): 79-125; see also idem, 'Harnack, Houston-Chamberlain and the First World War', JHMTh/ZNThG 22, no. 2 (2015): 190-230.

26 Although, there are formulations which could be integrated into racist Nazi-terminology without further adaption: 'Es gehört ein Herz von der Härte der Krokodilshaut dazu, um mit den armen ausgesogenen Deutschen nicht Mitleid zu empfinden und ... um die Juden nicht zu hassen, um diejenigen nicht $\mathrm{zu}$ hassen und zu verachten, ... die zu feige sind, dies Ungeziefer zu zertreten.' Paul LaGarde, Juden und Indogermanen. Eine Studie nach dem Leben (Göttingen: Dietrichsche Universitätsbuchhandlung, 1887), 330.

27 Stanley Stowers, 'The Concepts of "Religion", "Political Religion" and the Study of Nazism', Journal of Contemporary History 42, no. 1 (2007): 9-24, at 24. 
Thus, Gustav Adolf Wislicenus argued in 1864 (similar to Ernest Renan) that Galilee had a mixed population - hence Jesus could not have been a Jew. Wislicenus' thesis about Jesus' origin, and the fundamental antithesis he postulated between Jesus and Judaism, neatly intertwined and eventually led to a Jesus specifically compatible with the concept of an Aryan race. ${ }^{28}$ The non-Jewish Jesus and the anti-Jewish gospel went hand in hand in the Wilhemine period, that is, quite some decades before National Socialism's rise to power. The term Deutschchristentum (German Christianity) was coined by Adolf Bartels in 1913, advocating that there should be 'More Deutschchristentum; less Jewish Christianity.'29 Bartels adhered to the völkisch movement, which eventually became closely intertwined with Nazi ideology. Prevalent was the conviction concerning the inseparability of religion and race, hence the precondition of the 'Germanization' of Christianity was its Entjudung (de-Judaizing). Anti-Semitism was thus inherent to this perception of the interrelation of religion and race. The Deutsche Christen (German Christians) declared Jesus an Aryan, and original Christianity an Aryan religion. As such, it was the appropriate religion for all Germans. These concepts had formed before the First World War and provided the crucible for the ideology and propaganda of the National Socialists. ${ }^{30}$ The racialization of theology and biblical interpretation in particular thus combined with the idea of the 'Volk' developed by Herder, but they were not identical with it. Herder's notion of Volk was not inherently racist but could easily be assimilated to ideologies of racism. ${ }^{31}$ And this assimilation of ideologies of race and theology (in New Testament interpretation in particular) was not due to National Socialism; this assimilation happened before and was not limited to any particular ideologies of the conservative right. ${ }^{32}$ It was in this context that Deutsche Christen eventually formed an academic society (Bund für deutsches Christentum) in 1938, in the immediate aftermath of the Reichskristallnacht, and subsequently established the Institut für die Erforschung und Beseitigung des jüdischen Lebens auf das deutsche kirchliche Leben (1939). The racial argumentation by scholars like Gerhard Kittel and Walter Grundmann did not emerge in a vacuum, but rather should be seen as the tip of an iceberg which had formed over more than a century. Kittel and Grundmann had racialized New Testament scholarship in different ways. Kittel did not argue for an Aryan Jesus but, by setting up a sharp

28 Martin Leutzsch, 'Karrieren des arischen Jesus zwischen 1918 und 1945', in Die völkisch-religiöse Bewegung im Nationalsozialismus. Eine Beziehungs-und Konfliktgeschichte, ed. Uwe Puschner and Clemens Vollnhals, 2nd edn (Göttingen: Vandenhoeck \& Ruprecht, 2012), 195-218, at 199. (On Renan, see Halvor Moxnes' chapter - Eds.)

29 Adolf Bartels, Der deutsche Verfall, 3rd edn ((1913) Zeitz: Sis-Verlag, 1919), 37.

30 Cf. Uwe Puschner, "One People, One Reich, One God", The Völkische Weltanschauung and Movement', German Historical Institute Bulletin 24, no. 1 (2002): 5-25.

31 The leading theologian of the Deutsche Christen, Reinhold Krause, considered the OT to be the expression of the inappropriate morals of a people of cattle traders and pimps, and Paul to be a Jewish Theologian, which obviously was not meant as an expression of appreciation and respect. Cf. Susannah Heschel, 'Rassismus und Christentum. Das Institut zur Beseitigung des jüdischen Einflusses auf das deutsche kirchliche Leben', in Die völkisch-religiöse Bewegung im Nationalsozialismus: Eine Beziehungs-und Konfliktgeschichte, ed. Uwe Puschner and Clemens Vollnhals, 2nd edn (Göttingen: Vandenhoeck \& Ruprecht, 2012), 249-64.

32 As is evident in the Berliner Antisemitismus-Streit triggered by Heinrich von Treitschke's publication 'Unsere Aussichten', Preussische Jahrbücher 44 (Berlin: Reimer Verlag, 1879): 560-76, in which the Jews were identified as constituting an obstacle, even a threat, to the inner consolidation of the unified German Reich. 
dichotomy between true Israelite (Old Testament) religion - of which Jesus was the true representative - and post-biblical degenerate Judaism, he nevertheless argued on a racial basis for true Christianity which could not have anything to do with the degenerate Jewish tradition and race. Grundmann, in his early work, had attempted to 'rescue' Jesus from his Jewishness by arguing that he was not racially bound since as the son of God he is above and beyond any racial connotation, a truly new creation. ${ }^{33}$ However, in his later publications Grundmann embraced the dejudaized Jesus, who fitted the needs of a Christianity compatible with Nazi ideology. This Galilean Jesus was by no means a purely theological construct. Jesus' Jewishness was questioned on the basis of racist arguments. ${ }^{34}$ But not all German New Testament scholarship of the period prior and up to 1945 embraced racist ideologies and terminology. Significantly, one of the most prominent scholars of the early twentieth century did not.

\section{Harnack and 'the Third Kind'}

In a context where racism and the idea of the 'Volk' were advocated by a significant number of biblical scholars as being inherently intertwined with the true understanding of Christianity and its role in the German Reich, it is quite significant that a highly regarded scholar, Adolf von Harnack, who had very close connections to Kaiser Wilhelm II (who was certainly open to anti-Semitism and cherished Houston Stewart Chamberlain's Die Grundlagen des 19. Jahrhunderts, published in 1899), did not integrate racist arguments into his writings. Although, unlike his contemporaries, he did not engage in serious debate with Jewish academics at all (he did not take seriously Leo Baeck's Das Wesen des Judentums, which constituted a response to von Harnack's Das Wesen des Christentums), ${ }^{35}$ he did oppose the political anti-Semitism of contemporaries like historian Heinrich von Treitschke and Theologian Adolf Stöcker in their request to exclude Jews from serving as civil servants of the German Reich (and other anti-Semitic political requests such as the expulsion of Jews who did not have German nationality). ${ }^{36}$ Nevertheless, he famously argued that Marcion had been correct to consider the Old Testament as not part of the Christian canon and advocated that now was the time to act upon this and cease to view the Old Testament as canonical. ${ }^{37}$ This is not the place to consider all aspects of his writings concerning the Jewish Question, but I will focus on that which is immediately relevant for our

${ }^{33}$ Walter Grundmann, Religion und Rasse: Ein Beitrag zur Frage nationaler Aufbruch und lebendiger Christusglaube (Werdau: Meister, 1933), 16.

34 Walter Grundmann, Totale Kirche im totalen Staat: Kirche im Dritten Reich (Dresden: O. Günther, 1934), 29.

35 See note 8.

36 Cf. Karsten Krieger, ed., Der „Berliner Antisemitismusstreit“ 1879-1881: Eine Kontroverse über die Zugehörigkeit der deutschen Juden zur Nation. Kommentierte Quellenedition (München: Saur, 2004); also for example, Jürgen Malitz, “Auch ein Wort über unser Judenthum”, Theodor Mommsen und der Berliner Antisemitismusstreit', in Theodor Mommsen: Gelehrter, Politiker und Literat, ed. Josef Wiesehöfer (Stuttgart: Franz Steiner Verlag, 2005), 137-64.

37 Adolf von Harnack, Marcion: Das Evangelium vom fremden Gott. Eine Monographie zur Grundlegung der Katholischen Kirche (Leipzig: Hinrichsche Buchhandlung, 1924). 
discussion - the passage in the seventh chapter of his second book, Die Mission und Ausbreitung des Christentums in den ersten drei Jahrhunderten (first edition 1902), where he deals with the notion of Christianity as a third entity. ${ }^{38}$

Harnack discusses the different perceptions in the first two centuries from an emic and etic perspective. He notes that pagan writers as well as early church fathers were interested to find a category into which Christ-followers could be classified. In his excursus, 'Die Beurteilung der Christen als drittes Geschlecht seitens ihrer Gegner', Harnack sets out that pagan writers differentiated clearly between Jews who were considered a people (Volk) like other peoples (Völker), however distinct in their practices, and the 'Christians' (as Harnack calls them). Thus, in the first century, references to Christians as a superstitio abound (Suetonius, Nero 16; Pliny, Ep. 10.96; Tacitus, Ann. 15.44). ${ }^{39}$ In the second and third centuries Christians are considered to be crazy enthusiasts (halbverrückte Schwärmer) or a horrendous 'natio' which falls outside the category of humans. Harnack notes that the Latin term 'natio' should not be overrated here, since it does not refer to a 'Volk' in the sense of a nation (state). He indicates in a footnote that 'natio' here refers to a group rather than a nation in the contemporary sense. ${ }^{40}$ Further references include Origen's Contra Celsum (8.55) where

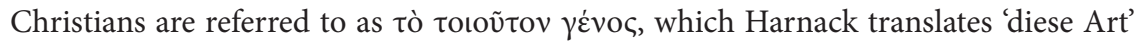
('this kind'). ${ }^{41}$ Discussing Tertullian's references in Ad Nationes to pagan labelling of the Christianoi as a 'tertium genus', Harnack concludes that this label was common in Carthage around $200 \mathrm{CE}$ and that it referred exclusively to a third kind of worshipping and perception of a deity, with Greeks, Romans, and all those who mutually recognized each other's gods being regarded as the 'genus primum', and the Jews as the 'genus alterum'. Harnack is convinced that Tertullian's presentation of the pagans' perception is accurate and he refers to a passage in Nat. 1.20 where Tertullian apparently specifies that 'tertium genus (dicimur) de ritu.' ${ }^{\prime 2}$

For Harnack, it is evident beyond doubt that the terminology does not refer to any sequence of peoples (Völker) nor any other aspect like the sexual asceticism or libertinism of Christianoi. This etic evidence coincides, according to Harnack, with the emic evidence that Christianoi considered themselves in the second century as 'tertium genus', as displayed in the earliest written version of this expression from the fragment of the 'Preaching of Peter' (transmitted in Clem. Alex. Strom. 6.5.41) where the Christianoi are warned not to worship God according to the pattern/kind of

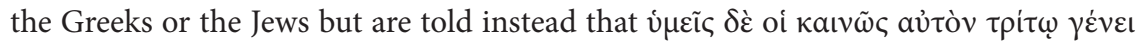

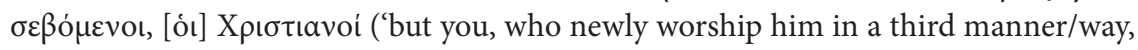

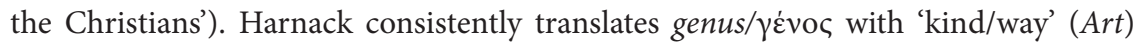
and emphasizes that Greek and Roman writers obviously noted the different kinds/ ways (Arten) of relating to the divine. Thus, Harnack is adamant in identifying the worshipping practices as that which distinguishes the Christianoi from pagans and Jews.

\footnotetext{
38 Adolf von Harnack, Die Mission und Ausbreitung des Christentums in den ersten drei Jahrhunderten, 4th edn ((1902) Leipzig: Hinrichsche Buchhandlung, 1924), 259-89.

39 Harnack, Mission, 282.

40 Harnack, Mission, 283.

${ }^{41}$ Harnack, Mission, 284.

42 Harnack, Mission, 286.
} 
He emphasizes explicitly that the author does not present a categorization of peoples but a classification of worshippers. ${ }^{43}$ We may or may not agree with his assessment of the second-century literature, but it is evident, in my view, that in his assessment of the attempts at categorizing Christianoi in the second century the concept and terminology of Rasse/race was not considered, nor was it even remotely an adequate means of translating the ancient classifications. As we have noted above, racist ideology and terminology was certainly available as an acceptable option for Harnack. The fact that he did not use it in any way in relation to categorizations in antiquity can also not be attributed to a positive perception of Judaism, although he was convinced of the inherent link between the Christianoi and Judaism in the first century CE. This was a historical insight which did not impact on his perception of the Judaism of the nineteenth and twentieth centuries, which he considered a legalistic, degenerate petrification of the biblical tradition. Nevertheless, he did not argue in his writings in a racist vein, and the translation of the Greek and Latin terminology by a linguist of his stature should not be ignored. Harnack did of course note that the Christianoi eventually referred to themselves as a people/Volk. Significantly, they claimed the heritage of Israel and as such were both the ancient and new people superseding the Jewish people. ${ }^{44}$ This perception, however, was relevant in the internal debates, and Harnack translates and interprets second-century texts which refer to this aspect of the self-perception of the Christianoi only when the Greek $\lambda$ aó claim to the title people of God. ${ }^{45}$ Particularly with reference to Paul, Harnack explicitly states that the Christian church is not a third Volk, Rasse, or Geschlecht alongside or besides the others but the new step in human history at its end point which transcends or rather renders ineffective the distinctions between peoples as well as differences of social status and gender. In this new creation, both Jews and Greeks are 'aufgehoben' - encompassed, not obliterated. ${ }^{46}$ Thus Harnack sees initial aspects of the church as an entity that transcends the dichotomy of Jews and Greeks (or circumcised and uncircumcised) in the writings of Paul, but he does not see this as evidence for the church being identified in terms of peoplehood or race. That the church eventually from the second century onwards - is considered a third entity (genus) and eventually claims in self-references a designation as Volk/people as those who encompass in the new creation both Jews and Greeks is not denied but distinguished in careful terminological analysis from any racial connotations. The Volks-Theologie which emerges from this argumentation is not without problems, of course, but it cannot in my view be conflated with racial connotations.

The new humanity (not new race!) which Harnack saw emerging in the Christmovement, however, left no room for people who were not Christian, particularly not for Jews who in Harnack's view had petrified the message of the Old Testament in Rabbinic Judaism. The new humanity could only be Christian and was identified by him with German Protestantism as the form of Christianity which had come closest

43 Harnack, Mission, 265.

44 Harnack, Mission, 268.

45 Harnack, Mission, 262.

46 Harnack, Mission, 261. The German term is notoriously difficult to translate. It wavers between 'integrated' or 'merged' and 'suspended' or 'abrogated'. 
to the envisaged new humanity or new creation. Although, as a profound philologist, Harnack did not use racial terminology in his translation of $\gamma \dot{\varepsilon} v o \varsigma$ and $\varepsilon$ z $v$ vo but remained as close as possible to the meaning of these terms as he saw them in the cultural context of their time, his interpretation was inherently problematic for all those who did not fit into this universalizing image of Christianity.

\subsection{Racism, stereotyping, and xenophobia}

Harnack's solid philological work is being taken seriously by contemporary German colleagues who consider it inconceivable that the concept of Rasse could play any role in their research on collective identities in the first century. This is not only because the shadow of the Shoah is ever present, but also because there was already, prior to the events between 1933 and 1945, a vigorous debate concerning the terminology and concepts with which to categorize the groups out of which Christianity and Judaism, as they were later known, emerged, as is evident from the examples discussed above.

The omission of the term Rasse at the Bad Soden conference is thus not an accident. Certainly when considered in the German context, there can be no rehabilitation of the term Rasse/race. It is inherently bound up with racism and its consequences of the worst imaginable kind during the National-Socialist regime. This indicates that the Bad Soden conference differentiated the terminology and concept of Rasse/race from the terminologies and concepts of Volk, Nation, and Reich. These are not identical or analogous with the former. The terms and concepts of Volk, Nation, and Reich were open to being harnessed by National-Socialist ideology, but they were not inherently part of an ideology of explicit contempt as such. Although 'Volk' and 'Nation' too acquired specific meaning in the German context, their ideological baggage is of a different kind to that of the terminology and concept of race and racism. Race/Rasse is a concept, when applied to human beings, that never existed apart from racism. It is used only in connection with racist ideologies. Hence, I am of the view, as I have argued elsewhere, that it is problematic to postulate a neutral use of the term. ${ }^{47}$ Since 'race' is a construct of the racist theories of early modernity, I consider it inaccurate to speak of race and racism in antiquity - even in a sociocultural sense. ${ }^{48}$ That xenophobia and stereotyping existed is beyond doubt, but, as many theorists emphasize, these categories should not be conflated or confused with each other or with racism. It is noteworthy that in stereotyping in antiquity, although bodily features were discussed, such bodily features were not applied in the stereotyping

47 See Kathy Ehrensperger, 'Paulus, sein Volk und die Rasseterminologie. Kritische Anfragen an den "Race"-Diskurs in neuerer englischsprachiger Paulus-Forschung', Kirche und Israel 27 (2012): 11933; ET 'Paul, His People, and Racial Terminology', Journal of Early Christian History 3, no. 1 (2013): 17-33. Debates concerning contemporary ethnicity and race-related issues are controversial and complex as is evident, for example, in Andreas Wimmer, 'Race-centrism: A Critique and a Research Agenda', Ethnic and Racial Studies 38, no. 13 (2015): 2186-205.

48 Benjamin Isaac, who has been quoted frequently in discussions concerning such terminology, carefully refers in his study to 'proto-racism' rather than racism per se in antiquity (despite the title of his book). See Benjamin Isaac, The Invention of Racism in Classical Antiquity (Princeton, NJ: Princeton University Press, 2004), 515. 
of Jews at any time. ${ }^{49}$ The physical categorizations distinguished rather three major types: the northerners who were pale, the southerners who were dark, and those in the middle, the 'normal' people of the Mediterranean. These categorizations could be used alongside others and were not merely negative but served descriptive purposes as well. And those categorized as normal did not all belong to the ruling people (Greeks or Romans); hence this categorization was not exclusively hierarchical as later racist categorizations always were. And as mentioned, Jews, in these categorizations, were one of the 'normal' Mediterranean peoples.

There is a date for the emergence of racism, but there is none for the emergence of xenophobia and stereotypes; and as Karin Priester notes, there are no systematized ideologies or doctrines of xenophobia and stereotypes, but there certainly are racist ideologies and doctrines. ${ }^{50}$ The English word 'race' is attested from 1508, but as applied to humans only from 1580. It does not occur in the KJV other than in the sense of racing (as in running a race). ${ }^{51}$ Priester also notes that although since its emergence in the fourteenth/fifteenth century there have been numerous forms of racism, with divergent connotations, inherent to all of them was the aim to re-establish hierarchical structures of domination and subordination. ${ }^{52}$ Thus the fact that racial terminology in German-language New Testament interpretation was predominantly used in explicitly racist approaches and is unimaginable in any current interpretations might serve as a voice of caution for the New Testament academic community.

\section{Ethnicity and identity in current German- language New Testament interpretation}

Compared with English-language publications, the number of publications which focus explicitly on ethnicity in contemporary German-language New Testament approaches is rather limited. There is no widespread discourse concerning ethnicity in contemporary German-language scholarship, although a number of colleagues engage with English-language publications on this topic to some extent.

49 Shaye J. D. Cohen has drawn attention to the idea that 'Jews and gentiles were corporeally, visually, linguistically, and socially indistinguishable'; Shaye J. D. Cohen, 'Those Who Say They Are Jews and Are Not: How Do You Know a Jew in Antiquity When You See One?', in idem, The Beginnings of Jewishness: Boundaries, Varieties, Uncertainties (Los Angeles: University of California Press, 1999), 25-68, at 37. See also the highly informative discussion by Jonathan P. Roth, 'Distinguishing Jewishness in Antiquity', in A Tall Order: Writing the Social History of the Ancient World. Essays in Honor of William V. Harris, ed. Jean-Jacques Aubert and Zsuzsanna Várhelyi (München and Leipzig: Saur, 2005), 37-58. He particularly notes that 'what is surprising, is that in all the ancient Greek and Roman references to Jews, including anti-Semitic ones, there are no references to the Jews having any distinctive physical features whatsoever with the exception of circumcision. Even here, it is almost always referred to as part of the Jewish cultus, not corpus, that is, as a ritual feature of Judaism ... and not part of any "Jewish body" (41).

50 Karin Priester, Rassismus und kulturelle Differenz (Münster: Lit Verlag, 1997), 13-14.

51 Shawn Kelley, Racializing Jesus: Race, Ideology, and the Formation of Modern Biblical Scholarship (London: Routledge, 2002), 26.

52 Priester, Rassismus, 14. 
This does not mean that research into the emerging identity of the Christmovement is marginal; rather the discussion is based more on theoretical approaches to collective identity ${ }^{53}$ or, in more traditional terminology, is formulated as a question of ecclesiology. ${ }^{54}$ In the context of the reception of cultural anthropology in particular, Wolfgang Stegemann has critically interacted with approaches which attempt to avoid the anachronistic concept of religion in their reconstruction of the emerging identity of the Christ-movement. ${ }^{55}$ Building on the recognition that the term and concept of religion are both anachronistic for the period in question, for Stegemann, the concept of ethnicity serves as a more accurate template for the characterization of the early Christ-movement. Significantly, Stegemann follows Stanley Stowers, and others, in their emphasis on the paradigm of ethnicity as a concept which encompasses the intertwined aspects of traditions and ethos, including cult practice and rituals, as well as rules and regulations. In her overview of recent Anglo-American Pauline interpretation Christina Tuor-Kurth notes the focus on the genealogical link with Abraham as a decisive commonality in approaches which emphasize the ethnicizing terminology in Paul. ${ }^{56}$ Although she follows Caroline Johnson Hodge in many respects, it is significant that, alongside acknowledging the relevance of the genealogical aspect in relation to the ethnically perceived Christmovement, Tuor-Kurth maintains that the dimension of a shared ethos is a decisive factor for the constitution of a group. The genealogical constitution of a new group - the Christ-movement as related to but not replacing the people Israel - is thus constituted not only through the genealogical link but also through a shared habitus, a shared ethos which in turn defines the group through shared practices and values. ${ }^{57}$ The interrelation between ethos and collective identity has been highlighted by Michael Wolter, although without the focus on ethnicity as a category applicable to the Christ-movement. Wolter maintains that the social dimension of a community manifests itself in its practice or activities. ${ }^{58}$ This emphasis on ethos as a decisive aspect of collective identity can be found in other German-language publications as well, whether in positive interaction with English-language publications on ethnicity or differentiating themselves from them.

Markus Öhler, in a recent article, considers a number of aspects of the relevance of ethnic identities in relation to the Christ-movement and, like others, notices the importance of ethnic belonging and its inseparability from the religious dimension. ${ }^{59}$ He draws attention to ethnically defined voluntary associations but, particularly in

${ }^{53}$ For example, Sandra Hübenthal, Das Markusevangelium als kollektives Gedächtnis (Göttingen: Vandenhoeck \& Ruprecht, 2014).

54 For example, Wolfgang Kraus, Das Volk Gottes: Grundlagen der Ekklesiologie bei Paulus (Tübingen: Mohr Siebeck, 1996).

55 Wolfgang Stegemann, 'The Emergence of God's New People: The Beginnings of Christianity Reconsidered', HTS 62, no. 1 (2006): 23-40.

56 Christina Tuor-Kurth, 'Abraham, Vater aller Glaubenden? Neuere Zugänge zur Frage der Abstammung der Christus-Gläubigen bei Paulus', Kirche und Israel 31 (2016): 33-49.

57 Tuor-Kurth, 'Abraham, Vater aller Glaubenden', 44.

58 Michael Wolter, 'Ethos und Identität in den paulinischen Gemeinden', NTS 43, no. 3 (1997): 430-44.

59 Markus Öhler, 'Ethnos und Identität. Landsmannschaftliche Vereinigungen, Synagogen und christliche Gemeinden', in Kult und Macht: Religion und Herrschaft im syro-palästinensischen Raum, ed. Anne Lykke and Friedrich Schipper (WUNT 2.319; Tübingen: Mohr Siebeck, 2011), 221-48. 
his discussion of New Testament passages, he emphasizes traditional perceptions of Paul as arguing for the overcoming or irrelevance of ethnic belonging when it comes to the identity of those in Christ. Although he carefully distinguishes Paul's language from later New Testament texts and notes that it is in 1 Peter that we find

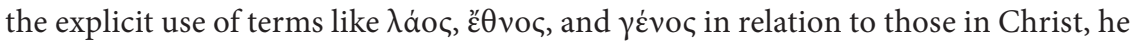
does not further discuss the implications of this use. He refers to Harnack's insight that the use of these terms becomes relevant for the self-understanding of those in Christ from the second century onwards as the notion of being a third entity (Geschlecht) emerges. Significantly, Öhler never uses race-related terminology, but discusses definitions of ethnicity prevalent generally in the discourse in Englishlanguage publications (of Frederik Barth, Jonathan Hall, et al.). The use of $\gamma \varepsilon \dot{v} o \varsigma$, $\lambda \dot{a} o \varsigma$, and $\varepsilon \dot{\varepsilon} v o \varsigma$ terminology in the New Testament is not considered as a case of ethnic reasoning by Öhler, nor does he argue that by these terms the Christmovement considers itself or should be considered an ethnic entity. Thus, although ethnic categorizations are considered and viewed as relevant for New Testament interpretation, Öhler concludes that the characteristic of the Christ-movement is precisely the overcoming or irrelevance of these ethnic distinctions. The collective identity of those in Christ, although considered in the context of ethnic diversity (rather than religious diversity or theological differences), is eventually identified as universal, with analogies to some non-ethnically defined associations, in that ethnic differences are rendered obsolete.

In a recent and very informative article Lukas Bormann emphasizes the significance of 'ethnicity as a helpful analytical category for the understanding of culture, religion, and politics in antiquity. ${ }^{60}$ But in the references to recent publications about this important analytical category that he considers relevant there is only one Germanlanguage publication! He cautions that, in order to arrive at valuable new insights rather than mere terminological innovation, contemporary concepts of ethnicity need to be considered in light of potential analogies to the categorization of concepts in antiquity itself. Bormann draws attention to the tension in constructivist concepts of ethnicity even in relation to its modern use, something which Irad Malkin has formulated as follows: 'Clearly DNA is irrelevant for the formation of historical groupings; however, if ethnic identity persists for some centuries and keeps functioning historically, it becomes primordial both in terms of how outsiders see a group ... and when defined as such also from inside. ${ }^{31}$ Bormann argues that this is particularly relevant when we take seriously that in antiquity the concept of religion, like other aspects of collective belonging, could not be separated from what in modern terms is called ethnicity. ${ }^{62}$

${ }^{60}$ Lukas Bormann, 'Griechen und Juden - Skythen und Barbaren: Ethnizität, kulturelle Dominanz und Marginalität im Neuen Testament', in Alternative Voices: A Plurality Approach to Religious Studies: Essays in Honour of Ulrich Berger, ed. Afe Adogame, Magnus Echtler, and Oliver Freiberger (Göttingen: Vandenhoeck \& Ruprecht, 2013), 116-33, at 116.

${ }_{61}$ Irad Malkin, 'Between Collective and Ethnic Identities', Dialogues d'histoire ancienne supplément 10 (2014): 283-92, at 284.

62 Bormann, 'Griechen und Juden', 118. 
Since the issue under discussion is collective rather than individual identity, or the social aspect of individual identity, ${ }^{63}$ then we might ask if collective identity as such could not also be labelled ethnic - as the term $\varepsilon^{\prime} \theta v o \varsigma$ is a collective term? If with ethnicity this collective aspect of a group of people who relate to each other with a sense of belonging is meant (as is the case in the narrative of belonging to which the New Testament writings witness), then their identity might be called ethnic in this broad sense. However, the question is whether any added insight is thereby gained compared with other options. Bormann notes that, when discussing the issue for the period in question, the frame of reference for the term $\varepsilon^{\prime} \theta v o \varsigma$ in its specific context needs to be considered in the first place. He draws particular attention to the fact that inherent to the perception of an $\ddot{\varepsilon} \theta v o \varsigma$ is the notion that such a group is constituted by their

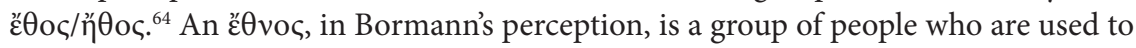
living together according to identifiable customs and traditions, whether these have been transmitted orally or in written form. The terms which refer to these traditions are most frequently derived from the legal sphere with the groups attributing their application and interpretation often to specific categories of people within the group, such as priests or lawyers. Hence, for Rome, this $\varepsilon \theta$ oc/ Greek cities it is referred to as the rátpıo vó $\mu$ ol. In Judaism, this is obviously the Torah associated with Moses. Other aspects of course complement this perception of what

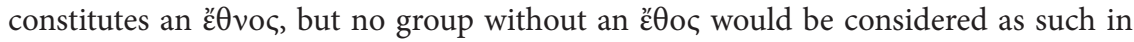
antiquity, according to Bormann. ${ }^{65}$

An interesting variation of this perception of an $\varepsilon \theta v o \varsigma$ is Bormann's reference to Cicero's contemplation concerning Roman identity. With the expansion of the imperium and the inclusion of the Italian tribes into Roman citizenship, the option of dual or eventually triple identity became viable. Hence, in Cicero's perception - and later - one could be Roman, Greek, and Messapian all at the same time; the three aspects of one's identity were not mutually exclusive. ${ }^{66}$ The question arises, however, whether this means that such a person would have three identities, or is a confluence of ethnic identities, or an ethnic hybrid? Interestingly, in the perception of

${ }^{63}$ Cf. Henri Tajfel, ed., Differentiation Between Social Groups: Studies in Social Psychology of Intergroup Relations (London: Academic Press, 1978), and the reception of Social Identity Theory in Philip F. Esler, Conflict and Identity in Romans: The Social Setting of Paul's Letter (Minneapolis: Fortress, 2003); Petri Luomanen, 'The Sociology of Knowledge, the Social Identity Approach and the Cognitive Science of Religion', in Explaining Christian Origins and Early Judaism: Contribution to Cognitive and Social Science, ed. Petri Luomanen, et al. (Leiden: Brill, 2007), 199-229; J. Brian Tucker, You Belong to Christ: Paul and the Formation of Social Identity in 1 Corinthians 1-4 (Eugene, OR: Pickwick, 2010).

64 Benedikt Eckhardt has analysed this aspect in detail in his Ethnos und Herrschaft. Politische Figurationen Judäischer Identität von Antiochos III. bis Herodes I (Berlin: deGruyter, 2013). His focus being on the use of $\varepsilon$ $\theta v o c$ in the period after Alexander the Great, he notes that the term was a categorization term which could include numerous diverse groups in the first place, but then was also used in a more specific way as a term denoting a subjugated status, especially in Seleucid and Ptolemaic usage. It is a 'differentiation' term, labelling 'us' and 'them', in a vein similar to the Roman differentiation of the populus Romanus and the gentes/nationes as all the 'others', particularly those in the realm of the Roman imperium.

65 Bormann, 'Griechen und Juden', 119.

${ }^{66}$ Cicero, Leg. 2.5 - patria loci sive natura - patria iuris sive civitatis. (A local or natural fatherland - a fatherland according to law or citizenship.) 
contemporaries, neither of these modern categories would fit as the different aspects of their 'identity' neither mingled nor fused, nor were they cumulative. They could possibly best be described as forms of cultural and political bi- or multiculturalism, or should we say these aspects of identity intersect?

Bormann concludes his important article by emphasizing that the overcoming or transcending of ethnic identities was inconceivable for the period in question. He maintains that Paul's universalism is a particular universalism, that is, a universalism from within the Jewish symbolic and social universe. As such, it is an ethnically specific universalism. I consider Bormann's approach quite convincing as it comes close to a perception of the Pauline vision of a diversity of peoples forming a unity in Christ without giving up their particularity, as I have argued elsewhere. ${ }^{67}$ The traditions which nurture the Pauline vision(s) were Jewish in their relation to the scriptures, and their diverse interpretations, as expressions of the relationship to the one God. Of course, all of these were not culturally enclosed traditions (I nowhere argue a purist stance), but part of the vivid cultural interactions of the period, intersecting with numerous other traditions of the time. And although Paul probably had hopes that his vision might be shared by all his Jewish contemporaries, he refrained from considering those who did not see things the way he did as excluded from being God's beloved. The incoming of the $\varepsilon \theta v \eta$ does not replace Israel, but is part of the mysterious ways of God which leads to the saving of $\pi \tilde{a} \varsigma^{\prime} I \sigma \rho a \eta j \lambda$ (Rom. 11.26) ${ }^{68}$ Her specific place in the purpose of God is never in doubt, as God's 'gifts and calling are irrevocable' (Rom. 11.29) ${ }^{69}$

\section{Conclusion}

Where does this leave us? The categories of ethnicity are certainly referred to and reflected upon in some recent German-language scholarship, but there seems to be a reluctance to embrace the discourse as fully as it has been embraced in AngloAmerican scholarship. The German-language discussion nevertheless engages in the critical debates concerning the concept of religion, which significantly influenced the search for alternative concepts to understand the processes which, at the end of the fourth century, led to identifiable and more or less distinct entities, Christianity and Judaism. The terminology and concepts in which this discussion is phrased, however, differ mostly from the English-language debates in that open terms such as collective

67 Paul at the Crossroads of Cultures: Theologizing in the Space Between (LNTS 456; London: Bloomsbury

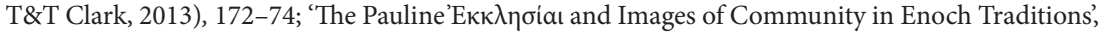
in Paul the Jew: Rereading the Apostle as a Figure of Second Temple Judaism, ed. Gabriele Boccacini and Carlos Segovia (Minneapolis: Fortress, 2016), 183-216.

${ }^{68}$ Israel is not equivalent with being in Christ but remains a distinct entity which is neither replaced by, nor 'aufgehoben' in Christ.

69 I have dealt with this in two articles, see Kathy Ehrensperger, 'Reading Romans "in the Face of the Other": Levinas, the Jewish Philosopher Meets Paul, the Jewish Apostle', in Reading Romans with Contemporary Philosophers and Theologians, ed. David Odell Scott (Romans Through History and Cultures 7; London and New York: T\&T Clark, 2007), 115-54, and also 'The Mystery of Paul's "Mysterion" in Rom 11.25-36', in Religious Secrecy as Contact: Secrets as Promoters of Religious Dynamics, ed. A. Akasoy, et al. (Leiden: Brill, forthcoming). 
identity are preferred, thus leaving the precise definition of the nature and essence of these groups more open than specific terms like ethnicity or race would allow. The rather open terminology also takes into account that the terms $\varepsilon \dot{\theta} \theta 0 \varsigma, \gamma \varepsilon \dot{\varepsilon} v \varsigma, \lambda \dot{\alpha} \circ$, , and so on, were used in a wide variety of ways in antiquity and need to be analysed in their specific sociocultural, linguistic, and literary contexts in order to come to any solid conclusions as to their potential meanings. The fact that, certainly in New Testament texts, they were part of, and embedded in, the symbolic and social world of first-century Judaism indicates that attempts at dealing with their meaning need to take this context into account. The cautious reluctance of German-language scholarship to embrace ethnic or racial language without critical caveats as the solution to the terminological and conceptual categorization of the early Christ-movement should not merely be seen as a reaction to terminology prevalent in the period of 1933-45 but rather indicates that this debate needs to be seen in light of earlier debates concerning the appropriate categorization and terminology applicable to the early Christ-movement, including

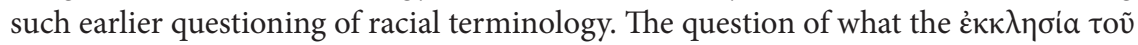
$\theta \varepsilon$ cov precisely is, remains an open question, maybe not unlike Ammianus' question noted at the outset.

\section{References}

Arendt, Hanna. Elemente und Ursprünge totaler Herrschaft: Antisemitismus, Imperialismus, totale Herrschaft. Munich: Piper, 1986 (German Translation of The Origins of Totalitariansim. New York: Harcourt Brace Jovanovich, 1951).

Ascough, Richard. Paul's Macedonian Associations: The Social Context of Philippians and 1 Thessalonians. WUNT 2.161. Tübingen: Mohr Siebeck, 2003.

Bartels, Adolf. Der deutsche Verfall. 3rd edn. [1913] Zeitz: Sis-Verlag, 1919.

Bormann, Lukas. 'Griechen und Juden - Skythen und Barbaren: Ethnizität, kulturelle Dominanz und Marginalität im Neuen Testament'. In Alternative Voices: A Plurality Approach to Religious Studies: Essays in Honour of Ulrich Berger, edited by Afe Adogame, Magnus Echtler, and Oliver Freiberger, 116-33. Göttingen: Vandenhoeck \& Ruprecht, 2013.

Brubaker, Roger. Ethnicity without Groups. Cambridge, MA: Harvard University Press, 2004.

Buell, Denise K. Why This New Race: Ethnic Reasoning in Early Christianity. New York: Columbia University Press, 2005.

Cohen, Shaye J. D. 'Those Who Say They Are Jews and Are Not: How Do You Know a Jew in Antiquity When You See One?'. In idem, The Beginnings of Jewishness: Boundaries, Varieties, Uncertainties, 25-68. Los Angeles: University of California Press, 1999.

Eckhardt, Benedikt. Ethnos und Herrschaft. Politische Figurationen Judäischer Identität von Antiochos III. bis Herodes I. Berlin: deGruyter, 2013.

Ehrensperger, Kathy. 'Reading Romans "in the Face of the Other": Levinas, the Jewish Philosopher meets Paul, the Jewish Apostle. In Reading Romans with Contemporary Philosophers and Theologians, edited by David Odell Scott, 115-54. Romans Through History and Cultures 7. London and New York: T\&T Clark, 2007.

Ehrensperger, Kathy. 'Paulus, sein Volk und die Rasseterminologie. Kritische Anfragen an den „Race“-Diskurs in neuerer englischsprachiger Paulus-Forschung. Kirche und Israel 
27 (2012): 119-33. English Translation: 'Paul, His People, and Racial Terminology'. Journal of Early Christian History 3, no. 1 (2013): 17-33.

Ehrensperger, Kathy. Paul at the Crossroads of Cultures: Theologizing in the Space Between. LNTS 456. London: Bloomsbury T\&T Clark, 2013.

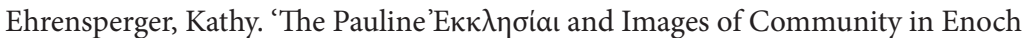
Traditions.' In Paul the Jew: Rereading the Apostle as a Figure of Second Temple Judaism, edited by Gabriele Boccacini and Carlos Segovia, 183-216. Minneapolis: Fortress, 2016.

Ehrensperger, Kathy. 'The Mystery of Paul's "Mysterion” in Rom 11.25-36'. In Religious Secrecy as Contact: Secrets as Promoters of Religious Dynamics, edited by A. Akasoy, et al. Leiden: Brill, forthcoming.

Erbe, Walter. 'Einleitung. In Was bedeuten uns heute Volk, Nation, Reich?, edited by Walter Erbe et al., 3-11. Schriftenreihe der Friedrich Naumann-Stiftung zur Politik und Zeitgeschichte 3. Stuttgart: Deutsche Verlags-Anstalt, 1961.

Esler, Philip F. Conflict and Identity in Romans: The Social Setting of Paul's Letter. Minneapolis: Fortress, 2003.

Gerdmar, Anders. Roots of Theological Antisemitism: German Biblical Interpretation and the Jews, from Herder and Semler to Kittel and Bultmann. Leiden: Brill, 2008.

Grundmann, Walter. Religion und Rasse: Ein Beitrag zur Frage nationaler Aufbruch und lebendiger Christusglaube. Werdau: Meister, 1933.

Grundmann, Walter. Totale Kirche im totalen Staat: Kirche im Dritten Reich. Dresden: O. Gunther, 1934.

von Harnack, Adolf. Das Wesen des Christentums: Sechzehn Vorlesungen vor Studierenden aller Fakultäten im Wintersemester 1899/1900 am der Universität Berlin gehalten. Leipzig: Hinrich, 1901.

von Harnack, Adolf. Die Mission und Ausbreitung des Christentums in den ersten drei Jahrhunderten. 4th edn. [1902] Leipzig: Hinrichsche Buchhandlung, 1924.

von Harnack, Adolf. Marcion: Das Evangelium vom fremden Gott. Eine Monographie zur Grundlegung der Katholischen Kirche. Leipzig: Hinrichsche Buchhandlung, 1924.

Herder, Johann Gottfried. 'Ideas for the Philosophy of the History of Mankind'. In Herder on Social and Political Culture, translated and edited by F. M. Barnard, 255-326. Cambridge: Cambridge University Press, 1969.

Heschel, Susannah. 'Rassismus und Christentum. Das Institut zur Beseitigung des jüdischen Einflusses auf das deutsche kirchliche Leben'. In Die völkisch-religiöse Bewegung im Nationalsozialismus: Eine Beziehungs-und Konfliktgeschichte, edited by Uwe Puschner and Clemens Vollnhals, 249-64. 2nd edn. Göttingen: Vandenhoeck \& Ruprecht, 2012.

Homolka, Walter. 'Adolf von Harnack und Leo Baeck: Zwei liberale Theologen, ein fiktiver Dialog. In Wende-Zeit im Verhältnis von Juden und Christen, edited by Siegfried von Kortzfleisch, 189-217. Berlin: EB-Verlag, 2009.

Horrell, David G. ' "Race", "Nation", "People”: Ethnic Identity-Construction in 1 Peter 2.9'. NTS 58, no. 1 (2012): 123-43.

Hübenthal, Sandra. Das Markusevangelium als kollektives Gedächtnis. Göttingen: Vandenhoeck \& Ruprecht, 2014.

Isaac, Benjamin. The Invention of Racism in Classical Antiquity. Princeton, NJ: Princeton University Press, 2004.

Judge, Edwin A. 'On This Rock I Will Build My Ekklesia: Counter-Cultic Springs of Multiculturalism'. In idem, The First Christians in the Roman World, 619-68. Tübingen: Mohr Siebeck, 2008. 
Kelley, Shawn. Racializing Jesus: Race, Ideology, and the Formation of Modern Biblical Scholarship. London: Routledge, 2002.

Kinzig, Wolfram, ed. 'Der Kaiser und der „Evangelist des Rassismus“. Houston Stewart Chamberlains Brief an Anne Guthrie über seine erste Begegnung mit Wilhelm II, mit einer Einleitung. ZNThG/JHMTh 11 (2004): 79-125.

Kinzig, Wolfram. 'Harnack, Houston-Chamberlain and the First World War'. JHMTh/ ZNThG 22, no. 2 (2015): 190-230.

Kraus, Wolfgang. Das Volk Gottes: Grundlagen der Ekklesiologie bei Paulus. Tübingen: Mohr Siebeck, 1996.

Krieger, Karsten, ed. Der „Berliner Antisemitismusstreit“1879-1881: Eine Kontroverse über die Zugehörigkeit der deutschen Juden zur Nation. Kommentierte Quellenedition. München: Saur, 2004.

LaGarde, Paul. 'Über die gegenwärtige Lage des Deutschen Reiches'. In idem, Deutsche Schriften, 98-167. Göttingen: Dietrichsche Verlagsbuchhandlung, 1878.

LaGarde, Paul. Juden und Indogermanen. Eine Studie nach dem Leben. Göttingen: Dietrichsche Universitätsbuchhandlung, 1887.

Lessing, Gotthold Ephraim. 'Hamburger Dramaturgie'. In Werke. Volume 4. Munich: Carl Hanser, 1973.

Leutzsch, Martin. 'Karrieren des arischen Jesus zwischen 1918 und 1945'. In Die völkischreligiöse Bewegung im Nationalsozialismus. Eine Beziehungs-und Konfliktgeschichte, edited by Uwe Puschner and Clemens Vollnhals, 195-218. 2nd edn. Göttingen: Vandenhoeck \& Ruprecht, 2012.

Löchte, Anne. Johann Gottfried Herder, Kulturtheorie und Humanitätsidee der Ideen, Humanitätbriefe und Adrastea. Würzburg: Königshausen \& Neumann, 2005.

Luomanen, Petri. 'The Sociology of Knowledge, the Social Identity Approach and the Cognitive Science of Religion'. In Explaining Christian Origins and Early Judaism: Contribution to Cognitive and Social Science, edited by Petri Luomanen, et al., 199-229. Leiden: Brill, 2007.

Malitz, Jürgen. “'Auch ein Wort über unser Judenthum”, Theodor Mommsen und der Berliner Antisemitismusstreit'. In Theodor Mommsen: Gelehrter, Politiker und Literat, edited by Josef Wiesehöfer, 137-64. Stuttgart: Franz Steiner Verlag, 2005.

Malkin, Irad. 'Between Collective and Ethnic Identities'. Dialogues d'histoire ancienne supplément 10 (2014): 283-92.

Nanos, Mark. The Mystery of Romans: The Jewish Context of Paul's Letter. Minneapolis: Fortress, 1996.

Nanos, Mark. 'To the Churches within the Synagogues of Rome'. In Reading Paul's Letter to the Romans, edited by Jerry L. Sumney, 11-28. Atlanta: Scholars Press, 2012.

Nongbri, Brent. Before Religion: A History of a Modern Concept. New Haven: Yale University Press, 2013.

Öhler, Markus. 'Ethnos und Idenität. Landsmannschaftlichen Vereinigungen, Synagogen und christliche Vereinigungen'. In Kult und Macht: Religion und Macht im syropalästinensischen Raum, edited by Anne Likke and Friedrich T. Schipper, 221-48. WUNT 2.319. Tübingen: Mohr Siebeck, 2011.

Priester, Karin. Rassismus und kulturelle Differenz. Münster: Lit Verlag, 1997.

Puschner, Uwe. "'One People, One Reich, One God', The Völkische Weltanschauung and Movement'. German Historical Institute Bulletin 24, no. 1 (2002): 5-25.

Roth, Jonathan P. 'Distinguishing Jewishness in Antiquity'. In A Tall Order: Writing the Social History of the Ancient World. Essays in Honor of William V. Harris, edited by Jean-Jacques Aubert and Zsuzsanna Várhelyi, 37-58. München and Leipzig: Saur, 2005. 
Schinkel, Dirk. Die himmlische Bürgerschaft: Untersuchungen zu einem urschristlichen Sprachmotiv im Spannungsfeld von religiöser Intergration und Abgrenzung im 1. und 2. Jahrhundert. Göttingen: Vandenhoeck \& Ruprecht, 2007.

Sechrest, Love. A Former Jew: Paul and the Dialectics of Race. London and New York: T\&T Clark, 2009.

Stanley, Christopher D. 'The Ethnic Context of Paul's Letters'. In Christian Origins and Hellenistic Judaism: Social and Literary Contexts of the New Testament, edited by Stanley E. Porter and Andrew W. Pitts, 177-202. Leiden: Brill, 2013.

Stegemann, Wolfgang. 'The Emergence of God's New People: The Beginnings of Christianity Reconsidered'. HTS 62, no. 1 (2006): 23-40.

Stowers, Stanley. 'The Concepts of "Religion", "Political Religion" and the Study of Nazism'. Journal of Contemporary History 42, no. 1 (2007): 9-24.

Tajfel, Henri, ed. Differentiation Between Social Groups: Studies in Social Psychology of Intergroup Relations. London: Academic Press, 1978.

Treitschke, Heinrich von. 'Unsere Aussichten'. Preussische Jahrbücher 44 (Berlin: Reimer Verlag, 1879): 560-76.

Tucker, J. Brian. You Belong to Christ: Paul and the Formation of Social Identity in 1 Corinthians 1-4. Eugene, OR: Pickwick, 2010.

Tuor-Kurth, Christina. 'Abraham, Vater aller Glaubenden? Neuere Zugänge zur Frage der Abstammung der Christus-Gläubigen bei Paulus'. Kirche und Israel 31 (2016): 33-49.

Weber, Cornelia. Altes Testament und völkische Frage: Der biblische Volksbegriff in der alttestamentlichen Wissenschaft der nationalsozialistischen Zeit, dargestellt am Beispiel von Johannes Hempel. Tübingen: Mohr Siebeck, 2000.

Whaley, Joachim. 'Reich, Nation, Volk. Early Modern Perspectives'. The Modern Language Review 101, no. 2 (2006): 442-55.

Wiese, Christian. Challenging Colonial Discourse: Jewish Studies and Protestant Theology in Wilhelmine Germany. Leiden: Brill, 2005.

Wimmer, Andreas. 'Race-centrism: A Critique and a Research Agenda'. Ethnic and Racial Studies 38, no. 13 (2015): 2186-205.

Wolter, Michael. 'Ethos und Identität in den paulinischen Gemeinden'. NTS 43, no. 3 (1997): 430-44.

Woods, David. 'Ammianus 22.4.6: An Unnoticed Anti-Christian Jibe'. JTS 49 (1998): 145-48. 


\title{
From Ernest Renan to Anders Behring Breivik: Continuities in Racial Stereotypes of Muslims and Jews
}

\author{
Halvor Moxnes
}

The purpose of this essay is to look at continuities in racial stereotypes of Muslims and Jews from the nineteenth to the twenty-first century, through two examples, the French philologist and history of religion scholar Ernest Renan (1823-92) and the Norwegian terrorist and mass murderer Anders Behring Breivik (b. 1979), whose attack was carried out on 22 July 2011. I suggest that there is a continuity of stereotypes not only over time, but also over the divide of scholarly presentations and popular views. ${ }^{1} \mathrm{My}$ contention is that racial stereotypes are not only part of popular prejudices, but that they also form the (unconscious?) substructure of scholarly discussions. ${ }^{2}$ Therefore I will argue that it is relevant to compare the rhetoric of race and religion in Renan's philological and religious studies, and the largely undocumented and manifestly false positions in Breivik's manifesto 2083 - A European Declaration of Independence. ${ }^{3}$ Renan has been chosen because he is regarded as one of the originators of Orientalism and also accused of legitimizing anti-Semitism. On the contemporary scene Anders Behring Breivik is an obvious choice as a focus for many Islamocritical groups and individuals. ${ }^{4}$ Of course, most of them distance themselves from his acts of terror, but they share many of his positions on Islam and on European governments that are accused of promoting Islamism.

1 See Marianne Gullestad, Plausible Prejudice: Everyday Experiences and Social Images of Nation, Culture and Race (Oslo: Universitetsforlaget, 2006).

2 My argument is similar to that of Shawn Kelley, Racializing Jesus. Race, Ideology and the Formation of Modern Biblical Scholarship (London and New York: Routledge, 2002), but he studies how racialized thinking continued as an intellectual substructure from the nineteenth to the twentieth century, while I explore the influence of popular views upon academic studies.

3 Anders Behring Breivik, Complete Manifesto. 2083 - A European Declaration of Independence. Available online: https://publicintelligence.net/anders-behring-breiviks-complete-manifesto-2083a-european-declaration-of-independence (accessed 9 February 2017).

4 See further Sindre Bangstad, Anders Breivik and the Rise of Islamophobia (London: Zed Books, 2014), esp. 13-25, 144-74, and $\$ 3$ below. 


\section{Ernest Renan}

\subsection{Renan's historical Jews in the image of contemporary Muslims}

What makes Ernest Renan particularly interesting in a study of racism in biblical studies is his Life of Jesus from $1863 .{ }^{5}$ Renan's book was one of the most influential - and controversial - books on Jesus in the nineteenth century. ${ }^{6}$ With his studies of language Renan shaped the terminology of Semitic and Indo-European languages and races, and he was influential in shaping Orientalist discourse, which is still with us today. Orientalism, as Edward Said has argued, ${ }^{7}$ was a discourse established in the nineteenth century, which, from the position of the West, constructed the Orient in terms of being 'the Other' in contrast to 'the Self'. Both religion and race were important categories in this construction. This Orientalism influenced perceptions of the beginning of Christianity as a break with Judaism.

It has long been recognized that Renan's picture of Jews in his Life of Jesus was negative, and with his racialized philology he has been accused of initiating antiSemitism. ${ }^{8}$ Thus, since anti-Semitism is now understood as referring to Jews only, it should be noted that Renan included Arab-speaking Muslims in the races that spoke Semitic languages. Therefore, Renan's writings may also be considered as one of the sources of modern Islamophobia.

What has not been observed, however, is the linkage in The Life of Jesus between negative views of Jews at the time of Jesus and of Muslims from Renan's own time. Renan based the negative picture of Jews as the opponents of Jesus to a great extent on analogies with his impressions of the Arab Muslims that he encountered in Syria and Jerusalem when he was writing the book. Thus, the negative picture of the Jews was not only based on deductions from his highly respected philological studies, that had rendered Semitic languages as 'dead' and inferior to Indo-European languages, but also upon a less scholarly source: his own personal experiences of the Levant. Thus, he brings references to Muslims in his own time ('the present') directly into the historical description of Jesus in his time. We have here an example of what Karla Malette observed in her study of Renan and Orientalism: that history represents 'the reconfiguration of the past in the image of the present.'

The description of Jesus' first encounter with Jerusalem is a typical example of the analogy between Jews and Muslims:

5 Ernest Renan, Vie de Jésus (Paris: Michel Lévy, 1863); The Life of Jesus (New York: Modern Library, 1927).

6 See now the authoritative account in Robert D. Priest, The Gospel According to Renan: Reading, Writing and Religion in Nineteenth-Century France (Oxford: Oxford University Press, 2015); see also Halvor Moxnes, Jesus and the Rise of Nationalism: A New Quest for the Nineteenth Century Historical Jesus (London: I. B. Tauris, 2012), 121-47.

7 Edward W. Said, Orientalism (New York: Random House, 1978).

8 Susannah Heschel, The Aryan Jesus: Christian Theologians and the Bible in Nazi Germany (Princeton, NJ: Princeton University Press, 2008), 33-8.

9 Karla Malette, 'Orientalism and the Nineteenth Century Nationalist: Michele Amari, Ernest Renan, and 1848', The Romanic Review 96 (2005): 233-52, at 248. 
Jerusalem was then nearly what it is to-day, a city of pedantry, acrimony, disputes, hatreds and littleness of mind. Its fanaticism was extreme .... The Pharisees were dominant; the study of the Law, pushed to the most insignificant minutiae, and reduced to questions of casuistry, was the only study .... It was something analogous to the barren doctrine of the Mussulman fakir, to that empty science discussed round about the mosques, ... by no means calculated to advance the right discipline of the mind. ${ }^{10}$

Renan continues this comparison between the Jewish student of the Law and the Muslim fakir and scholar (and also adds in 'the old catholic theologian'), and concludes: 'The Jewish scribe, ... had the same contempt for Greek culture which the learned Mussulman of our time has for European civilization.' Here the historical Jewish Scribes and Pharisees are presented as analogous to the 'learned Mussulman' of Renan's time in their contempt for Greek culture and European civilization, respectively. Whether it was Jewish study of the Law or the 'empty science' of the Muslim, they were both futile and sterile. This notion of the 'empty science' of the Muslims is significant, for it points to the important role Renan gives to 'science' to distinguish between European and Muslim, and also between European Christianity and Judaism. ${ }^{11}$ This was a distinction in terms of civilization, which was the achievement of Europe, and it placed Europe in a superior position to that of Muslims (and Jews).

\subsection{Science as sign of European civilization}

The difference between the Europeans and the Semites (Jews and Muslims) in relation to science was a major theme in Renan's inaugural lecture as Professor of Hebrew at the Collége de France in $1862 .{ }^{12}$ The lecture gave a summary of Renan's high estimation of the historical Jesus, who, leaving behind the particularity of the Jewish religion, founded a religion of humanity. This religion was established in Europe as a result of the progress of civilization that had only happened in the West and that made Europe superior to the Orient, especially the Muslim world. For Renan, science represented progress and respect for mankind and freedom, that is, the most important values of French and European civilization.

In his 1882 lecture, 'Islam and Science, ${ }^{13}$ Renan develops his negative view on Islam and science throughout history. He had to face the objection that there were periods in which science flourished in Islamic countries - in Baghdad in the eighth century and in Spain in the thirteenth century. In order to meet these objections, Renan must

10 This and the following quotations are from Renan, Life of Jesus, 214.

11 On the importance of science in Renan's thought, and in particular on the opposition between science and faith/religion, see Tzvetas Todorov, On Human Diversity: Nationalism, Racism, and Exoticism in French Thought (Cambridge, MA: Harvard University Press, 1993), 118-23, 148-53.

12 Ernest Renan, De la part des peuples sémitiques dans l'historie de la civilisation (Paris: Lévy, 1862); see Priest, The Gospel According to Renan, 60-6.

13 Ernest Renan, Islam and Science: A Lecture Presented at La Sorbonne 29 March 1883, trans. Sally P. Ragep, 2nd edn (McGill University, 2011). Available online: https://www.mcgill.ca/islamicstudies/ files/islamicstudies/renan_islamism_cversion.pdf (accessed 2 May 2017). 
specify what he means by 'Islam'; therefore he goes on to provide 'precision in the use of words that designate nations and races. ${ }^{\prime}{ }^{14}$

He starts by listing all the different forms of social and political groups that are designated as 'Muslim, and speaks of 'the current inferiority of Muslim countries, the decadence of states governed by Islam, the intellectual sterility of races that derive their culture and education from that religion alone. ${ }^{15}$ For Renan, it is the religion of Islam that creates the problem: It makes a true believer absolutely closed to science. Because of his faith that God alone determines human fate, 'the Muslim has the deepest contempt for education, for science, for all that constitutes the European spirit'. ${ }^{16}$

Thus, it appears that it was religion, not race that was the reason behind the Muslim contempt for science. So how can Renan explain that, as he admits, for 500 years (from the middle of the eighth century until the middle of the thirteenth) there were distinguished thinkers in Muslim countries? Here race reappears as part of the explanation, in the combination of the Arab race with Islam in its first period. Arabs were not inclined to philosophy, Renan declares, and therefore, 'as long as Islam was in the hands of the Arab race, ... there did not occur in its midst any intellectual movement of a secular character. ${ }^{17}$ This changed, when about 750 CE Persia took over the hegemony, and the centre of Islam was moved to Baghdad with the civilization of the Sassanid Persians. The caliphs of this period were 'barely Muslims', Renan claimed, so that during their reign 'free thought developed', with Syrian Christian scholars translating Greek philosophy and science into Arabic. Thus, even if its language was Arabic, the philosophy itself was in fact Greek. In Renan's system, Arabic, as a Semitic language, belonged to the 'dead' languages, while philosophy belonged to the IndoEuropean, the 'living' languages. However, it was not only the language that was 'dead'; this verdict spilled over into Arabs as a racial category, since it was Arabs as a race who had no interest in philosophy.

Similarly, Renan did not consider Arabic philosophy in Spain in the Middle Ages to be a Muslim achievement; it was a result of translations of Greek philosophy. In the early Middle Ages Europe had been dependent upon these Arab translations. However, from the end of the thirteenth century the Muslim countries fell into intellectual decay, whereas Western Europe entered 'upon this great path of scientific research for truth. ${ }^{18}$ So what happened to Islam in the period from the thirteenth until the nineteenth century? Renan's explanation is partly built on race: Islam 'fell into the hands of the Tartar and Berber races, races which are coarse, brutal and without intellect.' ${ }^{19}$ The other explanation was that 'the absolute reign of dogma' took over Islam and dominated civilian life. ${ }^{20}$ The result was a system with no separation between the spiritual and the temporal, that is, the Muslim state.

14 Renan, Islam and Science, 1.

15 Renan, Islam and Science, 1 (emphasis added).

16 Renan, Islam and Science, 3.

17 Renan, Islam and Science, 5 (emphasis added).

18 Renan, Islam and Science, 13.

19 Renan, Islam and Science, 16-17.

${ }^{20}$ Renan, Islam and Science, 17. 
In response to those who would attribute the growth of philosophy to the influence of Islam, Renan claimed that it was a movement 'which occurred despite Islam, against Islam, and that Islam, fortunately, was unable to prevent.$^{21}$ His conclusion is that 'what essentially distinguishes the Muslim is the hatred of science, ... because it is in competition with God'. For Renan, in contrast, science was, in effect, a kind of secular religion that characterized Europe. It represented what he considered the ultimate goal for humanity, since 'ultimately it will serve only progress, I mean true progress, that which is inseparable from respect of mankind and freedom.22 Thus, with his distinctions between Arab language and philosophy, by ascribing philosophy to Christians and Persians who lived in Muslim states, Renan established a European ownership of science and philosophy in Muslim states. The 'real' Islam, on the other hand, was in its essence an opponent of science.

\subsection{Muslim objections to Renan}

Renan's lecture caused strong reactions and criticism among Muslim intellectuals, and resulted in public responses, similar to the reactions from Catholic theologians to his Life of Jesus. The most interesting reactions came from Jamal al-Din Al-Afghani, a prominent Modernist Muslim intellectual. ${ }^{23}$ He moved between many Muslim countries as a political activist, especially against British imperialism. In his response, he puts his finger directly on the two main points of Renan's lecture: 'The eminent philosopher applied himself to proving that the Muslim religion was by its very essence opposed to the development of science, and that the Arab people, by their nature, did not like either metaphysical sciences or philosophy.24 Although he shared many of Renan's views on the relations between science and religion, Al-Afghani criticizes the way Renan essentializes the opposition of Muslim religion to science, and makes it absolute. Instead, Al-Afghani says, all religions are intolerant, but Christian societies had liberated themselves and had advanced rapidly 'on the road of progress and science'. In the same manner, he says, Muslim societies may also break the bonds of religion and march 'resolutely in the path of civilization someday after the manner of Western society. ${ }^{25} \mathrm{Al}$-Afghani is here pointing to the way Renan described how Christianity, following the example of Jesus, liberated itself from Judaism. However, Renan did not allow for the possibility that Muslim societies could do the same, but ascribed to them an essentially static character. Renan recognized Al-Afghani as a Modernist thinker, but saw him as an exception, so he did not change his position on Islam or the Arabs.

21 This and the following quotation, Renan, Islam and Science, 19 (emphasis added).

22 Renan, Islam and Science, 24.

${ }^{23}$ See Monica M. Ringer and A. Holly Shissler, 'The Al-Afghani-Renan Debate, Reconsidered', Iran Nameh 30, no. 3 (2012): xxviii-xlv.

24 Jamal al-Din Al-Afghani, 'Answer of Jamal al-Din to Renan', Journal des Débats (1883), in Nikki R. Keddi, Imperialism, Science and Religion: Two Essays by Jamal al-Din al-Afghani, 1883 and 1884 (Modern Middle East Sourcebook Project, 2004), 2-3. Available Online: https://disciplinas.stoa.usp. br/pluginfile.php/2004379/mod_resource/content/1/KEDDIE,\%20Nikki.pdf (accessed 10 February 2017).

25 Al-Afghani, 'Answer', 3. 


\subsection{Parallels between Jews and Muslims}

We are now in a better position to understand how the past, that is, the picture of Jewish Scribes and Pharisees, could be reconfigured in the image of modern Muslims. Renan saw Jesus - and the origins of Christianity - as the beginning of European civilization, based on progress, respect for mankind, and freedom. In that context, Pharisees and Scribes represented the contempt for Greek culture just as modern Muslims showed contempt for European civilization. Renan saw parallels between the essential, nonscientific character of contemporary Muslim societies and the static character of Judaism in contrast to Jesus. This analogy between Jews and Muslims in opposition to what characterized European civilization occurs at many instances in The Life of Jesus, for instance, when Renan says that 'neither the Jews nor the Mussulman has understood the delightful theology of love. ${ }^{26}$

The way Renan conceived of himself and the ideal European is another example of 'the reconfiguration of the past in the image of the present. ${ }^{27}$ The historical example is the negative reception Jesus received from the Samaritans (they believed that he had the same prejudices as the Jews). Renan comments that this was a reaction in the same manner as in our day the European free-thinker is regarded as an enemy of the Mussulman who always believes him to be a fanatical Christian. ${ }^{28}$

In Renan's argument, Islam was primarily a religion that was characterized by dogmatism and fanaticism. It lacked all that science represented: progress, respect for humanity, and freedom. For Renan, it was these attributes of science that characterized Jesus; thus 'science' became a term for the religion of Europe. But Islam was also associated with race. It was when Islam came under the dominion of the Arab, Berber, and Tartar races, which were coarse, brutal, and without intellect, that it became filled with dogmatism and fanaticism. Moreover, it was this dogmatism that dominated the Muslim state, in which there was no separation between the spiritual (religion) and the temporal (civic life). The result was a reign with coercion and corporal punishment, a system with acts of torture only surpassed, according to Renan, by the Spanish Inquisition.

With regard to religion, race, and state, Islam and 'the Muslim' represented 'the Other' to 'the Self' of Renan, France, and other European civilizations. The Muslim was the essentialist opposite. If there were periods of apparent similarity between the Muslim world and Europe, for example, periods in which there was evidence of Muslim science and philosophy, these were ascribed to European ownership and stripped of their Muslim character.

Renan's discussion of the contrast between Jesus and the Jews, especially the Scribes and the Pharisees, follows along similar lines. The religion of the Jews is also characterized as dogmatic, and in the Jerusalem temple, religion and state were intertwined. The most difficult aspect to disentangle was the issue of race, or blood, ${ }^{29}$

26 Renan, Life of Jesus, 83.

27 See note 9.

28 Renan, Life of Jesus, 174.

29 On the difficulty of establishing a fixed meaning for 'race' in Renan's works, see Moxnes, Jesus and the Rise of Nationalism, 137-45; Priest, The Gospel According to Renan, 85-9. 
which is the term Renan uses when he describes Jesus as the one 'who has contributed most to efface the distinction of blood in humanity'. The primary example of this contribution is seen in Jesus' conflict with the Jewish leaders over the boundaries of the Jewish religion; Renan sees Jesus as having founded 'the religion of humanity, established not upon blood, but upon the heart. ${ }^{30}$ Thus, Renan linked Jewish religion and race in contrast to Jesus, who founded 'the religion of humanity', which did not have any place for race.

For Renan, Islam, Muslim, and Arab were essentialist categories, with character traits that could not change. Due to the combination of religion and race these people were inferior to Europeans in terms of intellect, philosophy, and science. This was part of the way scholars of various fields in the nineteenth century saw the world divided into different civilizations, of which the superior one was Europe. The result was the creation of the homo islamicus, different from and inferior to 'the Western Man. ${ }^{31}$ The image of Jews followed the same lines, with Pharisees and Scribes as typical examples of the fanaticism and racial thinking that characterized them and their religion. Thus, Renan contributed to the way Muslims and Jews were depicted as stereotypes and essentialized because of their race, religion, and political systems. Although there were protests and criticisms already at Renan's time, ${ }^{32}$ these assumptions have remained influential down to the present day and reappear in new contexts.

\section{Anders Behring Breivik}

\subsection{The terrorism of 22 July 2011 and contemporary Islamophobia}

A particularly chilling reappearance of stereotypes of Muslims literally exploded in Norway on 22 July 2011. Before the Norwegian terrorist Anders Behring Breivik went on to blow up the government headquarters and to massacre sixty-seven youths at a Labour Party summer camp, he posted a large tract on the internet - $2083-A$ European Declaration of Independence ${ }^{33}$ - and sent it to many ultra-conservative and fascist contacts in Europe. With this tract he wanted to start a civil war in Europe in order to stop the Islamicization of Europe, which would otherwise be completed by the year 2083. Moreover, he wanted to stop the Europeans who contribute to this Islamicization, whom he named 'cultural Marxists'. Among these was the governing Labour Party in Norway, hence the attack against the Centre of Government and the massacre of the future leaders of the party.

But we should not attribute the opinions in Breivik's tract to one individual only; it became obvious that his views, partly in a modified form, were shared by many

${ }^{30}$ Renan, Life of Jesus, 226.

31 Zachary Lockman, Contending Visions of the Middle East: The History and Politics of Orientalism (Cambridge: Cambridge University Press, 2004), 74, referring to a term used by Maxime Rodinson, Europe and the Mystique of Islam, trans. R. Veinus (Seattle: University of Washington Press, 1987), 60.

32 On Renan and his critics, see Lockman, Contending Visions, 78-83.

33 Available online: https://publicintelligence.net/anders-behring-breiviks-complete-manifesto-2083a-european-declaration-of-independence/ (accessed 9 February 2017). 
right-wing groups in Europe and Norway. Most of this long tract builds, often in a cut-and-paste fashion, on international Islamophobic writings and their adaptation by Norwegian bloggers, writers, and politicians. ${ }^{34}$ 'Islamophobia' is a recent and contested term $;^{35}$ it has been charged with being tendentious, a libel against legitimate fears. However, I think it is a useful term in that it exposes an essentialist way of defining all Muslims, as a basis for attitudes and actions directed against Muslims. It has been defined as 'socially reproduced prejudices and aversion against Islam and Muslims, and actions and practices which attack, exclude and discriminate against people on account of these people either being, or being presumed to be Muslim, and to be associated with Islam. ${ }^{36}$ This definition is similar to that of anti-Semitism, ${ }^{37}$ a term that, despite its name, refers to anti-Jewish attitudes only. ${ }^{38}$ 'Anti-Semitism' is also a contested term, since it is both an accusation and an analytical category. The sociologist Helen Fein has given this definition: 'A persistent latent structure of hostile beliefs towards Jews as a collective, manifested in individuals as attitudes and in cultures as myths, ideology, folklore and imagery, and in actions - social or legal discrimination, political mobilization against the Jews, and collective or state violence - which results in and/or is designated to distance, displace or destroy Jews as Jews. ${ }^{39}$

Thus, with Islamophobia we appear to be in a setting similar to that of Renan: Islam and Muslims as 'the Other' to the modern, European, Christian 'We', where the 'Other' is stereotyped into an essentialist figure. Anti-Semitism is not so directly visible in Islamophobic discourses. However, in a central element of Islamophobia, the hypothesis of the Eurabia conspiracy, there is a striking structural similarity with the influential hypothesis of a Jewish conspiracy to take over the world in the anti-Semitic forgery The Protocols of the Elders of Zion. ${ }^{40}$

${ }^{34}$ I draw most of the material of this discussion, in addition to Breivik's tract, from a study by the Norwegian anthropologist Sindre Bangstad, Anders Breivik and the Rise of Islamophobia (London: Zed Books, 2014).

35 It appears to have been used first in 1910; then by Edward Said in 1985. But it became a commonly used term through the report by the British Runnymede Trust in 1997, Islamophobia: A Challenge for Us All; Bangstad, Breivik, 19.

36 Bangstad, Breivik, 19, quoting M. Gardell, Islamofobia (Oslo: Spartacus, 2011), 17 (emphasis added); see also the discussion in Sindre Bangstad, 'Eurabia Comes to Norway', Islam and Christian-Muslim Relations 24 (2013): 369-91, at 369-70.

37 Edward Said argued that Islamophobia, understood as 'hostility towards Islam in the modern Christian West', had historically been 'nourished by the same sources as Anti-Semitism'; idem, 'Orientalism Reconsidered', in Orientalism: A Reader, ed. A. M. Lyon (New York: New York University Press, 1985), 345-61; quoted by Bangstad, Breivik, 19.

38 According to Priest (The Gospel According to Renan, 44-6), the term 'anti-Semitism' was first used by Moritz Steinschneider (1860) in a criticism of Renan's prejudices against Semites as a race and as inferior to the Aryan race. It was later used exclusively about attitudes towards Jews.

39 Helen Fein, 'Dimensions of Antisemitism: Attitudes, Collective Accusations and Actions', in The Persisting Question: Sociological Perspectives and Social Contexts of Modern Antisemitism. Current Research in Antisemitism, Vol. 1, ed. Helen Fein (Berlin and New York: de Gruyter, 1987), 67; quoted in a report by the Center for Studies of the Holocaust and Religious Minorities (CSHRM), Antisemitism in Norway? The Attitudes of the Norwegian Population towards Jews and Other Minorities (Oslo, 2012), 10 (emphasis original). Available online: http://www.hlsenteret.no/ publikasjoner/antisemitism-in-norway-web.pdf (accessed 2 May 2017).

40 First published in Russia in 1903 and widely circulated. For instance, in the 1920s, Henry Ford financed the printing of 500,000 copies to be distributed in the United States. 
For Renan, the suppression of science in Islam was due to an absolute rule of dogmatism that did not separate the spiritual and the temporal. The result was a reign with coercion, corporal punishment, and torture, with no respect for freedom. Thus, it was the opposite of European civilization. Renan was secure in his conviction of the superiority of European civilization over the Muslim Orient, a conviction that of course was also built on the military, economic, and political superiority of Europe over the Muslim Levant, with the Ottoman Empire as 'the sick man of Europe'.

In modern Islamophobia we find a similar evaluation of the inferiority of Islam, but the confidence in European civilization is gone. The conspiracy theory that is central to Islamophobia builds on a fear of the takeover of Europe by Islam. Europe is portrayed as a civilization under threat. Central to this fear is the growing number of Muslims in Europe. Even if it is a small percentage, much emphasis is put on demographics, with (badly founded) hypotheses that within this century (by 2083, according to Breivik) Muslims will make up the majority population in Europe. ${ }^{41}$

\subsection{The power of language: Redefining 'racism' and 'indigenous'}

This hypothesis does not seem plausible to many, so how can Breivik and other Islamophobists think that they can convince people? The answer reminds us of Renan, who with his philological definitions of 'Arab' and 'Muslim' sought to establish the right understanding of nations and races. Breivik also wishes to establish the right understanding of the nations and races in Norway and Europe through definitions of central terms like 'multiculturalism' and 'race'.

'Multiculturalism' is a term that it is notoriously difficult to define; it is a 'floating signifier'. Breivik never explains it, but combines it with 'cultural Marxist' to indicate something very bad, for instance when he says that multiculturalism is 'as evil and racist as Nazism and as brutal as Stalinism. ${ }^{42}$ It is obvious that for Breivik 'multiculturalism' has to do with the presence of Muslims in Europe. He holds that it is promoted by European governments that 'are still committing genocide against the indigenous peoples of Europe by exposing them to more than twenty-five million Muslims. ${ }^{43}$ The terminology here is chilling. With this definition of 'multiculturalism' as 'committing genocide against the indigenous peoples of Europe' Breivik aims to justify not only his destruction of the Centre of the Norwegian Government, but also the massacre of teenagers who might become future political leaders.

The term 'indigenous' is increasingly used by Islamophobes and far-right political parties in Europe to speak not of minorities but of the majority, white, and (mostly) Christian population as victims and those who experience grievances. ${ }^{44}$ By portraying 'the indigenous peoples of Europe' as those who suffer genocide, Breivik also wishes to turn around the meaning of 'race' and 'racism'. He gives the following advice:

41 See Bangstad, Breivik, ch. 3: 'The fear of small numbers', 71-106.

42 Bangstad, Breivik, 92.

43 Breivik, 2083, 3:23; quoted in Bangstad, Breivik, 89.

${ }_{44}$ Francois Soyer, 'Faith, Culture and Fear: Comparing Islamophobia in Early Modern Spain and Twenty-first-century Europe', Ethnic and Racial Studies 36, no. 3 (2013): 399-416, at 412. 
Don't let the multiculturalist define what racism is or isn't. ... Loving your extended family/your ethnic group and fighting for ethnic and/or indigenous rights does not make you a racist, quite the opposite in fact. It makes you a civil rights activist. ... Anyone who calls you a racist ... is therefore an anti-European racist supporting the anti-European hate ideology known as multiculturalism. ${ }^{45}$

Here the language of racism is turned upside down: It is no longer non-white minorities living under structural discrimination, poverty, and violence that suffer racism, it is the white majority population. And Breivik employs the well-known terminology of ethno-nationalism, family and ethnic group, which in recent years has been used to deadly ends in political conflicts in Europe, Africa, and Asia.

\subsection{The dream of a fixed racial and national identity}

Breivik outlines a Norwegian ethnicity that is threatened by a multiculturalism that allows Muslims to infiltrate the Norwegian population. He speaks of it as 'the multicultural glorification of race mixing and interracial relations'. If this is allowed to continue for four to five generations, 'the Germanic/Nordic race in several countries will be diluted or annihilated to such an extent that there will be no one left with Nordic physical characteristics: blond hair, blue eyes, high forehead, sturdy cheekbones' ${ }^{46}$

This description of 'the Germanic/Nordic race' could have been taken directly from the Nazi ideology of the Second World War. It is Breivik's dream of a Norway of a bygone era, in the 1950s when 'we were more or less a pure Nordic country', before the start of the immigration of 'non-Nordics. ${ }^{47}$ It is the idea of a fixed national identity, which does not include hybridity and fluidity; this is the dream of Breivik that he wants to restore. In the process, he attributes to Muslim and Islam just the fixity and homogeneity that Norway has lost.

\subsection{A monolithic Islam}

Breivik starts his manifesto by saying that 'Islam is less a personal faith than a political ideology that exists in a fundamental and permanent state of war with non-islamic civilizations, cultures and individuals. ${ }^{48}$ This way to define Islam primarily as a political ideology has become common among right-wing political parties in Europe, comparing it to other ideologies like communism and Nazism. ${ }^{49}$ That of course serves to underline the threat that Islam poses to Europe. Breivik says that Islam has been in a 'civilizational war' with Christendom and Europe for more than 1,400 years. It is a civilizational war that Europe is in the process of losing. This is where the idea of Eurabia enters: The political governments, as well as the cultural and social elites of Europe, have accepted the influence of Islam, which will result in a Europe dominated and governed by Islam,

45 Breivik, 2083, 3:799; quoted in Bangstad, Breivik, 90-1.

46 Breivik, 2083, 3:84; quoted in Bangstad, Breivik, 93.

47 Breivik, 2083, 1:353; quoted in Bangstad, Breivik, 102.

48 Breivik, 2083, 1:5; quoted in Bangstad, Breivik, 233 note 24.

49 Bangstad, Breivik, 130. 
and therefore renamed Eurabia. This situation is termed 'dhimmitude', a fabricated word used by Islamophobes for those who accept this situation. ${ }^{50}$ It is this process that Breivik thinks will be completed by 2083 , as the title of his tract indicates.

But in addition to this willing attitude of the multiculturalists, Breivik sees Al-Qaeda as the force behind this war against Europe, and as the 'true Islam. ${ }^{51}$ Most people, whether Muslims or Christians, will absolutely disagree with this view; consider, for example, how American presidents (up until the current president Donald Trump) have distinguished between Muslim terrorists and the large majority of peaceful Muslims. However, Breivik will not accept this distinction; he argues that all Muslims have the same goal: the ultimate dominance and control over Europe by Muslims. Those who pretend that they are peaceful are just practising taqiyya, that is, 'dissimulation. ${ }^{52} \mathrm{His}$ view is that no Muslim can ever be trusted.

This is where Breivik's fantasy of fixed identities comes in. His fear of the loss of a fixed Norwegian identity corresponds to a fear - and admiration - of a static and unchangeable Muslim identity. In Bangstad's words, the 'figure of the Muslim ... is overdetermined by the person's allegiance to Islam and unaffected by local contexts and particularities. ${ }^{53}$ This figure represents the homo islamicus, an unchangeable stereotype in the manner of Shakespeare's Shylock the Jew.

\section{Norwegian anti-Muslim positions}

Breivik was a 'lone rider'; he had no accomplices in his terrorist attacks. But his views of Muslims are shared by a number of extremist bloggers, and more and more, although in milder versions, by politicians, intellectuals, and many of the general population. These views have increasingly been spread by social media as well as by mass media. Thus, instead of an absolute contrast between Breivik's extreme positions and the opinion of most Norwegians, it may be more accurate to speak of a continuum of negative attitudes..$^{54}$

The Letter to America: Europe in Danger by a former Conservative Parliamentarian, Hallgrim Berg, is an example of the position of mostly rightist politicians. ${ }^{55}$ Berg addressed the letter to America because he found that the United States represented 'freedom and enlightenment'. These values were now under threat in Europe because of its tolerance for the intolerant Muslims, 'who want to destroy democracy and replace it with sharia laws. ${ }^{56}$ This intolerance is of course seen as a result of the influence of religion; Berg holds that 'the more loyal to the Qur'an a Muslim happens to be, the more concerned he is with mixing religion and politics. ${ }^{\text {' }}{ }^{5}$ Berg also shares Breivik's

50 Bangstad, Breivik, 73-4, 148-50.

51 Bangstad, Breivik, 98-9; Breivik, 2083, 3:155.

52 Bangstad, Breivik, 130-1; Breivik, 2083, 1:5.

53 Bangstad, Breivik, 100.

54 Bangstad, Breivik, 107-43.

55 Hallgrim Berg, Amerikabrevet: Europa i fare (Oslo: Koloritt, 2007); Bangstad, 'Eurabia Comes to Norway', 374-5.

56 Berg, Amerikabrevet, 9; quoted in Bangstad, 'Eurabia', 374.

57 Berg, Amerikabrevet, 57; quoted in Bangstad, 'Eurabia', 375. 
criticism of multiculturalism and the refusal to be accused of xenophobia, rejecting what he sees as the current situation in which 'anyone wanting to preserve democracy at the level of the nation state is to be portrayed as suffering from xenophobia. ${ }^{58}$

There are many examples of similar statements in social and public media. Taking into account that the only racially motivated terrorist attack in Norway was carried out by a white, rightist Norwegian, it is surprising and disappointing that the public discussion after 2011 has not been concerned with the potential danger of these views to the social fabric of Norwegian society. The debate has increasingly concerned the right to express Islamophobic views, invoking the right of free speech, which is highly valued in Norway. ${ }^{59}$

\section{Anti-Semitism and attitudes to other minorities in Norway}

It is difficult to know how representative such views, which are very vocal in the public debate and on social media, are for Norwegians at large. A comparison of attitudes to Jews and to Muslims in the Norwegian population may be instructive. In 2012 the Center for Studies of the Holocaust and Religious Minorities undertook a survey of anti-Semitism in Norway. ${ }^{60}$ We must take into consideration that the Jewish population in Norway is very small, less than 2000 of a population of five million. It is officially recognized as one of several national minorities. During the Second World War one-third of the Jewish population in Norway, around 800 people, were deported to concentration camps, with few survivors.

A full-scale study of attitude to Jews had not been undertaken before, so no comparison with results over time was possible, only a comparison with other European countries. Norway came out at the lower end, together with the UK, the Netherlands and other Scandinavian countries, with 12.5 per cent considered as significantly prejudiced against Jews. The survey wanted to see anti-Semitism in context; therefore it also measured attitudes to immigrants and foreigners, and people belonging to other religions, especially Muslims. ${ }^{61}$

The respondents were not asked about their own positions, but what they thought the attitudes of the Norwegian population were in relation to the various questions. With regard to the comparison between attitudes to Jews and to other minorities, the report stated that 'the social distance to most other groups is greater than to Jews. The Norwegian population is most negative towards contacts with Muslims, Somalis and Romani (gypsies). However, those with the strongest anti-Semitic attitudes also most strongly reject other groups' (esp. Muslims, Somalis, and Romani). 'Seventy-six per cent of those who distance themselves socially from Jews display similar attitudes towards Muslims. ${ }^{62}$

58 Berg, Amerikabrevet, 14; quoted in Bangstad, 'Eurabia', 374.

59 Bangstad, Breivik, 175-219.

${ }^{60}$ CSHRM, Antisemitism (see note 39).

${ }^{61}$ Other relevant contexts were attitudes to the Holocaust and the Middle East, that is, IsraeliPalestinian conflict.

62 CSHRM, Antisemitism, 10. 
Behind these differences in attitudes towards Jews and Muslims, there seem to be differences as to which factors were ascribed most importance. ${ }^{63}$ Twenty-one per cent responded that they believed there were negative attitudes to Jews in the Norwegian population. Among the reasons given, there was little emphasis upon religion, but much upon the role of Israel in the Middle East conflict. There was also little emphasis on personal contacts with Jews, most likely because of the small number of Jews living in Norway.

In contrast, as many as 87 per cent of the respondents believed that there were widespread negative attitudes towards Muslims. Here there were more responses that reflected social contact with or knowledge of Muslims: some mentioned crime, negative behaviour, and unwillingness to become integrated. However, other reasons were also given, for instance that Muslims were foreign, that they were religious fundamentalists, and that this fundamentalism was linked to terrorism and suppression of women. Several of these reasons must be called stereotypical, attributing to Muslims an essentialist character. When confronted with a list of traditional stereotypes of Jews, ${ }^{64}$ few identified with them. A major finding of the survey was that most Norwegians consider Jews to be less 'foreign' than Muslims.

\section{5 'Religionization' or politicization of identities}

Here it is in order to comment upon the names of the groups that have been compared, especially the use of 'Muslim' and 'Somali' as two separate categories. Somali is used of people from the state of Somalia, but they are also overwhelmingly Muslims in terms of religion. Thus, they might also be included in the group 'Muslims', which is made up of people from various ethnic and national groups (e.g. from Turkey, Iran, Pakistan, Morocco, Syria, Iraq, Afghanistan). That all these different groups are lumped together as 'Muslims' is in itself an essentializing element, and it is an indication of the 'religionization' of various ethnic and national groups that has happened in Europe over the last few years. Or, is it an opposite process, so that religion has become part of a political identity?

During the last few decades there has been a significant change in terminology used of immigrants and refugees from countries with a dominant Muslim population. From the 1970s with the first large wave of immigrants (in Germany called 'guest workers') to Europe, they were identified with the names of their country of origin. In Norway they were mostly Turks, then Pakistanis, Moroccans, together with refugees from Vietnam and Chile. Religion was viewed as only one part of their identities as foreigners, immigrants, or ethnic minorities. But from the 1990s, and especially after 9/11 2001, religion, that is, Islam, started to take on more significance as an identity marker. ${ }^{65}$

63 CSHRM, Antisemitism, 34-7.

64 For example, that Jews 'consider themselves to be better than others'; 'have too much influence on the global economy'; 'have enriched themselves at the expense of others'; 'largely have themselves to blame for being persecuted'; CSHRM, Antisemitism, 20-1.

65 Although some are (also) still named after their country of origin, especially Somalis, who are the group with least education, and who have had most difficulty finding work and accessing education. 
Thus, 'Muslim' has become a common denominator for the identity of diverse groups and has been effectively used in negative stereotyping. The case of Anders Breivik and the ongoing discussion of many of the issues he raises - in the media, in scholarship and in public debate in Norway, and all over Europe - serve to construct and reify the existence of 'Muslim' populations in Europe.

This development seems to have had a parallel in many other countries. According to a study from the UK by Fiona B. Adamson, ${ }^{66}$ 'Muslim' has become a politicized identity category in the UK. Adamson finds insufficient the explanation that the growth of Islam as a category of identification is a reaction to lack of opportunities of political participation. Instead she invokes the geopolitical context and attributes to 'Muslim political entrepreneurs' in Western Europe a strategic use of the category of 'Muslim' to create a broader political constituency. This is relevant internally, with large umbrella organizations, Muslim Councils, and so on, that can act as interest groups vis-à-vis national governments. However, Adamson also points to the international scene, in which organizing people as Muslims serves to strengthen their identification with and political engagement for other Muslim populations around the world. Her suggestion, made in 2011, that this engagement is especially directed towards those who are in conflict with Western states or their allies, for example, in Palestine, Afghanistan, Iraq, Syria, has been confirmed by later developments.

Thus, there seem to be similar dominant mentalities and ideologies both on the Muslim side and on the side of the non-Muslim, post-Christian majority population in European countries. Radical groups and their supporters on both sides have common interests to reify and essentialize identities. These radical terrorists and entrepreneurs also work to problematize the interchanges, mixtures, and hybridization of identities that are going on all over Europe, and that are necessary for integration and social cohesion in European societies.

\section{Postscript: Reconfiguring the history of Jesus in the moral image of Jesus today}

Finally, I return to the task of writing a history of Jesus that Renan undertook 150 years ago. As noted above, Karla Malette commented that writing history represents 'the reconfiguration of the past in the image of the present. ${ }^{67}$ In the case of Renan, he portrayed Jesus and his opponents, the Jewish leaders, within the antagonistic context of his own world, with the powers of the West standing over against the Orient. When we observe that this pattern is repeated in our world also, with Islamophobia as a pressing reality, we realize that history as 'the reconfiguration of the past in the image of the present' is not an objective matter. It brings us up against a moral challenge: There are many images of the present. Anders Behring Breivik and people who share his worldview have a completely different image of the present world than mine. I find his - and their - 'image of the present' a dangerous image that destroys communality

${ }^{66}$ Fiona B. Adamson, 'Engaging or Contesting the Liberal State? "Muslim" as a Politicised Identity Category in Europe', Journal of Ethnic and Migration Studies 37 (2011): 899-915.

${ }^{67}$ Malette, 'Orientalism', 248 (cf. note 9). 
and respect for human lives in their complexities. Therefore, it is necessary to make an absolute break with that kind of image, and therefore to break with a configuration of the past that supports the idea of a closed and 'pure' community (e.g. Norway in the 1950s).

In the history of the study of the historical Jesus we have an example of such a break with an 'image of the present' that could no longer be supported, with the result that the history of Jesus had to be reconfigured. The aftermath of the Second World War had such an effect. Strangely enough, it was not the war itself but the later awareness of the Holocaust, created by conscious efforts of Jewish groups, that forced the churches to make a break with anti-Semitism, to rewrite anti-Jewish liturgical texts and to establish dialogues between Christian and Jewish groups. That led to a reconsideration of the way the Gospels had been read as stories of conflict between Jesus and his Jewish opponents. The ultimate result of this conflict was found in the death sentence over Jesus by the Sanhedrin. A rereading led to the recognition that the passion stories were polemical constructions directed against the Jewish leadership at the time of writing, thereby hiding the responsibility of the Romans, who historically must have been responsible for the arrest and execution of Jesus. This was an extraordinary reconfiguration of the past of Jesus' history in light of a new understanding of the present. It has now become the historical truth about the death of Jesus, although with little recognition of the processes that have led to this rewriting.

There is a need for further new challenges to established images of Jesus in the present that can lead to fresh reconfigurations of the past. The present image of Jesus is without doubt the Jewish Jesus. This has become the dominant picture to such an extent that aspects that might seem to cast doubt on it, for example, that the itinerant Cynics may have inspired the Gospels in their picture of Jesus, are almost regarded as scholarly heresy. But what are the ideological presuppositions underlying this presently dominant picture of Jesus the Jew? There may be an idea of Jewishness as a fixed category, in line with modern orthodox understanding of Judaism. This translates into an image of Jesus as ethnically and culturally 'pure', so that there can be no other elements in the idea of Jewishness. ${ }^{68}$ This notion corresponds to the idea of a 'pure' nation, of a national identity that is fixed and permanent and that represents 'us' in contrast to the 'others'. This is the bottom line of Islamophobia and of political opposition to immigration of persons who are 'culturally different' from 'us'.

If we chose a different image of the present, not of purity, but of 'cultural complexity', 69 we might look at the gospel narratives with a different set of questions. Cultural complexity confronts us with the situation of a world and societies that are composed of people from many different cultures and backgrounds. With the Jewish Jesus as the ruling paradigm, focus has been on identity as religion, and on Jesus practising Jewish religion. But that makes religion, a nineteenth-century concept, the model for reading a first-century text from a very different world. If we instead take for granted that the

68 See William E. Arnal, The Symbolic Jesus: Historical Scholarship, Judaism and the Construction of Contemporary Identity (London: Equinox, 2005).

69 Thomas Hylland Eriksen, 'What is Cultural Complexity?', in Jesus Beyond Nationalism: Constructing the Historical Jesus in a Period of Cultural Complexity, ed. Halvor Moxnes, Ward Blanton, and James Crossley (London: Equinox, 2009), 9-23. 
Gospels place Jesus within the geographical area of Judea and Galilee with their border areas, and with Jewish cult as a given fact, we can observe the diversity of people whom Jesus encounters. There are fishermen and peasants, slaves and householders, there are women who are mothers, sisters, but also 'sinners'. They come from a variety of backgrounds: Samaritan, Syro-Phoenician, and non-Jewish Gerasenes who keep pigs. In addition, there are Roman or Herodian officers. There are leaders among the people, Scribes and Pharisees, but also outsiders like tax collectors. There are people in many different marginal positions: possessed, sick, paralysed. These are groups of people that cannot be described in a simplistic way with any one category; we need categories that allow for the complexities and hybridities of societies.

If we start from the cultural complexity that we experience in the present, we will realize that the past can be reconfigured as a parallel complexity. This opens up for us an inclusive image of Jesus that represents a very different ideal, making it possible to break with stereotypes.

\section{References}

Adamson, Fiona B. 'Engaging or Contesting the Liberal State? "Muslim" as a Politicised Identity Category in Europe.' Journal of Ethnic and Migration Studies 37 (2011): 899-915.

Al-Afghani, Jamal al-Din. 'Answer of Jamal al-Din to Renan'. Journal des Débats, Paris, 18 May 1883. In Nikki R. Keddi, Imperialism, Science and Religion: Two Essays by Jamal al-Din al-Afghani, 1883 and 1884 (Modern Middle East Sourcebook Project, 2004), 2-6. Available Online: https://disciplinas.stoa.usp.br/pluginfile.php/2004379/ mod_resource/content/1/KEDDIE,\%20Nikki.pdf (accessed 10 February 2017).

Arnal, William E. The Symbolic Jesus: Historical Scholarship, Judaism and the Construction of Contemporary Identity. London: Equinox, 2005.

Bangstad, Sindre. 'Eurabia Comes to Norway'. Islam and Christian-Muslim Relations 24 (2013): 369-91.

Bangstad, Sindre. Anders Breivik and the Rise of Islamophobia. London: Zed Books, 2014.

Berg, Hallgrim. Amerikabrevet: Europa i fare. Oslo: Koloritt, 2007.

Breivik, Anders Behring. 2083 - A European Declaration of Independence. Available online: https://publicintelligence.net/anders-behring-breiviks-complete-manifesto2083-a-european-declaration-of-independence/ (accessed 9 February 2017).

Center for Studies of the Holocaust and Religious Minorities. Antisemitism in Norway? The Attitudes of the Norwegian Population towards Jews and other Minorities. Oslo, 2012. Available online: http://www.hlsenteret.no/publikasjoner/antisemitism-innorway-web.pdf (accessed 2 May 2017).

Eriksen, Thomas Hylland. 'What is Cultural Complexity?' In Jesus Beyond Nationalism: Constructing the Historical Jesus in a Period of Cultural Complexity, edited by Halvor Moxnes, Ward Blanton, and James Crossley, 9-23. London: Equinox, 2009.

Fein, Helen. 'Dimensions of Antisemitism: Attitudes, Collective Accusations and Actions'. In The Persisting Question: Sociological Perspectives and Social Contexts of Modern Antisemitism. Current Research in Antisemitism, Volume 1, edited by Helen Fein, 67-85. Berlin and New York: De Gruyter, 1987. 
Gullestad, Marianne. Plausible Prejudice: Everyday Experiences and Social Images of Nation, Culture and Race. Oslo: Universitetsforlaget, 2006.

Heschel, Susannah. The Aryan Jesus: Christian Theologians and the Bible in Nazi Germany. Princeton, NJ: Princeton University Press, 2008.

Kelley, Shawn. Racializing Jesus. Race, Ideology and the Formation of Modern Biblical Scholarship. London and New York: Routledge, 2002.

Lockman, Zachary. Contending Visions of the Middle East: The History and Politics of Orientalism. Cambridge: Cambridge University Press, 2004.

Lyon, A. M., ed. Orientalism: A Reader. New York: New York University Press, 1985.

Malette, Karla. 'Orientalism and the Nineteenth Century Nationalist: Michele Amari, Ernest Renan, and 1848'. The Romanic Review 96 (2005): 233-52.

Moxnes, Halvor. Jesus and the Rise of Nationalism: A New Quest for the Nineteenth Century Historical Jesus. London: I. B. Tauris, 2012.

Priest, Robert D. The Gospel According to Renan: Reading, Writing and Religion in Nineteenth-Century France. Oxford: Oxford University Press, 2015.

Renan, Ernest. De la part des peuples sémitiques dans l'historie de la civilisation. Paris: Lévy, 1862.

Renan, Ernest. Vie de Jésus. Paris: Michel Lévy, 1863; English translation, The Life of Jesus. New York: Modern Library, 1927.

Renan, Ernest. Islam and science. A Lecture presented at La Sorbonne 29 March 1883, translated by Sally P. Ragep. 2nd edn. McGill University, 2011. Available online: https:// www.mcgill.ca/islamicstudies/files/islamicstudies/renan_islamism_cversion.pdf (accessed 2 May 2017).

Ringer, Monica M. and A. Holly Shissler. 'The Al-Afghani-Renan Debate, Reconsidered'. Iran Nameh 30, no. 3 (2012): xxviii-xlv.

Rodinson, Maxime. Europe and the Mystique of Islam, translated by R. Veinus. Seattle: University of Washington Press, 1987.

The Runnymede Trust. Islamophobia: A Challenge for Us All. London: Runnymede Trust, 1997.

Said, Edward W. Orientalism. New York: Random House, 1978.

Soyer, Francois. 'Faith, Culture and Fear: Comparing Islamophobia in Early Modern Spain and Twenty-first-century Europe'. Ethnic and Racial Studies 36, no. 3 (2013): 399-416.

Todorov, Tzvetas. On Human Diversity: Nationalism, Racism, and Exoticism in French Thought. Cambridge, MA: Harvard University Press, 1993. 


\title{
Other Problems from a British Perspective: 'Jewishness', Jesus, and the New Perspective on Paul
}

\author{
James G. Crossley
}

In terms of discourses concerning 'race' in the history of New Testament studies, the relationship between (on the one hand) Jesus, Paul, and the early church and (on the other) an assumed 'Jewish background' has been dominant. Over the past forty years, this relationship has been understood against the background of a Judaism often constructed in ways inspired by debates about the New Perspective on Paul. The story of the New Perspective on Paul, and its accompanying constructions of Judaism, is familiar enough to New Testament scholars. E. P. Sanders' Paul and Palestinian Judaism challenged the dominant construction of Judaism in Lutheran-influenced analyses of Paul in which Judaism was negatively stereotyped as legalistic in contrast to the loving religion of grace advocated by Paul. Sanders famously coined the term 'covenantal nomism' to describe 'common Judaism', which was understood to be the combination of ideas of gracious election and the maintenance of the covenantal relationship through observance of the commandments (ideas Sanders distinguished with the two key notions of 'getting in' and 'staying in'). ${ }^{1}$ Whatever diversity of scholarship comes under the umbrella of the New Perspective on Paul, the idea of 'covenantal nomism' has become its most unifying feature. Given that the concern was to locate Paul against or (largely) within a more positive appraisal of the 'Jewish background', it is unsurprising that the influence of Sanders' reading of Judaism spread beyond Pauline studies. Indeed, Sanders also contributed significantly to the now dominant scholarly view of placing Jesus within, or largely within, a more positively constructed Jewish context. ${ }^{2}$

Two of the most prominent figures in both the New Perspective on Paul and the study of the 'Jewish Jesus' have been the British scholars N. T. Wright and James Dunn. Indeed, the term 'New Perspective on Paul' itself was heralded by James Dunn in 1983, ${ }^{3}$

1 See E. P. Sanders, Paul and Palestinian Judaism: A Comparison of Patterns of Religion (London: SCM, 1977), for example, 17.

2 E. P. Sanders, Jesus and Judaism (London: SCM, 1985).

3 James D. G. Dunn, 'The New Perspective on Paul', Bulletin of the John Rylands Library 65 (1983): 95-122. 
though Wright already in 1978 showed the influence of Sanders' groundbreaking work and used the phrase 'new perspective. ${ }^{4}$ Both have since produced landmark works on Jesus and Paul that have dominated the respective subfields. ${ }^{5}$ And throughout their numerous works on Jesus and Paul they have been as influential as anyone in developing what has become a common academic discourse. As Michael Bird has pointed out, such language includes 'nationalism,' 'boundary markers,' 'story, symbol and praxis', 'a web of social and religious commitments,' 'ethnicity', and so on. ${ }^{6}$ In analysing such concepts, we might follow those who see discourses about 'religious' and 'social' boundary markers as 'post-racial' in the sense that older, less palatable ideas of constructing 'race' (and especially involving physical racial features) are now rethought in more acceptable terms in mainstream political discourses. 'Racial' language, though occasionally still lingering, is now typically denied in the categorization process but the older patterns of collective identifications (e.g. ethnicity, dress, food, associates, beliefs, repeated behaviours, alleged national identifications) can still be used to single out, construct, and categorize minority groups. ${ }^{7}$ This more acceptable form of collective classification, while denying 'racist' intent and even having anti-racist intentions, is most clearly seen in governmental and popular treatments of Muslims in European and North American political discourses and the claims to be identifying the ideology associated with certain people, their behaviours, and even their dress codes, as part of the desire for their assimilation to the liberal nation state. ${ }^{8}$ As we will see, a related and benignly presented discourse is what we find in contemporary treatments of early Judaism where such language is not just about classifying Judaism but classifying an implicitly superior Jesus and Paul in relation to and in distinction from this assumed 'Judaism' collectively constructed as concerned with nationalistic and ethnic boundary markers (e.g. Sabbath, land, circumcision, Torah). As this language of religious-ethnic group differentiation and notions of (our) superiority would suggest, ideas about race, ethnicity, and nation are continually being rethought and constructed in this era of scholarship.

The rest of this essay will look at why such work came to prominence when it did, why there is such a heavy emphasis on Jewishness, and the significance of the relationship with ongoing post-racialized discourses in contemporary British politics and culture (and beyond). Mostly for reasons of space, I will focus particularly on the work of Wright. Yet Wright is also a particularly important figure because he effectively bookends the New Perspective era. Just as he was present at its inauguration so his recent scholarly work on Paul effectively marks its end or at least a major transition. ${ }^{9}$

4 N.T Wright, 'The Paul of History and the Apostle of Faith', TynBul 29 (1978): 61-88.

5 Among the most prominent are: N.T. Wright, Jesus and the Victory of God (London: SPCK, 1996); idem, Paul and the Faithfulness of God (2 vols; London: SPCK, 2013); James D.G. Dunn, The Theology of Paul the Apostle (Grand Rapids, MI: Eerdmans, 1998); idem, Jesus Remembered (Grand Rapids, MI, and Cambridge: Eerdmans, 2003).

6 Michael F. Bird, The Saving Righteousness of God: Studies on Paul, Justification and the New Perspective (Milton Keynes: Paternoster, 2006), 105.

7 See, for example, Alana Lentin and Gavan Titley, The Crises of Multiculturalism: Racism in a Neoliberal Age (London: Zed Books, 2011), 67-70.

8 See, for example, Liz Fekete, A Suitable Enemy: Racism, Migration and Islamophobia (London: Pluto Press, 2009); Arun Kundnani, The Muslims Are Coming! Islamophobia, Extremism, and the Domestic War on Terror (London: Verso, 2014).

9 Wright, Paul and the Faithfulness of God; idem, Paul and His Recent Interpreters, (London: SPCK, 2015). 
This is not to say that New Perspective questions have gone away but rather that a series of different ones have gained greater prominence (e.g. empire, apocalyptic, philosophy, gender), and Wright himself recognizes this in his engagement with some of them. ${ }^{10}$ As it happens, and whatever the reasons might be, Wright's career also maps on to some of the major ideological changes in Anglo-American politics and culture relating to different ways of understanding issues of post-racial identity that will frame this essay: the rise and crises of neoliberalism and postmodernity. Before turning to Wright's work in particular, we first turn to a broader outline of New Testament scholarship and its construction of 'Jewishness'.

\section{1 'Jewishness' according to New Testament scholarship}

The story of questions relating to ethnicity, race, and Jewishness in pre-1970s New Testament scholarship is increasingly well known. ${ }^{11}$ For instance, the nineteenthcentury Lives of Jesus also involved a concern for the 'great man' and his relationship to people, land, and nation, all as part of the developing European (and particularly Germanic) nationalisms. ${ }^{12}$ Questions of Jews and Judaism regularly functioned as a negative foil for Jesus, as they did in regard to the nation state. This would feed into the developing anti-Semitism which would culminate in Nazi fascism. By the end of the nineteenth century, Houston Stewart Chamberlain was advocating an Aryan Galilee (and thus an Aryan Jesus), a de-Judaizing of Jesus and Christian Origins which was developed further in Nazi New Testament scholarship, whether in Walter Grundmann's work on the Aryan Jesus or in the various contributions to the influential Theological Dictionary of the New Testament, edited by the Nazi propagandist, Gerhard Kittel. ${ }^{13}$ But the anti-Jewish rhetoric did not disappear with the Nazis. After the Second World War, the Lutheran-influenced construct of Judaism as a harsh, legalistic religion of works-righteousness persisted despite the prominence of anti-Nazi German scholars like Rudolf Bultmann, such was its embeddedness in the field. Indeed, even in the 1960s Ernst Käsemann could claim that Paul 'strikes at the hidden Jew in all of us, at the man who validates rights and demands over against God on the basis of God's past dealings with him and to this extent is serving not God but an illusion. ${ }^{14}$ In terms of the Historical Jesus, Form Criticism ensured, as Maurice Casey put it, 'that out from

10 Wright, Paul and His Recent Interpreters, for example, 135-338.

11 Cf. Shawn Kelley, Racializing Jesus: Race, Ideology and the Formation of Modern Biblical Scholarship (London and New York: Routledge, 2002).

12 See Halvor Moxnes, Jesus and the Rise of Nationalism: A New Quest for the Nineteenth Century Historical Jesus (London and New York: I. B. Taurus, 2011).

13 For details see, for example, Maurice Casey, 'Some Anti-Semitic Assumptions in The Theological Dictionary of the New Testament', NovT 41 (1999): 280-91; Peter Head, 'The Nazi Quest for an Aryan Jesus', JSHJ 2 (2004): 55-89; Susannah Heschel, The Aryan Jesus: Christian Theologians and the Bible in Nazi Germany (Princeton, NJ: Princeton University Press, 2008). (See also Kathy Ehrensperger's chapter - Eds.)

14 Ernst Käsemann, New Testament Questions of Today (London: SCM, 1969), 186; for discussion of this remark, which was also broadcast on radio, see, Daniel Boyarin, A Radical Jew: Paul and the Politics of Identity (Berkeley: University of California Press, 1994), 213-14. 
under the Synoptic Gospels there could never crawl a Jewish man.15 Indeed, if we take Form Criticism's focus on Sitz im Leben seriously, then one of the reasons (among many) for its failure (at least in the mid-twentieth century) to provide sustained social contextualization of forms was its avoiding Jewish social life. ${ }^{16}$

The 1970s saw a shift in the constructions of Judaism. In 1973, Géza Vermes' Jesus the Jew caught the Zeitgeist for the beginnings of changing scholarly perceptions. ${ }^{17}$ The work of Sanders in 1977 blew open the established constructions of Judaism in the field while simultaneously showing how anti-Jewish and anti-Semitic attitudes were deeply embedded in post-war New Testament scholarship. Nevertheless, Vermes' title and emphasis caught on in Historical Jesus studies, and today there are numerous books with titles emphasizing Jesus in (positive) relation to Judaism, such is the discourse embedded in the field. ${ }^{18}$ What some of the polemics over Jesus' Jewishness have revealed is that Historical Jesus scholarship repeats clear, blunt, and essentializing assumptions about what Jewish identity must be and what it must not be. Whether historically right or wrong, clearly it is impossible, according to a certain logic about Jesus' Jewishness, for Jesus to have been both a Cynic-like or Hellenistic philosopher and at the same time Jewish. But this post-racial categorizing tells us more about the scholarly constructions of Judaism than ancient historical realities. Typically, this construction of identity involves essentializing views about attitudes to purity, family, apocalypticism, ethnicity, circumcision, Torah, Temple, Sabbath, and/or gender as a marker of what is or is not to be deemed appropriate for Jesus, irrespective of whether a given ancient figure self-identifies in such a way or was identified in such a way. ${ }^{19}$

That it is correct to reconstruct a 'Jewish Jesus' has now become so obvious that it is simply part of scholarly common sense. Yet, as so often with common sense ideas, they do not always reflect how things have supposedly always been, even if it might seem that way. In fact, one of the more perplexing things in Historical Jesus and New Testament studies is just how long the Jewishness of Jesus took to be widely emphasized in European and North American scholarship. By this I do not mean the issue of Jesus' ethnicity as such - after the Nazi era virtually everyone has long accepted that Jesus was born Jewish - but the stress on, and debates over, Jesus' or Paul's teachings which must be classified as Jewish, in contrast to the rhetoric of hard dissimilarity from Judaism

15 Maurice Casey, 'Who's Afraid of Jesus Christ? Some Comments on Attempts to Write a Life of Jesus', in Writing History, Constructing Religion, ed. James Crossley and Christian Karner (Aldershot: Ashgate, 2005), 129-46, at 133.

${ }^{16}$ James G. Crossley, Why Christianity Happened: A Sociohistorical Account of Christian Origins 26-50CE (Louisville, KY: WJK, 2006), 3-22.

17 Géza Vermes, Jesus the Jew (London: SCM, 1973).

${ }_{18}$ For example, James H. Charlesworth, Jesus within Judaism: New Light from Exciting Archaeological Discoveries (London; SPCK, 1989); John Dominic Crossan, The Historical Jesus: The Life of a Mediterranean Jewish Peasant (Edinburgh: T\&T Clark, 1991); Géza Vermes, The Religion of Jesus the Jew (London: SCM Press, 1993); John P. Meier, A Marginal Jew: Rethinking the Historical Jesus (4 vols; New Haven, New York and London: Doubleday, 1991-2009); Seán Freyne, Jesus, a Jewish Galilean: A New Reading of the Jesus-Story (London and New York: T\&T Clark, 2004).

19 See William Arnal, The Symbolic Jesus: Historical Scholarship, Judaism and the Construction of Contemporary Identity (London and Oakville: Equinox, 2005); James G. Crossley, Jesus in an Age of Terror: Projects for a New American Century (London: Routledge, 2008); idem, 'A "Very Jewish" Jesus: Perpetuating the Myth of Superiority', JSHJ 11 (2013): 109-29. 
that dominated much of twentieth-century scholarship until such rhetoric began to break down in the 1970s.

So why did it take until the 1970 s to see such a significant rhetorical shift? It might have been thought that the Holocaust would have prompted a more immediate rethink of attitudes towards Jewishness and Judaism. The polemical use of the Jewishness of Jesus in debates against the Jesus Seminar and those who proposed Cynic-like Jesuses - both of which allegedly denied Jesus' Jewishness despite such claims never being made - puzzled William Arnal and in response he gave several plausible reasons for the emergence of the debate over Jewishness, particularly the scholarly insistence on a stable and relatively fixed first-century Jewish identity. ${ }^{20}$ Arnal argued that an emphasis on fixed Jewish identity is partly a reaction against fractured cultural identities associated with 'globalisation' and postmodernity over the past forty years. He further argued that the emergence of the emphasis on Jewishness at a time when no one now denies Jesus was Jewish has partly been a reaction against the dominance of pre-1970s German scholarship and the shifts in the geographical centre of scholarship towards the UK and North America.

In my own work, I have added further reasons for understanding this shift in Historical Jesus scholarship towards positive rhetoric about Jews and Judaism, in particular the change in attitudes towards the state of Israel since 1967. The decisive 'Six Day War' in 1967 brought about geopolitical changes in a part of the world most directly associated with Christian origins. There is little doubt that this war signalled a dramatic shift in American attitudes towards Israel, from a kind of indifference to high levels of staunch support for Israel over against the Palestinians, particularly in light of the contrast with perceived failures in Vietnam. ${ }^{21}$ This has become a major trend found across party politics, mass media, higher education, and culture more broadly, including in the UK. A crucial post-1967 development in terms of sympathizing with Jews, Judaism, and Israel has involved the memorializing of the Holocaust. As Peter Novick and Norman Finkelstein have shown in their own different ways, the Holocaust became increasingly significant in American culture after 1967. ${ }^{22}$ For Novick, this new or increased interest in the Holocaust also involved American Jewish perceptions of 'new anti-Semitism' and the increasing prominence of issues surrounding assimilation and identity politics, with the wars of 1967 and 1973 forging tighter bonds between America and Israel. ${ }^{23}$

But something else was going on amidst the philo-Semitism in New Testament scholarship. It remains that one of the dominant issues in contemporary scholarship involves lip service being paid to 'Jesus the Jew', at least in terms of Jewish identity as constructed in modern scholarship. And so, Jesus is frequently seen to be 'Jewish' or 'very Jewish' but noticeably different from his Jewish context. For all John Meier's emphasis on the Jewish Jesus, his Jesus does remain a marginal Jew. ${ }^{24}$ In crucial

20 Arnal, The Symbolic Jesus.

21 See Crossley, Jesus in an Age of Terror, 143-94.

22 Peter Novick, The Holocaust and Collective Memory (London: Bloomsbury, 1999); Norman Finkelstein, The Holocaust Industry: Reflections on the Exploitation of Jewish Suffering, 2nd edn (London and New York: Verso, 2003).

23 Novick, Holocaust and Collective Memory, 127-203.

24 See Maier, Marginal Jesus. 
ways, then, some things do not in fact change from pre-Vermes times, even if the rhetoric shifts from being 'radical' in terms of Law and grace to being socioreligiously 'radical', but still over against the rest of Judaism. ${ }^{25}$ This pattern of finding ways for Jesus to 'transcend' or intensify Judaism, or at least do something new and unparalleled within Judaism, remains a serious trend in contemporary Historical Jesus scholarship. Subtly or otherwise, this pattern is found from the more obscure Jesus scholarship through to the major works, whether the transcending moment is discovered on the issue of forgiveness of the wicked, or burying the dead, purity, food, oaths, attitude towards women, Sabbath, and so on. ${ }^{26}$ In terms of Pauline scholarship we might think, for instance, of how Dunn and Wright locate Paul 'within Judaism' but present Judaism as being different in terms of being too ethnocentric in its adherence to badges of national identity like circumcision or Sabbath. ${ }^{27}$

Some of this tension reflects the lengthy history of the perceived superiority of Christianity over Judaism that goes back centuries and has dominated the field of New Testament studies. But there are other cultural reasons which help explain why these expressions of superiority are found alongside the simultaneous philoSemitism. There are, to put it mildly, some tensions in the various contemporary relationships with Israel which are related to religious and cultural superiority. In many ways, the Christian Zionist relationship with Israel ought to be a strange one, even if it is obviously pragmatic from the perspective of some Israeli Jews and some Jewish Zionists. After all, Jews must convert and become one of 144,000 Jewish Billy Grahams, to use Hal Lindsey's memorable phrase, ${ }^{28}$ or, ultimately, burn with the rest of the non-Christians, liberals, communists, and homosexuals. An extreme example, certainly, but the pattern of an asymmetrical relationship runs deep. In American politics, it is difficult to see the dominant pro-Israel policy being done out of eternal love for Israelis. The pressure group, the Project for the New American Century, which contained important and staunch supporters of Israeli actions, was, after all, an attempt to establish American values, and this is part of a long political tradition in the aftermath of $1967 .{ }^{29}$ In British terms, we might, for instance, note Mark Curtis' observation that a 1970 Foreign Office report on future British policy did not opt for an entirely pro-Israeli policy but simply could not endorse a pro-Arab policy, not only because of public and political attitudes in the UK but also because of US pressure 'to keep us in line in any public pronouncements or negotiations on the dispute. ${ }^{30}$

25 See Amy-Jill Levine, The Misunderstood Jew: The Church and the Scandal of the Jewish Jesus (San Francisco: HarperCollins, 2006).

${ }^{26}$ For more discussion on this, see Crossley, 'A "Very Jewish" Jesus'.

27 For example, James D. G. Dunn, Romans 1-8 (WBC 38A; Waco, TX: Word, 1988), lxix-lxxii ("the law as a source of ethnic pride for the typical devout Jew ... circumcision as the focal point for this sense of privileged distinctiveness', lxxii); N.T. Wright, The Climax of the Covenant: Christ and Law in Pauline Theology (Edinburgh: T\&T Clark, 1991), 3: 'The boundary-marker is faith in Christ and not Jewish race, with its badges of circumcision, kosher laws, sabbath observance'.

28 Hal Lindsey, Late Great Planet Earth (Grand Rapids, MI: Zondervan, 1970), 111.

29 Crossley, Jesus in an Age of Terror, 143-94.

30 Mark Curtis, Unpeople: Britain's Secret Human Rights Abuses (Vintage: London, 2004), 155-7. 


\section{Neoliberalism, postmodernity, and race}

But we might also understand such rhetoric further in the context of neoliberalism or postmodern capitalism of the sort that has developed and dominated economic and cultural discourses since the end of the 1960s until the serious challenges to its hegemony after the 2008 financial crash. In this respect, we might point to the extensive work of David Theo Goldberg on race and racializing discourses perpetuated in the age of neoliberalism and how anti-racist rhetoric in political institutions, universities, and academic discourse - despite good intentions - still perpetuates unconscious and implicit racializing distinctions, of the sort described in the language of the 'post-racial' above. ${ }^{31}$ An example of this might be Dunn's obviously well-intentioned suggestion that one of the five points of the New Perspective on Paul is that justification, in stark contrast to the pre-New Perspective period, can now help combat 'nationalism and racialism. ${ }^{32}$ Yet the unmentioned implications of this for the scholarly construction of Judaism seem somewhat negative to say the least: Non-Pauline Judaism is all about nationalism and racialism. We might similarly point to Slavoj Žižek's argument that liberal Western multicultural inclusiveness is typically an acceptance of the Other without the Otherness. ${ }^{33}$ Put another way, part of the narrative of Western liberalism, and the liberal nation state, is to include the Other without the too unpalatable bits and to extract those bits which are palatable. Put yet another way, Vermes' Jesus might have provided, for the Christian or nonJewish academic at least, an experience of the Other with all the Otherness, a fully caffeinated Jesus $^{34}$; but in response to Vermes what has emerged is the dominant rhetoric of a 'very Jewish' Jesus where problematic parts of Judaism are transcended or dropped because of their incompatibility with Jesus. ${ }^{35}$

${ }^{31}$ David Theo Goldberg, The Threat of Race: Reflections on Racial Neoliberalism (Oxford: WileyBlackwell, 2009).

32 James D. G. Dunn, The New Perspective on Paul: Collected Essays (Tübingen: Mohr Siebeck, 2005), 15. Compare also Shawn Kelley's critique of the history of distinction-making in parable scholarship where he comments: 'There are times when racial thought shuns the vile rhetoric of the demagogue in favor of the dignified discourse of the poet and the intellectual .... This form of racial thinking appears in discourse that is decidedly gentle and in rhetoric that can tend towards the inspirational .... The aesthetic ideology is more than capable of prospering in the rarefied air of postmodern criticism'; Kelley, Racializing Jesus, 192, 208.

${ }^{33}$ See Slavoj Žižek, 'Multiculturalism, or, the Cultural Logic of Multinational Capitalism', New Left Review I/225 (1997): 28-51; Welcome to the Desert of the Real! Five Essays on September 11 and Related Dates (London and New York: Verso, 2002); The Puppet and the Dwarf: The Perverse Core of Christianity (Cambridge, MA: MIT Press, 2003); 'Liberal Multiculturalism Masks an Old Barbarism with a Human Face, Guardian, 3 October 2010; Living in the End Times, rev. edn (London and New York: Verso, 2011).

${ }^{34}$ I am alluding to, for example, Žižek, Puppet and the Dwarf, 96: 'On today's market, we find a series of products deprived of their malignant property: coffee without caffeine, cream without fat, beer without alcohol .... And the list goes on ... up to today's tolerant multiculturalism as an experience of the Other deprived of its Otherness ...? Virtual Reality simply generalizes this procedure of offering a product deprived of its substance: it provides reality itself deprived of its substance ... just as decaffeinated coffee smells and tastes like real coffee without being the real coffee, Virtual Reality is experienced as reality without being so.'

${ }^{35}$ See James G. Crossley, Jesus in an Age of Neoliberalism: Quests, Scholarship, Ideology (London: Routledge, 2012); idem, 'A "Very Jewish" Jesus'. 
A general feature of the New Perspective on Paul has involved dealing with difference from Judaism without bringing in the triumphalism and negativity associated with the Old Perspective on Paul. To do this, the New Perspective era instead brought us the language of Jewish boundary markers and Jewish nationalism, and how Paul rejects these categories when they impact upon the early church. Yet, as with Jesus the Jew, the superiority myth is perpetuated implicitly and with a liberalizing credible overlay, and the difficult and strange aspects are put to one side. A key aspect of this liberal, postracial turn, so to speak, is the 'secularization' of the scholarly language. To contextualize Bird's list of scholarly language and the New Perspective noted above, a new academic vocabulary, with terms such as 'nationalism', 'boundary markers', 'common Judaism, 'story, symbol and praxis', 'a web of social and religious commitments', 'ethnicity', and so on, has begun to replace the normative language of the Old Perspective era with its terms such as 'imputed righteousness', 'justification by faith', 'righteousness of God', salvation, and so on'. Much of this new critical language is, of course, integral to Wright's work ${ }^{36}$ but Wright also reveals awareness of the tensions between the so-called 'secular' historian and the theologian which need to be resolved:

For a start, Paul will reassure both sides that they are full partners in his work. As we shall see when we examine his worldview, the symbols, praxis and stories which contribute to it are none of them simply about 'ideas' and 'beliefs'. They are about the creator God, his world and his people - and this world and these people are creatures of space, time and matter, open by definition to historical enquiry, living life in public without shame, modelling a way of life which is precisely in and for the world, affirming the goodness of the creator's universe and of human beings within it. Yes, says Paul to the suspicious slave-master History: I am your partner! You and I belong together! ${ }^{37}$

With this in mind, Francis Watson was perhaps going too far in his claim that the New Perspective emphasizes 'presuppositionless exegesis' in the sense that proponents are freed from prior theological commitments, ${ }^{38}$ but it remains the case that there has obviously been a tendency to downplay, to some degree, an overtly Protestant (and typically Lutheran) background in the language of the New Perspective. Indeed, despite their own self-identifications and overt theological interests, both Wright and Dunn regularly attack the ways in which Protestant presuppositions, abstract theology, and church traditions distort historical and exegetical analysis. ${ }^{39}$ However, as Watson recognizes, one of the functions of this academic language is to give credibility or legitimacy to the New Perspective and partly discredit the 'too theological' Old Perspective. ${ }^{40}$

36 See, for example, Wright, Paul and the Faithfulness of God, 28, 31, 42.

37 Wright, Paul and the Faithfulness of God, 72; cf. 72-4.

38 Francis B. Watson, 'Not the New Perspective' (paper presented at the British New Testament Conference (BNTC), Manchester, 2001).

39 For example, Dunn, Romans 1-8, lxiv-lxvi (lxv: 'The point is that Protestant exegesis has for too long allowed a typically Lutheran emphasis on justification by faith to impose a hermeneutical grid on the text of Romans'); Wright, Climax, 258-62; idem, Victory of God, 13.

40 Watson, 'Not the New Perspective'. 
But in doing so, this move simultaneously perpetuates a theological agenda masked, mystified, or deflected by 'secular' academic language. A related point has been made about the 'secularization' of theological language which has become a hallmark of contemporary evangelical New Testament scholarship. As part of his extensive analysis of evangelical biblical scholarship, Stephen Young argues that self-representation as academics and the 'insider' language of the academic have become significant protective strategies. ${ }^{41}$ In this sense, we might note that the most obvious unifier of the New Perspective is the endorsement of Sanders' 'covenantal nomism' as a critical model which is emphatically not perpetuating a specifically Lutheran view of Judaism. Nevertheless, 'covenantal nomism' is simultaneously a model influenced by categories from Christian systematic theology which imposes onto Judaism the categories of grace and works - both of which were certainly present in early Judaism but neither of which seem to have been particularly systematized - as well as being a model that is deemed to make Judaism worthy of positive respect. Furthermore, as already suggested in a different way, does not the New Perspective simply perpetuate a post-racial myth of religious/theological superiority through such 'secularizing' language, at least in those readings of Paul which ditch the problematic Jewish practices? If we tie this back to earlier arguments, the construction of a kind of reasonable, critical, tolerant 'centrism' of the New Perspective, of the sort we might associate with Wright and Dunn, is part of the legitimation process of a neo-liberal or postmodern perpetuation of older categories of race, ethnicity, and nationalism but now in various 'post-racial' senses identified above and as we will see in more detail below.

\section{N. T. Wright's Jewish (but not that Jewish) Jesus and Paul}

This construction of superiority over against Judaism is typical of Wright's presentation of Jesus and Paul. Wright brings together a number of key trends in contemporary scholarship perhaps more than any other scholar. Both Jesus and Paul are presented by Wright as 'very Jewish', but the various ethnic and national symbols or badges of Judaism are presented as being transcended by both, even if Judaism is now positively constructed. As Wright puts it about his own reconstruction of Jesus, he has presented 'a very Jewish Jesus who was nevertheless opposed to some high-profile features of first-century Judaism. ${ }^{42}$ A good example of this perpetuation of discourses of negative difference under a benign guise is Wright's handling of the saying 'Let the dead bury their dead' (Mt. 8.21-22//Lk. 9.59-60) where he effectively follows Sanders' acceptance of Martin Hengel's view ${ }^{43}$ that this saying was shocking to Jews, even though no Jews appear shocked in the Gospel passages. The use of Hengel's work is, however, particularly curious. Hengel's interpretation - like much, if not most, of his work - is dominated by the distinctively Old Perspective 'Law versus Gospel' model, that is,

${ }^{41}$ Stephen L. Young, 'Protective Strategies and the Prestige of the "Academic": A Religious Studies and Practice Theory Redescription of Evangelical Inerrantist Scholarship', BibInt 23 (2015): 1-35.

42 Wright, Victory of God, 93.

43 Sanders, Jesus and Judaism, 252-4. 
the driving myth behind the scholarship Sanders shattered in the 1970s and 1980s. In his discussion of Mt. 8.21-22//Lk. 9.59-60, Hengel expresses the typical pre-Sanders and Protestant-sounding claims, such as that 'any casuistic legal codification was repugnant' to Jesus, that the 'decisive thing is a faith that is put into practice', and that 'Jesus' answer ... in a unique way expresses his sovereign freedom in respect of the Law of Moses'. ${ }^{44}$

Crucially, this language is not used in Wright's analysis of the passage though his conclusion is effectively the same as Hengel's, but this time in benign dress. Wright claims, with particular reference to Hengel and Sanders as key sources, that Jesus' declaration 'is, quite frankly, outrageous. Many scholars have pointed out that Jesus is here advocating behaviour that his contemporaries, both Jewish and non-Jewish, would have regarded as scandalous. ${ }^{35}$ However, according to Wright, there is the necessary qualification that Judaism is still understood positively because Jesus 'set a time-bomb' beside the symbol of ethnicity and that such a symbol had now 'become (not wicked, or shoddy, but) redundant.'6 Yet, despite rejecting Hengel's use of anachronistic Protestant language, is not Wright actually perpetuating the very thing against which he has so fiercely reacted? Wright even mocks the very view that Hengel attempted to spread, namely that of 'events which showed the clash between false religion (here represented by sixteenth-century legalists or formalists thinly disguised as Pharisees) and the true one offered by Jesus. ${ }^{47}$ As Wright informs us, 'it used to be thought that Jesus' clashes with the Pharisees ... consisted of his standing up against the "petty legalism" of the Pharisees ... . There is no historical verisimilitude in the picture of the Pharisees as petty, and perhaps Pelegian, legalists.'8 Given Wright's concern to avoid the language and arguments of Protestant anachronism, would he have been so enthusiastic about using Hengel without Sanders' endorsement? Quite possibly. Nevertheless, I think we have to conclude that this is indeed a perpetuation of old ideas about the Jewish Question while claiming the exact opposite, much like Goldberg said of the tacit and ongoing (post-) racializing in academic structures and concepts.

The assumed static and collective nature of Judaism is stressed even more in his more recent and major book on Paul - Paul and the Faithfulness of God - where the phrase 'essentially Jewish' is ubiquitous and is the basis for allowing Paul to transcend Judaism's perceived limitations. ${ }^{49}$ Among numerous examples of a static Judaism, we might mention 'this essentially Jewish narrative,' 'Paul's essentially Jewish ... exposition, 'an essentially Jewish message', and, in a telling image with original

44 Martin Hengel, The Charismatic Leader and His Followers ((1968) English Translation; Edinburgh: T\&T Clark, 1981), quotations from pages 9 and 14 respectively.

45 Wright, Victory of God, 401.

46 Wright, Victory of God, 399-402.

47 Wright, Victory of God, 13.

8 See Wright, Victory of God, 107-8.

49 See James G. Crossley and Katie Edwards, 'Paul and the Faithfulness of God as Postmodern Scholarship', in God and the Faithfulness of Paul: A Critical Examination of the Pauline theology of N.T. Wright, ed. Christoph Heilig, J. Thomas Hewitt and Michael F. Bird (Tübingen: Mohr Siebeck, 2016), 603-21; cf. Chris Tilling, 'Paul and the Faithfulness of God: A Review Essay (Part 1)', Anvil 31 (2015): 45-56, at 48 . 
italics, 'the same essentially Jewish olive tree. ${ }^{50}$ Wright also applies this beyond Paul's message to 'the life of his communities' which 'remained essentially Jewish. ${ }^{51}$ Further, when talking about 'the Jewish objection to the entire Roman view of the gods' (an 'essentially Jewish view'), Wright claims that this was 'not simply about monotheism (though that was of course the basis of the standard critique of idolatry), nor even about election (their belief that they, rather than the Romans or anybody else, were the chosen people of the one true God)'. Instead, this 'was about eschatology' and 'their belief that the one God had determined on a divine justice that would be done, and would be seen to be done, in a way that Roman imperial justice somehow never quite managed. ${ }^{52}$ This too does not allow much room for manoeuvre in the construction of Jewish identity in the ancient world, or for a wider variety in ancient perceptions about Jewish identities. In this respect, we might ask more questions: What if some Jews were more accommodating to, or indifferent about, Roman views about gods? What if some Jews foregrounded 'monotheism' or 'election' rather than 'eschatology'? Wright may well concede that these points were possibilities, but what we have is Wright's text (and plenty of it) as our data, and it reveals strongly essentialist formulations about what Judaism is and what it is not.

Wright's construction in Paul and the Faithfulness of God also includes an essentialist and bounded Jewish-pagan binary, partly inherited from the primary sources and their long reception history. Certainly, Wright notes that his use of 'pagan' is a 'convenient shorthand' ${ }^{53}$ but even so, the labelling still functions throughout as a category employed typically in strict opposition to Judaism. Wright claims not only that 'what Paul thought he was doing was offering an essentially Jewish message to the pagan world'54 but also that a range of different philosophical traditions represent 'paganism'. And, for Wright, this philosophical 'paganism' is not to be understood as the source of concepts in Paul's or Jewish writings, irrespective of whether there are overlaps in language. When discussing the Wisdom of Solomon, Wright argues that it raises issues that 'would of course have been anathema not only to Epicureans, but also to Stoics, Platonists, and more or less everyone else across the spectrum of paganism. ${ }^{55}$ Wisdom of Solomon might use the language of such 'pagan' philosophy, but Wright views this as evidence for an essentialist Jewish identity. According to Wright, Wisdom of Solomon 'has made it ['pagan' philosophy] serve, decisively, an essentially Jewish vision of reality.56 It might be argued that another function of Wright's discourse is to construct an orthodox path through history and protect the Christian message from being tainted by anything deemed idolatrous. This might incorporate the influence of what Luke Timothy Johnson called the 'Hengel sidestep' by which he meant that 'any possible influence of Greco-Roman culture on the New

\footnotetext{
50 Wright, Paul and the Faithfulness of God, 1279, 1303, 1439, and 1449, respectively.

51 Wright, Paul and the Faithfulness of God, 1440, cf. 385.

52 Wright, Paul and the Faithfulness of God, 342.

53 Wright, Paul and the Faithfulness of God, xxi.

54 Wright, Paul and the Faithfulness of God, 200 (italics original).

55 Wright, Paul and the Faithfulness of God, 241.

56 Wright, Paul and the Faithfulness of God, 241.
} 
Testament is systematically filtered through Hellenistic Judaism, which, presumably, renders it non-toxic for Christianity' ${ }^{57}$

This essentialist approach to Jewish identity continues in Wright's construction of more recent Jewish identity. In Paul and the Faithfulness of God, he pays some attention to Hannah Arendt and Walter Benjamin who, in the extreme conditions of the mid-century crisis, understood the urgency of present action ... . Something has to be done, and done now. ${ }^{58}$ Wright quotes from Arendt that what is needed is 'a new guarantee which can be found only in a new political principle, in a new law on earth, whose validity this time must comprehend the whole of humanity while its power must remain strictly limited, rooted in and controlled by newly defined territorial entities. ${ }^{59}$ In a similar way, Wright suggests that Benjamin 'offers a reminder that the ancient Jewish vision, in which the Messiah and the redemption of history have played such an important role', brings 'the challenge to action in the world itself' ${ }^{60}$ As Wright summarizes, 'One does not have to fill in too many gaps to see that this is essentially a Jewish vision: a world at one, with human authorities necessary but firmly under limitation.61 This assessment too works with a fixed view of Jewish identity across time which has been established by the scholarly interpreter, in this instance Wright. Of course, it can be acknowledged that Arendt and Benjamin (and indeed others in the Frankfurt School) were influenced by their Jewish backgrounds, but that is not the whole story. Most obviously, we might also factor in their Marxist influences. But we might wonder if Wright's essentially Jewish description even works historically. Is it possible that such a vision might be known in Christianity, nineteenth-century nationalism, the developing Labour movement of the early twentieth century, or whatever complex combinations of all of the above we might refer to? Might this vision have been something developed specifically in light of, as Wright puts it, 'the extreme conditions of the mid-century crisis'? And then there is the case of those identifying and identified as Jews, but who do not think of a world at one, 'with human authorities necessary but firmly under limitation'. Are they rejecting an essentially Jewish vision? Would not at least some of the well-established Jewish anarchists in the East End of London prior to the First World War have had difficulties with the idea of necessary 'human authorities', no matter how limited their power? Wright does not go into details about what we do with alternative Jewish visions, but their very existence again reveals the extent of the static and essentializing nature of Wright's 'Jewishness' which appears close to being a timeless categorization.

57 Luke Timothy Johnson, 'Review of Richard H. Bell, No one Seeks for God', RBL (1999). Available online: http://www.bookreviews.org/pdf/382_408.pdf (accessed 31 March 2017). On the construction of an orthodox path through history, compare also the following comments by Wright where he indicates heretical historical paths the historian best avoids: 'Two of the greatest poems in scripture, perhaps in all the world, are the psalms we call 19 and 119, the latter celebrating Torah from every possible angle, the former balancing it with the power and glory of the sun itself. That is what Torah is like. Not to recognize that is to take a large step towards Marcion, or indeed towards the gnosticism that would scorn the created order as well' (Paul and the Faithfulness of God, 101617).

58 Wright, Paul and the Faithfulness of God, 1474 (italics original).

59 Wright, Paul and the Faithfulness of God, 1474.

60 Wright, Paul and the Faithfulness of God, 1474.

61 Wright, Paul and the Faithfulness of God, 1474. 
Even the construction of 'paganism' remains when Wright discusses problematic modern identity. The 'horrible anti-semitism of Nazi ideology' was 'of course essentially pagan, though sometimes borrowing some clothes designed to look "Christian". ${ }^{62} \mathrm{We}$ might question the validity of such essentialism in academic analysis. What does it mean to say Nazism was 'essentially pagan' (whatever that seemingly broad category might contain) while anything seemingly 'Christian' is only wearing 'clothes designed to look' right? This is not, of course, to say that Nazism was essentially Christian, but clearly there were Nazi Christians who did identify as Christian and did borrow from earlier figures who also identified as Christian. Is it really the role of the historian to extract purest Christianity from any unfortunate contamination, not unlike the popular discourse of ISIS not being 'true Islam'? Perhaps not, but the point here is to show just how firmly essentialist Wright's binaries are and arguably the clearest example of what Arnal saw as a reaction against fragmented postmodern identities. ${ }^{63}$ And in the hands of Wright, it is Pauline theology which is the ultimate revelation of what such Judaism ought to be, once anything problematic for postmodern liberal discourses is removed.

\section{Concluding remarks}

We have seen how, through the example of the leading British New Testament scholar, N. T. Wright, and broader trends in contemporary scholarship, essentialized 'Judaism' and 'Jewishness' are part of wider cultural, geopolitical, and post-racial discourses. This includes their classifications of a particular minority in relation to a constructed set of collective behaviours, appearances, and relationship to notions of liberalism and the liberal nation state, irrespective of whether individual scholars are aware of this or not. Both Goldberg's claim that the lingering racialized categories recur in different and downplayed settings and Žižek's claim that liberal multiculturalism embraces the Other without problematic Otherness function as driving forces in the New Perspective on Paul and the contemporary quest for the Historical Jesus, as well as, on closer inspection, a specific proponent like Wright. This has been an examination of a more specifically British manifestation of the New Perspective on Paul and the Jewishness of Jesus, but it is one that has been influential in Anglophone scholarship. Indeed, despite Sanders' decisive intervention (and employment at Oxford in the 1980s), Wright and Dunn have been two of the most influential proponents of constructions of Judaism in relation to the New Testament and especially Jesus and Paul. Moreover, they have also been influential in American scholarship, or at least certain areas of American scholarship, and both have attracted many doctoral students from North America. But it is also an era that is coming to an end, and not only generationally. Since the 2008 financial crash, the neo-liberal settlement has been challenged like never before and more ethno-nationalist discourses have come to prominence - whether Trump in America or May and Brexit in the UK - as well as reactions against them. It will no doubt be engagement (implicit or explicit) with these kinds of competing discourses

62 Wright, Paul and the Faithfulness of God, 807.

63 See Arnal, The Symbolic Jesus; also note 20 and discussion above. 
that will leave their marks on the next generation of New Testament scholars and the Jesuses and Pauls they produce in relation to the ways in which concepts of race, ethnicity, and nation will become reconstructed. This alone should be warning enough that, despite using 'post-racial' in a fairly non-polemical way in this essay to describe the ways scholars categorize according to set and essentialized behaviours, we should take Goldberg's more forthright use of 'racial' seriously because he shows how such categories, despite appearances, can be used in malign ways. Indeed, such classificatory systems are continually used for monitoring and surveillance of minority groups by the liberal capitalist state and thereby perpetuating difference and the potential for discrimination. As we see with contemporary Muslims in Europe and North America, the potential for what might otherwise be called 'racial' or 'racist' profiling has hardly gone away.

\section{References}

Arnal, William. The Symbolic Jesus: Historical Scholarship, Judaism and the Construction of Contemporary Identity. London and Oakville: Equinox, 2005.

Bird, Michael F. The Saving Righteousness of God: Studies on Paul, Justification and the New Perspective. Milton Keynes: Paternoster, 2006.

Boyarin, Daniel. A Radical Jew: Paul and the Politics of Identity. Berkeley: University of California Press, 1994.

Casey, Maurice. 'Some Anti-Semitic Assumptions in The Theological Dictionary of the New Testament'. NovT 41 (1999): 280-91.

Casey, Maurice 'Who's Afraid of Jesus Christ? Some Comments on Attempts to Write a Life of Jesus'. In Writing History, Constructing Religion, edited by James Crossley and Christian Karner, 129-46. Aldershot: Ashgate, 2005.

Charlesworth, James H. Jesus within Judaism: New Light from Exciting Archaeological Discoveries. London: SPCK, 1989.

Crossan, John Dominic. The Historical Jesus: The Life of a Mediterranean Jewish Peasant. Edinburgh: T\&T Clark, 1991.

Crossley, James G. Why Christianity Happened: A Sociohistorical Account of Christian Origins 26-50 CE. Louisville, KY: WJK, 2006.

Crossley, James G. Jesus in an Age of Terror: Projects for a New American Century. London: Routledge, 2008.

Crossley, James G. Jesus in an Age of Neoliberalism: Quests, Scholarship, Ideology. London: Routledge, 2012.

Crossley, James G. 'A “Very Jewish” Jesus: Perpetuating the Myth of Superiority'. JSHJ 11 (2013): 109-129.

Crossley, James G. and Katie Edwards. 'Paul and the Faithfulness of God as Postmodern Scholarship'. In God and the Faithfulness of Paul: A Critical Examination of the Pauline theology of N.T. Wright, edited by Christoph Heilig, J. Thomas Hewitt and Michael F. Bird, 603-21. Tübingen: Mohr Siebeck, 2016.

Curtis, Mark. Unpeople: Britain's Secret Human Rights Abuses. Vintage: London, 2004.

Dunn, James D. G. 'The New Perspective on Paul'. Bulletin of the John Rylands Library 65 (1983): 95-122.

Dunn, James D. G. Romans 1-8. WBC 38A. Waco, TX: Word, 1988. 
Dunn, James D. G. The Theology of Paul the Apostle. Grand Rapids, MI: Eerdmans, 1998.

Dunn, James D. G. Jesus Remembered. Grand Rapids, MI, and Cambridge:

Eerdmans, 2003.

Dunn, James D. G. The New Perspective on Paul: Collected Essays. Tübingen: Mohr Siebeck, 2005.

Fekete, Liz. A Suitable Enemy: Racism, Migration and Islamophobia. London: Pluto Press, 2009.

Finkelstein, Norman. The Holocaust Industry: Reflections on the Exploitation of Jewish Suffering. 2nd edn. London and New York: Verso, 2003.

Freyne, Seán. Jesus, a Jewish Galilean: A New Reading of the Jesus-Story. London and New York: T\&T Clark, 2004.

Goldberg, David Theo. The Threat of Race: Reflections on Racial Neoliberalism. Oxford: Wiley-Blackwell, 2009.

Head, Peter. 'The Nazi Quest for an Aryan Jesus'. JSHJ 2 (2004): 55-89.

Hengel, Martin. The Charismatic Leader and His Followers. [1968] English Translation: Edinburgh: T\&T Clark, 1981.

Heschel, Susannah. The Aryan Jesus: Christian Theologians and the Bible in Nazi Germany. Princeton, NJ: Princeton University Press, 2008.

Johnson, Luke Timothy. 'Review of Richard H. Bell, No one Seeks for God'. RBL

(1999). Available online: http://www.bookreviews.org/pdf/382_408.pdf (accessed 31 March 2017).

Käsemann, Ernst. New Testament Questions of Today. London: SCM, 1969.

Kelley, Shawn. Racializing Jesus: Race, Ideology and the Formation of Modern Biblical Scholarship. London and New York: Routledge, 2002.

Kelley, Shawn. 'Hear Then No More Parables: The Case against "Parable"'. JSHJ 11 (2013): 153-69.

Kundnani, Arun. The Muslims Are Coming! Islamophobia, Extremism, and the Domestic War on Terror. London: Verso, 2014.

Levine, Amy-Jill. The Misunderstood Jew: The Church and the Scandal of the Jewish Jesus. San Francisco: HarperCollins, 2006.

Lindsey, Hal. Late Great Planet Earth. Grand Rapids, MI: Zondervan, 1970.

Lentin, Alana and Gavan Titley. The Crises of Multiculturalism: Racism in a Neoliberal Age. London: Zed Books, 2011.

Meier, John P. A Marginal Jew: Rethinking the Historical Jesus. 4 volumes. New Haven, New York and London: Doubleday, 1991-2009.

Moxnes, Halvor. Jesus and the Rise of Nationalism: A New Quest for the Nineteenth Century Historical Jesus. London and New York: I. B. Taurus, 2011.

Novick, Peter. The Holocaust and Collective Memory. London: Bloomsbury, 1999.

Sanders, E. P. Paul and Palestinian Judaism: A Comparison of Patterns of Religion. London: SCM, 1977.

Sanders, E. P. Jesus and Judaism. London: SCM, 1985.

Tilling, Chris. 'Paul and the Faithfulness of God: A Review Essay (Part 1)'. Anvil 31 (2015): 45-56.

Vermes, Géza. Jesus the Jew. London: SCM, 1973.

Vermes, Géza. The Religion of Jesus the Jew. London: SCM Press, 1993.

Watson, Francis B. 'Not the New Perspective'. Paper presented at the British New Testament Conference, Manchester, 2001.

Wright, N. T. 'The Paul of History and the Apostle of Faith'. TynBul 29 (1978): 61-88. 
Wright, N. T. The Climax of the Covenant: Christ and Law in Pauline Theology. Edinburgh: T\&T Clark, 1991.

Wright, N. T. Jesus and the Victory of God. London: SPCK, 1996.

Wright, N. T. Paul and the Faithfulness of God. 2 volumes. London. SPCK, 2013.

Wright, N. T. Paul and His Recent Interpreters. London: SPCK, 2015.

Young, Stephen L. 'Protective Strategies and the Prestige of the "Academic": A Religious Studies and Practice Theory Redescription of Evangelical Inerrantist Scholarship'. BibInt 23 (2015): 1-35.

Žižek, Slavoj. 'Multiculturalism, or, the Cultural Logic of Multinational Capitalism'. New Left Review I/225 (1997): 28-51.

Žižek, Slavoj. Welcome to the Desert of the Real! Five Essays on September 11 and Related Dates. London and New York: Verso, 2002.

Žižek, Slavoj. The Puppet and the Dwarf: The Perverse Core of Christianity. Cambridge, MA: MIT Press, 2003.

Žižek, Slavoj. 'Liberal multiculturalism masks an old barbarism with a human face'. Guardian. 3 October 2010.

Žižek, Slavoj. Living in the End Times. Revised edn. London and New York: Verso, 2011. 



\author{
Part Three
}

\title{
Challenging White, Western Traditions of Interpretation: Critique and Alternatives
}





\title{
Anachronistic Whiteness and the Ethics of Interpretation ${ }^{1}$
}

\author{
Denise Kimber Buell
}

'Whiteness' was not a legible concept or set of embodied practices among the inhabitants of the early Roman empire. ${ }^{2}$ So, why invoke whiteness when discussing ancient constructions of identity? What do I mean by whiteness? This essay extends the 'prismatic' approach I take in Why This New Race: Ethnic Reasoning in Early Christianity, an approach that modulates among three nodes: (1) our current locations and investments, by which I mean not simply political and cultural ones but also methodological and theoretical ones; (2) the histories of our fields in context and thus the ways in which the relatively recent past - meaning at least the last 150 years - informs how we approach the study of the ancient Christian past and our understandings of race, ethnicity, and religion; and (3) the ancient materials we engage to reconstruct meanings legible to us and putatively also to ancient audiences and actors. ${ }^{3}$

'Whiteness', anachronistic as it may be for antiquity, relates directly to the first two nodes. But we cannot understand the third without the other two operating upon us, which raises the question of how I am using this term. In the United States and,

1 For their comments and suggestions on this essay, I thank Melanie Johnson-DeBaufre, Jacqueline Hidalgo, Jason Josephson, James Manigault-Bryant, Saadia Yacoob, Zaid Adhami, Lloyd Barba, and Katherine Hockey. I also thank David Horrell for the opportunity to participate in the symposium in which an earlier version was presented.

2 Those who produced the texts and practices that we retrospectively interpret as presaging or constituting early forms of Christianity did not have racial subjectivities, practices, and structures as we understand and inhabit them. Nonetheless, I and others have argued for the legitimacy of examining ancient formations of difference in relation to modern practices of 'race'. See, for example, Denise Eileen McCoskey, Race: Antiquity and its Legacy (London and New York: I. B. Tauris, 2012); Denise Kimber Buell, Why This New Race: Ethnic Reasoning in Early Christianity (New York: Columbia University Press, 2005). My goal is neither to explore colour symbolism in early Christianity, something Gay Byron has already done effectively, nor to explore colour symbolism as it contrasts or resonates with the various meanings and forms of social organization that have arisen around imputed differences pertaining to skin colour in medieval, early modern, modern, or current contexts. Both of these goals are important and, indeed, part of the transformation of biblical and early Christian studies that needs to continue. See Gay L. Byron, Symbolic Blackness and Ethnic Difference in Early Christian Literature (New York: Routledge, 2002); see also Miriam EliavFeldon, Benjamin Isaac, and Joseph Ziegler, eds, The Origins of Racism in the West (Cambridge: Cambridge University Press, 2009).

3 See Buell, Why This New Race, 33. 
in different ways, in the UK, Europe, Africa, Australia, and other parts of the globe, 'whiteness' gets its embodied meanings in relation to the structures of power steeped in histories of settler colonialisms, modern slavery, Christian missionizing, and forms of white supremacy (including South African apartheid and US Jim Crow legal formations). Over the last twenty years many scholars have written about whiteness, including from intersectional perspectives that attend to the mutual imbrication and production of race with gender, as well as to their contextual production in relation to religious, economic, and national formations. ${ }^{4}$ For this piece, Sara Ahmed's 2007 article 'A phenomenology of whiteness' serves as my point of entry and orientation. ${ }^{5}$ The critical study of race, including whiteness, has been developed especially in US contexts but Ahmed, as a British scholar based in the UK, demonstrates that the contemporary saliency of whiteness is not restricted to the United States. ${ }^{6}$

Ahmed eloquently states that 'whiteness' is 'real, material, and lived' as 'an effect of racialization', 'as an ongoing and unfinished history, which orients bodies in specific directions'. Rather than an ontological given, 'whiteness' is 'received, or becomes given, over time.' She argues that 'whiteness [is] a category of experience that disappears as a category through experience', which helps to explain why it so easily remains unarticulated or backgrounded on the one hand and, on the other, why it persists as an unmarked site for the marking of other bodies racialized as non-white. Indeed, one of the key insights of those writing about whiteness has been to call attention to the ways that many of us who are viewed as white or who view ourselves as white either do not view ourselves as having a race at all or speak about race as if it is really only about those viewed as non-whites. As George Yancy puts it, whiteness 'functions, paradoxically, as that which signifies the "superior" race while precisely obfuscating its status as raced ... whiteness functions as a transcendental norm, as that which defines nonwhite bodies as different and deviant.' ${ }^{8}$ When whiteness is the operative condition, he writes, 'white bodies comport themselves with no particular need to see themselves

4 I cannot be exhaustive, but see, for example, Peggy McIntosh, 'White Privilege: Unpacking the Invisible Knapsack', Peace and Freedom July/August (1989): 10-12; George Lipsitz, The Possessive Investment in Whiteness: How White People Profit from Identity Politics, rev. and exp. edn ((1993) Philadelphia: Temple University Press, 2006); Thandeka, Learning to be White: Money, Race, and God in America (New York: Continuum, 1999); Jennifer Harvey, Karin A. Case, and Robin Hawley Gorsline, eds, Disrupting White Supremacy from Within: White People on What We Need to Do (Cleveland: Pilgrim, 2004).

5 Sara Ahmed, 'A Phenomenology of Whiteness', Feminist Theory 8, no. 2 (2007): 149-68.

6 Given the UK context of the symposium in which this essay was first delivered, I intentionally chose to foreground a British feminist scholar based in the UK. Ahmed is certainly not the only scholar to showcase the saliency of whiteness or its intersectional relations with religion, class, and gender outside of the United States. See, for example, Vron Ware and Les Back, Out of Whiteness: Color, Politics, and Culture (Chicago: University of Chicago Press, 2002) and the special issue of the journal borderlands 3, no. 2 (2004), which focused on critical whiteness studies from Australian, British, and North American perspectives.

Ahmed, 'A Phenomenology of Whiteness', 150.

8 George Yancy, 'Introduction: Framing the Problem', in Christology and Whiteness: What Would Jesus Do? ed. George Yancy (New York: Routledge, 2012), 1-18, at 8. 
as white. ${ }^{9}$ We ought to expose 'white' as a racialized formation and lift up the difficulties and possibilities in reorienting away from 'whiteness. ${ }^{10}$

Individual reorientations of those of us habituated into whiteness is a necessary but not sufficient piece of the work to overcome racism and white privilege: 'Insofar as racism is a system that reproduces itself ... then only a major reorganization of society will address it, not simply a revision of personal attitudes where everything else remains the same.' ${ }^{11}$ We may recognize explicit racism and reject it, but it is much more difficult to see and address implicit forms of racism that reinforce structural privileges which unequally advantage those of us racialized as 'white' and disadvantage those racialized as 'people of colour'. Those of us raised to be white social subjects are 'embedded within structures that privilege [us] against [our] will' and that do not change merely because we dislike or disavow racism. ${ }^{12}$ Thus, overcoming racism is not solely a matter of individual agency. Such structural asymmetries and embodied habits are of course not restricted to racism and are enacted together with other social and material axes, including gender, sexuality, age, class, ability, and religious affiliation that are neither static, completely arbitrary, nor fully in our control.

Whiteness operates through bodies as a set of capacities and limits in a context that both exceeds those bodies and requires things of them. Ahmed's piece helps me to understand better how my own embodied accumulation of experiences, as well as the institutional and social contexts in which I work and live, pose significant challenges to reorienting myself, even as a self-conscious feminist working to overcome racism, anti-Judaism, and Islamophobia. That is, Ahmed helps to connect the dots between whiteness as an effect of racialization produced in some individual bodies and the whiteness of institutions or disciplines, regardless of the demographic identifications its individual participants might avow or be assigned.

How does 'whiteness' come to be? Ahmed proposes, drawing on the work of Bourdieu and Merleau-Ponty, that 'whiteness "holds" through habits':

[We] can think about the habitual as a form of inheritance. It is not so much that we inherit habits, although we can do so: rather the habitual can be thought of as a bodily and spatial form of inheritance ... . If habits are about what bodies do, in ways that are repeated, then they might also shape what bodies can do ... the habitual body does not get in the way of an action: it is behind the action. I want to suggest here that whiteness could be understood as 'the behind'. ... white bodies do not have to face their whiteness; they are not oriented 'towards' it, and this 'not' is what allows whiteness to cohere, as that which bodies are orientated around. ${ }^{13}$

9 Yancy, 'Introduction', 2.

10 See Sara Ahmed, 'Declarations of Whiteness: The Non-Performativity of Anti-Racism', borderlands 3, no. 2 (2004). Available online: http://www.borderlands.net.au/vol3no2_2004/ahmed_declarations. htm (accessed 3 April 2017).

11 Robert Bernasconi, 'Waking up White and in Memphis', in White on White/Black on Black, ed. George Yancy (Lanham, MD: Rowan \& Littlefield, 2005), 17-25, at 20.

12 Yancy, 'Introduction', 8.

13 Ahmed, 'A Phenomenology of Whiteness', 156. 
The terms 'habit' and 'inheritance' already make clear that whiteness is not simply a trait that individual bodies may manifest. Habituated bodies are formed in and shape larger contexts:

Spaces also take shape by being oriented around some bodies, more than others. We can also consider 'institutions' as orientation devices, which take the shape of 'what' resides within them. After all, institutions provide collective or public spaces. When we describe institutions as 'being' white, we are pointing to how institutional spaces are shaped by the proximity of some bodies and not others: white bodies gather, and cohere to form the edges of such spaces .... Whiteness is only invisible for those who inhabit it, or those who get so used to its inheritance that they learn not to see it, even when they are not it. Spaces are oriented 'around' whiteness, insofar as whiteness is not seen. We do not face whiteness, it 'trails behind' bodies, as what is assumed to be given. The effect of this 'around whiteness' is the institutionalization of a certain 'likeness', which makes non-white bodies feel uncomfortable, exposed, visible, different, when they take up this space. ${ }^{14}$

As this framing makes clear, whiteness is not reducible to skin colour, even if that is what we use as shorthand. As I discuss below, to participate in New Testament studies means participating in institutional spaces oriented 'around' whiteness.

An example from another discipline can help to set the stage for further discussion of New Testament and early Christian studies. Philosopher Robert Bernasconi offers a productive articulation of how institutional and social contexts operate in and through individual bodies:

Philosophers are largely in denial not only about the role of some of the most exalted philosophers in the history of racism and in preparing for other crimes against humanity, but also about philosophy's current problems: the fact that philosophers in the United States are overwhelmingly white; the fact that Black philosophers, like women philosophers, often seem to have to leave philosophy for other disciplines in order to get a senior position; the fact that non-Western philosophy, although it is much sought after by undergraduates, is rarely taught and that graduate schools do not prepare new $\mathrm{PhDs}$ to teach it; and the fact that the philosophical canon alone in the humanities has not been revised to accommodate multiculturalism. ${ }^{15}$

Invoking whiteness impels us to talk about what is rendered invisible by dominant interpretive approaches, including in New Testament and early Christian studies. Doing so sets the stage for academic disciplines and specific academic units to rethink their curricula, their pedagogies, and their modes of recruitment and mentoring in ways that transform not only the demographics of a field, institution, or department,

14 Ahmed, 'A Phenomenology of Whiteness', 157.

15 Bernasconi, 'Waking Up White', 23. 
but its entire orientation. ${ }^{16}$ In the case of biblical studies, this process is also entangled with the ways that the Bible has been one of the vectors for producing modern racial formations, including whiteness. ${ }^{17}$

To develop the implications of these perspectives on whiteness for biblical studies and the study of early Christianity, I proceed in three sections, corresponding to the three prismatic nodes mentioned above. Section 1 discusses how 'whiteness' offers a way to call attention to present concerns and challenges. Section 2 briefly discusses the histories of our academic fields and sociocultural and political landscapes. These sections thus attend to our current locations and the histories of our fields, the first and second nodes of my prismatic approach. In Section 3, I offer two examples of how examining whiteness opens up new possibilities to engage New Testament and early Christian materials.

\section{The whiteness of New Testament and early Christian studies}

The orientation of New Testament and early Christian studies is 'white' not because all scholars in these fields are white; in the most recent survey of members of the major professional society, the Society of Biblical Literature, 85 per cent of members described themselves as of European descent and 76 per cent as male. ${ }^{18}$ Instead, the

16 Bernasconi has helped to recruit and mentor especially African-American doctoral students in Philosophy, making his department at Pennsylvania State University worthy of a cover story in the The Chronicle of Higher Education; see Vimal Patel, 'Diversifying a Discipline', The Chronicle of Higher Education, 27 March 2016. Available online: http://www.chronicle.com/article/Diversifyinga-Discipline/ (accessed 3 January 2017).

17 See, for example, Peter Harrison, 'Religion' and the Religions in the English Enlightenment (Cambridge: Cambridge University Press, 1990); Maurice Olender, The Languages of Paradise: Race, Religion, and Philology in the Nineteenth Century, trans. Arthur Goldhammer ((original French, 1989) Cambridge, MA: Harvard University Press, 1992); Bruce Lincoln, Theorizing Myth: Narrative, Ideology, and Scholarship (Chicago: University of Chicago Press, 1999), 47-137; James Perkinson, White Theology: Outing Supremacy in Modernity (New York: Palgrave MacMillan, 2004); Colin Kidd, The Forging of Races: Race and Scripture in the Protestant Atlantic World, 1600-2000 (Cambridge: Cambridge University Press, 2006); J. Kameron Carter, Race: A Theological Account (Oxford: Oxford University Press, 2008); Jared Hickman, 'Globalization and the Gods, or the Political Theology of "Race"', Early American Literature 45, no. 1 (2010): 145-82; Willie James Jennings, The Christian Imagination: Theology and the Origins of Race (New Haven: Yale University Press, 2010); Mark Vessey et al., eds, The Calling of the Nations: Exegesis, Ethnography, and Empire in a Biblical-Historic Present (Toronto: University of Toronto Press, 2011).

18 Although commenting upon membership in the major professional society for biblical studies rather than the specific demographics of PhD recipients, the 2015 Annual Report of the Society of Biblical Literature contains telling data upon the gendered and racialized character of participation (see Society Report, November 2015. Available online: https://www.sbl-site.org/assets/pdfs/SR2015 online.pdf (accessed 23 March 2017)). The report summarizes, 'A plurality of members is 31-50 years of age. Fewer than one in ten members is 30 years of age or younger... About one in six members is over 65 years of age. ... Nearly one-fourth of members are female, while $76.2 \%$ of members are male. Transgender records number 3 and account for $0.1 \%$ of membership.... Presently, $85 \%$ of members who claim to be United States citizens are of European descent, 3.8\% are multiethnic, and 3.4\% are of African descent. Members of Asian descent account for 2.3\%, Latina/o descent totals $1.7 \%$, and Native American, Alaska Native, or First Nation descent is 0.2\%' (22). See also Elisabeth Schüssler Fiorenza, Rhetoric and Ethic: The Politics of Biblical Studies (Minneapolis: Augsburg Fortress, 1999), esp. 17-30. 
orientation is 'white' because of 'the world that is inherited, or which is already given before the point of an individual's arrival', ${ }^{19}$ the histories and approaches of our fields, and the ways that students are disciplined into the field. Whiteness functions 'as both norm and core, that against which everything else is measured, and as residue, that which is left behind after everything else has been named.20

Think about the contemporary dynamics of biblical education and specifically what bodies of knowledge and skills are required. ${ }^{21}$ Take language requirements, for example. Those of us trained in New Testament studies, at least in most programmes in the United States, must take biblical Hebrew but not Aramaic; Septuagint may be on the menu but not Talmud. By not training students in languages and texts contemporaneous with the composition of the texts of the New Testament and the centuries in which early Christian formations were emerging, New Testament studies reinforces an old paradigm of 'late Judaism' for the early Christian context even after most of us have rejected it. Syriac is gaining in vogue now, especially due to contemporary interest in Islam, but as Gay Byron has noted, Ge'ez and Ethiopic history and traditions remain almost entirely out of view. ${ }^{22}$

Moreover, the interpretive approaches within the study of the New Testament and early Christian history deemed most credible and authoritative demand that interpreters distance themselves from any current commitments and structural constraints, which really means that some commitments and constraints are rendered invisible and acceptable while others are hypervisible and a cause for suspicion or challenge. For example, there is still an unmarked category, 'biblical interpretation', in distinction from, say, feminist or Latino/a biblical interpretation. As Jacqueline Hidalgo rightly notes, 'academic fields at large, but perhaps biblical studies especially, are circumscribed by a certain politics of reading: the "acceptable" canon of scholarly sources within any particular field, the authority that adheres to the reading of certain texts and not others, and the practices of authorization that surround and enable only certain ways of reading these texts. ${ }^{23}$

Indeed, although 'other ways of reading and other politics of reading' are possible and exist in biblical and early Christian studies, ${ }^{24}$ there are very few doctoral programmes in the United States in which students of all backgrounds are required to demonstrate competency in scholars, methods, or interpretive approaches associated with 'underrepresented' groups, be they racially, sexually, religiously, or

19 Ahmed, 'A Phenomenology of Whiteness', 153.

20 Ruth Frankenberg, White Women, Race Matters: The Social Construction of Whiteness (Minneapolis: University of Minnesota Press, 1993), 238.

${ }^{21}$ Melanie Johnson-DeBaufre, 'Mapping the Field, Shaping the Discipline: Doctoral Education as Rhetorical Formation', in Transforming Graduate Biblical Education: Ethos and Discipline, ed. Elisabeth Schüssler Fiorenza and Kent Harold Richards (Atlanta: SBL Press, 2010), 319-53.

${ }^{22}$ Gay Byron, 'Ancient Ethiopia and the New Testament: Ethnic (Con)texts and Racialized (Sub)texts', in They Were All Together in One Place? Toward Minority Biblical Criticism, ed. Randall C. Bailey, Tat-siong Benny Liew, and Fernando F. Segovia (Atlanta: SBL Press, 2009), 161-90.

23 Jacqueline M. Hidalgo, 'The Politics of Reading: US Latinas, Biblical Studies, and Retrofitted Memory in Demetria Martínez's Mother Tongue, Journal of Feminist Studies in Religion 29, no. 2 (2013): $120-31$, at 121 .

24 Hidalgo, 'Politics of Reading', 121; she cites, among others, Musa Dube, ed., Other Ways of Reading: African Women and the Bible (Atlanta: SBL Press, 2001). 
otherwise minoritized. In programmes in the UK, Europe, and Nordic countries, doctoral students arrive with a dissertation project and thus do not even have the opportunity through coursework to engage alternative perspectives. In both contexts, the institutional structures thus have a deeply conserving effect on what counts as authoritative knowledge frameworks.

One might also look to the location of the institutions and publishing houses that continue to be viewed and counted as most authoritative. 'Top' universities are generally those in 'white majority' countries: the United States, Canada, the UK, Western Europe, and Nordic countries (maybe we can add Australia); regardless of how an individual is racialized, getting one's academic credentials in a 'top' university gives one more professional standing. Likewise, when academics look to publishers as a sign of prestige, it is still a fairly narrow band of American, British, and European presses that are generally viewed most favourably.

We see the effects of these habits also in our professional societies. Among the programme units at Society of Biblical Literature conferences, some have a 'visible' interpretive approach (ideological criticism, LGBTQ hermeneutics, Paul and Politics, ecological hermeneutics, feminist hermeneutics of the Bible) where others do not (Pauline Epistles, Book of Acts, Gospel of Luke, etc.). Those for whom the 'unmarked' units feel like 'home' or the 'centre' of the field might do more to question the persisting homogeneity of the spaces, in terms of approaches and questions entertained in them, as well as in terms of whose embodied presences are taken for granted and whose bodies are viewed as 'adding diversity'. The audience and panellists at these 'unmarked' sessions are, not coincidentally, overwhelmingly white and male. Even with a recent upturn of interest in 'ethnicity' in biblical studies in these 'unmarked' sessions, the focus remains one in which contemporary racialized contexts are almost never mentioned but instead biblical texts and contexts are discussed as if the current interpretive context has no bearing, with virtually no reference to the scholarship produced by those who more regularly present in other programme units. Our citational practices reveal much about which interpretive approaches we value, and function to transmit generationally a narrow genealogy of legitimate voices (I use the reproductive imagery deliberately); too often these citational practices erase voices that are not 'white'.

The persisting underrepresentation of male-identified scholars from ethnic and racial groups other than 'European' as well as female-identified scholars of all racial and ethnic groups has not gone unnoticed, as evidenced by long-standing institutional groups such as the Society of Biblical Literature's Committee for Underrepresented Ethnic and Racial Minorities and the Status of Women in the Profession Committee, as well as many specific SBL programme units (e.g. African-American Biblical Hermeneutics, Asian and Asian-American Hermeneutics, Latino/a and Latin American Biblical Interpretation, Feminist Hermeneutics of the Bible). Given the historic and persisting inequities of race and gender in the academy, programme units that focus on marginalized and minoritized approaches and perspectives continue to play a vital role in the field; nevertheless, the existence of these committees and programme units is important but not sufficient to alter the whiteness of biblical and early Christian studies. 
It is thus of crucial importance to attend to what is habitual and routine in our methods and approaches and not only to the 'body count' of who gets $\mathrm{PhDs}$, appointments, tenure, and promotion. That is, attention to who participates at the undergraduate, graduate, and faculty levels in New Testament and early Christian studies matters but always in the context of the very shapes and orientations of the spaces, physical and intellectual, in which this work unfolds. Reorienting the fields of biblical and early Christian studies is an undertaking that also requires deep engagement with the histories of our interpretive approaches and willingness to adopt new perspectives.

\section{Inheritances: The construction of the fields of biblical and early Christian studies}

It is now well understood that 'Higher Criticism' developed especially in Germany to study biblical texts and histories so as to make them objects of scientific investigation rather than simply to reinforce dogma; even so, the research results also functioned to support goals for contemporary theological and political reforms. These studies often transpose contemporary concerns about intra-European or intraAmerican identifications and rights into biblical studies. ${ }^{25}$ In this regard, even with a methodological insistence on historical rupture, studying biblical pasts held the promise to inform the present 'home context', including the meaning and place of religion in relationship to racial and national identifications in North America and Europe. $^{26}$

Early Christian studies was also seen as relevant for understanding relationships between metropole and colonies, especially in the context of Christian missionary efforts. As Elizabeth Clark has shown, when church history emerged as a subfield in the late nineteenth century, its proponents viewed 'church history [as] essential for training missionaries for the Orient'; as Union Theological Seminary Professor Roswell Hitchcock put it in 1872-3 in his course notes, church history should be used to inform contemporary attempts to convert to Christianity 'Heathen, Moslems, and Jews. ${ }^{27}$ Sydney Cave, a Christian missionary, writing at the turn of the twentieth century, claims that 'any one familiar to some extent with the writings of the early fathers of the Church will feel, if he lives in India, that he is living in a world surprisingly like theirs ... books such as Harnack's Expansion of Christianity ... would, mutatis mutandi,

25 See especially Susannah Heschel, Abraham Geiger and the Jewish Jesus (Chicago: University of Chicago Press, 1998); Shawn Kelley, Racializing Jesus: Race, Ideology and the Formation of Modern Biblical Scholarship (London and New York: Routledge, 2002); Sylvester A. Johnson, The Myth of Ham in Nineteenth Century American Christianity: Race, Heathens, and the People of God (New York: Palgrave, 2004).

26 For a careful analysis on emergent nationalisms, see Halvor Moxnes, Jesus and the Rise of Nationalism: A New Quest for the Nineteenth-Century Historical Jesus (London: I. B. Tauris, 2012).

27 Roswell Hitchcock, lecture notes for course delivered in 1872-3 at Union Theological Seminary in New York City on Church History (cited in Elizabeth A. Clark, Founding the Fathers: Early Church History and Protestant Professors in Nineteenth-Century America (Divinations; Philadelphia: University of Pennsylvania Press, 2011), 154). 
serve, far better than any missionary reports would, to describe the religious situation in India today. ${ }^{28}$ And, as Sylvester Johnson has shown, African-American preachers Henry McNeal Turner and Edward Blyden argued for racial unity between African Americans and Africans as descendants of Ham while insisting on a stark gap between civilized Christians and degenerate uncivilized heathens. At the same time, they also struggled with the fact that the racial uplift they argued was made possible through conversion to Christianity did not erase or resolve racist treatment of both Africans and African Americans. ${ }^{29}$

Scholarship on Christian origins and early Christian history that remains influential for New Testament and early Christian studies has been undertaken where local concerns range from citizenship and civil rights in Europe and North America to colonialism and Christian missionary efforts. But it is not simply that scholars have composed histories of early Christians in modern historical contexts that are racialized and interconnected with modern religious movements. It is also that these historical narratives correlate the racialized bodies of colonized and formerly enslaved peoples as well as the (usually) white bodies of colonizers with the kinds of bodies who received and promulgated forms of early Christian teachings and practices. These correlations inform narratives about the emergence of Christianity. In other words, many reconstructions of early Christian history echo modern racial discourse when they depict early Christianity as a movement with a single origin that, even if aspirationally universal, risked contamination from Greeks and other 'heathens', from Jews, as well as from impure insiders, framed as 'heretics.' ${ }^{30}$

If non-Christians, whether framed as 'Jews' or 'heathens', have been racialized as problematic others in modern Christian missionary efforts, we should be attentive to how Christian belonging is correspondingly racialized, not simply akin to whiteness but, in Europe and North America, sometimes as whiteness. In North America, this working out of whiteness has a specifically Protestant dimension, as the majority of scholars of Christian origins were Protestants whose characterization of Roman

${ }^{28}$ Sydney Cave, The Religious Quest of India: Redemption Hindu and Christian (London: Humphrey Milford, 1919), 1-2. See also the work of biblical scholar Burnett Hillman Streeter who offers an even more striking statement along these lines based on his own trip to India: Anyone who has studied the intellectual religious and social background of the Early Church as recovered by recent research, and then visits India, wakes up to find that, so far as the religious situation is concerned, the centuries have vanished and he is again ... in the Graeco-Roman Empire of the second century' (Burnett Hillman Streeter and Aiyadurai Jesudasen Appasamy, The Sadhu: A Study in Mysticism and Practical Religion (London: Macmillan, 1923), 253); discussed in Denise K. Buell, 'The Afterlife is Not Dead: Spiritualism, Postcolonial Theory, and Early Christian Studies', Church History 78, no. 4 (2009): 862-72.

29 Johnson, Myth of Ham, 73-108, esp. 75-91.

30 See Buell, Why This New Race, 10-29; and eadem, 'Challenges and Strategies for Speaking about Ethnicity in the New Testament and New Testament Studies', Svensk Exegetisk Årsbok 49 (2014): 33-51. In discussions of conversion to Christianity in the nineteenth century, 'race' and 'religion' are frequently positioned as contrasting concepts, either to disable arguments for conversion of certain racialized groups or to insist that conversion cannot alter social inequities deemed to be racially based, as Sander Gilman, among others, has shown for late-nineteenth-century Germany (The Case of Sigmund Freud: Medicine and Identity and the Fin de Siècle (Baltimore: The Johns Hopkins University Press, 1993)), Sylvester Johnson for nineteenth-century American Christianity (Myth of $\mathrm{Ham}$ ), and Gauri Viswanathan for nineteenth- and twentieth-century India (Outside the Fold: Conversion, Modernity, and Belief (Princeton, NJ: Princeton University Press, 1998)). 
Catholicism often portrayed its adherents as embodying a degenerate form of Christianity, an argument correlating with nineteenth-century social and political rhetoric about the racial and ethnic differences among European immigrants to the United States. The excellent work on how various European immigrants to the United States 'became white', including various Catholic immigrants and Jews, could benefit from further examination of the co-concealing and co-constituting relations of race and religion. ${ }^{31}$

Moreover, to reorient rather than recentre whiteness, those in New Testament and early Christian studies need to engage more deeply with work that has already been undertaken to highlight the multiple ways that people outside of emerging academic disciplines have interpreted, ignored, used, and refracted biblical texts and historical narratives.

\section{Re-encountering ancient sources}

Invoking whiteness does not simply concern the present or recent past. Our interpretive approaches allow us to ask and produce knowledge about antiquity. To attempt to understand ancient materials and their legibility and impact within their contexts of production and circulation is always an exercise in imagination and an act in and of the present. Using explicitly contemporary lenses can, of course, be an act of imposition and projection, collapsing historical and cultural differences. But there is no lens we can use that lacks a prescription, so to speak. ${ }^{32}$ Nonetheless, using explicitly contemporary lenses also has the potential to enable us to encounter the strangeness of antiquity and potentially reorient our relation to the present and future.

Unlike gender or ethnicity, which are terms that scholars have accepted as viable for ancient Greek, Roman, Jewish, and Christian materials, race and certainly 'whiteness' jar as anachronistic. But gender, ethnicity, and religion are no less anachronistic than race or whiteness if we mean that our discursive and material productions of these concepts differ significantly from ancient formations. In this section, I offer two examples of how attention to whiteness may be illuminating for how we approach New Testament and early Christian texts.

31 Gil Anidjar, Semites: Race, Religion, Literature (Stanford, CA: Stanford University Press, 2008), makes this important point about religion and race as 'coextensive and, moreover, co-concealing categories' (28). See also Karen Brodkin, How the Jews Became White Folks and What That Says about Race in America (New Brunswick, NJ: Rutgers University Press, 1998); and Matthew Jacobson Frye, Whiteness of a Different Color: European Immigration and the Alchemy of Race (Cambridge, MA: Harvard University Press, 1998); David R. Roediger, The Wages of Whiteness: Race and the Making of the American Working Class, rev. edn ((1991) London and New York: Verso, 1999).

32 I thank Elisabeth Schüssler Fiorenza for her use of Audre Lorde to make this very point. Lorde, 'Contact Lenses', in Black Unicorn: Poems (New York: Norton, 1978), 94; cited in Schüssler Fiorenza, But She Said: Feminist Practices of Biblical Interpretation (Boston: Beacon, 1992), 1. 


\subsection{Pneuma, psyche, and the Christian body}

One of the lessons of thinking through whiteness has been to nuance my own articulation of what I have called ethnic reasoning. In Why This New Race, I offer many examples of early Christians defining membership 'in Christ' as joining and participating in an $\ddot{\varepsilon} \theta v o \varsigma, \gamma \varepsilon$ v́v, or $\lambda$ aó, , and argue that the transformations so depicted were rhetorically crafted to be legible as collective belonging that has meaningful content but is acquirable. After reading Why This New Race, Karen King asked me 'What did it look like, in practice, to become a member of a Christian है $\theta$ voc?'

Ahmed's analysis of the habituation of bodies and spaces into whiteness can help to answer this question. To recall, she writes, 'The habitual body does not get in the way of an action: it is behind the action ... whiteness could be understood as "the behind". White bodies are habitual insofar as they "trail behind" actions: they do not get "stressed" in their encounters with objects or others, as their whiteness "goes unnoticed". ${ }^{33}$ In turning to Ahmed's approach to whiteness, I am not linking it to colour symbolism that does appear in early Christian writings, which Gay Byron has ably explored. ${ }^{34}$ Rather, Ahmed's suggestion that we think of the habituated body to understand whiteness, a body whose habits are both inherited but also produced from a field of not fixed but also not infinite possibilities, offers a way to conceptualize the limits of fluidity (or racial or other kinds of identifications) without viewing fixity as its alternative.

When early Christians posit membership as belonging to a people, the imagery includes rebirth and acquisition of kin relations (ranging from Abraham, Jesus, God, fellow believers). But membership is also enacted through shared liturgy as well as daily practices and dispositions. Early Christians did in fact share many practices and views with their non-Christian contemporaries; nonetheless, early Christian writings often frame the process of becoming 'in Christ' or part of the 'people of God' as one that entails a break from existing practices and habits depicted as misguided. This framing is, of course, rhetorical reorientation: Texts exhort readers to question and challenge what they allegedly took for granted previously or to assert that their current membership in a Christian $\gamma \varepsilon$ vo involved such a reorientation. So, one way to explore these ancient sources via Ahmed is to notice how texts set up a case for the need to reorient oneself.

Inspired by Phillip Webster's recently completed dissertation at the University of Pennsylvania, I turn very briefly to Clement of Alexandria's three-volume Paedagogus, which offers a great example of a text attempting to reframe the habitual body. ${ }^{35}$ Clement's detailed instructions about how his Christian students ought to comport themselves in books two and three of the Paedagogus might be read as an attempt to reorient them, to get them to produce, in effect, altered habits that would result in a different 'behind'. I do not mean that the 'Greek' paideia and social behaviours that Clement engages and tweaks were 'white' in direct relation to whiteness today.

33 Ahmed, 'A Phenomenology of Whiteness', 156-57, quoted more fully above.

34 Byron, Symbolic Blackness and Ethnic Difference, see note 2.

35 Phillip Webster, 'Psukhai that Matter: The Psukhē in and behind Clement of Alexandria's Paedagogus' (PhD thesis, University of Pennsylvania, 2016). 
Nonetheless, Ahmed's approach to whiteness enables us to examine the Paedagogus as a text that explicitly speaks to the capacities of bodies and prescribes actions and limits.

As Webster rightly notes, the framing analogy Clement uses in the opening of the Paedagogus is one of illness. Clement's writings need not be taken as representing Alexandrian reality per se; nonetheless, he critiques the putative orientation of his audience as epitomizing illness and diseased living. The Paedagogus provides instructions for healing the $\psi v \chi \eta ்$ that has been made ill from $\pi a ́ \theta \eta$ :

Just as, therefore, the body of those who are suffering needs a doctor, so too the $\psi v \chi \eta ́$ of those who are sick needs a pedagogue, in order that our passions might be healed. (1.1.3.1-3)

Even as the Logos, acting as Pedagogue, is the one Clement presents as able to heal one's afflicted $\psi v \chi \eta$, the bulk of the text consists of exhortations concerning what we might think of as daily habits: eating, drinking, clothing, bathing, sleeping, and sex. To give just one example, he writes:

Just as a hand that is bandaged or an eye that is smeared over indicate by their appearance a deeper meaning (v́róvolav) - disease - so too, cosmetics and dyes

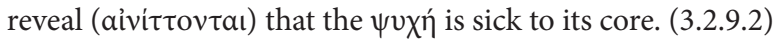

Note that Clement offers a form of physiognomic interpretation, by proposing that surfaces tell us about depths. The lesson - that someone wearing makeup has a sick soul - may not immediately seem relevant to talking about race or ethnicity, although the modern histories of race do indeed include assertions that inner essences are legible on surfaces. But if one's orientation to life both manifests a sick soul and takes the form of 'diseased' behaviours, one can read Clement as diagnosing his audience as lacking a sufficient awareness of the dire costs and implications of the habits they have inherited, that 'trail behind' them. ${ }^{36}$ The behaviours Clement unfolds as requiring Christian attention and altered habits in the name of healing work to produce not only new individual experiences but also an extension of these into space, to support and produce a new collective sense of belonging.

Someone who followed Clement's instructions would not necessarily have been assessed as a member of a distinct 'Christian ethnos'. Clement is not particularly innovative in his view of the human or his exhortations, drawn as they are from a range of Stoic, middle Platonic, and other precedents. The instructions include moderation with alcohol, avoidance of exotic foods, not dyeing one's hair or wearing jewels, wearing simple and undyed clothing, among other practices. Indeed, his instructions imply that his presumed audience occupies a social status for which norms of 'Helleneness' might have been their aspiration. His examples presume that his readers own slaves and have

${ }^{36}$ My thanks to Jacqueline Hidalgo for helping me arrive at this insight. 
the means to access the luxury items and practices under discussion; moreover, his instructions are differentiated by age and gender. ${ }^{37}$

As this section has suggested, we can ask whether insights about whiteness as it is produced and functions now can help us to notice and think differently about reconstructions of early Christian history and about the very production of membership

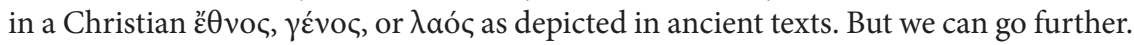

\subsection{Rethinking reconstructions of Christian boundaries}

Historical-critical approaches to the New Testament in their early articulations have functioned especially as a way for some European Protestants to authorize their own visions of 'true' Christianity over and against both institutionalized forms of contemporary Protestantism and especially against Catholicism, not to mention over and against those identified as anything other than 'Christian'. An insistence on the gap between the past and present goes hand in hand with the argument that New Testament writings offer a site for recovering the path from which 'original' Christianity strayed. ${ }^{38}$ Such approaches align Christian origins with a racialized logic of essential essences. ${ }^{39}$

This history of Historical Criticism may make it tempting to assert that 'whiteness', as it has been inherited and inhabited, including in Christian theology, is merely a kind of deforming infection to an otherwise blameless Christian essence. For George Yancy and many others, 'Christian theology and whiteness ... are incompatible', and whiteness should be viewed as a kind of 'structural sin'. ${ }^{40}$ We see a version of this also in Kameron Carter's work, which diagnoses 'racialized' and proto-racist thinking as symptomatic of Christian heresy, thereby insisting that there is an orthodox and thus authentic core of early Christianity available to anti-racist Christians today to reactivate.

The universalizing claims and aspirations we see in New Testament and early Christian writings are usually hailed as the key evidence to assert the essential non-racism or even anti-racism of Christianity. I have argued, in contrast, that the universalizing claims and aspirations in these ancient sources are fully compatible with defining belonging in Christ as entering into membership in a people, with acquisition of new ancestry and concomitant inheritance rights for gentiles. Furthermore, the possibility of belonging in Christ simultaneously communicates an implicit, if not explicit, assertion of the problem for those who fail to take up this membership. ${ }^{41} \mathrm{My}$ arguments are compatible with Victor Anderson's point that 'the gospel of Jesus is a scandalous gospel that carries within itself its own history of supersessions, which

37 Denise K. Buell, 'Ambiguous Legacy: A Feminist Commentary on Clement of Alexandria’s Works', in The Feminist Companion to Patristic Literature, ed. Amy-Jill Levine with Maria Mayo Robbins (London and New York: T\&T Clark, 2008), 26-55.

38 For one great example critically analysing this function of Protestant scholarship, see Jonathan Z. Smith, Drudgery Divine: On the Comparison of Early Christianities and the Religions of Late Antiquity (Chicago: University of Chicago Press, 1990).

39 See Buell, Why This New Race, 1-29.

40 George Yancy, 'Introduction', 5, 4, respectively.

${ }^{41}$ See Buell, Why This New Race, 138-65; and eadem, 'Early Christian Universalism and Modern Forms of Racism', in The Origins of Racism in the West, ed. Miriam Eliav-Feldon, Benjamin Isaac, and Joseph Ziegler (Cambridge: Cambridge University Press, 2009), 109-31. 
mimetically join Christology and whiteness; for the gospel of Jesus is good news for some and bad news for others. ${ }^{42}$

This double-edged and ambivalent legacy is one that demands interpretive approaches that show their 'work' in any reconstruction. One way to do so is to stress the stakes of interpretation and the context of production. As Frank Yamada has compellingly argued, the experience of Japanese Americans in the United States during the Second World War offers a productive lens to read Gen. 2-3; this juxtaposition highlights not 'original sin' or 'fall' but rather 'a setting of mistrust and control, marked by the arbitrary command of a suspicious ruling authority. ${ }^{43}$ I teach early Christian interpretations of Gen. 2-3, and specifically Nag Hammadi interpretations of Gen. 2-3, alongside Yamada's work, which offers an additional way to reorient our approaches to interpreting early Christian materials and reconstructing the varieties of early Christian perspectives.

Many of my students find it difficult to make sense of how Nag Hammadi texts such as the Hypostasis of the Archons and the Secret Revelation of John read Gen. 2-3 so as to refute the legitimacy of the one who commands Adam not to eat of the fruit of the tree of knowledge. ${ }^{44}$ Many of my students find these texts alienating and opaque because they are unfamiliar and non-canonical. Their non-canonical status makes some students suspicious of them before even beginning to read, since these texts have typically been classified as 'heretical' or 'heterodox'.

After discussing these ancient texts in class, I assign Frank Yamada's essay, which centres the experiences of Japanese-American Christians interred in detention camps such as Manzanar in the United States during the Second World War to frame his interpretation of Gen. 2-3. Yamada rightly notes that the disobedient humans in Genesis are not in fact put to death by God, as threatened, but instead cursed and exiled from the garden. He notes that 'when interpreters align their perspective with the divine point of view, human disobedience, which is usually equated with sin, creates a rift between God and humanity. ${ }^{35}$ But, in contexts including the experience of Japanese Americans' internment by their own government, we can ask whether 'ruling authority is justified in suppressing humanity's initiative, especially in the name of state security, ${ }^{36}$ whether the rule comes from a divine source or a human one. And, as Yamada points out, the Genesis narrative makes clear that, despite the threat of death and the imposed exile, humanity continues to thrive.

On the one hand, Yamada's essay helps students of all backgrounds to imagine the kinds of social contexts that might have produced readings of Gen. 2-3 such as appear in Nag Hammadi texts, thus serving to undermine conventional historical narratives

42 Victor Anderson, 'The Mimesis of Salvation and Dissimilitude in the Scandalous Gospel of Jesus', in Christology and Whiteness: What Would Jesus Do? ed. George Yancy (New York: Routledge, 2012), 196-211, at 196.

43 Frank Yamada, 'What Does Manzanar Have to Do with Eden? A Japanese American Interpretation of Genesis 2-3', in They Were All Together in One Place? Toward Minority Biblical Criticism, ed. Randall C. Bailey, Tat-siong Benny Liew, and Fernando F. Segovia (Atlanta: SBL Press, 2009), 97-117, at 115.

${ }^{44}$ For these texts in English translation, see Marvin Meyers, ed., The Nag Hammadi Scriptures: The International Edition (San Francisco: HarperOne, 2007).

45 Yamada, 'What Does Manzanar Have to Do with Eden?', 113.

46 Yamada, 'What Does Manzanar Have to Do with Eden?', 114. 
that render the texts products of elite heretics. Yamada notes that 'the tree of the fruit of the garden of good and evil functions initially as a way to distinguish between the divine and the human' and that this 'prohibition not to eat from the tree ... is arbitrary, ${ }^{47}$ a use of power to maintain - and I would suggest create - distance between the gods and humans. I could not read this without thinking of the arbitrariness of racial and ethnic distinctions deployed in the process of declaring Japanese Americans intrinsically suspect in the name of preserving 'American' loyalty during the Second World War.

On the other hand, juxtaposing these readings of Gen. 2-3 also raises important theological and ontological differences between them. Unlike the Nag Hammadi texts, which offer an alternative singular divine source of authority outside of the text of Gen. $2-3$, Yamada's essay shows that the very aspiration for a singular, totalizing authority divine or otherwise - is one that racially minoritized groups and individuals have good reason to question. I would say that the majoritized ought to be just as sceptical.

By modulating between specific historical or contemporary contexts and reading communities and ancient texts, I am calling attention to what is true of all biblical interpretation: It is located, situated, and partial. But majoritized forms of biblical studies continue to position the goal and ideal of biblical studies as a rejection or minimizing of these frames - a move that I see as aligned with perpetuating whiteness as normative, regardless of the embodiment of those who participate in the guild. To counter this, we need to expand biblical studies to include the production and interpretations of the Bible in specific contexts over time, so that the borders between New Testament and early Christian history no longer hold; so that the borders between New Testament and reception history no longer hold. ${ }^{48}$

\section{Conclusion: The price of the ticket}

'White people are not white: part of the price of the white ticket is to delude themselves into believing that they are. ${ }^{49}$ James Baldwin stresses the amnesia required of those who have become white in America, that white Americans cannot afford to confront the reasons for their presence in America and the losses this transition has entailed. At the same time, he rightly connects this amnesia with additional costs, borne especially

47 Yamada, 'What Does Manzanar Have to Do with Eden?', 108.

48 It is precisely in this spirit that much feminist (notably including that of Elisabeth Schüssler Fiorenza and Bernadette Brooten) and minoritized scholarship has been produced over the last four decades. One important institutional form this has taken is in the Institute for Signifying Scriptures (ISS), founded by Vincent Wimbush. See one of the fruits of contributors to the ISS, for example, Vincent Wimbush, ed., with the assistance of Lalruatkima and Melissa Renee Reid, Misreading America: Scriptures and Difference (Oxford: Oxford University Press, 2013); as well as Vincent Wimbush, White Men's Magic: Scripturalization as Slavery (Oxford: Oxford University Press, 2012) and Jacqueline M. Hidalgo, Revelation in Aztlán: Scriptures, Utopias, and the Chicano Movement (New York: Palgrave Macmillan, 2016). The Society of Biblical Literature's Semeia series is also an important publishing venue for scholars using interpretive approaches that offer important alternatives for biblical and early Christian studies.

49 James Baldwin, 'The Price of the Ticket', in idem, Collected Essays (New York: Library of America, 1998), 830-842, at 835 . 
by those of African descent: 'I know very well that my ancestors had no desire to come to this place; but neither did the ancestors of those who require of my captivity a song. They require of me a song less to celebrate my captivity than to justify their own., 50 Baldwin refers to his own Christian upbringing, to the exhortation to 'do our first works over', as a practice that white Americans do not observe, a practice that would call whiteness into question.

Reorienting away from whiteness in New Testament and early Christian studies would require those of us in these fields to 'do our first works over' in the sense of reassessing the costs of our dominant methodologies and transforming them in conversation with ones already available in minoritized, feminist, and other marginalized scholarship. This work is part of much larger academic concerns. ${ }^{51}$

My home institution, a top-tier undergraduate institution in the United States, has an institutional commitment to diversifying the student body, faculty, and staff, defining diversity in the historical context that has produced patterns of underrepresentation that persist in US higher education, especially by gender, race, ethnicity, and socioeconomic factors. Thus, in terms of hiring faculty, this commitment means first and foremost efforts to recruit faculty from ethnic and racial groups still underrepresented at my institution, and female faculty members of all backgrounds in fields where they are still underrepresented. But these efforts are most likely to be successful when academic units first have done the work to consider the values of their respective curricular areas: to ask why they consider certain methods, frameworks, questions, and content to be vital and others to be elective; to consider which pedagogies are recognized as valuable and effective and why; both to discuss what they currently do well and to educate themselves about new trends in their field(s), especially those directions being developed by scholars from groups still underrepresented in the field(s). This advance work makes it far more likely that a hiring unit will craft a position description attractive to candidates from underrepresented groups, and that the unit will be an actively supportive and informed context for a new hire to thrive. All of this work Ahmed helps us to understand as absolutely vital to reorienting us away from the institutional structures and habits that sustain whiteness, regardless of the racial identifications of the individual bodies in our institutional spaces.

\section{References}

Ahmed, Sara. 'Declarations of Whiteness: The Non-Performativity of Anti-Racism'. borderlands 3, no. 2 (2004). Available online: http://www.borderlands.net.au/ vol3no2_2004/ahmed_declarations.htm (accessed 3 April 2017).

Ahmed, Sara. 'A Phenomenology of Whiteness'. Feminist Theory 8, no. 2 (2007): 149-68.

Ahmed, Sara. On Being Included: Racism and Diversity in Institutional Life. Durham, NC: Duke University Press, 2012.

50 Baldwin, 'The Price of the Ticket', 842.

51 For a trenchant analysis, see Sara Ahmed, On Being Included: Racism and Diversity in Institutional Life (Durham, NC: Duke University Press, 2012). 
Anderson, Victor. 'The Mimesis of Salvation and Dissimilitude in the Scandalous Gospel of Jesus'. In Christology and Whiteness: What Would Jesus Do?, edited by George Yancy, 196-211. New York: Routledge, 2012.

Anidjar, Gil. Semites: Race, Religion, Literature. Stanford, CA: Stanford University Press, 2008.

Baldwin, James. 'The Price of the Ticket'. In idem, Collected Essays, 830-42. New York: Library of America, 1998.

Bernasconi, Robert. 'Waking up White and in Memphis'. In White on White/Black on Black, edited by George Yancy, 17-25. Lanham, MD: Rowan \& Littlefield, 2005.

Brodkin, Karen. How the Jews Became White Folks and What That Says about Race in America. New Brunswick, NJ: Rutgers University Press, 1998.

Buell, Denise Kimber. Why This New Race: Ethnic Reasoning in Early Christianity. New York: Columbia University Press, 2005.

Buell, Denise Kimber. 'Ambiguous Legacy: A Feminist Commentary on Clement of Alexandria’s Works'. In The Feminist Companion to Patristic Literature, edited by AmyJill Levine with Maria Mayo Robbins, 26-55. London and New York: T\&T Clark, 2008.

Buell, Denise Kimber. 'The Afterlife is Not Dead: Spiritualism, Postcolonial Theory, and Early Christian Studies'. Church History 78, no. 4 (2009): 862-72.

Buell, Denise Kimber. 'Early Christian Universalism and Modern Forms of Racism' In The Origins of Racism in the West, edited by Miriam Eliav-Feldon, Benjamin Isaac, and Joseph Ziegler, 109-31. Cambridge: Cambridge University Press, 2009.

Buell, Denise Kimber. 'Challenges and Strategies for Speaking about Ethnicity in the New Testament and New Testament Studies'. Svensk Exegetisk Årsbok 49 (2014): 33-51.

Byron, Gay L. Symbolic Blackness and Ethnic Difference in Early Christian Literature. New York: Routledge, 2002.

Byron, Gay L. 'Ancient Ethiopia and the New Testament: Ethnic (Con)texts and Racialized (Sub)texts.' In They Were All Together in One Place? Toward Minority Biblical Criticism, edited by Randall C. Bailey, Tat-siong B. Liew, and Fernando F. Segovia, 161-90. Atlanta: SBL Press, 2009.

Carter, J. Kameron. Race: A Theological Account. Oxford: Oxford University Press, 2008.

Cave, Sydney. The Religious Quest of India: Redemption Hindu and Christian. London: Humphrey Milford, 1919.

Clark, Elizabeth A. Founding the Fathers: Early Church History and Protestant Professors in Nineteenth-Century America. Divinations. Philadelphia: University of Pennsylvania Press, 2011.

Dube, Musa, ed. Other Ways of Reading: African Women and the Bible. Atlanta: SBL Press, 2001.

Eliav-Feldon, Miriam, Benjamin Isaac, and Joseph Ziegler, eds. The Origins of Racism in the West. Cambridge: Cambridge University Press, 2009.

Frankenberg, Ruth. White Women, Race Matters: The Social Construction of Whiteness. Minneapolis: University of Minnesota Press, 1993.

Frye, Matthew Jacobson. Whiteness of a Different Color: European Immigration and the Alchemy of Race. Cambridge, MA: Harvard University Press, 1998.

Gilman, Sander. The Case of Sigmund Freud: Medicine and Identity and the Fin de Siècle. Baltimore: The Johns Hopkins University Press, 1993.

Harrison, Peter. 'Religion' and the Religions in the English Enlightenment. Cambridge: Cambridge University Press, 1990.

Harvey, Jennifer, Karin A. Case, and Robin Hawley Gorsline, eds. Disrupting White Supremacy from Within: White People on What We Need to Do. Cleveland: Pilgrim, 2004. 
Heschel, Susannah. Abraham Geiger and the Jewish Jesus. Chicago: University of Chicago Press, 1998.

Hickman, Jared. 'Globalization and the Gods, or the Political Theology of "Race”. Early American Literature 45, no. 1 (2010): 145-82.

Hidalgo, Jacqueline M. 'The Politics of Reading: US Latinas, Biblical Studies, and Retrofitted Memory in Demetria Martínez's Mother Tongue. Journal of Feminist Studies in Religion 29, no. 2 (2013): 120-31.

Hidalgo, Jacqueline M. Revelation in Aztlán: Scriptures, Utopias, and the Chicano Movement. New York: Palgrave Macmillan, 2016.

Jennings, Willie James. The Christian Imagination: Theology and the Origins of Race. New Haven: Yale University Press, 2010.

Johnson, Sylvester A. The Myth of Ham in Nineteenth Century American Christianity: Race, Heathens, and the People of God. New York: Palgrave, 2004.

Johnson-DeBaufre, Melanie. 'Mapping the Field, Shaping the Discipline: Doctoral Education as Rhetorical Formation'. In Transforming Graduate Biblical Education: Ethos and Discipline, edited by Elisabeth Schüssler Fiorenza and Kent Harold Richards, 319-53. Atlanta: SBL Press, 2010.

Kelley, Shawn. Racializing Jesus: Race, Ideology and the Formation of Modern Biblical Scholarship. London and New York: Routledge, 2002.

Kidd, Colin. The Forging of Races: Race and Scripture in the Protestant Atlantic World, 1600-2000. Cambridge: Cambridge University Press, 2006.

Lincoln, Bruce. Theorizing Myth: Narrative, Ideology, and Scholarship. Chicago: University of Chicago Press, 1999.

Lipsitz, George. The Possessive Investment in Whiteness: How White People Profit from Identity Politics. Revised and expanded edn. [1993] Philadelphia: Temple University Press, 2006.

McCoskey, Denise Eileen. Race: Antiquity and its Legacy. London and New York: I. B. Tauris, 2012.

McIntosh, Peggy. 'White Privilege: Unpacking the Invisible Knapsack'. Peace and Freedom July/August (1989): 10-12.

Meyers, Marvin, ed. The Nag Hammadi Scriptures: The International Edition. San Francisco: HarperOne, 2007.

Moxnes, Halvor. Jesus and the Rise of Nationalism: A New Quest for the Nineteenth-Century Historical Jesus. London: I. B. Tauris, 2012.

Olender, Maurice. The Languages of Paradise: Race, Religion, and Philology in the Nineteenth Century, translated by Arthur Goldhammer. [Original French, 1989] Cambridge, MA: Harvard University Press, 1992.

Patel, Vimal. 'Diversifying a Discipline'. The Chronicle of Higher Education, 27 March 2016. Available online: http://www.chronicle.com/article/Diversifying-a-Discipline/ (accessed 3 January 2017).

Perkinson, James. White Theology: Outing Supremacy in Modernity. New York: Palgrave MacMillan, 2004.

Roediger, David R. The Wages of Whiteness: Race and the Making of the American Working Class. Revised edn. [1991] London and New York: Verso, 1999.

Schüssler Fiorenza, Elizabeth. But She Said: Feminist Practices of Biblical Interpretation. Boston: Beacon, 1992.

Schüssler Fiorenza, Elisabeth. Rhetoric and Ethic: The Politics of Biblical Studies. Minneapolis: Augsburg Fortress, 1999.

Smith, Jonathan Z. Drudgery Divine: On the Comparison of Early Christianities and the Religions of Late Antiquity. Chicago: University of Chicago Press, 1990. 
Society of Biblical Literature, Society Report, November 2015. Available online: https:// www.sbl-site.org/assets/pdfs/SR2015_online.pdf (accessed 23 March 2017).

Streeter, Burnett Hillman and Aiyadurai Jesudasen Appasamy. The Sadhu: A Study in Mysticism and Practical Religion. London: Macmillan, 1923.

Thandeka. Learning to be White: Money, Race, and God in America. New York: Continuum, 1999.

Vessey, Mark, Sharon V. Betcher, Robert A. Daum, and Harry O. Maier, eds. The Calling of the Nations: Exegesis, Ethnography, and Empire in a Biblical-Historic Present. Toronto: University of Toronto Press, 2011.

Viswanathan, Gauri. Outside the Fold: Conversion, Modernity, and Belief. Princeton, NJ: Princeton University Press, 1998.

Ware, Vron and Les Back. Out of Whiteness: Color, Politics, and Culture. Chicago: University of Chicago Press, 2002.

Webster, Phillip. 'Psukhai that Matter: The Psukhē in and behind Clement of Alexandria's Paedagogus'. PhD thesis, University of Pennsylvania, 2016.

Wimbush, Vincent. White Men's Magic: Scripturalization as Slavery. Oxford: Oxford University Press, 2012.

Wimbush, Vincent, ed., with the assistance of Lalruatkima and Melissa Renee Reid. Misreading America: Scriptures and Difference. Oxford: Oxford University Press, 2013.

Yamada, Frank. 'What Does Manzanar Have to Do with Eden? A Japanese American Interpretation of Genesis 2-3'. In They Were All Together in One Place? Toward Minority Biblical Criticism, edited by Randall C. Bailey, Tat-siong Benny Liew, and Fernando F. Segovia, 97-117. Atlanta: SBL Press, 2009.

Yancy, George. 'Introduction: Framing the Problem' In Christology and Whiteness: What Would Jesus Do? edited by George Yancy, 1-18. New York: Routledge, 2012. 


\title{
The Bible in the Bush: The First 'Literate' Batswana Bible Readers' ${ }^{1}$
}

\author{
Musa W. Dube
}

\section{A storyteller meets storytellers}

The title of this chapter is derived from Laura Bohannan's celebrated essay, 'Shakespeare in the Bush'. After briefly summarizing Bohannan's essay, I first consider the issues it raises for biblical translation, and turn next to discuss some of the first written responses of Batswana to Robert Moffat's translation of the Setswana Bible of 1857. ${ }^{2}$ I then consider how the responses of Batswana to this missionary translation represent subversive ways of reading, resisting the colonial perspective, and the wider challenges this poses for biblical translation and the issues of race and culture with which translation is bound up.

In her essay, Laura Bohannan, an American anthropologist from the University of Oxford, describes her second field trip to the Tiv, a Nigerian ethnic group, to observe some of their rare ceremonies. She had, mistakenly, chosen an inappropriate time for field work. She arrived when the swamps were rising, which hindered communication and interaction between different homesteads. Before the swamps dropped and ploughing could begin, the Tiv, hosting Bohannan, amused themselves with drinking beer, telling stories, singing, and dancing. There were no ceremonies performed because the swamps cut communication between various homesteads. So, Bohannan found herself with plenty of time on her hands and very little to do save to read a copy of Hamlet that was given to her, following an argument with a friend, who held that Americans tend to misunderstand Shakespeare, 'a very English poet', for they 'easily misinterpret the universal by misunderstanding the particular. ${ }^{3}$ Bohannan protested

1 A longer version of this article was first published in Translation 2 (Spring 2013): 79-103. This edited version is republished here by permission.

2 In this article 'Botswana' refers to the country; 'Batswana' refers to the people of Botswana; and 'Setswana' refers to the language and culture of Botswana. 'Motswana' is the singular of 'Batswana'. The colonial spellings were different: 'Bechuana' for 'Botswana' and 'Sechuana' for 'Setswana'.

3 See Laura Bohannan, 'Shakespeare in the Bush: An American Anthropologist Set Out to Study the Tiv of West Africa and Was Taught the True Meaning of Hamlet', Natural History 75 (1966): 28-33, at 28 . 
against this perspective, holding that 'human nature is pretty much the same the whole world over, at least the general plot and motivation of the greater tragedies would always be clear - everywhere - although some details of custom might have to be explained and difficulties of translation might produce other slight changes.' ${ }^{4}$ To end an argument they could not conclude, the friend gave Bohannan a copy of Hamlet 'to study in the African bush', hoping that it would lift her mind 'above its primitive surroundings' and that with prolonged meditation she might 'achieve the grace of correct interpretation', namely the English one. ${ }^{5}$ The more Bohannan read Hamlet, the more she became convinced that 'Hamlet had only one possible interpretation, and that one is universally obvious. ${ }^{6}$

It happened that one morning the Tiv invited Bohannan to tell them a story. Thinking to herself that 'here was my chance to prove Hamlet universally intelligible, ${ }^{7}$ Bohannan accepted the invitation to tell a story. And so she began in their own style of telling a story, 'Not yesterday, not yesterday, long ago a thing occurred!' Bohannan continued, 'One night three men were keeping watch outside the homestead of the great chief, when suddenly they saw the former chief approach them.' Disruption. The Tiv asked, 'Why was he no longer their chief?' 'He was dead,' Bohannan explained. ${ }^{9}$ 'Dead?' Dead people do not walk, according to the Tiv's beliefs. So one of the elders made a point of correction: 'Of course, it wasn't the dead chief. It was an omen sent by a witch. Go on. ${ }^{10}$ Altogether, I counted up to nineteen questions the Tiv posed to Bohannan, besides commentary, suggestions, and co-telling. This was the trend of their listening. They questioned, objected, commented, and provided explanations for the events that motivated the plot, quite freely placing the story within their cultural worldviews and then urging Bohannan to continue with the story. Midway through their active listening and rewriting of Hamlet Bohannan writes, 'Hamlet was again a good story to them, but it no longer seemed quite the same story to me.'11

Quite shaken by the elder's self-assured explanation, Bohannan continued, 'One of these three was a man who knew things.' ${ }^{\prime 2}$ This was the closest translation that she could find for a scholar, but unfortunately it also meant a witch among the Tiv. When she explained that the scholar associated the appearance of the dead chief with Hamlet, his son, the elders disapproved: Such omens were issues to be handled by chiefs and elders not youngsters. They were of the opinion that, at the most, Hamlet should have consulted a specialized diviner to seek clarification about the death of his father and then approached elders thereafter for them to handle the case for him. They began to debate among themselves and to provide reasons why Hamlet did not follow this path. They concluded that the diviner would have been afraid to divulge information about the most powerful man in the land, King Claudius.

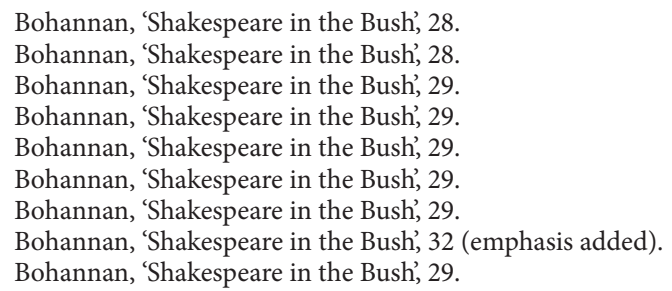


In the process of this major retelling of Hamlet, Bohannan became quite upset by the Tiv for taking the story from her and telling it in their own way. The point of whether the ghost was an omen or not, whether a ghost or omen can talk, walk, or cast a shadow, was an intense moment of debate between the Tiv and Bohannan. One old man pulled a Kola nut from his pocket, bit it, and gave it to her, thus making peace with Bohannan and asserting that it was not a fight but rather the art of storytelling. The listeners in most African cultures are not passive listeners. They participate, urging the storyteller to go on and providing commentary; indeed, in some African cultures the listeners are so active that they can take the story from the storyteller and tell it in another direction. The storytelling space, therefore, becomes a writerly moment, a moment of public production of new stories through old stories and with various other storytellers. The storyteller does not have the last word, nor does one story exist to the exclusion of others. Rather, a storytelling moment is a space of production of new stories within the existing field of other stories. ${ }^{13}$ It becomes a moment of networking of stories.

\section{My response and implications for translations}

There is much more that can be said about Bohannan's narrative from various perspectives than I have been able to summarize. Like Bohannan, who had crossed many boundaries to reach the Tiv and found herself hedged by the swampy season, 'the number of borders being crossed in one translation are always multiple ${ }^{14}$ as Hamlet in the bush amply demonstrates.

When I first read 'Shakespeare in the Bush', I was highly impressed by the Tiv community. They were an empowered audience, who listened critically, questioning, commenting, making suggestions, thereby rewriting the story within their own cultural worldview. While initially Bohannan thought her task was merely to find some 'equivalent' words such as using 'great chief' for 'king' or 'machete' for 'swords', the task involved much more. As translation studies have underlined, the translation of any work is not just a matter of formal, dynamic, or functional equivalents of words, phrases, sentences, meaning, or effect. Rather, translation work or processes involve 'the translation of cultures', fully informed by the agendas of the patrons, publishers, and purposes they serve. Consequently, translation studies 'no longer defines translation as an activity that takes place between two languages, but views it as an interaction between cultures.' ${ }^{15}$ The Tiv had asked for Bohannan's story and threatened not to tell her any of their stories unless she told them stories from her culture.

For the Tiv, it was an exchange of stories, within their ethnic space, within their cultural boundaries and within their own values. The Tiv acknowledged Bohannan's language limitation, saying, 'You must explain what we do not understand, as we do

13 Laura E. Donaldson, Decolonising Feminisms: Race, Gender, and Empire Building (Chapel Hill: University of North Carolina Press, 1992), 139.

14 See Edwin Gentzler, Contemporary Translation Theories, 2nd edn (Clevedon, UK: Multilingual Matters, 2001), 203.

15 Gentzler, Contemporary Translation Theories, 190. 
when we tell you our stories. ${ }^{16}$ As an anthropologist, Bohannan was a story collector. She had not forgotten that, as an anthropologist, she came primarily to collect African stories for a European audience. Thus the moment they said that madness is caused by witchcraft and creatures in the forest, Bohannan reports, 'I stopped being a storyteller and took out my notebook and demanded to be told more about these two causes of madness. Even while they spoke', she says, 'I jotted down notes, I tried to calculate the effect of this new factor on the plot.' ${ }^{17}$

It was quite intriguing to me, as an African, that Bohannan reached a point when, while her audience was enjoying the story, to her, it was no longer the same story. At this point I said, 'Laura Bohannan, welcome to the world!' For us Africans who come from largely oral communities, and in a historical context where the first written stories - whether they are cultures, history, religion, language - were written by Westerners, especially during colonial times, it has been excruciatingly painful to read the anthropological record, the travellers' story, the missionary record; for the most part, one cannot recognize herself. It is a different story, precisely because it is an African story that is grafted and interpreted within a Western culture. Unfortunately, the colonial context, which entailed the collection of the stories of the Other, who is different, was a time when the other was already despised. Consequently, the refraction of our stories was informed not only by Western cultures, but also by racism and Eurocentrism.

Similarly, when I first read 'Shakespeare in the Bush' I also wondered what kind of Bible translations would we have if our translators and communities were culturally empowered citizens involved in intra- and intercultural activity where there is more interactive intercourse between the source and the target text, not intercourse in the missionary style where the target culture is supposedly always submissively underneath, receiving male sperms from the source text - the biblical/Westernized cultures - but rather in a more interesting love-making where wrestling turns everybody, up, down, sideways, and all angles. What kind of Bible translations would we have?

Further, do we desire this type of translation, or do we build a hedge of theories, intuitions, policies, practices, ideologies, agendas, experts, publications, and cultures that often mute the targeted communities as subjugated 'recipient cultures'? 'Shakespeare in the Bush' posits a model of translation as a public hearing. It posits a model that calls us to regard targeted communities and their cultures as just as sacred as the stories we bring from other cultures, just as worthy of critical assessment for various forms of oppressions as all other cultures. It posits a model where recipient/ targeted communities are not the subjugated Other. Reading this story, I became quite interested in those historical moments when culturally empowered communities first heard the Bible and the translations they embarked upon to bring the story home, and how such translational spaces were negotiated - if we can exegete them from missionary narratives. This, of course, leads me to the second part of my essay, namely, the response of the first 'literate' Batswana readers to the Setswana Bible translation. I have placed the word 'literate' in quotation marks to indicate the fact that there is literacy in all cultures outside the Westernized school system.

\footnotetext{
16 Bohannan, 'Shakespeare in the Bush', 29.

17 Bohannan, 'Shakespeare in the Bush', 31.
} 


\section{The first Batswana Bible readers}

In this section, I seek to tell the story of the translated Setswana Bible and how the Batswana received the biblical story from the earliest translation presented to them. The translation was in stages, stretching from 1830, when the translation of the gospel of Luke was completed, to 1840 , when the New Testament translation was completed, to 1857 , when the first complete Bible was first printed in Kuruman, located in presentday South Africa. Since it is important to study the translators, their time, context, agenda, ideology, and patrons, a brief background of our Bible translator is in order.

The Scottish missionary, Robert Moffat, who started his work in Southern Africa in 1817 , is credited with translating the first Setswana Bible. The academic records of Moffat indicate that he was a gardener, who later trained as a farmer. He joined the London Missionary Society (henceforth LMS) in 1816 and arrived in South Africa in 1817 to start his job. ${ }^{18}$ Obviously, Moffat's training was close to nothing - one year or less. As Clement Doke points out, 'Moffat had never trained as a linguist' (nor a biblical scholar, I must add) and 'he came up against intricacies of Tswana. ${ }^{19}$ In addition, Moffat carried out his work and translation during the height of modern colonialism, fully immersed in its thinking and attitudes towards the colonized.

How did the Batswana respond to the translation? To explore this question, I will largely read the letters Batswana wrote to the editor of Mahoko a Becwana, a newspaper that was published by the LMS from Kuruman between 1883 and 1896. A number of 'literate' Batswana wrote letters on various subjects, which gives us a window into how they responded to the Setswana Bible translation. These letters were recently collected and made available in the volume Words of Batswana: Letters to Mahoko a Becwana 1883-1896. ${ }^{20}$ I will focus on those letters dealing with correct ways of writing Setswana, since the first written Setswana was associated with Bible translation. Perhaps the reader is wondering how and why Hamlet is comparable to the Setswana Bible. Just as Hamlet was a work of 'a very English poet', so the Setswana Bible was a work of a Scottish man, who was grafted into his worldview, which, at the time, was that of the British Empire. Would the Batswana readers demonstrate efforts to reclaim the Setswana culture like the Tiv of Nigeria? The analysis of their letters will greatly assist us in answering this question. In reading these letters, I seek to identify ways employed by the earliest Batswana Bible readers to resist colonizing translations and how their resistance was an assertion of their ethnic and cultural identity.

I must admit that comparing the Tiv with Batswana literate writers may be unfair on several levels. First, the Tiv had an opportunity to comment and rewrite the story of Hamlet as the story was being told. The Batswana writers were only making comments on a completed written translation - Moffat does not give us an elaborate description of their engagement with the biblical story in the process of translation. Their letters, written between 1883 and 1896, were drafted almost four decades after Moffat's New

${ }^{18}$ Clement Doke, 'Scripture Translation into Bantu Languages', African Studies 17, no. 2 (1958): 84-99.

19 Doke, 'Scripture Translation', 85.

${ }^{20}$ Part Themba Mgadla and Stephen C. Volz, trans. and eds, Words of Batswana: Letters to Mahoko a Bechwana, 1883-1896 (Van Riebeeck Society, Second Series 37; Cape Town: Van Riebeeck Society for the Publication of South African Historical Documents, 2006). 
Testament appeared in 1840. However, since the LMS newspaper allowed them to express their views - it was the first newspaper of its kind among Batswana speakers we could say that these are the first written responses we have to the translated version, addressed to the missionaries and fellow Batswana. Remarkably, forty years after the first Setswana New Testament publication, the debate was still hot. We may well say that these Batswana writers had been waiting to exhale!

Although I have not had access to the Batswana's first oral hearing and response to the biblical story, I have read Moffat's 642-page volume on Missionary Labours and Scenes in Southern Africa, a volume he published in 1842 in London, two years after he published the Setswana New Testament translation. The volume amply indicates that in the first decades Batswana resisted the biblical story, displaying significant indifference, which was frustrating to missionaries. Moffat thus observed that 'although they received much instruction, they appeared never for a moment to have reflected upon it, nor to retain traces of it in their memories, which are generally very tenacious. ${ }^{21}$ To illustrate the point, he cites two examples: one from his friend and another from his arch-enemy, the rain-ritualist, who is constantly named the rainmaker in Moffat's writing. Moffat describes his friend, Munameets, as a very supportive and intelligent Bechuana man who always travelled with him. Just before his death, however, Munameets rhetorically pleaded incapacity to understand Moffat's teaching due to age, deferring such a task to the future generations. Munameets said, 'Perhaps you may be able to make children remember your mekhua (customs). ${ }^{\prime 2}$ The second case, involving the speech of the rain-ritualist who received great acclaim, leads Moffat to remark that 'the poor missionary's arguments, drawn from the source of Divine truth, were thrown into the shade.23 Moffat narrates, 'When we attempted to convince them of their state as sinners, they would boldly affirm with full belief in their innate rectitude that there was not a sinner in the tribe. ${ }^{24}$ And so Moffat laments, 'Oh when shall the day-star arise in their hearts? We preach, we converse, we catechize, we pray, but without the least apparent success. ${ }^{25}$

These are largely reported accounts in Moffat's book, but I have not yet come across intense engagement concerning a particular biblical story, displaying dialogue, comparable to Bohannan's encounter with the Tiv. ${ }^{26}$ The letters to the editors, which began to come in 1883, the year that Moffat died, discussed his Bible translation,

${ }^{21}$ Robert Moffat, Missionary Labours and Scenes in Southern Africa (London: John Snow, PaternosterRow, 1842), 244.

22 Moffat, Missionary Labours, 246.

23 Moffat, Missionary Labours, 247.

24 Moffat, Missionary Labours, 254. See also Robert P. Carroll, 'Cultural Encroachment and Bible Translation: Observations on Elements of Violence, Race, and Class in the Production of Bibles', Semeia 76 (1996): 39-54, where he discusses a case of one missionary's attempt to deal with a lack of guilt among his target audience in Latin America by making a translation that said the particular group 'killed Jesus'.

25 Moffat, Missionary Labours, 285. See also Jean Comaroff and John Comaroff, Of Revelation and Revolution: Christianity, Colonialism and Consciousness in South Africa, Vol. 1 (Chicago: The University of Chicago Press, 1991), where they show that, in fact, Batswana were very resistant to Christian conversion, until a time when they realized that they had lost autonomy to the ever encroaching forces of colonialism.

26 See Comaroff and Comaroff, Of Revelation and Revolution, 228, attesting that some Bantus' response to the biblical text was to regard it as 'an instrument of divination'. 
focusing on the orthography, the various dialects of Setswana, the correct way of writing Setswana and various Christian teachings that clashed with Setswana culture, thus serve as my source for now.

\section{Setswana Bible translation: Whose interests are served?}

Given Moffat's accounts of Batswana's disinterest and indifference towards biblical teaching, it is clear that they hardly asked for the biblical translation. What was the purpose of this translation, when the community was quite indifferent? Who commissioned it, and who was served by such a translation? We can hardly place it in the hands and agenda of Batswana. As Part Mgadla and Stephen Volz point out:

Most African-language publications in the nineteenth century were produced by European missionaries as part of a larger project to make the Bible and other Christian teachings more widely available to potential converts. This process began in southern Africa in the 1820s and 1830s with the publication of biblical excerpts, catechisms and other materials in Setswana, Sesotho, and Isxhosa. The first complete vernacular Bible was in Setswana, published in 1857 by the LMS. ${ }^{27}$

The agenda behind the Bible translation lay outside Batswana's interest. It follows that it did not necessarily serve their interest or agenda. Obviously Moffat's Setswana was not perfect when he undertook the translation, and I have yet to discover literature that describes the indigenous people who helped him with the task. In his voluminous book, Missionary Labours and Scenes in Southern Africa, which I, as a native of that region, can only describe as a 'text of terror', Moffat speaks very disparagingly and bitterly of his interpreter for his poor translations, to a point where he holds that

a missionary who commences giving direct instruction to the natives, though far from being competent in the language, is proceeding on a safer ground than if he were employing an interpreter, who is not proficient in both languages, and who has not a tolerable understanding of the doctrines of the Gospel. Trusting to an ignorant and unqualified interpreter, is attended with consequences not only ludicrous, but dangerous to the very objects which lie nearest the missionary's heart. ${ }^{28}$

\section{An English Setswana}

And so, Moffat had produced a Setswana Bible translation before he had grasped the language, and with much distrust of the indigenous translators. Five to six decades later, different mission centres had used Moffat's Bible to develop better Setswana, even within the LMS; hymns and other books had appeared with an improved Setswana

27 Mgadla and Volz, Words of Batswana, xix.

28 Moffat, Missionary Labours, 294. 
orthography. So by 1883 there were varieties of written Setswana, Robert Moffat's Bible translation being the crudest of all. As the number of educated Batswana rose, they became dissatisfied with Moffat's translation, as their letters to the editor of Mahoko a Becwana attest. The debate regarding the correct way of writing and pronouncing Setswana became heated as soon as the newspaper (Mahoko a Becwana) was launched. Many Batswana writers insisted that Robert Moffat's earliest translation clearly indicated that he did not understand the language. They preferred the latest forms of writing and pronouncing Setswana. ${ }^{29}$

Since better ways of writing Setswana had been developed over the years, most Batswana readers also insisted that the latter should be adopted as the standard for the newspaper. At the centre of the debate were the letter $d$, which was translated with $l$ or $r$; the consonant $w$, which was written as oe; and the letter $t$, which in some words needed to appear with $l(t l)$, in some words with $h(t h)$ and in others with $l h(t h)$ together. If $l, h$, or $l h$ is left out of the letter $t$ where they need to be included, it creates different meanings than the intended. A good case in point is the verb 'created' in Gen. 1.1. When $h$ was left out of $t l$, the verb was written as 'tlola' ('jump') instead of 'tlhola' ('create'). The Moffat Bible thus read: 'In the beginning God jumped the heavens and the earth,' instead of 'In the beginning God created the heavens and the earth. ${ }^{30}$

Another debate centred around the vowels $e$ and $o$, whether they should be written plainly or with an accent and a macron, respectively (i.e. è and õ). In each case, using or not using the letters $d, w$, or the accented/marked $e$ and $o$, not only changed the pronunciation of the Setswana word, in some cases, it also changed the meaning, as elaborated above. In his letter to the editor, dated December 1889, Sekaelo Piti captures and illustrates the general concern. He wrote:

We have complained much about our language in the books, because they have not been representing true Setswana but rather Setswana and English - an English Setswana - that is read as only a reminder of the real thing. ${ }^{31}$ For example, ' $g o$ diha' [to make] has been written as 'go riha', 'didimala' [be quiet] as 'ririmala' or 'lilimala', also 'Modimo' [God] as 'Morimo', and 'legodimo' [heaven] as 'legorimo'. But when we saw hymn books in the year 1883 , we were very happy because a missionary had arrived who speaks the language of our mothers and who speaks proper Setswana. He says, 'Yesu kwana ea Modimo' [Jesus lamb of God] and not 'Yesu koana' or 'kuana'. This missionary also printed a spelling book in the year 1885. He is the one who knows the true language of Setswana. ${ }^{32}$

29 See Mgadla and Volz, Words of Batswana, 7-42.

30 Mgadla and Volz, Words of Batswana, 29.

31 This writer was spot on, for indeed when Moffat discusses how he designed the written Setswana, it is clear that he based it on Western languages and sounds. Giving guidance of how to pronounce Setswana, he says, 'Ch [is] represented in Bechuana by the Italian c, is sounded like ch in chance ... tl, like the Welsh 11 , preceded by a $t$; ng, which is represented in the written language by the Spanish $\tilde{n}$, has the ringing sound of ng in sing. This outline will enable anyone to read the language with tolerable correctness'; Moffat, Missionary Labours, 226. He goes on to discuss how the word Botswana was spelt differently among the Dutch or English, depending on whether they found an equivalent sound or not in their own languages.

32 Mgadla and Volz, Words of Batswana, 31. 
These concerns were quite legitimate for in some cases the changing or leaving out of one letter dramatically changed the meaning of the verses. For example, changing the $w$ in kwana to a $u$ created verses that, instead of reading 'Jesus the lamb [kwana] of God', or 'behold the lamb of God', actually read 'Behold the hat [kuana] of God.' If 'go diha' is used for the verb 'to make', it would easily be heard and understood as 'to drop something down' instead of to make or create. Going back to Gen. 1.1, suppose the translation chose the missionary spelling of 'to make' (that is used go diha) for 'to create', the Setswana translation could read: 'In the beginning when God dropped (diha) the earth and the heavens', instead of made (dira). In other cases, the translation created meaningless new words, such as 'ririmala' for 'didimala' (be quiet). The new word, ririmala, could possibly be read as referring to a hairy stomach, if it signifies anything at all.

In the same letter to the editor mentioned above (December 1889), Gomotsegang Magonaring provides a number of examples to illustrate how replacing the consonant $d$ with $r$ created new unintended meanings. For example, exchanging an $r$ for the $d$ in the word for 'thundering' or 'sounding' (duma) produces the word ruma, which means 'to devour.' With the $d$ replaced with $r$ in the verb duela (to pay), one reads ruela, which means 'to keep, domesticate, or possess something for someone. ${ }^{33}$ One can imagine that if a verse said Jesus paid (duela) for our sins it would now be read to mean he kept (ruela) our sins. Similarly, the word dumela - which is used in Setswana as areeting - meaning 'let's agree' or 'peace among us', written with an $r$ instead of $d$ would read rumela, which now means 'send'!

Second, Batswana were unhappy because, through translation and the written books (hymns, spelling books, dictionaries, Bible), their language was now infused with English and effectively an English version of Setswana. Piti called it 'an English Setswana - that is read only as a reminder of the real thing. ${ }^{34}$ As Banani Diphafe would state in his letter of January 1890, 'I see us becoming confused, only parallel to the language and speaking it like a white person who is just learning Setswana. He says "Modimo" [God] as "Morimo", and "dilo" [things] as "lilo." Speaking with a "d" sounds right but " $l$ " is ridiculous. ${ }^{35}$ In Setswana only little children, who are learning to speak, are expected to be unable to be pronounce words and say things such as 'lilo', instead of 'dilo'. Moffat's translation thus introduced changes that made readers sound like stuttering and stammering little babies who are still learning how to talk when they read the now Anglicized version of their own language. The translation had infantilized them. Hence each time they had to read the Bible they had to put on the persona of infants. Age among Batswana is traditionally an important social marker, far above gender, in fact; failing to recognize an elderly person and to treat them as a child is regarded as greatly disrespectful and insulting. Naturally Batswana readers would be upset by their Bible-reading experience, which, to them, sounded like children learning to speak.

33 Mgadla and Volz, Words of Batswana, 31.

${ }_{34}$ Mgadla and Volz, Words of Batswana, 36.

35 Mgadla and Volz, Words of Batswana, 35. 
In a letter dated 6 June 1883, the missionary editor (Alfred Gould), though patronizing, acknowledged that, indeed, the issue of the correct way of writing Setswana needed to be attended to. ${ }^{36} \mathrm{He}$ then promised to refer the issue for consideration by the General Missionary Council. This he did, although not until three years later. On his return, he reported that the Missionary Council had voted to return to the most 'original' written Setswana - one that was consistent with the earliest Bible translation of Robert Moffat, and to suppress the newer ways of writing, which were more appreciated by Batswana. This meant the retention of the most corrupted written Setswana. The report on the response of missionaries, dated 2 September 1889, is worth quoting at length:

In March this year, missionaries of the LMS who teach in the language of Setswana gathered at Kuruman. As they met, they took up the issue of the letters that are used for printing and writing. Many missionaries of other missions oppose some of the letters with which they have been writing. They reject them because they have never liked them. They reject the letter $d$ and they reject the letter $w$. These missionaries like the old way of printing, the one that is still used today for the Bible and the Testament. They also argue that the old printing is known by many more people. So, these things were discussed, and it was agreed that those letters should not be changed, and that writing and printing should be done only with the old letters. Now $w$ has been dropped so that it will be written 'banoe' (others) not 'bañwe' and it will be written 'rumela' [greet] not as 'dumela', and 'Morimo' God not 'Modimo', and 'lilo tse di thata' [difficult things] not 'dilo tse di thata'. It was agreed that è and õ should be changed and instead put as plain $e$ and plain $o$. Some letters will for the time being still be published as they are. The letter ' $h$ ' will be used to differentiate 'tlala' [hunger] from 'tlhala' [divorce]. ${ }^{37}$

The report indicates that one little but significant victory was won, concerning the inclusion of $h$ in the syllable $t l$. This meant that at last Gen. 1.1 could be read as, 'In the beginning God created (thola) the heavens and the earth', instead of, 'In the beginning God jumped (tlola) the heavens and the earth.' Indeed, Alfred Wookey's 1908 revised version of the Setswana Bible did just that.

The report from the missionary council meeting, however, had more bad news than good. The overall concerns with other central consonants and vowels such as $d, l, w, \tilde{o}$, and $\dot{e}$ ) were rejected. The reasons given are quite telling and patronizing, to say the least; the views and feelings of the missionaries were all that mattered. It was what they liked that would stand. The prevailing or current and better ways of writing, appreciated by Batswana speakers, were to be reversed. The protests of Batswana about their distorted, meaningless language, which was now reduced to 'an English Setswana - that is read only as a reminder of the real thing, ${ }^{38}$ did not matter, 'for these missionaries like the old way of printing. ${ }^{39}$ The report goes on to say, 'So these things were discussed, and

\footnotetext{
Mgadla and Volz, Words of Batswana, 15-16.

Mgadla and Volz, Words of Batswana, 27.

Mgadla and Volz, Words of Batswana, 29.

Mgadla and Volz, Words of Batswana, 27.
} 
it was agreed that those letters should not be changed, and that writing and printing should be done only with the old letters', that is, the Robert Moffat Setswana Bible translation. The missionaries preferred the English Setswana and insisted that it should be the standard way of writing. Their response assists us to answer better the question about whose agenda is served in the translation process.

\section{Decolonizing the English Setswana: Subversive ways of reading}

Following this report, the letters to the editor indicate that many Batswana objected to this decision and others pleaded for the decision to be reconsidered, to no avail. They were, in fact, protesting about something that had already been concluded, a nonnegotiable issue - until such time that it pleased the missionaries to reverse it. Shot down, forced to write and read Setswana according to the stuttering tongue of a child, forced to read and write in English Setswana, the Batswana were, nonetheless, not helpless. In fact, they had already developed strategies of reading that circumvented the imposed discourse of the 'English Setswana'. They had hoped it could be corrected, but now they had been informed that what would be maintained as the standard way of writing the Setswana language was what the missionaries liked. Consequently, the Batswana readers fell back upon their strategies of reading as resisting readers. Dikokwane Gaboutlwelwe, who wrote in response to the report using the example of Genesis 1, illustrates the point:

I see the old written Setswana in the Bible as we read in Genesis, chapter one. There we find it written like this: 'Morimo o lo ua tlola magorimo le lehatsi mo tsimologong.' ... but when we read it aloud we say, 'Modimo o lo wa thola magodimo le lehatshe mo tshimologong. ${ }^{40}$

Gaboutlwelwe reveals that their reading strategy overlooked the colonial missionaries' constructed English Setswana language. Instead they read the Moffat Bible from their oral base, putting back all the excluded consonants $d, h$, and $w$, and ignoring the new creations of $r, l$, and $u a$ that infantilize readers, create confusion or meaningless words and induce wrong meanings. So, in fact, even if the verse said 'In the beginning God jumped [tlola] the heavens and the earth', they read it as 'In the beginning God created [thola] the heavens and the earth.' This reading strategy is further confirmed by Sebotseng Loatile who also responded to the missionary's report:

I am very happy to receive the newspaper and to hear the words that I have been hearing. I hear news about other nations and the word of God. But about the letters that have been taken out, I am very concerned. I assumed that our Bible was printed as it is because the missionaries had not quite grasped our language. But

${ }^{40}$ Mgadla and Volz, Words of Batswana, 29. 
now they understand our language and they speak it very well. So I am surprised they are removing core letters $[d, w, \tilde{o}$, and $\dot{e}]$. Here everyone who reads books is not happy about the removal of the letters that have been removed. You should know that when we read our Bible we change the letters with our mouths. ${ }^{41}$

This strategy of reading from the base of the oral tradition is quite significant. What is in the oral base is the whole culture, another canon, embodied by the community. The refusal to change what was overtly wrong assisted Batswana readers to openly assert their oral tradition and understanding as the main reference point rather than to take the English Setswana Bible as the final authority on their culture. This was crucial because the English Setswana translation of the Bible involved more than just the replacement of key consonants and vowels with newly created (li ri) ones. It also included changing the Batswana spiritual world from sacred to evil in order to supplant it with Christianity. An excellent example of this, which I have previously examined, is the translation of badimo as 'demons. ${ }^{42}$ I re-narrate my encounter with this translation in order to illustrate how the Batswana ways of reading from the Setswana oral tradition base subverted the colonial discourse of darkness and heathens.

\section{Reclaiming Badimo as sacred figures: Batswana reading strategies}

In 1995 I carried out fieldwork research, seeking to read Mt. 15.21-28 with Batswana women. In the process, I discovered something else: That 'demons' had been translated as 'ancestors' in the Alfred Wookey revised Setswana Bible of $1908 .^{43}$ I did not have access to Robert Moffatt's original Bible of 1857 to verify where this use of 'ancestors' for 'demons' originated. Where in Mt. 15.21 the woman says, 'My daughter is severely possessed by demons', in the Setswana translation it reads, 'My daughter is severely possessed by badimo/ancestors.' Where Jesus casts out demons in the original, Jesus casts out the badimo/ancestors in the translation. I was so shocked by this translation that I pored over all the other New Testament passages where Jesus casts out demons to verify my stunning discovery.

And I discovered a very sad story: The word 'demons' had been consistently translated as 'ancestors' in the Setswana Bible. It was shocking. Almost desperately, I turned to Mark 5, where Jesus casts out the legion of demons that possessed and maddened a man in Gadarene. I discovered that in the Setswana Bible of 1908 Jesus cast out the legion of badimo, who ran into the sea and were buried beneath its waves. It was a textual burial of badimo/ancestors. I was virtually trembling, shocked that Batswana who first read the so-called word of God were made to discover that those they venerated as sacred figures were, in fact, just demons. Ancestors - the extended

${ }^{41}$ Mgadla and Volz, Words of Batswana, 33 (emphasis added).

42 See Musa W. Dube, 'Consuming a Colonial Cultural Bomb: Translating Badimo into "Demons" in the Setswana Bible', JSNT 73 (1999): 33-59.

${ }_{43}$ For the original description see Dube, 'Consuming a Colonial Cultural Bomb', 37-42. 
memory of the families and ethnic groups with their departed members - could not be reduced to demons without reducing everyone to the same. What a perfect way of proving that Batswana were helpless heathens lost in the darkness.

For more than 150 years Batswana Bible readers consumed this colonial bomb, planted to explode their cultures away, and they could not read Greek for themselves to check if this was representative or the closest 'equivalent' term. I was deeply shaken. But that was before I discovered that the first Batswana readers had long learnt to read the Bible from their oral cultural base rather than the missionaries' perspective of heathens in the darkness. As expressed by Gaboutlwelwe and Loatile: 'You should know that when we read our Bible we change the letters with our mouths. ${ }^{\text {'4 }}$ But how would they reinstate the demonized badimo?

Again, this was a separate but pleasant surprise and discovery. In the process of reading the Bible with non-academic women, who were church leaders in African Independent Churches, I found out that they read/use the Bible as a divination set. Now, divination among Batswana involves consulting badimo about all situations of concern for the living and finding useable solutions. It involves recognizing badimo as mediators between the living, the dead, and God. So, far from badimo functioning as demons in the service of negative power, in the Batswana ways of reading, badimo, together with Jesus, were divine forces of positive power. I could not have imagined this U-turn. This strategy of resistance depends on reading the Bible with and through Batswana oral cultures. It depends on using the authority of African traditions rather than giving the English Setswana Bible the final word. It is comparable to the strategy of the Tiv, taking a story that conflicted with their values and retelling it such that to them it was 'a good story again', although to Bohannan 'it no longer seemed quite the same story'. Like Bohannan, the travelling anthropologist, Bible translation and translators have long crossed many boundaries; they are already perched among elders and communities who seek to hear more stories told according to their own cultural terms, even if the story may no longer seem quite the same story to its bearers.

In the field of biblical translation we have a particularly rich archive for the study of cultural interaction. As Philip Noss writes: 'No other book has been translated over such a long period of time, portions of no other literary work have been rendered into many languages, and no other document is today the object of such intense translation activity as the Bible. ${ }^{35}$ By studying the first literate Batswana readers' response to the Moffat translation, we observed cultural interaction between the globalizing agents of mission and the inhabitants of the local context. To digress a little, as a biblical scholar, I think we have underutilized this major archive, since most of the time translation is not part of our biblical and religion departments, save for the exercises of those learning Greek, Hebrew, Syriac, French, German, and Spanish. It is good that there are independent schools of translation, but how did Bible translation as an area of study become so marginal from the academic studies of the Bible, given the record that Noss highlights? How did the theories of translation in the past six

44 See note 41.

45 Phillip A. Noss, ed., A History of Bible Translation (History of Bible Translation 1; Rome: Edizione di storia e letteratura, 2007), 1. 
decades become propounded largely among linguists, with a marginal participation of biblical scholars? Although we may be touching here on the power, patronage, agenda, and ideology of translation houses and their structures, ${ }^{46} \mathrm{I}$ still cannot explain why academic departments of the Bible and religion do not have full-fledged programmes on translation. In the light of what Noss tells us, it is a major gap. In a recent article I have argued for a curriculum shift in biblical studies in favour of studying the language of the first translated Bible in one's particular region. ${ }^{47}$ That is, instead of Two-ThirdsWorld biblical students being required to learn two more European languages on top of Greek and Hebrew, as is the standard requirement, they should rather learn and pass a language that was used to translate the first Bible translation in their region.

The preceding study of the battles over the translation of the Bible into Setswana illustrates how translations are embedded in wider cultural conflicts, bound up with ideologies of empire and race. The translation wars highlight that translations are informed by racialized constructions of different ethnicities. Bible translations are not neutral towards various ethnic identities, cultures, and their religions but often embody the power and interests of one group over against another. The ways in which Batswana readers resisted the imposed translation, and found ways to construct and sustain their own community readings, provides one model of how decolonizing readings might be developed. Such decolonizing community rewritings are long overdue.

\section{References}

Bohannan, Laura. 'Shakespeare in the Bush: An American Anthropologist Set out to Study the Tiv of West Africa and Was Taught the True Meaning of Hamlet'. Natural History 75 (1966): 28-33.

Carroll, Robert P. 'Cultural Encroachment and Bible Translation: Observations on Elements of Violence, Race, and Class in Production of Bibles in Translation'. Semeia 76 (1996): 39-54.

Comaroff, Jean and John Comaroff. Of Revelation and Revolution: Christianity, Colonialism and Consciousness in South Africa, Volume 1. Chicago: The University of Chicago Press, 1991.

Doke, C. 'Scripture Translation into Bantu Languages'. African Studies 17, no. 2 (1958): 84-99.

Donaldson, Laura E. Decolonising Feminisms: Race, Gender, and Empire Building. Chapel Hill: University of North Carolina Press, 1992.

Dube, Musa W. 'Consuming a Colonial Cultural Bomb: Translating Badimo into "Demons" in the Setswana Bible'. JSNT 73 (1999): 33-59.

Dube, Musa W. 'The Scramble for Africa as the Biblical Scramble for Africa: Postcolonial Perspectives'. In Postcolonial Perspectives in African Biblical Interpretations, edited by

${ }^{46}$ Gosnell L. O. R. Yorke, 'Bible Translation in Africa: An Afrocentric Interrogation of the Task', in Postcolonial Perspectives in African Biblical Interpretations, ed. Musa W. Dube, Andrew M. Mbuvi, and Dora R. Mbuwayesango (Atlanta: Society of Biblical Literature, 2012), 157-69.

47 Musa W. Dube, 'The Scramble for Africa as the Biblical Scramble for Africa: Postcolonial Perspectives', in Postcolonial Perspectives in African Biblical Interpretations, ed. Musa W. Dube, Andrew M. Mbuvi, and Dora R. Mbuwayesango (Atlanta: Society of Biblical Literature, 2012), 1-26, at 11-15. 
Musa W. Dube, Andrew M. Mbuvi, and Dora R. Mbuwayesango, 1-26. Atlanta: Society of Biblical Literature, 2012.

Gentzler, Edwin. Contemporary Translation Theories. 2nd edn. Clevedon, UK: Multilingual Matters, 2001.

Mgadla, Part Themba and Stephen C. Volz, trans. and eds. Words of Batswana: Letters to Mahoko a Bechwana, 1883-1896. Van Riebeeck Society, Second Series 37.

Cape Town: Van Riebeeck Society for the Publication of South African Historical Documents, 2006.

Moffat, Robert. Missionary Labours and Scenes in Southern Africa. London: John Snow, Paternoster-Row, 1842.

Noss, Phillip A., ed. A History of Bible Translation. History of Bible Translation 1. Roma: Edizioni di Storia e Letteratura, 2007.

Yorke, Gosnell L. O. R. 'Bible Translation in Africa: An Afrocentric Interrogation of the Task'. In Postcolonial Perspectives in African Biblical Interpretations, edited by Musa W. Dube, Andrew M. Mbuvi, and Dora R. Mbuwayesango, 157-69. Atlanta: Society of Biblical Literature, 2012. 


\title{
Exploring the (In)Visibility of the Christ- believers' 'Trans-ethnicity': A Lowland Filipina Catholic's Perspective
}

\author{
Ma. Marilou S. Ibita
}

Recently some Western scholars have problematized the issue of the alleged 'transethnicity' or universalism of the earliest Christ-believers based on new interpretations of biblical texts. ${ }^{1}$ From the perspective of my predominantly Roman Catholic upbringing in the Philippines, in this essay I shall argue that the Western-influenced view of trans-ethnic Christianity in relation to issues of ethnicity, race, and religion can be seen not only in the biblical text but also in relation to the identity of the Catholic biblical interpreter(s) and their choice of particular hermeneutical approaches and methods. ${ }^{2}$ Given these interrelated factors, I will explore the question of the possibility and/or desirability of 'breaking out' of these Western assumptions and offer suggestions for a way forward through a dialogical method.

\section{The lowland Filipino Catholic interpreter}

Let me begin with the interpreters. Currently about 80 per cent of Filipinos are Catholics. ${ }^{3}$ Most live in the 'lowland' setting which is generally influenced by

1 For a recent discussion, see David G. Horrell, 'Ethnicisation, Marriage and Early Christian Identity: Critical Reflections on 1 Corinthians 7, 1 Peter 3 and Modern New Testament Scholarship', NTS 62, no. 3 (2016): 439-60.

2 For a critical view, see R. S. Sugirtharajah, 'Introduction, and Some Thoughts on Asian Biblical Hermeneutics', BibInt 2, no. 3 (1994): 251-63; R. S. Sugirtharajah, The Bible and Asia: From the Pre-Christian Era to the Postcolonial Age (Cambridge, MA: Harvard University Press, 2013); Heikki Räisänen et al., Reading the Bible in the Global Village: Helsinki (Reading the Bible in the Global Village 1; Atlanta: Society of Biblical Literature, 2000); Fernando F. Segovia and Mary Ann Tolbert, eds, Reading from This Place. Vol. 2: Social Location and Biblical Interpretation in Global Perspective (Minneapolis: Fortress, 1995).

3 This means about 74,211,896 in 2010. See Philippine Statistics Authority, Philippines in Figures 2015 (Quezon City: Philippine Statistics Authority), 28. Available online: https://psa.gov.ph/sites/default/ files/2015\%20PIF\%20as\%20of\%20June\%202016.pdf (accessed 29 April 2017). 
Catholicism brought by the Spanish colonizers in $1521 .^{4}$ The riverine or coastal areas of the various islands are occupied by the major ethnic and linguistic groups of Tagalog, Cebuano, Ilocano, Visaya, Hiligaynon, Waray, and Bicol. The other ethnic groups and earlier Islamic groups that did not convert to Spain's brand of Roman Catholicism have been forced to go up into the mountains or live near the sea or on boats due either to Christian-Muslim conflict or because of the Christians' exploitative relationship with them. ${ }^{5}$ While consciousness of the varied ethnic and linguistic groups in the Philippines persists, the identity of being 'Filipino' and 'Catholic' was also embraced as a new way of affirming communal identity. The character of Filipino Catholics' transethnic identity was influenced by centuries of Spanish colonization (1521-1898), followed by American Christian missions (1898-1946), ${ }^{6}$ and, thus, is of a Western character. The changes brought about by Vatican II and the Second Plenary Council of the Philippines, particularly the shift from the model of Christendom to the Church of the Poor, emphasized this shared and dominant Filipino Catholic identity. ${ }^{7}$

In my observation, the perception of being a Filipino Catholic moves within a complex continuum of visibility-invisibility. The sense of being Filipino highlights our ethno-racial identity. Being a Catholic underscores our religious trans-ethnic identity of belonging to a more universal group, that is, the Roman Catholic Church, which often eclipses our awareness of other Christian rites and denominations worldwide. The relationship between 'Filipino' and 'Catholic' is also very complicated, without necessarily being directly proportional. Within the country, the Catholic and Filipino identities are visible even if being a Filipino tends to be dissected into the various ethno-linguistic identities. The identities 'Filipino' and 'Catholic' also strengthen each other in situations like a papal visit, pilgrimaging or working abroad, or when helping others during environmental disasters. Abroad, 'being Filipino' becomes more prominent (although regionalism persists) because Catholicity is often presupposed among Filipinos unless outward signs indicate otherwise. Yet, the two identities may also clash. For example, the issue of extra-judicial killings related to the government's so-called war on drugs contrasts with the official Catholic Church's teaching and stance on the sacredness of everyone's life. ${ }^{8}$ Being Catholic seems to be secondary to Filipinos who consider supporting the current administration's drug

4 See Renato Constantino and Letizia R. Constantino, A History of the Philippines: From the Spanish Colonization to the Second World War (New York: Monthly Review Press, 1975), 17-23. The issue of ethnicity, race, and religion in southern Philippines, particularly the Christian-Muslim and Lumads conflicts, is beyond the scope of this chapter. See Stuart J. Kaufman, 'Symbols, Frames, and Violence: Studying Ethnic War in the Philippines', International Studies Quarterly 55, no. 4 (2011): 937-58.

5 See Edgar Javier, Building Christian Community: A Case Study of the Ethnic Minority Communities of Mindoro, Philippines (Rome: Pontificia Universitas Gregoriana, Facultas Missiologiae, 1985).

6 For a concise treatment of Philippine history and its impact on biblical interpretation, see Niceta Vargas, Word and Witness: An Introduction to the Gospel of John (Quezon City: Ateneo de Manila University Press, 2013), 287-90.

7 See Julio X. Labayen, Revolution and the Church of the Poor (Quezon City: Claretians, 1995); William Holden, 'From the Church of the Powerful to the Church of the Poor: Liberation Theology and Catholic Praxis in the Philippines', in The Changing World Religion Map, ed. Stanley D. Brunn (Dordrecht: Springer, 2015), 3095-114.

8 See Roy Lagarde, 'Church and gov't should collaborate, not clash - Cardinal Rosales', CBCP News Online. Available online: http://cbcpnews.net/cbcpnews/church-and-govt-should-collaborate-notclash-cardinal-rosales/ (accessed 29 April 2017). 
'war' as being patriotic, without taking into account the Church's teaching on the sacredness of life.

Focusing on the influence of being Filipino and Catholic in interpreting the Bible, the degree of understanding of Filipino Catholics' trans-ethnicity (i.e. the blurring of Filipino ethnicity) differs slightly depending on the different groups of lowland Filipino Catholic Bible interpreters and their exposure to other ethnic, racial, and religious groups within the Philippines and in the global diaspora. Trained exegetes, Filipinos and non-Filipinos, who are in the Philippines and who are largely trained in Western universities and guided by mostly Western-born or Western-educated mentors tend to be more aware of the varied ethnicities in the Bible. Yet, since most of them belong to international religious orders or are members of the clergy, they either facilitate the recognition of the various ethnicities in the Bible in their academic work or unconsciously promote the trans-ethnicity of the Catholics in their pastoral engagement. This is a point that I will take up again below.

The fluidity in recognizing and promoting the Christ-believers' global transethnicity can also be found among the Filipinos and the international theology students (mostly Asians) as they prepare for priesthood or as part of their formation as religious/ consecrated persons, lay church workers, religion teachers, or catechists. They receive biblical formation mostly through formal studies in seminaries and formation centres, some of which are multi-ethnic settings. Groups like the Episcopal Commission on the Biblical Apostolate provide additional help to other biblical interpreters. The use of various media of communication also promotes Bible knowledge which does not necessarily delve into the issues of ethnicity, race, and religion and their intersections. Recent academic research on the Bible, including on these topics, is not necessarily accessible, distributed, or discussed by these various groups of interpreters, much less shared with the larger Catholic community. However, while the knowledge-sharing might be inadequate in relation to issues of ethnicity and religion, and trans-ethnicity is inadvertently promoted, universalism is communicated in an ethnically and linguistically differentiated manner (Filipino languages, English).

In my observation, the lowland Filipino Catholics' way of relating to issues of ethnicity, race, and religion is influenced by what Ernst Conradie calls 'doctrinal lenses' or 'heuristic keys'.

Heuristic keys are typically based on the dominant beliefs, doctrines, values, customs, theological trajectories, and habits of (ecclesial or academic) interpretative communities. They are not directly derived from either the Biblical texts or the contemporary world but are precisely the product of previous attempts to construct a relationship between text, tradition and context. ${ }^{9}$

The idea of Christianity as a trans-ethnic group can arguably be considered a doctrinal lens. It has been formed through the history of interpretation of the biblical text and it also influences the ongoing interpretation of the Bible while engaging the challenging

9 See Ernst Conradie, 'The Road Towards an Ecological Biblical and Theological Hermeneutics', Scriptura 93 (2006): 305-14, at 306; see also idem, 'Towards an Ecological Biblical Hermeneutics: A Review Essay on the Earth Bible Project', Scriptura 85 (2004): 123-35. 
issues of our times. This doctrinal lens of trans-ethnic Catholic Christianity is dominant among lowland Filipinos through the idea of 'fictive kinship'. It is based on the interpretation of the language of God's Fatherhood and the sibling references to the Christ-followers in the New Testament. The Catechism for Filipino Catholics describes self-identity as rooted in the Filipinos' family-orientation: God is the heavenly Father and Jesus is a brother (kapatid). ${ }^{10}$

The doctrinal lens of fictive kinship as applied to church members of different ethnicities promotes trans-ethnicity primarily through the Church's liturgy and sacraments. Mt. 6.9-13 is taught as the basic prayer that inculcates God's Fatherhood and projects an image of the Church as a universal fictive kinship group that goes beyond race, ethnicity, and nationality. Popular liturgical songs like Hesus na Aking Kapatid (Jesus, my Brother), which depicts Jesus like the poor Filipinos, also deepen the trans-ethnic sibling message. ${ }^{11}$ The sibling language in the liturgy communicates the invisibility (plurality and differences) and visibility (unity) of the trans-ethnic character of Catholicism. The Catholic lectionary convention of using 'brothers and sisters' as an introduction to the second liturgical reading when it is taken from one of the New Testament epistles also promotes trans-ethnic fictive kinship even if the word $\dot{\alpha} \delta \varepsilon \lambda \varphi o$ does not appear in the pericope being cited. Despite some variation, usage of $a \dot{\alpha} \delta \lambda \varphi$ oi as referring to the Christ-believers' fictive kinship is frequent in the Pauline corpus ${ }^{12}$ and the liturgical use today fosters the trans-ethnic idea of siblingship. The same is true with the direct sibling address in the liturgical/sacramental greetings and in the homily of a Filipino/non-Filipino priest, bishop, or the pope. ${ }^{13}$

The notion of fictive siblingship conveys an almost perfect image of Roman Catholics' trans-ethnicity when used by the pope in his messages, especially at Christmas and Easter before an international crowd waving their nations' flags, broadcasted worldwide in various media. ${ }^{14}$ Using sibling address in international gatherings such as the World Youth Days emphasizes trans-ethnicity too. Universalism is also achieved by the use of 'brothers and sisters' in official documents, especially those coming from the pope. The trans-ethnic character even extends to non-Catholics during ecumenical encounters and to non-Christians as exhibited in some of the papal encyclicals. ${ }^{15}$ Universal siblingship is also promoted by the titular usage of local and foreign missionaries who through or despite their multi-ethnic and multiracial origins refer to one another

${ }^{10}$ See Catholic Bishops' Conference of the Philippines, Catechism for Filipino Catholics (Manila: ECCCE/Word and Life, 1997), nos. 34-5.

11 Eduardo Hontiveros, 'Hesus Na Aking Kapatid', in Bayan, Umawit, ed. Jesuit Music Ministry (Quezon City: Jesuit Communications Foundation, 2015), 81.

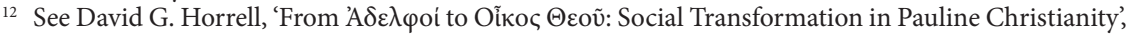
JBL 120, no. 2 (2001): 293-311.

13 For attempts to highlight the ethnic differentiation in the Bible in view of liturgical readings, see, for example, John J. Pilch, The Cultural World of Jesus: Sunday by Sunday, Cycle C (Collegeville, MN: Liturgical Press, 1997).

14 See, for instance, Pope Francis, 'Urbi et Orbi' (2016). Available online: https://w2.vatican.va/ content/francesco/en/messages/urbi/documents/papa-francesco_20161225_urbi-et-orbi-natale. html (accessed 29 April 2017).

15 For example, Benedict XVI, Caritas in Veritate. Available online: http://w2.vatican.va/content/ benedict-xvi/en/encyclicals/documents/hf_ben-xvi_enc_20090629_caritas-in-veritate.html (accessed 29 April 2017). The sibling term 'brothers and sisters' is found in paragraphs 1 and 78 of the encyclical, while 'brotherhood' is found in paragraphs 19, 55, and 59. 
as 'Brother Y' or 'Sister X' within their own religious congregation and among other people. Non-verbal expressions like statues/images similarly underline the Catholics' trans-ethnicity. For instance, the feast of the translation of the revered and well-loved image of the life-sized Black Nazarene in Quiapo as a poón (lord) underscores Jesus' identity as being God's Son, God's Fatherhood, and the devotee's fictive siblingship with the Nazarene and with fellow devotees. ${ }^{16}$ The Catholic trans-ethnic idea of fictive kinship is intensified by the Filipino way of treating other people as kapwa, that is, as one's self. Virgilio Enriquez, a pioneer in Filipino psychology, explains: 'The English word "others" is actually used in opposition to the "self," and implies the recognition of the self as a separate identity. In contrast, kapwa is a recognition of shared identity, an inner self shared with others.' ${ }^{17}$

Thus, the understanding of Catholic trans-ethnicity by the various groups of lowland Catholic Filipino biblical interpreters is shaped by Western influence through colonization. The doctrinal lens of fictive siblingship that nurtures the idea of Catholicism as a trans-ethnic identity is rooted in the teaching of God as Father and of the members as siblings through Jesus. Trans-ethnicity is communicated mostly through liturgy and other international Catholic gatherings and by non-verbal expressions. Along with the Filipinos' strong family-orientation and the concept of kapwa, the lowland Catholic Filipinos' awareness of identity moves in a continuum of visibility of ethnic differences to its invisibility (trans-ethnicity) with a stronger leaning towards the latter.

\section{The biblical text}

Additional Western-influenced factors affect the fluid perception of issues of ethnicity related to the biblical text. Filipino Catholics only had indirect access to the biblical narratives through catechesis, sermons, and liturgical readings. This prevailed until the reforms of Vatican II and the organization of Basic Ecclesial Communities. A more direct engagement was possible in the post-Vatican II period and after the massproduction of the Bible in various local languages. ${ }^{18}$ Only a few Filipino Catholics are actually aware that the Bible was originally written in Hebrew, Aramaic, and Greek.

Geographical and temporal distance from the biblical text in its historical settings likewise contributes to the difficulty in recognizing ethnic identities in the biblical text. For example, the reference to the Amalekites, Hittites, Jebusites, Amorites, and Canaanites in Num. 13.29 is crucial in geographically locating the promised land, but the places and ethnicities mentioned would seem abstract to the average

16 Mark Joseph Calano, 'The Black Nazarene, Quiapo, and the Weak Philippine State', Kritika Kultura 25 (2015): 166-87, esp. 173: 'While devotees know that the "Panginoong Hesus Nazareno" is the only true Son of God, by walking with him, an informant said, they become adopted as children of the Father and thus are "magkakapatid" (siblings to one another) regardless of social class or status.'

17 See Virgilio G. Enriquez, 'Kapwa and the Struggle for Justice, Freedom and Dignity', in Pamamaraan: Indigenous Knowledge and Evolving Research Paradigms, ed. Teresita B. Obusan, Angelina R. Enriquez, and Virgilio G. Enriquez (Quezon City: Asian Center, University of the Philippines, 1994), 1-181, at 3.

18 See Vargas, Word, 290. 
Filipino Catholic. The same goes for Acts 2.8-11, ${ }^{19}$ even if Judea, Egypt, Rome, and so on, recall present-day ethnic groups or geographic places where overseas Filipinos work. Advances in education and increased international economic migration have enlarged the chance of Filipinos being able to differentiate the ethnic identities found in the Bible. Yet the doctrinal lens of fictive siblingship continues to blur them and project unity with other Catholics worldwide.

The distribution of readings in the Church's liturgical year, fashioned after the Western hemisphere's seasons ${ }^{20}$ also influences the degree of visibility of the Catholics' trans-ethnicity. Advent and Christmas readings express the longing for the Jewish Messiah, but ethnicity is blurred when these readings are interpreted as presenting Jesus' birth not as a Jewish messianic fulfilment but a cosmic event that often overlooks his Jewish roots. Ordinary-time liturgical readings similarly tend to lessen the awareness of the specificities of ethnic identities since Jesus is portrayed and interpreted as ministering to people in need, but their varying ethnicities are overlooked. Texts like Mk 3.31-35//Mt. 12.46-50//Lk. 8.19-21 tend to be interpreted in today's preaching in the Philippines as setting aside Jesus' blood relationship and his Jewish ethnicity in favour of a more universalistic openness which should characterize present-day Christ-believers who hear God's word and put it into practice. When these biblical texts are popularized through audio-visual, symbolic and artistic forms, the trans-ethnic message is reinforced and perpetuated.

A different kind of example is found in the passion narratives read on Palm Sunday and Good Friday. Many preachers in Filipino churches tend to highlight the antagonists' Jewish ethnicity but inadvertently downplay Jesus' and his disciples' own Jewishness. Moreover, the Pabasa or Pasyon, as 'a type of religious verse that narrates the life of the Saviour and which has appeared in the major vernaculars in the Philippines ${ }^{21}$ since the Spanish colonization, continues in some areas until today. It encourages readers and hearers to identify with Jesus but with minimal focus on his Jewishness, even if he is recognized as a Galilean. ${ }^{22}$ The reasons behind the expulsion of the Jews in Spain in $1492^{23}$ most likely influenced the many ways Jews are negatively perceived both in Spain and its colonies. ${ }^{24}$ During the Spanish and American colonization, images from

19 For a recent work on ethnicity in Acts, see Eric D. Barreto, Ethnic Negotiations: The Function of Race and Ethnicity in Acts 16 (WUNT 2.294; Tübingen: Mohr Siebeck, 2010), 2-3 where he explains, 'Acts does not erase ethnic difference but employs the flexible bounds of ethnicity in order to illustrate the wide demographic ambitions of the early church movement but also the uneasy negotiations of ethnicity such a religious movement required.'

20 See Philip H. Pfatteicher, Journey into the Heart of God: Living the Liturgical Year (New York: Oxford University Press, 2013), 16.

${ }^{21}$ Rene B. Javellana, 'The Sources of Gaspar Aquino de Belen's Pasyon', Philippine Studies 32, no. 3 (1984): 305-21, at 305.

22 Reynaldo Clemeña Ileto, Pasyon and Revolution: Popular Movements in the Philippines, 1840-1910 (Quezon City: Ateneo de Manila University Press, 1997), 16.

23 The issue of ethnicity, race, and religion becomes more complicated in connection with the medieval Castilian passion narratives where Jesus and Mary are themselves portrayed as anti-Jewish. See Jessica A. Boon, 'Violence and the "Virtual Jew" in Castilian Passion Narratives, 1490s-1510s, Journal of Medieval Iberian Studies 8 (2016): 110-29.

24 See Minerva Generalao, 'Time to Check Pabasa for Anti-Semitic Contents, Says Caloocan Bishop'. Available online: http://newsinfo.inquirer.net/888866/time-to-check-pabasa-for-anti-semiticcontent-says-caloocan-bishop (accessed 29 April 2017). 
the Pasyon that speak of movement from death to life or from misery to salvation 'nurtured an undercurrent of millennial beliefs which, in times of economic and political crisis, enabled the peasantry to take action under the leadership of individuals or groups promising deliverance from oppression. ${ }^{25}$ Thus, a conflict within the realm of Jewish ethnicity has been evoked: The colonially oppressed Filipinos identified with the suffering Jesus, whose Jewish identity was (inadvertently) diminished, while the hated Spanish religious leaders and government officials were equated with the negatively characterized Jewish religious leaders and Jewish people. While the Catholic religion was (mis-)used by the colonizers to subjugate the local people, the Filipino Catholics' own re-appropriation of Jesus' message became their inspiration in the quest for freedom and a better life. The question of why the Jews were identified with the colonizers and at the same time Jesus' Jewishness was 'overlooked' demands closer future study.

Amy-Jill Levine, a Jewish New Testament scholar, who was a guest at the 2003 annual meeting of the Catholic Biblical Association of the Philippines, comments on the negative characterization of the Jews in the Pasyon:

I cannot help but wonder what those who hear this text recited thought about 'the Jews', especially since here the Roman soldiers disappear and 'the Jews' are the ones who mock, torture, and crucify Jesus. ... In case we miss the distinction between 'good Christians' and 'bad Jews', epithets accompany references: 'Scheming Jews' (882); 'ravenous Jews' (1615); ... this list does not even consider the epithets against the various Jewish groups, who are lumped together in any case. ${ }^{26}$

This example and the use of secondary literature, especially from the West, that inadvertently promotes (potential) anti-Judaism, presents a hermeneutical challenge in a post-Holocaust, post-Nostra Aetate world, even if some would consider the Philippines to be geographically far from Europe. ${ }^{27}$ It is, however, significant to recognize that despite the popularity of the eighteenth-century Pasyon, it did not necessarily lead to hatred towards particular Jews. The Philippines is one of the few countries that welcomed Jews fleeing the Holocaust and is the only one in Asia that voted for the creation of the State of Israel. ${ }^{28}$ It is the country with the second lowest percentage (3 per cent) of anti-Semitism in Asia. ${ }^{29}$ Presently, many Filipinos also work in Israel. ${ }^{30}$

25 Ileto, Pasyon, 14.

26 Amy-Jill Levine, 'A Jewish Reading of the New Testament', in Same Stories, Different Understandings: Jews and Catholics in Conversation (CBAP Lectures 2004; Manila: Catholic Biblical Association of the Philippines, 2004), 21-37, at 34.

27 See Levine, 'Jewish Reading', 30-7.

${ }_{28}$ For a concise history of Jewish presence in the Philippines, see Jonathan Goldstein, 'Shaping Zionist Identity: The Jews of Manila as a Case Study', Israel Affairs 15, no. 3 (2009): 296-304.

29 See Anti-Defamation League, 'Philippines'. Available online: http://global100.adl.org/\#country/ philippines/2014 (accessed 29 April 2017).

30 See Philippine Embassy, 'Profile of the Filipino Community in Israel'. Available online: http:// philippine-embassy.org.il/index.php?option=com_content\&view=article\&id=56:profile-of-thefilipino-community-in-israel\&catid=15\&Itemid=33 (accessed 29 April 2017). 
In sum, the history of accessing the biblical text, the geographical and temporal distance from the historical roots of the biblical text, the chosen readings according to the changing liturgical seasons, and the religio-socio-cultural and political influence in interpretations like the Pasyon, have various effects on the Filipino Catholic readers of the Bible. They become aware but not fully cognizant of the ethnic identities in the Bible. They develop close identification with Jesus' character in a way that tends to diminish the particularity of his Jewishness while identifying strongly with him in his ministry and passion, emphasizing his character's trans-ethnicity.

\section{Hermeneutics}

In addition to the interpreter and biblical text, hermeneutical processes marked by Western assumptions similarly influence the Filipino Catholics' lens in considering ethnicity in the Bible. From my lowland Filipino Catholic viewpoint, four aspects of the hermeneutical process show how the supposed universality and trans-ethnicity of Christian identity is infused with a clear Western bias: the language used in scholarship; the pattern of scholarly exchange; methodological preferences; and how the Bible is regarded.

First, the mainly Western languages used in biblical scholarship and the way ancient biblical languages are taught in Western universities highlight the issue of ethnic bias.

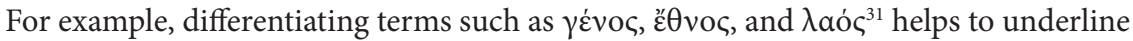
issues about ethnicity in the biblical texts, but it will be challenging for students of theology or religious studies in the Philippines to appreciate the differences, since they are not required to study the biblical languages, even if courses might be available in some educational institutions. For non-Western students, understanding critically the nuances of the debate is demanding. One needs to deal not only with the ancient languages and documents but also the different, mostly Western, languages of the secondary literature. Non-English native speakers similarly have some difficulties writing academic essays in the Western tradition. Western language courses do not fully solve the problem, because they are not necessarily geared towards exegetical issues or theological use of the Bible. Moreover, one's work is expected to be mostly written in English, and editing by a native speaker is expected, if it is for a publication or international conference presentation. Consequently, those who have good facility in these Western languages and who have access to or can pay a good language and stylistic editor have an immense advantage.

Second, the Western brand of trans-ethnicity in the interpretation process is likewise evident in the way biblical scholarly exchanges happen. Important opportunities to actively participate in the scholarly conversation are usually of Western origin using Western languages, ${ }^{32}$ following the Western hemisphere's academic calendar and

31 See David G. Horrell, “Race”, "Nation”, "People”: Ethnic Identity-Construction in 1 Peter 2.9', NTS 58, no. 1 (2012): 123-43.

32 For example, the Colloquium Biblicum Lovaniense (CBL) uses English, Dutch, French, and German. 
are held mostly in the West. ${ }^{33}$ Other factors make this similarly prohibitive: lack of available updated materials in preparing competitive papers that will be accepted in an international conference; travel and accommodation costs; and the unpredictability of securing a visa on time if one is travelling from the Philippines. ${ }^{34}$

Publication opportunities are also heavily Western focused. In 2013 I met with other Asian scholars in the context of the Society for New Testament Studies Asia Pacific Liaison Committee in Perth, Australia. I recall some of the difficulties that we discussed, such as the use of mainly Western criteria to determine whether or not a paper is worth publishing by mainly Western reviewers for Western journals that are deemed more preferable and reliable in the academy. Furthermore, these journals have prohibitive subscription rates whether in paper or digital form for non-Western scholars who may or may not have institutional support and who are mostly working within faith communities of modest budget. Likewise, non-Western styles of writing or methodology tend to be less likely to be published. This is not to mention the cultural journey of Asian students who are culturally trained to respect the wisdom of the elder and more established scholars and who need a lot of time and effort to 'overcome' their upbringing and adapt to Western ways of making 'critical' remarks. These factors make it difficult for non-Western scholars to participate actively and continuously in the global scholarly conversation. One of the dilemmas that I face is where to send my studies for publication: to Western journals (which generally are rated higher by project-approving bodies) or to the home-grown publications so that local knowledgesharing is enhanced and continued research is promoted? Which choice brings most benefits and in which ways? Is it the global, generally Western, audience who can be exposed to non-Western insights, or the local scholars who can benefit from new insights from a fellow Filipino scholar who has an increasingly hybrid exposure?

Third, varying preferences regarding the methods and approaches also highlight the Western bias and the ethnic differentiation of biblical scholars. The Pontifical Biblical Commission's document 'The Interpretation of the Bible in the Church' describes various hermeneutical approaches and methods including many that were developed in the West but with some openness for inculturation. ${ }^{35}$ Other approaches and methods have been developed since then which deal with the three worlds of the biblical text. ${ }^{36}$ They have their advantages and disadvantages depending on the context and preferences of the user, the kind of questions posed to the biblical text, and to what end these hermeneutical tools are being used. Many problematize the Western character of these methods and approaches while others have pointed out that they are all conditioned by

${ }^{33}$ July and August are the months for the Society of Biblical Literature's international conference (ISBL), the annual meetings of the European Association of Biblical Studies and Society for New Testament Studies, and for the CBL. The Philippine academic year, which starts in June, makes it difficult to participate in these conferences.

34 Although I could not be at the ISBL 2016 conference in Seoul, I was glad that it was held there in cooperation with the Korean Society of Old Testament Studies, The New Testament Society of Korea and the Society of Asian Biblical Studies. I hope that the opportunity led to genuine discussion and exchange between the various participants, from Asia and elsewhere.

35 See Pontifical Biblical Commission, 'The Interpretation of the Bible in the Church', Origins 23, no. 29 (1994): 497-524.

36 See Sandra M. Schneiders, The Revelatory Text: Interpreting the New Testament as Sacred Scripture (Collegeville, MN: Liturgical Press, 1999), 97-178. 
the one who uses them. ${ }^{37}$ Others underscore their limitations, recalling the remark of Audre Lorde, that 'the master's tools will never dismantle the master's house. ${ }^{38}$

Fourth, the Western academic preference of treating the Bible as ancient literature to be studied 'objectively' sometimes highlights the difference between them and Filipino Catholic Bible readers, including Filipino exegetes who (almost automatically) continue to regard the Bible also as God's Word, revelatory of God's will, with relevance to their own present context and a better future. In a complex way, the blurring of the ethnicities of Jesus and his early followers, that is, their trans-ethnicity, is then used to produce an inculturated and recontextualized interpretation of the Bible that responds to challenges in the Filipino context. The concern for the way Jesus' ministry was good news to the poor becomes more predominant than the question of the ethnicities of the biblical characters. This kind of engagement may or may not be supported by (Western) scholars who might find the research implications quite ideological. For example, the socio-political-cultural and economic contexts of the Philippines are motivating factors for the publications of Helen Graham, a long-time Maryknoll missionary to the Philippines from New York even before the Martial Law years, and for the late Carlos Abesamis, a Filipino Jesuit whose work is imbued with attempts to critically incorporate the Filipino context into his way of inculturating biblical interpretation. ${ }^{39}$ The Catholic Biblical Association of the Philippines' Annual Convention Papers also focus on a wider ecclesial theme based on the needs of the Catholic Church in the Philippines while using Western-inspired exegetical methods and other approaches. ${ }^{40}$

These four hermeneutical considerations, namely, the language used in scholarship, the pattern of scholarly exchange, methodological preferences, and how the Bible is regarded as a revelatory text in addition to being a subject of academic study, show how the hermeneutical methods and approaches, which generally stress the transethnicity and universality of Christian identity, actually continue to reflect and support their specific (ethnic) origin in the West, and thus continue to be problematic and inadequate for the lowland Filipino Catholic Bible readers. These readers need something more in addition to the academic information that one can gather from the biblical text and the currently available studies.

37 For a critical view see, for example, Fernando F. Segovia, 'The Emerging Project of Asian Biblical Hermeneutics: Reading Asian Readers', BibInt 2, no. 3 (1994): 371-3; Justin S. Ukpong et al., Reading the Bible in the Global Village: Cape Town (Global Perspectives on Biblical Scholarship 3; Atlanta: Society of Biblical Literature, 2002); Fernando F. Segovia, 'Criticism in Critical Times: Reflections on Vision and Task', JBL 134, no. 1 (2015): 6-29.

38 See Audre Lorde, 'The Master's Tools Will Never Dismantle the Master's House', in This Bridge Called My Back: Writings by Radical Women of Color, ed. Cherrie Moraga and Gloria Anzaldua (New York: Kitchen Table, 1983), 94-101. (See further Wei Hsien Wan's chapter - Eds.) Likewise, see Caroline Vander Stichele and Todd C. Penner, eds, Her Master's Tools? Feminist and Postcolonial Engagements of Historical-Critical Discourse (Global Perspectives on Biblical Scholarship 9; Atlanta: Society of Biblical Literature, 2005).

39 See Helen R. Graham, You Shall Be Handed Over: The Persecution Prediction in Mark 13:9-13 (Quezon City: Claretians, 1987); Carlos H. Abesamis, Salvation: Historical and Pastoral: Towards a Faith-Life that is Biblical, Historical, Indigenous (Integral Evangelization Series; Quezon City: JMC, 1978); idem, The Mission of Jesus and Good News to the Poor: Biblico-pastoral Considerations for a Church in the Third World (Nagliliyab 8; Quezon City: Claretians, 1987).

40 Available online: http://catholicbiblicalassociation.blogspot.be/ (accessed 29 April 2017). 
In sum, Parts 1 to 3 show that the identity of the interpreter, the biblical text itself and the hermeneutical processes employed, all affect the lowland Filipino Catholics' level of perception of the Western-influenced idea of trans-ethnicity in the Bible in relation to their own ethnic identity and context. While the first two show how an emphasis on trans-ethnicity promotes the 'Catholic' identity of the lowland Filipino people, the (Western) methodological choices indicate how the production of biblical interpretation continues to pose practical difficulties as well as to convey ideological and faith convictions which may relate awkwardly or unhelpfully to their ethnic identity as Filipino Catholics.

\section{Responding to the predominantly Western assumptions}

One of the aims of the 2016 Exeter conference on Ethnicity/Race/Religion: Identities, Ideologies, and Intersections in Biblical Texts and Interpretation was 'to explore and to problematize the extent to which the dominant models of biblical scholarship remain "Western" in their assumptions, and to consider what breaking out of these might entail ${ }^{41}$ Parts 1 to 3 enumerate some of the challenges related to this issue from a lowland Filipino Catholic's perspective. This part explores the question of 'breaking out' of the Western assumptions and offers some ways forward through a dialogical approach.

Many Filipino exegetes have been schooled in Western methodologies, and I am not so sure if we can, or if we need to, totally break out of 'Western assumptions., ${ }^{42}$ Yet a related challenge has been posed: While we who are non-Western endeavour to learn the Western methods, are Western scholars also ready to learn from us? ${ }^{43}$ This challenge raises more questions. How are the Western scholars who are in the West or in the Philippines supposed to practise or help develop Filipino biblical hermeneutics? Will it solve the problem of too much 'Western influence' or will it produce more challenges of 'Western imposition'? Do Filipino scholars only need to use indigenous methods? I believe that the world should be a global learning community, so I welcome the possibility of learning critically from each other and being enriched mutually by

${ }^{41}$ See the description of the conference at: http://humanities.exeter.ac.uk/theology/research/ conferences/identitiesideologiesandintersections/ (accessed 29 April 2017).

42 However, see Sugirtharajah, 'Introduction', 251-5. He laments: 'Asian biblical interpreters have yet to come up with a distinctive Asian mode of reading ... why are we so unoriginal?' (251). He differentiates between metropolitan and vernacular readings: 'Metropolitan readings' are those that use 'methodological and theoretical approaches worked out and originating in western academies [that] are creatively put to use to meet Asian needs' (252). But he comments that 'we have been the consumers of these methods and have not felt the need to transform them in a distinctively Asian direction' (252). 'Vernacular readings' are those that 'depend on another form of borrowing, but this time from Asia's past. It is an attempt to reclaim ancient reading theories and methods of storytelling'. He encourages neither of these but desires 'to work out a reading practice which will make use of Asian cultural perspectives to illuminate the biblical world' (255).

43 See Justin S. Ukpong, 'Reading the Bible in a Global Village: Issues and Challenges from African Readings', in Reading the Bible in the Global Village: Cape Town, 9-39; Musa W. Dube, 'Villagizing, Globalizing, and Biblical Studies', in Reading the Bible in the Global Village: Cape Town, 41-63. 


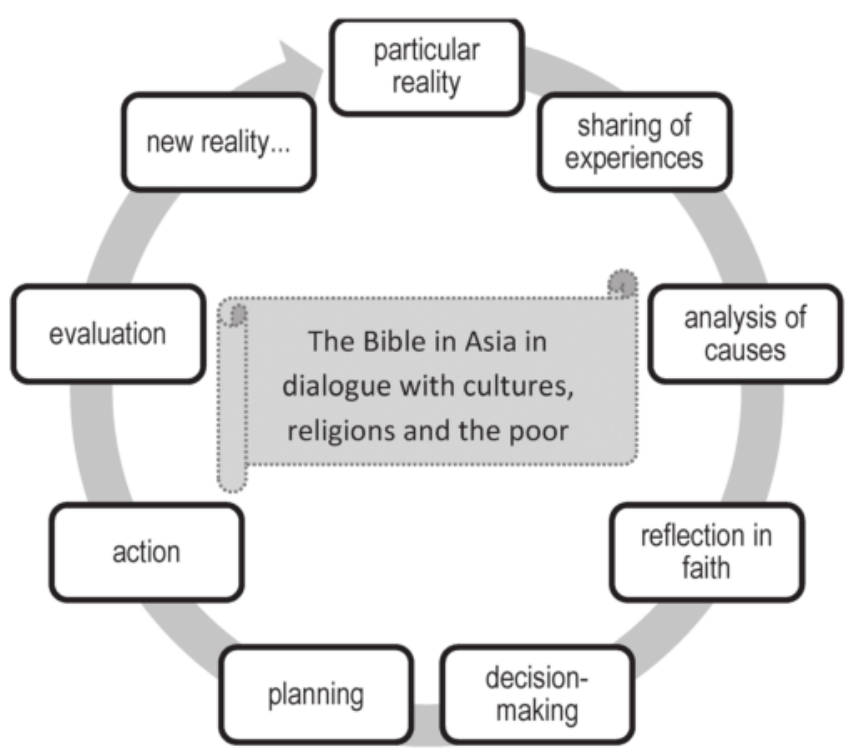

Figure 10.1 The Bible in Asia: In Dialogue with Culture, Religions, and the Poor within the Continued Pastoral Spiral

our differences and similarities. This position will clearly demand critical efforts, but the result of reciprocal cross-fertilization that is respectful of plurality today and in the future is worthy of this effort. ${ }^{44}$ Using the mat/wall-weaving metaphor inspired by common patterns of material construction in the Philippines, the idea of making interconnections between various strands beckons me to consider the dialogical approach in hermeneutics and explore some ways forward.

The Federation of Asian Bishops' Conference pointed out the need for a threefold dialogue with cultures, with other religions, and with the poor in inculturating and interpreting the Bible, especially Jesus' message in Asia. ${ }^{45}$ This threefold dialogue takes place in the context of a 'pastoral spiral' that includes a sequence of actions in a continuous circle (see Figure 10.1). ${ }^{46}$

The dialogical approach can be honed further to suit the changing context of lowland Filipinos by including those who are in the diaspora and the succeeding generations who have increasingly mixed ethnicities. This approach matches Abesamis' proposal

44 See Didier Pollefeyt and Reimund Bieringer, 'The Role of the Bible in Religious Education Reconsidered: Risks and Challenges in Teaching the Bible', in Normativity of the Future: Reading Biblical and Other Authoritative Texts in an Eschatological Perspective, ed. Reimund Bieringer and Mary Elsbernd (Annua Nuntia Lovaniensia 61; Leuven: Peeters, 2010), 377-402, esp. 393-4.

45 See Federation of Asian Bishops' Conference, 'Evangelization in Modern Day Asia: Statement and Recommendations of the First Plenary Assembly', in For All the Peoples of Asia: Documents from 1970-1991, ed. Gaudencio B. Rosales and Catalino G. Arevalo (Maryknoll: Orbis Books, 1992), $11-25$, at $13-16$.

46 See Orlando Quevedo, 'Asian Realities and Cultures: Their Implications to Education', in Proceedings of a Colloquium on Education in Asia: Toward a Formation-Oriented Education, ed. Vicente Cajilig (Manila: UST Printing Office, 1993), 7-20. 
for theologizing which can be adapted for biblical interpretation. He combines a range of factors: the immersion of the committed interpreter in the Filipino context with the capacity for social analysis, critical knowledge of salvation history, Vatican II, and Social Teachings; knowledge of Filipino and Asian psychology, history, religions, and cultures; ability to contemplate; possession of pastoral and other interdisciplinary skills; and awareness of church history, particularly its contemporary teachings, alongside contemporary global theologies and Western theological and philosophical traditions. ${ }^{47}$

This dialogical approach critically complements the Dialogue School pedagogy developed for Catholic schools in Belgium and Australia to nourish Catholic identity in the midst of increasing socio-cultural-religious diversity at the school level and in larger society. It is initiated by a team of mostly Western scholars in Leuven with whom I cooperate.

The Dialogue School ... is typified by a combination of maximal Catholic identity with maximal solidarity. It concerns a Catholic school in the middle of cultural and religious plurality in which both Catholics and other-believers can develop themselves maximally. A Dialogue School explicitly chooses to emphasise its Catholic inspiration and individuality through and thanks to a hermeneuticalcommunicative dialogue with the multicultural society. The multiplicity of voices, views and perspectives, is recognised as a positive contribution to an open Catholic school environment. Receptivity and openness to what is different is a chance to re-profile the Catholic faith amidst contemporary plurality (Recontextualisation). A preferential option for the Catholic message sets the tone for this dialogue. ${ }^{48}$

By adapting this pedagogy to the context of biblical hermeneutics, 'maximal Christian identity' opens the way to include the lenses of the specific and varied ethnicities of Christians. The 'trans-ethnic' character of 'maximal Christian identity' influencing biblical interpretation needs at the same time to recognize the plurality of ethnic identity among the Catholics who attempt to recontextualize critically ${ }^{49}$ the biblical message in the service of 'maximal solidarity' with others. Since 1999, the Catholic Biblical Association of the Philippines in its annual convention and interest-group meetings and lectures has provided a very good space for its members to continue their own research in dialogue with one another and to offer the membership services to the needs of the larger ecclesial community. ${ }^{50}$ In this venue, the issue of the Catholics' trans-ethnicity and its intersection with specific ethnic

47 See Carlos H. Abesamis, What Is Inside the Wooden Bowl? (Manila: Socio-Pastoral Institute, 1997), $50-1$.

${ }^{48}$ Didier Pollefeyt and Jan Bouwens, Identity in Dialogue: Assessing and Enhancing Catholic School Identity. Research Methodology and Research Results in Catholic Schools in Victoria, Australia (Christian Religious Education and School Identity 1; Zurich/Berlin: LIT Verlag, 2014), 63.

${ }^{49}$ See Pollefeyt and Bouwens, Identity, 173-5.

${ }^{50}$ For a short overview of the CBAP as an organization and its activities, see Randolf Flores, 'Catholic Biblical Association of the Philippines', Catholic Biblical Association of the Philippines, 10 January 2017. Available online: http://catholicbiblicalassociation.blogspot.be/ (accessed 29 April 2017). 
identities - including the interpreter's own ethnic identity and context - the biblical text, and the hermeneutical tools suited in their own context, can be discussed further communally.

I would like to suggest that historically-informed and inculturated ways of doing narrative criticism could be used beneficially to allow exegetes and the larger ecclesial community to explore the issue of trans-ethnicity and ethnic specificities, because this approach builds on the Asian and Filipino's preference for storytelling. ${ }^{51}$ The historical information available upon critical consideration helps in constructing the implied reader so that the biblical text is better understood, and insights can be recontextualized to become more relevant for Catholic life today and in envisioning a better future inspired by the biblical text. ${ }^{52}$ With a more conscious use of narrative conversation (the Filipino kwentuhan $)^{53}$ in analysing and reflecting on the biblical text, new insights and challenges can engage other interpreters, other hermeneutical tools, and the changing Filipino contexts at home and in the diaspora.

In addition, while English remains the main language in an international academic setting and in the Philippines, it will be helpful to prepare students to learn Greek and Hebrew in order to explore the meaning of words and texts, using their own language(s) for a more nuanced interpretation. Supporting efforts that critically adapt existing methods of biblical interpretation and finding or inventing new ones from our own culture, using various means of communication including digital and social media, can open the dialogue to more people. ${ }^{54}$ For the academic conversation to continue it would be helpful to nurture the efforts to adapt, rediscover, and invent new methods of interpretation and send the results of our studies to both local and international journals, online and otherwise. It is similarly important to continue to find means of participating actively in international gatherings to ensure a multiplicity of voices and to find ways of continued collaboration.

While I have tried to problematize the extent of 'Western' assumptions above, the predominantly Western setting of academic biblical scholarship, as it has evolved

51 See Ma. Marilou S. Ibita, 'Fostering Narrative Approaches to Scripture in Asia: The Primary Task of Explicit Recognition', East Asia Pastoral Review 46 (2009): 124-41; Teresita B. Obusan, Angelina R. Enriquez, and Virgilio G. Enriquez, eds, Pamamaraan: Indigenous Knowledge and Evolving Research Paradigms (Quezon City: Asian Center, University of the Philippines, 1994); Grant R. Osborne, The Hermeneutical Spiral: A Comprehensive Introduction to Biblical Interpretation, rev. and exp. (Downers Grove, IL: IVP, 2006), 200-21.

52 See, for example, Ma. Marilou S. Ibita, 'Including the Hungry Adelphoi: Exploring Pauline Points of View in 1 Corinthians 11:17-34', in By Bread Alone: The Bible through the Eyes of the Hungry, ed. Sheila E. McGinn, Lai Ling Elizabeth Ngan, and Ahida Calderon Pilarski (Minneapolis: Fortress, 2014), 159-84; eadem, 'Re-Reading the Lord's Supper Story in Corinth (1 Cor 11:17-34): A Normativity of the Future Perspective', in Normativity of the Future: Reading Biblical and Other Authoritative Texts in an Eschatological Perspective, ed. Reimund Bieringer and Mary Elsbernd (Annua Nuntia Lovaniensia 61; Leuven: Peeters, 2010), 239-77.

53 See Teresita B. Obusan, 'A Hiyang Approach', in Pamamaraan: Indigenous Knowledge and Evolving Research Paradigms, 89-110.

54 See the activities (such as Bible Anime, Bibliodrama, Original Gospel Song Festival, Basic Bible Seminar, etc.) listed in the Episcopal Commission on the Biblical Apostolate of the Catholic Bishops' Conference of the Philippines. Available online: http://www.ecba-cbcp.com/activities.htm (accessed 29 April 2017). 
through a history marked by globalization, diversifying membership, and growing critical awareness likewise provides new possibilities (inadvertently or not) that increasingly include non-Western insights. Support and active participation in alternative research groups such as the Society of Biblical Literature's 'Islands, Islanders, and Scriptures', 'Minoritized Criticism and Biblical Interpretation', and developing other new groups will be necessary to continue this diversification..$^{55}$ Inviting Western and non-Western scholars to come to the Philippines for critical and mutual sharing of expertise can also be reciprocally enriching.

\section{Conclusion}

In this essay I have tried to show from my lowland Filipino Catholic upbringing how the colonial and Western-influenced trans-ethnic sense of shared Catholic identity intersects with the specificities of Filipino ethnic identity and context, with how the information about ethnicities in the biblical text is understood, and with the choices of hermeneutical methodologies and approaches. I noted that the relationship is complex. Emphasis on the trans-ethnicity of Jesus and his early followers can further the sense of belonging to a bigger, international group like the Roman Catholic Church, blurring one's own specific ethnicity. Yet, the focus on the trans-ethnicity of the characters of Jesus and his followers also permits stronger inculturation of the Gospel message, recontextualizing it to the needs of specific ethnic groups, like the Filipinos, in their own context. In analysing the hermeneutical process and methods used, however, the Western character of the Catholic trans-ethnicity becomes more obvious, so that the inculturation of biblical interpretation in the Filipino context also becomes more challenging. Given this background, I also questioned the possibility and desirability of totally breaking out of Western assumptions, and I enumerated some ways in which they can be addressed critically through dialogical approaches that foster interconnections. From my Filipino background, Lorde's metaphor of dismantling is rather violent. Instead, I offer the mat/wall-weaving metaphor which finds strength in tools that facilitate tight intersections to work. Thus, my proposals invite critical tinkering with the existing tools, along with inventing new ones, so that they can be more multi-functional in ways that can go beyond our imagination and their original purpose. We cannot underestimate the power of the many people who interrelate, use, interchange, and revise tools and make new ones. In the process, they become the new masters who continuously shape the ever-changing outcomes of biblical interpretation, so that there will be not only a hugely renovated hermeneutical house, but also new houses to build and dwell in.

\footnotetext{
55 See Society of Biblical Literature 2017 Annual Meeting. Available online at: https://www.sblsite.org/meetings/Congresses_ProgramUnits.aspx?MeetingId=31 (accessed 29 April 2017). Among new groups see, for example, the European Association of Biblical Studies' 'The Bible and Ecology Research Group'. Available online: https://eabs.net/site/the-bible-and-ecology/ (accessed 29 April 2017).
} 


\section{References}

Abesamis, Carlos H. Salvation: Historical and Pastoral: Towards a Faith-Life that is Biblical, Historical, Indigenous. Integral Evangelization Series. Quezon City: JMC, 1978.

Abesamis, Carlos H. The Mission of Jesus and Good News to the Poor. Nagliliyab. Quezon City: Claretians, 1987.

Abesamis, Carlos H. What Is Inside the Wooden Bowl? Manila: Socio-Pastoral Institute, 1997.

Anti-Defamation League. 'Philippines'. Available online: http://global100.adl. org/\#country/philippines/2014 (accessed 29 April 2017).

Barreto, Eric D. Ethnic Negotiations: The Function of Race and Ethnicity in Acts 16. WUNT 2.294. Tübingen: Mohr Siebeck, 2010.

Benedict XVI. 'Caritas in Veritate'. Available online: http://w2.vatican.va/content/ benedict-xvi/en/encyclicals/documents/hf_ben-xvi_enc_20090629_caritas-in-veritate. html (accessed 29 April 2017).

Boon, Jessica A. 'Violence and the "Virtual Jew" in Castilian Passion Narratives, 1490s-1510s'. Journal of Medieval Iberian Studies 8 (2016): 110-29.

Calano, Mark Joseph. 'The Black Nazarene, Quiapo, and the Weak Philippine State'. Kritika Kultura 25 (2015): 166-87.

The Catholic Biblical Association of the Philippines. 'Annual Convention Papers'. Available online: http://catholicbiblicalassociation.blogspot.be/ (accessed 29 April 2017).

Catholic Bishops' Conference of the Philippines. Catechism for Filipino Catholics. Manila: ECCCE/Word and Life, 1997.

Conradie, Ernst. 'Towards an Ecological Biblical Hermeneutics: A Review Essay on the Earth Bible Project'. Scriptura 85 (2004): 123-35.

Conradie, Ernst. 'The Road Towards an Ecological Biblical and Theological Hermeneutics'. Scriptura 93 (2006): 305-14.

Constantino, Renato and Letizia R. Constantino. A History of the Philippines: From the Spanish Colonization to the Second World War. New York: Monthly Review Press, 1975.

Dube, Musa W. 'Villagizing, Globalizing, and Biblical Studies'. In Justin S. Ukpong et al., Reading the Bible in the Global Village: Cape Town, 41-63. Global Perspectives on Biblical Scholarship 3. Atlanta: Society of Biblical Literature, 2002.

Enriquez, Virgilio G. 'Kapwa and the Struggle for Justice, Freedom and Dignity'. In Pamamaraan: Indigenous Knowledge and Evolving Research Paradigms, edited by Teresita B. Obusan, Angelina R. Enriquez, and Virgilio G. Enriquez, 1-18. Quezon City: Asian Center, University of the Philippines, 1994.

European Association of Biblical Studies Research Groups. 'The Bible and Ecology Research Group'. Available online: https://eabs.net/site/the-bible-and-ecology/ (accessed 29 April 2017).

Episcopal Commission on the Biblical Apostolate of the Catholic Bishops' Conference of the Philippines. Available online: http://www.ecba-cbcp.com/activities.htm (accessed 29 April 2017).

Federation of Asian Bishops' Conference. 'Evangelization in Modern Day Asia: Statement and Recommendations of the First Plenary Assembly'. In For All the Peoples of Asia: Documents from 1970-1991, edited by Gaudencio B. Rosales and Catalino G. Arevalo, 11-25. Maryknoll: Orbis Books, 1992.

Flores, Randolf. 'Catholic Biblical Association of the Philippines'. Catholic Biblical Association of the Philippines, 10 January 2017. Available online: http:// catholicbiblicalassociation.blogspot.be/ (accessed 29 April 2017). 
Generalao, Minerva. 'Time to Check Pabasa for Anti-Semitic Contents, Says Caloocan Bishop'. Available online: http://newsinfo.inquirer.net/888866/time-to-check-pabasafor-anti-semitic-content-says-caloocan-bishop (accessed 29 April 2017).

Goldstein, Jonathan. 'Shaping Zionist Identity: The Jews of Manila as a Case Study'. Israel Affairs 15, no. 3 (2009): 296-304.

Graham, Helen R. You Shall Be Handed Over: The Persecution Prediction in Mark 13:9-13. Quezon City: Claretians, 1987.

Holden, William. 'From the Church of the Powerful to the Church of the Poor: Liberation Theology and Catholic Praxis in the Philippines'. In The Changing World Religion Map, edited by Stanley D. Brunn, 3095-114. Dordrecht: Springer, 2015.

Hontiveros, Eduardo. 'Hesus Na Aking Kapatid'. In Bayan, Umawit, edited by Jesuit Music Ministry, 81. Quezon City: Jesuit Communications Foundation, 2015.

Horrell, David G.. Ethnicity, Race, Religion Conference, Exeter, UK. Description. Available online: http://humanities.exeter.ac.uk/theology/research/conferences/ identitiesideologiesandintersections/ (accessed 29 April 2017).

Horrell, David G. 'From 'A $\delta \varepsilon \lambda \varphi$ oi to Oĩ̌oৎ $\Theta \varepsilon$ coũ: Social Transformation in Pauline Christianity'. JBL 120, no. 2 (2001): 293-311.

Horrell, David G. "Race”, "Nation", "People”: Ethnic Identity-Construction in 1 Peter 2.9'. NTS 58, no. 1 (2012): 123-43.

Horrell, David G. 'Ethnicisation, Marriage and Early Christian Identity: Critical Reflections on 1 Corinthians 7, 1 Peter 3 and Modern New Testament Scholarship'. NTS 62, no. 3 (2016): 439-60.

Ibita, Ma. Marilou S. 'Fostering Narrative Approaches to Scripture in Asia: The Primary Task of Explicit Recognition'. East Asia Pastoral Review 46 (2009): 124-41.

Ibita, Ma. Marilou S. 'Re-Reading the Lord's Supper Story in Corinth (1 Cor 11:17-34): A Normativity of the Future Perspective'. In Normativity of the Future: Reading Biblical and Other Authoritative Texts in an Eschatological Perspective, edited by Reimund Bieringer and Mary Elsbernd, 239-77. Annua Nuntia Lovaniensia 61. Leuven: Peeters, 2010.

Ibita, Ma. Marilou S. 'Including the Hungry Adelphoi: Exploring Pauline Points of View in 1 Corinthians 11:17-34'. In By Bread Alone: The Bible through the Eyes of the Hungry, edited by Sheila E. McGinn, Lai Ling Elizabeth Ngan, and Ahida Calderon Pilarski, 159-84. Minneapolis: Fortress, 2014.

Ileto, Reynaldo Clemeña. Pasyon and Revolution: Popular Movements in the Philippines, 1840-1910. Quezon City: Ateneo de Manila University Press, 1997.

Javellana, Rene B. 'The Sources of Gaspar Aquino de Belen's Pasyon'. Philippine Studies 32, no. 3 (1984): 305-21.

Javier, Edgar. Building Christian Community: A Case Study of the Ethnic Minority Communities of Mindoro, Philippines. Rome: Pontificia Universitas Gregoriana, Facultas Missiologiae, 1985.

Kaufman, Stuart J. 'Symbols, Frames, and Violence: Studying Ethnic War in the Philippines'. International Studies Quarterly 55, no. 4 (2011): 937-58.

Labayen, Julio X. Revolution and the Church of the Poor. Quezon City: Claretians, 1995.

Lagarde, Roy. 'Church and gov't should collaborate, not clash - Cardinal Rosales'. CBCP News Online. Available online: http://cbcpnews.net/cbcpnews/church-and-govtshould-collaborate-not-clash-cardinal-rosales/ (accessed 29 April 2017).

Levine, Amy-Jill. 'A Jewish Reading of the New Testament'. In Same Stories, Different Understandings: Jews and Catholics in Conversation, 21-37. CBAP Lectures 2004. Manila: Catholic Biblical Association of the Philippines, 2004. 
Lorde, Audre. 'The Master's Tools Will Never Dismantle the Master's House'. In This Bridge Called My Back: Writings by Radical Women of Color, edited by Cherrie Moraga and Gloria Anzaldua, 94-101. New York: Kitchen Table, 1983.

Obusan, Teresita B. 'A Hiyang Approach'. In Pamamaraan: Indigenous Knowledge and Evolving Research Paradigms, edited by Teresita B. Obusan, Angelina R. Enriquez, and Virgilio G. Enriquez, 89-110. Quezon City: Asian Center, University of the Philippines, 1994.

Obusan, Teresita B., Angelina R. Enriquez, and Virgilio G. Enriquez, eds. Pamamaraan: Indigenous Knowledge and Evolving Research Paradigms. Quezon City: Asian Center, University of the Philippines, 1994.

Osborne, Grant R. The Hermeneutical Spiral: A Comprehensive Introduction to Biblical Interpretation. Revised and expanded. Downers Grove, IL: IVP, 2006.

Pfatteicher, Philip H. Journey into the Heart of God: Living the Liturgical Year. New York: Oxford University Press, 2013.

Philippine Embassy. 'Profile of the Filipino Community in Israel'. Available online: http:// philippine-embassy.org.il/index.php?option=com_content\&view=category\&layout=bl og\&id=10\&Itemid=28 (accessed 29 April 2017).

Philippine Statistics Authority. Philippines in Figures 2015. Quezon City: Philippine Statistics Authority. Available online: https://psa.gov.ph/sites/default/files/2015\%20 PIF\%20as\%20of\%20June\%202016.pdf (accessed 29 April 2017).

Pilch, John J. The Cultural World of Jesus: Sunday by Sunday, Cycle C. Collegeville, MN: Liturgical Press, 1997.

Pollefeyt, Didier, and Reimund Bieringer. 'The Role of the Bible in Religious Education Reconsidered: Risks and Challenges in Teaching the Bible'. In Normativity of the Future: Reading Biblical and Other Authoritative Texts in an Eschatological Perspective, edited by Reimund Bieringer and Mary Elsbernd, 377-402. Annua Nuntia Lovaniensia 61. Leuven: Peeters, 2010.

Pollefeyt, Didier, and Jan Bouwens. Identity in Dialogue: Assessing and Enhancing Catholic School Identity. Research Methodology and Research Results in Catholic Schools in Victoria, Australia. Christian Religious Education and School Identity 1. Zurich/Berlin: LIT Verlag, 2014.

Pontifical Biblical Commission. 'The Interpretation of the Bible in the Church'. Origins 23, no. 29 (1994): 497-524.

Pope Francis. 'Urbi et Orbi' (2016). Available online: https://w2.vatican.va/content/ francesco/en/messages/urbi/documents/papa-francesco_20161225_urbi-et-orbinatale.html (accessed 29 April 2017).

Quevedo, Orlando. 'Asian Realities and Cultures: Their Implications to Education'. In Proceedings of a Colloquium on Education in Asia: Toward a Formation-Oriented Education, edited by Vicente Cajilig, 7-20. Manila: UST Printing Office, 1993.

Räisänen, Heikki, Elisabeth Schüssler Fiorenza, R. S. Sugirtharajah, Krister Stendahl, and James Barr. Reading the Bible in the Global Village: Helsinki. Reading the Bible in the Global Village 1. Atlanta: Society of Biblical Literature, 2000.

Schneiders, Sandra M. The Revelatory Text: Interpreting the New Testament as Sacred Scripture. Collegeville, MN: Liturgical Press, 1999.

Segovia, Fernando F. 'The Emerging Project of Asian Biblical Hermeneutics: Reading Asian Readers'. BibInt 2, no. 3 (1994): 371-3.

Segovia, Fernando F. 'Criticism in Critical Times: Reflections on Vision and Task'. JBL 134, no. 1 (2015): 6-29. 
Segovia, Fernando F. and Mary Ann Tolbert, eds. Reading from This Place. Volume 2: Social Location and Biblical Interpretation in Global Perspective. Minneapolis: Fortress, 1995.

Society of Biblical Literature. 'Annual Meeting Programme Units'. 2017. Available online: https://www.sbl-site.org/meetings/Congresses_ProgramUnits.aspx?MeetingId=31 (accessed 29 April 2017).

Sugirtharajah, R. S. 'Introduction, and Some Thoughts on Asian Biblical Hermeneutics'. BibInt 2, no. 3 (1994): 251-63.

Sugirtharajah, R. S. The Bible and Asia: From the Pre-Christian Era to the Postcolonial Age. Cambridge, MA: Harvard University Press, 2013.

Ukpong, Justin S. 'Reading the Bible in a Global Village: Issues and Challenges from African Readings'. In Justin S. Ukpong et al., Reading the Bible in the Global Village: Cape Town, 9-39. Global Perspectives on Biblical Scholarship 3. Atlanta: Society of Biblical Literature, 2002.

UN General Assembly Resolution 181 (Partition Plan) 29 November 1947. Available online: http://www.mfa.gov.il/mfa/foreignpolicy/peace/guide/pages/un\%20general\%20 assembly\%20resolution\%20181.aspx (accessed 29 April 2017).

Vander Stichele, Caroline and Todd C. Penner, eds. Her Master's Tools? Feminist and Postcolonial Engagements of Historical-Critical Discourse. Global Perspectives on Biblical Scholarship 9. Atlanta: Society of Biblical Literature, 2005.

Vargas, Niceta. Word and Witness: An Introduction to the Gospel of John. Quezon City: Ateneo de Manila University Press, 2013. 


\title{
Double Vision for Revolutionary Religion: Race Relations, Moral Analogies, and African-American Biblical Interpretation
}

\author{
Love L. Sechrest
}

Today, the dominant mode in African-American biblical interpretation considers the ways that Black people actually read the Bible and comments on how the Bible can function as an instrument of oppression or opportunity. ${ }^{1}$ In this essay, I place Martin Luther King Jr's reading of the Gospel of Luke in his February 1968 speech entitled 'To Minister in the Valley' alongside my own interpretation of one of the passages he engages in that speech: Lk. 10.25-31. ${ }^{2}$ Through analysis of the 'Valley' speech and juxtaposition with my own exegesis of Lk. 10.25-31, this essay examines the ways that these interpretations exhibit a dual concern for intra-racial and interracial relations via construction of metaphorical analogues between contemporary social dynamics and the discourse in the Gospel of Luke. I contend that this simultaneous focus on internal and external issues arises out of what W. E. B. DuBois dubbed the doubleconsciousness of African-American life by which Blacks are always engaged in seeing themselves through both their own eyes and through the eyes of the other. ${ }^{3}$ AfricanAmerican interpreters in the Kingian tradition ${ }^{4}$ deploy a dualistic hermeneutic that

1 Joseph Scrivner, 'African American Interpretation', in The Oxford Encyclopedia of Biblical Interpretation, ed. Steven L. McKenzie (Oxford: Oxford University Press, 2014). Available online: http://www.oxfordreference.com/view/10.1093/acref:obso/9780199832262.001.0001/acref9780199832262-e-90 (accessed 17 February 2017).

2 King, Martin Luther, Jr 'To Minister in the Valley', 1968, unpublished manuscript. This speech, along with King's other unpublished sermons and speeches, is available at the King Library and Archives at the Martin Luther King Jr. Center for Nonviolent Social Change in Atlanta, Georgia, United States.

3 W. E. B. DuBois, The Souls of Black Folk, with a New Introduction by Randall Kenan (New York: Signet, 1995), 45: 'It is a peculiar sensation, this double-consciousness, this sense of always looking at one's self through the eyes of others, of measuring one's soul by the tape of a world that always looks on in amused contempt and pity. One ever feels his twoness - an American, a Negro; two souls, two thoughts, two unreconciled strivings; two warring ideals in one dark body, whose dogged strength alone keeps it from being torn asunder.'

4 By the phrase 'Kingian tradition' I describe a hermeneutic often found in King's work, but do not imply that the associative reasoning at the heart of the method was unique to King. 
was born of the double burden of seeing life through a natural lens and also an alien one; I argue that this burden, this double vision, also inculcates a capacity to see and have concern for other marginalized people.

Broadly, African-American biblical interpreters explicitly eschew the problematic notion that any reading of the Bible can produce the single correct and/or objective interpretation of the meaning in the text. ${ }^{5}$ Though all readings are 'interested' and thus invested with a particular viewpoint, African-American and womanist interpretation is a contextual reading that seeks to promote the liberation and flourishing of the marginalized in society, challenging Eurocentric silence and/or assumptions about Black characters, themes, or interests in the text. ${ }^{6}$ Randall Bailey's and Vincent Wimbush's work in African-American biblical interpretation has been influential in promoting the analysis of the social and political effects of the Bible in American life, analysing how African Americans interpret the Bible and interrogating appropriations of scripture in African-American spirituals, sermons, and speeches.? Practitioners of African-American hermeneutics often do research at the intersection of anti-Black prejudice and biblical criticism, and these scholars explore the way that biblical themes and stories promote, sustain, or resist ethnic prejudice, racism, sexism, and homophobia as they appear in modern society. ${ }^{8}$

Another move in this domain can be seen in Brian Blount's Can I Get a Witness?, a book that blends historical, literary, and cultural critical analyses for the purposes of promoting anti-racist agency among African-American readers. ${ }^{9}$ Blount sees an analogy between the African-American struggle for civil rights and anti-imperialistic witness in the Apocalypse. Here Blount gains critical leverage by connecting the biblical text to African-American political resistance instead of the more common focus on how African Americans have interpreted scripture. Blount's implicit use of analogy and the way that his interpretive lens fuses an interest in interpretation and moral exhortation in its attention to the concerns of African-American readers illustrates King-like associative reasoning, and work in this register demonstrates the power of analogy as a hermeneutical resource for thinking about race relations.

5 Vincent Wimbush, 'Introduction: Reading Darkness, Reading Scriptures', in African Americans and the Bible: Sacred Texts and Social Textures, ed. Vincent Wimbush (New York: Continuum, 2000), 8-9; also see Brian Blount et al., 'Introduction', in True to Our Native Land: An African American New Testament Commentary (Minneapolis: Fortress, 2007), 1-7.

6 See Michael Joseph Brown's account of the rise and aims of African-American biblical interpretation in The Blackening of the Bible: The Aims of African American Biblical Scholarship (Harrisburg, PA: Trinity Press International, 2004), and Mitz Smith's overview of the development of womanist interpretation, along with new and seminal essays in I Found God in Me: A Womanist Biblical Hermeneutics Reader (Eugene, OR: Cascade Books, 2015).

7 Randall C. Bailey, 'Academic Biblical Interpretation among African Americans in the United States', in African Americans and the Bible: Sacred Texts and Social Textures (New York: Continuum, 2000), 696-711; Wimbush, 'Introduction', 1-43.

8 Cf. Emerson Powery who names 'liberation, resistance and survival' as the tripod upon which any black reading rests in 'African American Criticism', in Hearing the New Testament: Strategies for Interpretation, ed. Joel B. Green, 2nd edn (Grand Rapids, MI: Eerdmans, 2010), 326-49.

9 Brian K. Blount, Can I Get a Witness? Reading Revelation through African American Culture (Louisville, KY: WJK, 2005). 


\section{Revolutionary religion: Interracial and intra-racial analogues in 'To Minister in the Valley' (1968)}

According to Richard Lischer, Martin Luther King Jr. ended up 'abandoning many of the critical theories about the Bible' learnt in his liberal training, reverting to 'techniques of interpretation that were more ancient than the African-American church such as allegory and typology, because they allowed his congregations a greater opportunity to identify their struggles with those portrayed in the Bible. ${ }^{10}$ While Lischer's description implies that King's handling of the Bible is connected to his particular genius in the pulpit, he also rightly notes that King's method participates in the broader trajectory of exhortation that invites readers of the biblical text to see themselves metaphorically as participants in the drama played out on its pages. King's preaching and the preaching of other readers in the Black church is an interpretive poetry that correlates the shape of the biblical text to material conditions in the contemporary world. This work of correlation requires the development of compelling analogies between the biblical stories and contemporary life.

Originating from the Greek word àva入oyía, which refers to a state of right relationship involving proportion, one often employs analogies to suggest that if two objects share enough characteristics in some dimensions, then one can infer that they are similar in other ways as well. ${ }^{11}$ We could say that a biblical situation is analogous to a modern situation if they share - or can be suggested to share - important characteristics with respect to the human condition despite originating in vastly different cultures. In terms of developing contemporary ethics from biblical teaching as King did, we might say that the easier it was for his hearers to imagine themselves as participants in the biblical situation, the more morally compelling was his analogical interpretation of the biblical teaching.

Consideration of King's late February 1968 speech entitled 'To Minister in the Valley' can help illustrate some of these concepts. King delivered the speech at the Southern Christian Leadership Council's (SCLC) Ministers' Leadership Training Program in Miami, Florida, just months ahead of the start of the Poor People's March on Washington; he used the speech to rally support among the SCLC for the coming campaign. King's speeches are often deeply saturated in scripture and this one echoes Lk. 3.5 in articulating its thesis, while also appealing to Lk. 4.16-30, 16.19-31, Rev. 7.917, and Lk. 10.25-37 as supporting texts in three of its four major acts. The speech argues that SCLC leaders are called to minister in metaphorical 'valleys of despair' caused by poverty, war, and racism because the call of the gospel is to see that 'every valley will be exalted, and every mountain and hill will be made low; the rough places will be made plain, and the crooked places straight' (Lk. 3.5; cf. Isa. 40.4). He speaks of the Valley of Poverty, which instead of being remedied by Congress is being exacerbated, citing pending legislation that will cut food subsidies to the children of welfare mothers. In

${ }^{10}$ Richard Lischer, The Preacher King: Martin Luther King, Jr. and the Word that Moved America (Oxford: Oxford University Press, 1997), 7-8.

11 See, for example, Julian Wolfreys, Ruth Robbins, and Kenneth Womack, Key Concepts in Literary Theory (Edinburgh: Edinburgh University Press, 2006), 7. 
discussing the Valley of War, King insists that his generation has experienced more war than any other in the nation's history, naming the Second World War, the Cold War, the Korean War, and the war in Vietnam. He also talks about the Valley of Racism in which Blacks were in lasting and deep despair. These three themes - poverty, war, and racism - were the trio of evils that would dominate King's speeches and sermons in the final intense three-year period before his assassination in 1968.

In the speech King encourages the SCLC by insisting that the group has both the talent and determination to make an impact in the cities of the South, exhorting members to make a difference in their communities by advocating politically for improved housing and programmes that feed the poor, and by working in the churches to regain the attention of young Black Americans. King freely confesses to this audience that the Black church has sometimes been lax in confronting the poverty of its own members. He suggests that the Black clergy is sometimes more concerned about garnering cars and money for themselves than in caring for their parishioners and inspiring young people who are becoming disenchanted with Christianity, thinking of it as the religion of whites:

We can get those young men and women ... to see that Jesus was a serious man precisely because he ... was concerned about their problems. He was concerned about bread. He opened and started Operation Breadbasket a long time ago. He initiated the first sit-in movement. [He is] the greatest revolutionary that history has ever known, and when people tell us that when we stand up like we stand up that we got our inspiration from this or that ... go back and let them know where we got our inspiration. ${ }^{12}$

And alluding to Lk. 4.16-30, King proclaimed that there is a revolutionary urge in Christianity that many have failed to see:

You don't have to go to Karl Marx to learn how to be a revolutionary. I didn't get my inspiration from Karl Marx. I got it from a man named Jesus, a Galilean savior. He said he was anointed to deal with the problems of the poor, and those who were in captivity, and preached the acceptable year of the Lord. That's revolutionary. And that is where we get our inspiration..$^{13}$

Intriguingly, these lines represent an analogical movement from a discussion of the themes of Jubilee and relief for the poor in the Sermon at Nazareth (Lk. 4.18-20) to King's political insistence that these ideas depict a 'revolutionary Christianity' at the centre of the Jesus movement. It is as if Jesus' proclamation of Jubilee for both Jewish and Gentile peasants in antiquity inspires and becomes an analogue for King's own preaching in the fledgling Poor People's Campaign that hoped to build an interracial coalition for poverty relief in the United States.

12 King, 'To Minister in the Valley'.

13 King, 'To Minister in the Valley'. 
The third part of the speech discusses King's sense of urgency about the upcoming Poor People's Campaign in Washington. This section is the heart of the speech and has three scenes in which King describes the social context for the Poor People's Campaign, urges that the campaign needs to be supported by the SCLC, and boldly asserts that the campaign is for the church. In discussing the context for the Poor People's Campaign, King links the explosions of Black violence over the preceding few summers to Black despair regarding unrelenting poverty and bad economic conditions. Though he is empathetic about the despair that provokes these disruptions, he pragmatically asserts that such riots are impractical because the suffering and loss of life and property outweigh any gains:

We have to face this as an honest fact that no substantive change has come to America or to any city as a result of a riot .... And yet something has to be done, to get this nation to see that it has a moral responsibility to see that everybody in this country should have a job or an income. ${ }^{14}$

King saw the list of demands that were to be presented to the nation's leaders at the Poor People's March as a constructive alternative to riots and 'timid supplications for justice', arguing that 'this country never moves on the question of civil rights or genuine equality for the [Blacks] until it's made to move through pressure'. Illustrating this point, King notes that the Civil Rights Commission had recommended everything that protestors wanted a full three years before the march in Birmingham, but pointed out that nothing was done until people faced police dogs and fire hoses. Similarly, the Civil Rights Commission had recommended everything protestors wanted two years before the dramatic marches in Selma that finally moved lawmakers to action. In this section, King is certain that nothing will be done in securing economic justice for Blacks and others trapped in poverty until there are massive protests.

The speech goes on to outline the strategy of the campaign that will begin with an intense effort to train 3,000 poor people in non-violent direct action in a first wave, followed by thirty to sixty days of successive waves of marchers descending on Washington who will clog up highways and live in make-shift shanty-towns in the capital to symbolize Blacks' living conditions. According to King, 'you don't deal with pharaoh's hardened heart with just one plague. [You've] got to keep plaguing pharaoh..15 Protests would escalate as would these 'plagues' and would include a plan to collect garbage from the marchers' shanty-towns and Washington D.C. ghettos and dump it on Capitol Hill. In this case, King allegorically sees marchers as representing God's agency in afflicting Egypt and moving the pharaoh of Congressional will to liberate the Black poor from the shackles of economic slavery.

The next scene in this section represents King's moral argument about why the campaign needs to be supported by SCLC and the broader church. This section contains an extended interaction with the parable of the rich man ('Dives' in King's speech) and

14 King, 'To Minister in the Valley'.
15 King, 'To Minister in the Valley'. 
Lazarus in Lk. 16.19-31, a parable that featured frequently in King's sermons. ${ }^{16}$ King's proposition in this section is that Blacks in the SCLC and the Black middle class in America must not let their poorer brothers and sisters be ignored while lacking the resources of the richer members of the community. ${ }^{17}$ King's exegesis of the parable begins by noting what he thinks is not taught in the parable, making the point that the parable is not a sweeping indictment against all kinds of wealth, but rather represents the need for deep reflection about how one handles wealth. Indeed, King asserts that, as a rich man who fails to handle wealth well, 'Dives went to hell because he sought to be a conscientious objector in the war against poverty. ${ }^{18}$

Who in the modern context does King see as analogous to the rich man of the parable? In this 1968 'Minister in the Valley' speech, King is not nearly as subtle as he was in earlier sermons on this text as he boldly proclaimed that 'America is going to hell' and that 'America is Dives' (emphasis added). King's heightened global sensitivities in 1968 led him to the conclusion that America has 'participated in the economic exploitation of Africa, and Asia, and Latin America, and he notes that spending 4-5 per cent of the nation's GDP could rid the earth of poverty and bridge the gulf between the haves and the have-nots in this country as well. In this case echoing language from the parable of the Prodigal Son, King declares: 'This Congress, if it does not come to itself, is going to hell; a hell that God has planned.' Thus, in correlating Dives with America, King draws an analogy between the first world and the rich man, on the one hand, and between the two-thirds world and Lazarus, on the other. But note that King also continues his penchant for exploring intra-community tensions when he talks about the gulf between haves and have-nots in this country, implicitly correlating America's haves and Dives, on the one hand, and America's have-nots and Lazarus, on the other. He creates a biblical amalgamation of correspondences in which Congressional America is Dives, on the one hand, who is going to hell because of how he handles wealth, and the Prodigal Son, on the other hand, a move that sets this Congressional moral failure inside the context of the family.

In the next section, King's vision of the Poor People's Campaign imaginatively appropriates the imagery of the Apocalypse to describe his vision of how poor people will march out of their economic oppression in the cities and towns across the country and stream into Washington D.C. in a way that is analogous to the gathering of the great multitude from every people tribe and nation pictured in Rev. 7.9-17. In place of the innumerable multitude of white-robed saints who have escaped from great tribulation, King imagines thousands of poor people descending on Washington for a month-long period of demonstrations. Instead of the question and answer exchanged between the elder and John about the identity of the multitude in Rev. 7.13-17, King imagines a conversation in which an unnamed congressman asks questions about the massive size of the Poor People's Campaign crowd:

16 This text was also the focus in two other of King's sermons: 'To Serve the Present Age', 1967, unpublished manuscript; 'Dives and Lazarus', 1963, unpublished manuscript.

${ }_{17}$ In 1967, King argues that the church, 'in order to serve the present age, will have to call on the nation and all men [sic] of good will to be rid of the triple evils of racism, poverty, and war' (King, 'To Serve the Present Age').

18 King, 'To Minister in the Valley'. 
And after we get to moving, people will be coming from everywhere. And I want some Congressman to go to the window and look out, and say, 'I see a lot of people on these highways. Where are these people coming from? Who are they?' And I want somebody to go in there and say 'They are coming up, out of Mississippi and Alabama.' I want somebody to go by there and say, 'They are coming from the ghettoes of Chicago and Detroit, Newark, New York, and Philadelphia.' I want somebody to say 'They are coming up out of great trials and tribulation. They are coming up out of years of neglect, and years of hurt' .... And I want somebody else to ask 'How many do you see out there?' I want somebody just to say, 'I've been trying to count them all the week. But it seems to me to be a number that no man can number.' ${ }^{19}$

Rather than a statement that the poor are coming 'from every nation, from all tribes and peoples and languages' as in Rev. 7.9, King notes that the multitude in D.C. come from states in the deep south and from major US cities, especially those experiencing race riots. Thus, in both cases the multitude is one that comes out of great tribulation though the causes of the tribulation differ in details. The great distress of the protestors in Washington D.C. comes from the twin evils of racism and poverty. According to King 'they are coming up out of years of neglect, years of hurt', while the distress of the innumerable crowd in the Apocalypse comes from a variety of sources alluded to in Rev. 2-3, from pressure to participate in empire and its corrupting wealth, from interethnic tension, and from socio-economic deprivation. ${ }^{20}$

King's exegesis in the final scene takes up analysis of the parable of the Good Samaritan and uses it to comment on the state of race relations in his context. In this section King argues that the civil rights movement demands from clergy and from the SCLC a 'committed empathy and a kind of dangerous altruism' that is analogous to the courageous and gracious action of the Samaritan in Lk. 10.25-37. King skims the details of the well-known story, and only momentarily dwells on the fact that the Samaritan was a man of 'another race'. He imagines that the Priest and Levite bypassed the robbery victim not out of religious duty or obligation, but out of fear: 'Maybe the robbers are still around ... . If I stop to help this man, what will happen to me?' Evocatively, similar to the way that Jesus shifts a question about 'who is my neighbour?' to one that dwelt on the matter of 'being a neighbour' (Lk. 10.36), King insists that the heroism of the Samaritan emerged when he reversed the question 'What will happen to me?' by asking 'If I do not stop to help this man, what will happen to him?' Analogously connecting this to the Poor People's Campaign, King in effect poses an intra-racial challenge to the SCLC to act like the Samaritan and imagine what will happen to Black brothers and sisters inside the Black community who are suffering in poverty if they do not take a stand. Then, just as his earlier invocation of the story of Dives and Lazarus did double

19 King, 'To Minister in the Valley'.

20 For analogues that similarly connect the contemporary Black Lives Matter civil rights protest movement to womanist exegesis of Revelation, see Love Sechrest, 'Antitypes, Stereotypes, and Antetypes: Jezebel, the Sun Woman, and Contemporary Black Women', in Womanist Interpretations of the Bible: Expanding the Discourse, ed. Gay L. Byron and Vanessa Lovelace (Semeia Studies 85; Atlanta: Society of Biblical Literature, 2016), 113-38. 
duty by symbolizing inter-group and intra-group conflict, King adds an inter-group illustration by drawing a parallel between the Samaritan story and a period in his own life when he took a public stand against the Vietnam War. He tells about how much that posture cost him in terms of lost support in the press, diminished regard from the Johnson administration, and broken relationships with white allies and with Blacks in the movement alike, to say nothing of the material costs of lost donations to the SCLC under King's leadership. In reply to a reporter who asked about the damage to his reputation for taking this unpopular stand against the Vietnam War, King answered:

Sir, I'm sorry, you don't know me. I'm not a [consensus] leader. I don't determine what is right and wrong by looking at the budget of the Southern Christian Leadership Conference, or by taking a Gallup [Poll] of the majority opinion. Ultimately a genuine leader is not a searcher for consensus but a molder of consensus. On some positions, cowardice asks the question 'Is it safe?' Expediency asks the question 'Is it politic?' And vanity comes along and asks the question 'Is it popular?' But conscience asks the question 'Is it right?' And there comes a time when one must take a position that is neither safe nor politic nor popular, but he must do it because conscience tells him that it is right. And this is where ... we must go as ministers of the gospel. ${ }^{21}$

Thus, King's interpretation of the Good Samaritan does double duty by focusing on inter-group and intra-group conflict, and we shall see that this same dual concern for internal and external issues prevails in my own reading of this parable.

\section{A second look at the Good Samaritan: An African-American reading of Lk. 10.25-32}

Few treatments of the parable of the Good Samaritan adequately explore the relationship of the parable to its literary context in Lk. 9.51-10.24. Interpreters note that Luke has six episodes featuring Samaritans in Luke-Acts, in contrast to a complete absence of this group in Mark and single appearances in Matthew and John. ${ }^{22}$ The brief mention of Jesus' foray into Samaritan territory in Lk. 9.51-56 serves to highlight Jesus' rejection by Samaritans, ${ }^{23}$ and this tableau is consistent with the long history of ethnic conflict between Samaritans and Jews, arising from disagreements about the rival temple institutions and debates about the canon. ${ }^{24}$

${ }^{21}$ King, 'To Minister in the Valley'.

22 Samaritan episodes in Luke-Acts: Lk. 9.51-56; 10.25-37; 17.11-19; Acts 1.8; 8.4-25; 15.3; cf. Mt. 10.5; Jn 4.4-40; cf. 8.48.

23 Joel B. Green, The Gospel of Luke (NICNT; Grand Rapids, MI: Eerdmans, 1997), 405. Robert C. Tannehill (Luke (Abingdon New Testament Commentaries; Nashville: Abingdon Press, 1996), 170) notes that both of these episodes prefigure Jesus' final rejection in Jerusalem at the cross.

24 J. Daniel Hays, From Every People and Nation: A Biblical Theology of Race (Leicester/Downers Grove, IL: Apollos/IVP, 2003), 166; Klyne Snodgrass, Stories with Intent: A Comprehensive Guide to the Parables of Jesus (Grand Rapids, MI: Eerdmans, 2008), 346. 
Luke 9.51-10.24 also appeals to imagery from the Elijah-Elisha cycle. While the connection with Elijah-Elisha imagery is explicit in Lk. 4.25-27, the connection is more allusive in 9.51-10.24. Jesus' journey with his disciples to Jerusalem, the place where he will be taken up, echoes Elijah and Elisha's journey to Jericho, the place where Elijah would be caught up (2 Kgs 2.1-2). ${ }^{25}$ The allusions to the Elijah-Elisha cycle are even more marked with the mention of 'fire from heaven' in 9.54-55. In these verses the disciples are angry at the Samaritans' rejection of Jesus and ask to call down heavenly fire upon them, in effect reprising Elijah's response to the affront arising from Ahaziah's idolatry (2 Kgs 1.1-3, 10-14). However, Jesus' refusal to sanction the recalcitrant Samaritans in this way contrasts with Elijah's fiery solution and is more similar to his handling of the rejection of his own people in Nazareth at 4.30 and at 9.5 where he advises disciples to shake the dust off their feet when they are not welcomed in Israelite towns. Jesus' restraint indicates that he did not regard Samaritans as idolaters or heretics like Ahaziah, but that he sees them as insiders in that he responds to their rejection in a way similar to that proposed for Israelites in 9.5. ${ }^{26}$ Jesus' characterization of Samaritans as 'foreigners' in 17.18 acknowledges that most Jews would count Samaritans as outsiders, but his foray into Samaritan territory and his response to Samaritan rejection tacitly acknowledges the difference between the Samaritans of Lk. 9 and Ahaziah's idolatry in 2 Kgs 1 , as a closer examination of Lk. 10.25-37 will confirm. ${ }^{27}$

The connection between 9.51-56 and the narrative in 9.58-10.24 builds on the observation that Jesus sees Samaritans as insiders - departed brethren if you will inasmuch as the gathering of the seventy (9.58-62) and the sending of the seventy (10.124) function to develop the theme of Jesus' mission to re-gather Israel. ${ }^{28}$ As others have remarked, these sayings function literarily as the gathering of the seventy. ${ }^{29}$ This suggests to some that these disciples will be venturing into Gentile territories, though the judgements against Chorazin, Bethsaida, and Capernaum still seem to have a Jewish context in mind for this mission. It is plausible that the note about eating and drinking in 10.7 simply recognizes that there was more variety concerning degrees of kashrut observance in the Diaspora than in Palestine. ${ }^{30}$ What is especially important for our purposes is that the juxtaposition of this episode with Jesus' prior entry into Samaritan territory implies that Samaritans would have been welcome to the company of the seventy.

Thus the literary context of the Good Samaritan concerns the intra-racial gathering of disciples for a mission to Israel, and indeed may be pictured as the conclusion, or

25 Tannehill, Luke, 169.

26 See I. Howard Marshall, The Gospel of Luke: A Commentary on the Greek Text (Grand Rapids, MI: Eerdmans, 1978), 403-4 and especially Martina Böhm, Samarien und die Samaritai bei Lukas: Eine Studie zum religionshistorischen und traditionsgeschichtlichen Hintergrund der lukanischen Samarientexte und zu deren topographischer Verhaftung (WUNT 2.111; Tübingen: Mohr Siebeck, 1999), 205-38.

27 See Snodgrass, Stories, 342-3 for a survey of the range of Jewish opinion on relations with Samaritans; also see Böhm, Samarien, 37-203 on this point.

28 Böhm also sees 9.51-56 as initiating a mission to Israel, rather than a prophecy of the mission to Gentiles (Samarien, 205-38).

29 On this passage as the gathering of the seventy, see, for example, Green, Gospel of Luke, 400; Tannehill, Luke, 174.

30 John M. G. Barclay, Jews in the Mediterranean Diaspora: From Alexander to Trajan (323 BCE-117 CE) (Edinburgh: T\&T Clark, 1996), 434-7; cf. Lk.10.8. 
perhaps even an interruption, in Jesus' discourse with the seventy. ${ }^{31}$ The foray into Samaritan territory hints that Samaritans are to be included in this mission as members of Israel, and suggests that the re-gathering of the family is not simply a matter of geography, but also involves reconciliation of long-standing breaches in the family. If the disciples had missed the subtle implications of his attempt to gather co-workers from among the Samaritans, they would have a harder time missing the implications of the parable of the Good Samaritan: In Jesus' eyes Samaritans are Israelites, too. ${ }^{32}$

Moving now to a consideration of the parable itself, we find that it is most often interpreted as a simple example story that illustrates the idea that for Jesus love of neighbour interracially bridges ethnic and religious boundaries. ${ }^{33}$ The hero of the piece is a Samaritan who is despised by the religious leaders of Israel, but who also manages to outdo them in obedience to Torah. ${ }^{34}$ The most prominent elements in the first section suggest that interpretation of the Law is the central issue in this discourse.$^{35}$ In addition, we note that the lawyer's summary of the two tables of the Law, which group the Ten Commandments into a vertical group that concern worship of God and a horizontal group that concern justice within the community, is one which garners Jesus' assent (10.28) and is consistent with a broad swathe of Jewish interpretation in the period. In 10.27 the lawyer recites the Shema from Deut. 6.5 which is the confession about the Israelites' devotion to God that still stands at the heart of Jewish identity alongside the command to love the neighbour as self from Lev. 19.18. However, we should note that the ensuing dialogue makes it clear that the obligation to love the resident alien as self from nearby Lev. 19.34 is also close to hand. ${ }^{36}$ In one sense the parable may be interpreted as a contrast between the lawyer's desire to discuss the Israelite neighbour as in Lev. 19.18 with Jesus' interests in pushing the boundaries of love of neighbour to include everyone living in the community as in Lev. $19.34 .{ }^{37}$

The boundaries that determined who was and was not a neighbour were an issue not only among Pharisees and others who seem regularly to have debated the topic but also for Luke's first gentile-Christian readers. ${ }^{38}$ Some texts from the Second Temple period suggest that one should not do good to sinners and the ungodly (cf. Sir. 28.4; 1QS 1.1-3, 9-10; Tob. 4.17), while others show that love of neighbour was understood

${ }^{31}$ For more on Jewish constructions of race and ethnicity in the period, see Love L. Sechrest, A Former Jew: Paul and the Dialectics of Race (LNTS 94; London: T\&T Clark, 2009).

${ }^{32}$ Contra Darrell Bock, Luke (2 vols; Baker Exegetical Commentary on the New Testament; Grand Rapids, MI: Baker Academic, 1994), 2:970.

${ }_{33}$ See especially Hays, From Every People and Nation, 166-71, 204.

${ }^{34}$ Snodgrass, Stories, 348; also see Steven L. McKenzie, All God's Children: A Biblical Critique of Racism (Louisville, KY: WJK, 1997), 93-7.

${ }_{35}$ The most prominent sections are marked throughout with the imperfective verbal aspect, here

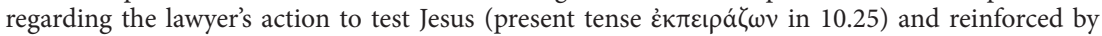

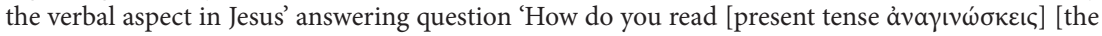
law]?' Similarly, though on other grounds, see Green, Gospel of Luke, 428.

${ }^{36}$ Luke Timothy Johnson (The Gospel of Luke (SP; Collegeville, MN: Liturgical Press, 1991), 172) raises an interesting point about the way that the LXX translates the idea of 'resident alien' from the Hebrew of 19.34 by using the Greek word 'proselyte', a translation that essentially collapses Lev. 19.18 and 19.34 into a single imperative that commands love within the Israelite community.

${ }^{37}$ For an excellent take on this perspective, see Green, Gospel of Luke, 424-32. Johnson's reading (Gospel of Luke, 173-5) is an unusual case in that it concurs with much of what is presented here, while still reading Jesus' final question as a change of topic.

${ }^{38}$ Johnson, Gospel of Luke, 172-3. 
by many Jews to extend to those outside of the Jewish people (Jos. Asen. 27-29; T. Iss. 5.2; 7.6). ${ }^{39}$ Given this context, it may be that the lawyer asks whether the kinshiplove of Lev. 19.18 should be extended to strangers and converts, a question that would be vitally important as Jesus gathers the seventy for a new and broader mission to marginalized Israelites in the Diaspora.

Luke 10.30-31 describes the victim's journey down from Jerusalem, and the travel of the priest on that same road may imply the common Judean origin of the two men, though this common identity is not at all required. ${ }^{40}$ We might also suppose that the other characters have been chosen to represent the leaders of Israel. ${ }^{41}$ However, Michel Gourgues suggests that here we have an allusion to a tripartite formula that was frequently used in Judaism whereby such stories feature priests and Levites followed by someone who is a representative of the ordinary Israelite. ${ }^{42}$ An example of this formula from the Babylonian Talmud seems similar to the situation in this parable: ${ }^{43}$

R. Meir used to say, 'Whence do we know that even an idolater who studies Torah is equal to a High Priest? From the following verse: "Ye shall therefore keep My statutes and My ordinances which, if a man do, he shall live by them." It does not say "If a Priest, Levite, or Israelite do, he shall live by them," but "a man"; here, then, you can learn that even a heathen who studies the Torah is equal to a High Priest!' (b. 'Abod. Zar. 3a; cf. b. Sanh. 59a)

Thus, where one would expect an ordinary Jew to complete the triadic priest, Levite, and Israelite formula, in Luke we find a Samaritan instead. While some might conclude that Jesus is extending the obligations to outsiders which are normally reserved for insiders in this parable, it might be more in keeping with the function of such triadic formulas to conclude that Jesus is here suggesting that Samaritans are Israelites, even if they are members who had been then long outcast. ${ }^{44}$ Though some might suggest that Lk. 17.18, where Jesus labels a Samaritan a 'foreigner', resists this interpretation, it may be that that passage makes a point similar to the one made in this parable. Contrary to expectations, it is the Samaritan who fills the role of the 'ordinary Israelite', exhibiting faithfulness to the commandments beyond the behaviour exhibited by the elite. ${ }^{45}$

More significant for our purposes is the tantalizing possibility that 2 Chron. 28.8-15 provides an intertestamental LXX analogy for this parable. According to the Chronicler,

39 For more on ancient texts that shed light on this passage, see the helpful summary in Snodgrass, Stories, 338-43, 45-47.

40 Green, Gospel of Luke, 429 n. 114.

${ }^{41}$ Johnson, Gospel of Luke, 173.

42 Michel Gourgues, 'The Priest, the Levite, and the Samaritan Revisited: A Critical Note on Luke 10:31-35', JBL 117 (1998): 709-13.

43 See William Stegner, 'The Parable of the Good Samaritan and Lev 18:5', in The Living Text, ed. Dennis E. Groh and Robert Jewett (Lanham, MD: University Press of America, 1985), 27-38.

44 There is evidence that there were varying opinions on the status of Samaritans among Jews during the period: see Snodgrass, Stories, 342-3 citing m. Nid. 7.3; b. Nid. 56b; cf. Josephus, War, 3.35-53, as well as the longer discussion in Böhm, Samarien, 37-203.

45 Similarly Böhm, who emphasizes the Samaritan as an example of halachic rigour in the parable of the Good Samaritan (Samarien, 259-60). 
King Ahaz of Judah was defeated by King Pekah of Israel in Samaria because the Judahites had abandoned the Lord (28.6; cf. 2 Kgs 15.27, 37). When Pekah's conquering army returns to the capital city of Samaria with thousands of Judahite captives and great booty, a prophet confronts the army insisting that it is sinful to kill the captives and to subjugate them as slaves: 'Send the captives back whom you have taken from your kindred' (28.11). In vv. 12-15, leaders from the tribe of Ephraim also stand up against the army and act as 'good' Samaritans in terms that are reminiscent of our passage in Luke. These Samarians

took the [Judahite] captives, and they clothed all their naked ones from the spoil; and they gave them clothes and sandals, fed them and gave them drink, anointed them with oil, led all their feeble ones on donkeys, and brought them to Jericho, the city of palm trees, to their brothers; then they returned to Samaria. (2 Chron. 28.15; cf. Lk. 10.30, 34)

It is not too difficult to see that the Good Samaritan of Lk. 10 is analogous to the good Samarians of 2 Chron. 28. In 2 Chron. 28, a conquering Samarian army treats their Judahite captives like the kinsmen they are, whereas in Lk. 10 a Samaritan treats a man who may be a Jew with kindness, despite a long history of enmity between their peoples. In both cases the victims were (apparently) from Jerusalem, unclothed, beaten, and without possessions (2 Chron. 28.5, 6-8, 15; Lk. 10.30). In both cases, Samari(t)ans transport the victims by donkey, anoint them, and take them to recuperate in Jericho (2 Chron. 28.15; Lk. 10.30, 34-35). ${ }^{46}$ Read through the lens of 2 Chron. 28, it is as if Jesus is saying that the Samaritan helps the injured man because he recognizes his kinship with that man as a Jew, a reasonable if not required assumption about the victim's identity; indeed, we could say that he is moved to compassion by the mere possibility that the injured man was a kinsman. This plea for recognition of the common kinship between Samaritan and Jew is a plea for acceptance of the intra-racial marginalized within the community. This plea goes beyond the idea that an obligation to the other is uncircumscribed by the normal calculus of kinship as in the traditional reading of this parable. In a striking way, our parable goes beyond that message by demanding that we add the calculus of kinship to our vision of the other and begin to view the outsider as family.

As described above, Jesus does not answer the original question from 10.29 - 'Who is my neighbour?' - but asks a different one - 'Who acted like a neighbour (10.36)?'47 Hence, most judge that the question in 10.36 is one that subtly shifts the terms of the debate, from one about the extent of obligations to neighbour to one that focuses on the characteristics of neighbourliness, a shift that forces the lawyer to acknowledge the

46 This list of similarities is inspired by a similar accounting by Spencer, though several of his adduced parallels between the prophets and leaders in 2 Chron. 28 and the priest and Levite in Lk. 10 are less than compelling (see F. Scott Spencer, '2 Chronicles 28:5-15 and the Parable of the Good Samaritan', WTJ 46 (1984), 322-7). One key difference between the Lucan version of the tale of the Good Samaritan and this OT Vorlage concerns the emphasis on the Samaritan's return which is foregrounded in Lk. 10 but lacks a counterpart in 2 Chron. 28.

47 Snodgrass insinuates that this kind of odd reversal also occurs elsewhere in Luke: 7.36-50; 12.13$15 ; 17.20-12 ; 18.18-23$ and parallels (Stories, $342-3$ ). It may be that $7.36-50$ is a valid analogue, but there are other explanations for the shifts in the other passages, including the interpretation of the so-called reversal offered here. 
Samaritan as the moral exemplar. ${ }^{48}$ The question is the most heavily marked verse in the episode with the main verb $\delta$ ok $\dot{\varepsilon} \omega$ foregrounded in the present tense and the even more heavily marked front-grounding of yivoua in the perfect tense: 'Which of these

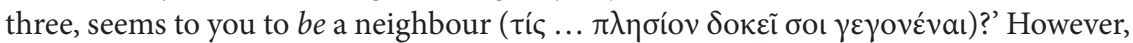
our understanding of the intertextual relationship between Lk. 10 and 2 Chron. 28 suggests that Jesus does respond to the lawyer's question after all. The key to unlocking this parable is to understand the real question asked by the lawyer in 10.29. When the lawyer asks 'Who is my neighbour?' he is not asking 'To whom should I show love?' as is commonly assumed - interpreters are correct in noting that the latter question is never really answered. Rather, we should understand the lawyer's question to be 'Who constitutes the Israelite neighbour being discussed in Lev. 19.18?' or 'How does one identify the Israelite about whom the commandments in Lev. 19.18 are concerned?' In other words, the question at stake in Lk. 10.30 is: Of the three people in the parable, which one reveals himself to be ( $\gamma \varepsilon \gamma o v \varepsilon$ val; 10.36) a true member of Israel? This question is directly answered by the parable: It is the one who lives obeying the two tables of the law regarding love of God (Deut. 6.5) and love of family (Lev. 19.18; cf. 19.34). ${ }^{49}$

I suggest that the passage forms a conclusion to Jesus' instructions for a broader Jewish mission. Adjacent as it is to the sending of the seventy assistants who re-gather the dispersed of Israel, it is a story that helps the seventy identify those formerly outcast from Israel. Thus, the parable prophesies the reconciliation between Israel and Samaritans which is fulfilled later in Acts 8. As with the Chronicler in 2 Chron. 28 , Jesus is here primarily concerned about the unity of Israel and is at pains to heal schisms within the community of faith which are painfully exhibited throughout Acts and especially at the end in Acts 28.25-28. On this reading, the parable is an intra-racial exhortation for Jews to recognize Samaritans as brothers and sisters and as Israelites; it rebukes attitudes like the lawyer's which try to justify an exclusivist posture towards other marginalized people in the community like sinners and tax collectors.

Thus an analogy for the intra-Israel reading offered above might involve an associative correlation between the ancient Samaritan-Jewish conflict and contemporary ethno-racial tension regarding the 'forever foreigner' trope in the United States as applied to all Americans of colour. This trope, in which people of colour are viewed as outsiders who are 'not real Americans, ${ }^{50}$ is primarily associated

${ }^{48}$ See, for example, Johnson, Gospel of Luke, 173; Spencer, '2 Chronicles 28:5-15', 341-2; Green, Gospel of Luke, 432; Marshall, Gospel of Luke, 445-6.

${ }_{49}$ Spencer ('2 Chronicles $28: 5-15$ ', 335) notes that Lev. 19.17-18 is 'a composite unit, we find the command to love one's neighbor ... which concludes $v 18$ as nothing but the positive reversal of the negative exhortation opening $v$ 17: "You shall not hate your brother ('ah) in your heart".

${ }^{50}$ A recent global survey of 1,500 people surveyed across 33 countries found that people often overestimate the number of foreign-born people in their country. In the United States the average guess was that 33 per cent of residents were foreign-born while the actual was 14 per cent. The comparable overestimates in Canada were 39 per cent estimated versus 21 per cent actual; in the UK 25 per cent estimated versus 13 per cent actual; in France, 26 per cent estimated versus 12 per cent; and in Italy 26 per cent estimated versus 9 per cent actual (Ipsos MORI, 'Perils of Perception Survey', 2015. Available online: https://www.ipsos.com/ipsos-mori/en-uk/perils-perception-2015 (accessed 22 June 2017)). It is worth noting that in the United States the guess that 33 per cent of residents in the country are foreign-born is uncomfortably close to the actual number of citizens of color in the country, which could suggest that in the view of some at least, every non-white person seen is not a 'real American' notwithstanding their citizenship status. 
with racist attitudes that exclude Asian Americans from insider status because of phenotypical differences, ${ }^{51}$ but its contours were also evident in the so-called 'Birther' movement during the Obama presidency, which challenged the native-born citizenship of the first African-American president and hence contested his eligibility to hold the office. The reading of the parable above suggests that marginalized persons are indeed real citizens who can be moral exemplars despite being regarded as outsiders by some; it suggests that the marks of true citizenship are deeds of mercy to marginalized insiders.

The idea that Blacks, Muslims, Mexicans and other citizens of colour are not regarded as 'real' members of the American family is rampant in US politics in the Trump era, and this reading of the parable calls for intra-national moral courage on behalf of all of those occupying these marginalized spaces in the context of an ascendant white nationalist xenophobia. For example, Japanese Americans, who remember the hostility of the American public in the aftermath of the Second World War-era Pearl Harbour attacks, are Samaritans when they stand in solidarity with Muslim Americans who occupy an analogous position in society ever since the September 2001 terrorist attacks on New York and Washington D.C..$^{2}$

In fact, this intra-racial interpretation mimics the results of the traditional interracial interpretation by defining the kinship community as analogous to a single national 'family'. Hence, my intra-Israel reading of the parable works when considering tensions within ethno-racial subgroups as well as tensions within the national community by using elastic boundaries with respect to the definition of kinship or family. Just as King used the parable to criticize the Black clergy for lack of concern about the plight of poor Blacks, so too could intra-racial analogues to my reading exhort middle-class African-American Christians to eschew the respectability politics that inhibits many of them from direct ministry to the black casualties of the prisonindustrial complex..$^{53}$ Thus, my own reading of the parable exhibits the dual vision that was so characteristic of King's preaching and activism, a vision that simultaneously leverages readings of scripture for impact on interracial relations as well as tensions within the Black church.

${ }^{51}$ K. Kale Yu, 'Christian Model Minority: Racial and Ethnic Formation in Asian American Evangelicalism' Journal of Race, Ethnicity, and Religion, 7, no. 4, (2016). Available online: http:// raceandreligion.com/JRER/JRER.html (accessed 17 February 2017); also see Sechrest, A Former Jew, for more on comparisons between ancient and modern conceptions of ethno-racial difference.

52 See, for example, Kimberly Veklerov, 'Formerly Interned Japanese Americans Stand Up against Muslim Hate', San Francisco Chronicle, 22 December 2015. Available online: http://www.sfgate.com/ bayarea/article/Formerly-interned-Japanese-Americans-stand-up-6716136.php. (accessed 18 June 2017).

53 A similar situation may prevail regarding middle-class Mexican Americans with respect to the policing of their communities. For more on the over-policing of Blacks and Latinos in the US prison-industrial complex, see Michelle Alexander, The New Jim Crow: Mass Incarceration in the Age of Colorblindness (New York: The New Press, 2010). See also Patricia Hill Collins' discussion of respectability politics (e.g. a desire to exhibit superlative public respectability as a way of eschewing stereotyped behaviour and earning white approval) in the African-American community in Black Sexual Politics: African Americans, Gender, and the New Racism (New York: Routledge, 2004). 


\section{Conclusion: Analogues to the Parable of the Good Samaritan in African-American interpretation}

King utilizes the unknown victim in the parable to develop both intra-racial and interracial analogues in his speech to the SCLC. By asking the SCLC leaders to act like the Samaritan vis-à-vis the poorest of the poor in the Black community and imagine what will happen to Black brothers and sisters who are suffering in poverty if they do not take a stand, King calls them to the kind of intra-racial love of family that is also at the heart of my interpretation of the Good Samaritan, especially when it is seen in light of its own inter-canonical analogy with the story in 2 Chron. 28. However, King broadens the scope of his interpretation through an interracial use of analogical reasoning when he illustrates the message of the parable by means of his isolating and unpopular moral stance against the Vietnam War, much as the traditional interpretation focuses on relationships with unknown outsiders. King imaginatively reads himself into the parable by asking 'What would happen to the Vietnamese people, the more than five hundred thousand of our own soldiers, [and] the soul of our nation if I did not take a stand against it?'54 Together King's appeal to inner-Black familial dynamics as well as external and international dynamics in the kinship of the human family represents an authentic and powerful contemporary reading of the parable of the Good Samaritan that honours the parable's own intertextual relationship with the traditions of Israel, as well as those modern readers who see in it a perfect description of other-regard that can address interracial conflict.

Indeed, King brings this same capacity for double vision to his interpretation of the conflict at Nazareth in Lk. 4.18-20. Though some might decide that this passage is a simple story about intra-racial conflict between Jesus and the Nazarenes, in King's hands the echoes of Jubilee and the allusion to interracial relations in Jesus' response in 4.24-27 becomes an analogue for a multiracial coalition for poverty relief in the United States through the Poor People's Campaign. Likewise, his appeals to the story of Dives and Lazarus are characterized by concern with intra-racial and interracial issues: first with respect to relations between the Black middle and poor classes, and second with concern about tensions between the haves and the havenots across the United States broadly. His double vision manifests itself again as he then uses the story to articulate concerns about poverty relief on an interracial/ international scale.

My own interpretation of the Samaritan story also participates in a similar interpretive trajectory, but it does so through an intra-racial familial focus on a story that is widely seen as an exhortation about easing interracial tensions and thus extending Christian concern to the despised outsider. It manifests intra-racial and interracial concerns by creating analogues with expansive and narrow definitions of family. My reading implicitly recognizes that concern for the marginalized within one's own family is an important expression of King's revolutionary Christianity, but the interpretation also recognizes that concern for the poor and outcast in one's own family is the other side

54 King, 'To Minister in the Valley'. 
of the coin of international concern for the poor and outcast. Building on instincts of DuBois and the African-American interpreters before me, I suggest that there is something about the African-American experience of race that brings with it a capacity for recognizing that there is something deeply amiss in a community's self-conception when it marginalizes those in its own communities. More broadly, a diminished capacity to see ourselves as others see us inevitably diminishes our capacity to engage those outside of our direct line-of-sight. Indeed, this capacity to discern a difference between what one sees and what one knows that others see has long been a condition of African-American experience, and it is this impulse that stands at the centre of an African-American reading of scripture in the tradition of Martin Luther King Jr.

\section{References}

Alexander, Michelle. The New Jim Crow: Mass Incarceration in the Age of Colorblindness. New York: The New Press, 2010.

Bailey, Randall C. 'Academic Biblical Interpretation among African Americans in the United States'. In African Americans and the Bible: Sacred Texts and Social Textures, edited by Vincent Wimbush, 696-711. New York: Continuum, 2000.

Barclay, John M. G. Jews in the Mediterranean Diaspora: From Alexander to Trajan (323 BCE-117 CE). Edinburgh: T\&T Clark, 1996.

Blount, Brian K. Can I Get a Witness? Reading Revelation through African American Culture. Louisville, KY: WJK, 2005.

Blount, Brian, Cain Hope Felder, Clarice J. Martin, and Emerson B. Powery. 'Introduction'. In True to Our Native Land: An African American New Testament Commentary, 1-7. Minneapolis: Fortress, 2007.

Bock, Darrell. Luke. 2 volumes. Baker Exegetical Commentary on the New Testament. Grand Rapids, MI: Baker Academic, 1994.

Böhm, Martina. Samarien und die Samaritai bei Lukas: Eine Studie zum religionshistorischen und traditionsgeschichtlichen Hintergrund der lukanischen Samarientexte und zu deren topographischer Verhaftung. WUNT 2.111. Tübingen: Mohr Siebeck, 1999.

Brown, Michael Joseph. The Blackening of the Bible: The Aims of African American Biblical Scholarship. Harrisburg, PA: Trinity Press International. 2004.

Byron, Gay L. and Vanessa Lovelace, eds. Womanist Biblical Interpretation: Expanding the Discourse. Semeia Studies 85. Atlanta: Society of Biblical Literature, 2016.

Collins, Patricia Hill. Black Sexual Politics: African Americans, Gender, and the New Racism. New York: Routledge, 2004.

DuBois, W. E. B. The Souls of Black Folk, with a New Introduction by Randall Kenan. New York: Signet, 1995.

Gourgues, Michel. 'The Priest, the Levite, and the Samaritan Revisited: A Critical Note on Luke 10:31-35'. JBL 117 (1998): 709-13.

Green, Joel B. The Gospel of Luke. New International Commentary on the New Testament. Grand Rapids, MI: Eerdmans, 1997.

Hays, J. Daniel. From Every People and Nation: A Biblical Theology of Race. Leicester/ Downers Grove, IL: Apollos/IVP, 2003.

Ipsos MORI. 'Perils of Perception Survey', 2015. Available online: https://www.ipsos.com/ ipsos-mori/en-uk/perils-perception-2015 (accessed 22 June 2017). 
Johnson, Luke Timothy. The Gospel of Luke. Sacra Pagina. Collegeville, MN: Liturgical Press, 1991.

Lischer, Richard. The Preacher King: Martin Luther King, Jr. and the Word that Moved America. Oxford: Oxford University Press, 1997.

McKenzie, Steven L. All God's Children: A Biblical Critique of Racism. Louisville, KY: WJK, 1997.

Marshall, I. Howard. The Gospel of Luke: A Commentary on the Greek Text. Grand Rapids, MI: Eerdmans, 1978.

Powery, Emerson. 'African American Criticism'. In Hearing the New Testament: Strategies for Interpretation, edited by Joel B. Green, 326-49. 2nd edn. Grand Rapids, MI: Eerdmans, 2010.

Scrivner, Joseph. 'African American Interpretation'. In The Oxford Encyclopedia of Biblical Interpretation, edited by Steven L. McKenzie. Oxford: Oxford University Press, 2014. Available online: http://www.oxfordreference.com/view/10.1093/acref:o bso/9780199832262.001.0001/acref-9780199832262-e-90 (accessed 17 February 2017).

Sechrest, Love L. A Former Jew: Paul and the Dialectics of Race. LNTS 410. London: T\&T Clark, 2009.

Sechrest, Love L. 'Antitypes, Stereotypes, and Antetypes: Jezebel, the Sun Woman, and Contemporary Black Women'. In Womanist Interpretations of the Bible: Expanding the Discourse, edited by Gay L. Byron and Vanessa Lovelace, 113-38. Semeia Studies 85. Atlanta: Society of Biblical, 2016.

Smith, Mitzi, ed. I Found God in Me: A Womanist Biblical Hermeneutics Reader. Eugene, OR: Cascade Books, 2015.

Snodgrass, Klyne. Stories with Intent: A Comprehensive Guide to the Parables of Jesus. Grand Rapids, MI: Eerdmans, 2008.

Spencer, F. Scott. '2 Chronicles 28:5-15 and the Parable of the Good Samaritan'. WTJ 46 (1984): 322-7.

Stegner, William. 'The Parable of the Good Samaritan and Lev 18:5'. In The Living Text, edited by Dennis E. Groh and Robert Jewett, 27-38. Lanham, MD: University Press of America, 1985.

Tannehill, Robert C. Luke. Abingdon New Testament Commentaries. Nashville: Abingdon Press, 1996.

Veklerov, Kimberly. 'Formerly Interned Japanese Americans Stand Up against Muslim Hate. San Francisco Chronicle, 22 December 2015. Available online: http://www.sfgate. com/bayarea/article/Formerly-interned-Japanese-Americans-stand-up-6716136.php. (accessed 18 June 2017).

Wimbush, Vincent. 'Introduction: Reading Darkness, Reading Scriptures'. In African Americans and the Bible: Sacred Texts and Social Textures, edited by Vincent Wimbush, 1-43. New York: Continuum, 2000.

Wolfreys, Julian, Ruth Robbins, and Kenneth Womack. Key Concepts in Literary Theory. Edinburgh: Edinburgh University Press, 2006.

Yu, K. Kale. 'Christian Model Minority: Racial and Ethnic Formation in Asian American Evangelicalism. Journal of Race, Ethnicity, and Religion 7 (2016). Available online: http://raceandreligion.com/JRER/JRER.html (accessed 17 February 2017). 


\title{
Re-examining the Master's Tools: Considerations on Biblical Studies' Race Problem
}

\author{
Wei Hsien Wan
}

In her now-famous comments made during a New York University Institute of Humanities conference in 1984, Audre Lorde called out the organizers of the conference - and white feminist academics as a whole - for their heteronormative and racial blind spots:

I stand here as a black lesbian feminist, having been invited to comment within the only panel at this conference where the input of black feminists and lesbians is represented. ... To read this program is to assume that lesbian and black women have nothing to say about existentialism, the erotic, women's culture and silence, developing feminist theory, or heterosexuality and power. And what does it mean in personal and political terms when even the two black women who did present here were literally found at the last hour? What does it mean when the tools of a racist patriarchy are used to examine the fruits of that same patriarchy? It means that only the most narrow perimeters of change are possible and allowable. ${ }^{1}$

By muting the voices of 'poor women, black women, third-world women, and lesbians', Lorde argued, white feminism simply reproduced the same dynamics of silencing and erasure that so characterized patriarchy. So long as this was the case, she said:

The master's tools will never dismantle the master's house. They may allow us temporarily to beat him at his own game, but they will never enable us to bring about genuine change. ${ }^{2}$

Lorde's logic here is straightforward: You cannot defeat structural oppression with the mechanisms used to produce it in the first place. The logic of exclusion that governs systems of domination cannot at the same time be used to dismantle them.

1 Audre Lorde, 'The Master's Tools Will Never Dismantle the Master's House', in Sister Outsider: Essays and Speeches (Berkeley: Crossing Press, 1984), 110-13, at 110-11.

2 Lorde, 'Master's Tools', 112. 
The present essay is an attempt to think about the questions of race and method in modern biblical studies and what we, as a guild of scholars, perhaps should and can do differently. I take as my starting point Lorde's comments above because, in the decade or so I have spent as a formal student of the Bible in the United States, Europe, and the UK, I have often found myself troubled by similar thoughts regarding the tools or methods of modern biblical studies. Where have these tools come from, and what kind of structures have been built - and continue to be built - with them? What should one do if one wanted to build a different future for the study of the Bible and its related texts? It should not surprise anyone that I do not have anything resembling a complete answer - not by a long shot! - yet I hope, nonetheless, that readers here will think with me as I work out my own reflections on this matter in the public context of scholarly conversation.

My title assumes that academic biblical studies has a race problem. On one level, this is a rather obvious point to make. One only need look at the sheer proportion of white to non-white academics represented in our institutions, conferences, and publications. For example, in its 2015 Annual Report, the Society of Biblical Literature (SBL) reported the following ethnic breakdown of its members who were US citizens: 85.1 per cent of white or European descent; 3.8 per cent of mixed ethnicity; 3.3 per cent of African descent; 2.3 per cent of Asian descent; 1.7 per cent Latina/o; and 0.2 per cent Native American, Alaskan Native, or First Nation descent. ${ }^{3}$ Commenting on this data, the SBL Committee on Underrepresented Racial/Ethnic Minorities in the Profession (CUREMP) rightly observed in its twenty-fifth anniversary report that

the self-identified minoritized scholars were disproportionately small, even by the standards of the broader US academy. ... These numbers compel us as a Society to wonder about what kind of scholarship we are truly committed to; if we recognize that diversity is about both numbers of bodies as well as a substantive intellectual commitment to varying perspectives and approaches, then we do have to think strategically about what makes our Society and the field of biblical scholarship comparatively restraining of diversity. ${ }^{4}$

In its conclusion, the Committee delivers an important injunction: It calls for transformation of 'not only the demography but also the discourses and practices that have restrained demographic diversification. ${ }^{5}$

3 Society Report, 22 November 2015. Available online: https://www.sbl-site.org/assets/pdfs/SR2015_ online.pdf (accessed 5 April 2017).

4 '25 Years and Counting! Reflecting on the Past and Future of SBL's Committee on Underrepresented Racial/Ethnic Minorities in the Profession', 2016, 1. Available online: https://www.sbl-site.org/ assets/pdfs/CUREMP_25th_Anniv.Society_Report_final.pdf (accessed 5 April 2017).

5 '25 Years and Counting!', 3. One could rightly ask, I suppose, whether the scenario within a North American organization such as the Society of Biblical Literature should be taken as representative of the field as a whole. In response, I would simply say that, although neither the Society nor its heavily weighted North American membership exhausts the academic study of the Bible across the globe, it remains an inescapable fact that, at an international level, the Society constitutes the largest single professional body as far as biblical studies is concerned, drawing members from all over the world and exercising decisive influence in shaping the discipline far beyond the borders of the United States. Moreover, this dominance of white European scholars in traditionally influential academic bodies and institutions outside the United States such as the British New Testament Conference (BNTC) or the European Association of Biblical Studies (EABS) is, not surprisingly, a remarkably stable phenomenon. 
What I would like to do in this essay is to think about how the discourses and practices of modern biblical studies contribute to the startlingly lop-sided demographics we find so prevalent. I want to look at the ways in which the discipline of biblical studies, in the variety of its present forms, constitutes a racialized arena of inquiry. Unless we make fundamental changes to our practices and habits of thinking, I argue, the demographics will remain as they are at present, rendering null our expressions and hopes of greater inclusivity in the discipline's future. As for how we might change, I will return to Lorde for wisdom on this matter.

\section{The historico-geographical legacy}

To begin, I want to consider how biblical studies as a discipline is heir to a specific historico-geographical legacy - a temporal and spatial particularity that is inextricably connected to the question of race. The time is the sixteenth century and the space is Europe.

As both Jonathan Sheehan and Michael Legaspi have recently demonstrated, modern biblical studies emerged as an academic discipline in post-Reformation Europe owing to a theological - and sociopolitical - crisis. ${ }^{6}$ The fierce disputes over the interpretation of the Bible between Catholics and the Reformers - as well as among the Reformers themselves - that coalesced during the Reformation period had a twopronged effect in the ensuing decades. First, these divergent interpretations not only shattered an earlier theological consensus, but also destabilized the status of the Bible as revelatory scripture. The scandal of disagreement over how texts were to be understood made it increasingly difficult for Christians of any confession to claim that the Bible could be reliably interpreted. This tumult in meaning was linked, quite paradoxically, to a second effect: what Legaspi terms the 'textualization' of the Bible - that is, an intensified focus on the Bible as a textual object. ${ }^{7}$ Because the controversies of the age transformed the Bible into a heated site of theological contest, its textual purity and material integrity as an authoritative source became paramount. As such, the Bible became increasingly conceived as text qua text, independent of the Church's authority to accord it with authoritative status as 'scripture.' The more intense the disagreements over the Bible's meaning, the more rigorous the attempts to construct its textuality without recourse to the authority of the Church. This reflected, no doubt, the burden placed by the Reformers on the Bible to become an authority in itself, distanced from the regulatory powers of ecclesial hierarchies.

To illustrate these points, I will cite one example, borrowed from Legaspi. ${ }^{8}$ Among the points of contention during the Reformation was whether or not the pointing of the Masoretic Hebrew text constituted 'tradition' rather than 'scripture. The French Catholic priest Jean Morin (1591-1698) argued that the Jews had intentionally

6 Jonathan Sheehan, The Enlightenment Bible: Translation, Scholarship, Culture (Princeton, NJ: Princeton University Press, 2007); Michael C. Legaspi, The Death of Scripture and the Rise of Biblical Studies (Oxford Studies in Historical Theology; Oxford: Oxford University Press, 2010).

See esp. Legaspi, Death of Scripture, 18-25.

Legaspi, Death of Scripture, 19-21. 
corrupted the Hebrew text, such that correct interpretation was only possible on the basis of the Septuagint and the Vulgate, versions faithfully preserved by the Church. In this line of argumentation, therefore, the Church was the guarantor of right reading and thus of revelation itself. In rebuttal, however, the Reformed theologian Louis Cappel (1585-1658) argued that textual variants did not ultimately compromise the integrity of the Bible as divine revelation, since the clarity of its meaning could be established by restoring the authentic text by means of sound textual criticism, as well as rigorous interpretation of said text by a well-trained interpreter. In Cappel's schema, therefore, the philologist, not ecclesial authority, guaranteed scripture's reliability and perspicacity. While they were aimed at establishing correct interpretations of the divine word, debates such as this underscored the Bible's volatile textuality in unprecedented ways.

Both the destabilization of the Bible's meaning and heightened focus on its textual nature, in turn, took place alongside a series of bloody religious conflicts and wars that were occurring in a religiously fragmented, increasingly sectarian Europe. The need thus arose for a way to read the Bible that would, it was hoped, arbitrate these violent disputes and put an end to religious turmoil. To this end, textual criticism and philological study became key. The idea was to deploy these tools to recover the true meaning and so mend confessional discord - a sentiment reflected in Joseph Scaliger's (1540-1609) dictum: 'Religious discord depends on nothing except ignorance of grammar.' The publication of polyglot Bibles may be taken as indicative of the spirit of the age: They not only made available the biblical texts in their original languages, but also furnished these with other ancient translations for comparison, copious annotations, lexica, and scholarly prefaces. By supplying the scholar with unprecedented tools, these editions were part of an initiative to forge an 'ecumenical, methodologically transparent mode of interpretation. ${ }^{10}$

The science of biblical interpretation in early modern Europe, then, was aimed ultimately at irenicism. By the second half of the eighteenth century, the project of biblical interpretation and its goal - to create a unified Europe by healing exegetical disputes that lay at the heart of religious conflict - had been incorporated into the institution of the university (iconically, Legaspi argues, at the University of Göttingen). The non-confessional, academic study of the Bible was thus born. In this brief outline of its genealogy, we can already see two contours that remain prominent today: Philological expertise coupled with passionate commitment to dispassionate reading.

At this juncture we can sketch another intersecting line of development - one which situates the emergence of biblical studies within the highly racialized world of early modern Europe. Colonial expansionism meant that European societies encountered difference in unprecedented ways, contributing to the emergence of 'race' as a primary category of social classification. Societies of the conquered and colonized were theorized into an evolutionary schema in which their civilizational inferiority

9 'Non aliunde discordiae in religione pendent quam ab ignoratione grammaticae.' Cited in Herbert Jaumann, Critica: Untersuchungen zur Geschichte der Literaturkritik zwischen Quintilian und Thomasius (Leiden, New York and Köln: Brill, 1995), 138. The translation is from Legaspi, Death of Scripture, 22.

${ }^{10}$ Legaspi, Death of Scripture, 23. 
was explained in terms of genetic inferiority, a primary indicator of which, in many instances, was skin colour. This racialized way of conceptualizing human difference, so integral to European epistemologies of the time, exercised a decisive influence on how the histories and cultures of non-European peoples were understood. The ways in which biblical texts and biblical history were interpreted were, unsurprisingly, entangled in these distortions.

It is not coincidental, for example, that the work of someone like Johann David Michaelis, a pioneer in Hebrew Bible scholarship at Göttingen and of modern biblical studies as a whole, should evidence explicitly racist orientations. In his quest to study the classical Hebrew, Michaelis simultaneously dismissed his contemporary European Jewish peers as unreliable sources, and turned rather to Arab-speaking communities to inform his study of biblical Hebrew. His rationale for this move was telling: Arabicspeaking communities of his time, he believed, reliably preserved their linguistic and cultural links to biblical times since they had not evolved or progressed since then:

Had we not some knowledge of Arabian manners, we should very seldom be able to illustrate the laws of Moses, by reference to the law of usage. But among a race of people $[$ Arabs] ... ancient manners have maintained themselves so perfectly, that, in reading the description of a wandering Arab, one might easily suppose one's-self in Abraham's tent. ${ }^{11}$

On this point, Michaelis is representative of a strategy which anthropologist Johannes Fabian terms 'allochronism' - the practice of casting another contemporary society into some other, regressive time (what Fabian elsewhere terms 'denial of coevalness'). ${ }^{12}$ This strategy of writing allowed European anthropologists to portray societies of the colonized as barbaric, backward, stuck in the past - sentiments which then justified colonization as a civilizing mission. ${ }^{13}$

Such tendencies remain with us. Michaelis' type-casting of the 'primitive Arab' who is frozen in time, as James Crossley has pointed out, is still operative among some very influential contemporary scholars. ${ }^{14}$ Crossley furnishes concrete examples of how the work of contemporary American scholars, for example, continues to draw from interpretive models that assume the primitivity of the Arab - the same rhetoric that fuels the othering of Arabs/Muslims in American political discourse and foreign policy. In a recent essay, Deane Galbraith draws attention to the ways in which nineteenth-century racialized models of cultural evolution continue to shape contemporary scholarship with regard to Num. $13-14 .{ }^{15}$ By means of a survey of the history of scholarship on this

11 John David Michaelis, Commentaries on the Laws of Moses. Vol. 1, Art. 3, trans. Alexander Smith (London and Edinburgh: F. C. and J. Rivington, 1814), 9-13, at 12.

12 Johannes Fabian, Time and the Other: How Anthropology Makes its Object (New York and Chichester, UK: Columbia University Press, 1983), 25-32, esp. 31-32.

13 See Fabian, Time and the Other.

14 James G. Crossley, Jesus in an Age of Terror: Scholarly Projects for a New American Century (London and Oakville: Routledge, 2008).

15 Deane Galbraith, 'The Perpetuation of Racial Assumptions in Biblical Studies', in History, Politics and the Bible from the Iron Age to the Media Age, ed. James G. Crossley and Jim West (Library of Hebrew Bible/Old Testament Studies 651; London: Bloomsbury T\&T Clark, 2017), 116-34. 
passage, Galbraith argues that 'historical criticism's racially based foundations have become embedded and disguised within what is purported a purely text-based analysis of the spy narrative.' ${ }^{16}$

What I am most interested in in the racialized world in which biblical studies began is not the racial categories themselves, but rather the way in which Europe again and again emerges as the centre of this world, as the pinnacle of progress and learning. New communities encountered in the age of colonialism were mapped in relation to this centre according to different criteria. Skin colour was key, but it was not the only criterion; other physical features (e.g. height), the evolutionary 'stage' of indigenous religions, and the presence of writing, were also part of this matrix of evaluation. To the extent that a people-group reflected qualities which Europeans identified as proper to 'civilization', such a people was 'civilized'. This system of classification, of charting human societies on an evolutionary model, was by no means an innocent project: It was designed precisely to separate and distance non-European societies temporally and spatially from the European metropolis. Fabian writes: 'There would be no raison dêtre for the comparative method if it was not the classification of entities or traits which first have to be separate and distinct before their similarities can be used to establish taxonomies and developmental sequences. ${ }^{17}$ In all this we find an underlying theme of racial ideology: Europe as the canon of civilization, of the measure of humanity itself.

These intersecting lines of inquiry make this much clear: Our discipline began as a project to mend a religiously divided Europe that was at the same time asserting its dominance over the known world. But why, one might ask, focus on this early history of the discipline? Because, I contend, the contours established at this time of origins continue to shape the discipline: Biblical studies at the present time remains a largely European project in which non-European voices remain subordinated as 'other'. The latter can participate under regulated conditions, that is, insofar as they approximate whiteness - the unmarked particularity of the white, European 'norm' that universalizes its own perspective and measures others against it - but always in such a way as to remain on the periphery. ${ }^{18}$ As long as this is true, biblical studies will always have a race problem.

\section{Markers of biblical studies' Eurocentrism}

What are some indicators that biblical studies remains largely European in character? I would like to point to two markers of its particularity. These features do not manifest themselves equally in all branches of the discipline, but they more or less hold true across them.

16 Gallbraith, 'Racial Assumptions', 130 (emphasis original).

17 Fabian, Time and the Other, 27.

18 (For further reflection on 'whiteness' in the context of biblical studies, see Denise Kimber Buell's essay - Eds.) 


\subsection{Assumed canon}

The first marker, and I think the most plainly observable, is the assumed canon of the Bible. I think it is fair to say that the common understanding of what we mean when we say 'Bible' is almost always the Bible of Reformation Europe. As a guild of scholars, when we say 'Bible', we do not usually mean any of the following: the Armenian canon that includes Joseph and Aseneth and the Testament of the Twelve Patriarchs; the Ethiopian canon that is a whole third longer than the Protestant one; the early Peshitta of the Syriac churches with its shorter New Testament of only twenty-two books and not twentyseven; or the Coptic canon which sometimes includes the letters of Clement as well as the Apostolic Constitutions. This implicit but unmarked canon that continues to dominate scholarly focus is not innocent: By privileging one canon - that is, the Protestant one - we already define the boundaries of the discipline in an exclusionary way. The term 'canon' itself may have originated from the term for a straight reed that was used to determine whether other lines were straight or crooked. If we extend this meaning, it becomes obvious that the normative canon we assume in biblical studies is already a loaded construct that determines the rules of the game. A canon not only establishes which texts and questions are 'straight' and which are 'queer', but it also arranges texts in a hierarchy of importance, determining which ones are primary and which are secondary, which are 'core' and which are ancillary. Concretely, it means that the lion's share of our efforts - not to mention funding and publications - are poured into establishing definitive editions of certain texts, exegeting their meaning, and studying their effects or reception.

\subsection{Commitment to objectivity}

The second marker centres on the idea of objectivity. Despite widespread and longstanding acceptance of the notion that all exegesis is shaped by presuppositions, by convictions, and by context, there nonetheless remains a common commitment to the idea that exegesis should be governed, as far as possible, by the ideal of objectivity. In this context, objectivity primarily means the notion that it is possible to ascertain, and that scholarly effort is best exerted to ascertain, what the text actually meant to its original author and/or original readers (i.e. an 'authentic' meaning). This is often contrasted to less 'authentic' meanings assigned to it by later readers such as the institutionalized Constantinian church, medieval scholastics, modern fundamentalist preachers, contemporary political discourse, and so on. The very concept of a text's objective meaning, so crucial to the post-Reformation project, as we have seen, engenders a complex epistemological problem. Aníbal Quijano has argued that the view of knowledge as the relationship between a subject and an object is itself a distinctly, though perhaps not exclusively, European way of construing 'rationality' (from Descartes' 'cogito'?). ${ }^{19}$ For the purposes of this essay, however, I will focus on one particular aspect of objectivity: what it implies about the knowing subject.

In order to discern 'objective meaning', the knowing subject is constructed as someone who is not bound or conditioned by his own subjectivity - the male pronoun here is chosen deliberately, let the reader understand - such that the act of knowing

19 Aníbal Quijano, 'Coloniality and Modernity/Rationality', Cultural Studies 21, no. 2 (2007): 168-78. 
or apprehension takes place independently of his embeddedness in space and time, cultural habits, or social trends. Either that, or he is not decisively impeded by his own subjectivity, as suggested in statements that begin, 'No one can be completely objective, but ... ? What a scholar means when he claims to offer an objective reading - or a reading that is as close to objective as possible - of a biblical text is that, even though he works within a discipline whose methods and boundaries are shaped and delineated by European history and experience, his methods and results are untainted by these parameters, or at least, that they 'transcend' the limits of this particularity. This is not only a matter of the social location of the exegete; it is also about the location of the very paradigms and the tools he applies - tools that have a particular history, originating in a particular time and place and fashioned out of a particular ideology. My point here is

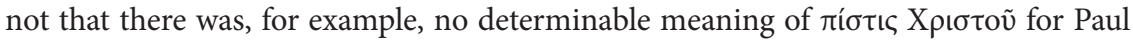
or his recipients; it is simply that our quest for this meaning is already inflected by our situatedness in time and space - and by the whole European cargo of this modern discipline we call 'biblical studies'. The kinds of questions we ask (even who gets to define what is or is not a respectable question), the media by which we ask them, and the tools we use to answer them - all these remain predominantly Eurocentric. To see this more clearly, one only need look to standard introductions to the Hebrew Bible or the New Testament - what they cover, what they omit, and what they identify as 'key issues.

\section{Owning our situatedness}

What happens when we own up to the European situatedness of the discipline? For one, it exposes the forces at work in our production of knowledge, including the temporal and spatial circumstances that animate our quest and mould our answers. If we want to ask how biblical studies can become something more than a discipline dominated by a white elite, we must begin first by looking at how it came to be this way and how existing practices continue to replicate this state of affairs. To ask this is to interrogate the politics of our knowledge - how it continues to draw from roots in its early modern, racialized, colonizing European context. These roots remain influential in numerous ways, including the dynamics of tenure and publication, funding criteria, gatekeeping in professional associations, how we decide which $\mathrm{PhD}$ and postdoctoral proposals get funding, who gets to sit on review committees, how we evaluate job applicants, and so on.

To a significant extent, the 'alternative' criticisms - feminist criticism, postcolonial criticism, minority criticism, contextual Bible study, and soon - have already inaugurated this self-examination. Nevertheless, they are often treated (and labelled) as 'other' such that traditional historical criticism continues to be the mainstay of 'proper biblical studies', its operations left intact despite all other criticisms. ${ }^{20}$ During a

20 For a recent expression of the sentiment that biblical studies has a historical core around which other methods orbit, see Larry W. Hurtado, 'Fashions, Fallacies and Future Prospects in New Testament Studies', JSNT 36, no. 4 (2014): 299-324. For a critique of Hurtado's piece, see Michael Sandford, 'On the Past and Future of New Testament Studies: A Response to Larry Hurtado', Relegere: Studies in Religion and Reception 4, no. 2 (2015): 229-40. 
recent conference lunch that took place after a plenary session on the reception history of a Gospel text among deaf communities, a participant was overheard asking, 'That was interesting, but is it really biblical studies though?' The same question, 'Is it really biblical studies though?', is both explicitly and implicitly asked to those who engage in anything other than traditional historical-critical exegesis. Unless other critical perspectives are allowed to challenge, disrupt, and transform historical criticism itself, biblical studies will remain a Eurocentric project. These 'alternative' voices may be heard, even honoured, but they will never become canonical.

\section{Moving towards interdependence}

But we need, I think, something more than methodological or theoretical inclusivity. The necessary turn, I propose, requires an ethical commitment to the other. At this juncture, I want to return to Lorde's comment that 'the master's tools will never dismantle the master's house. ${ }^{21}$ By this, she did not mean that the master's house will never be dismantled, but that to do so we must use a different set of tools - tools that are not fashioned in the master's workshop. A key aspect of the solution, I believe, lies in what Lorde says about handling difference: not simply by using a different set of methods, but reorienting ourselves towards the different other in a wholly new way. To merely tolerate difference - and here she is thinking not only of differences in approaches to the problem but even more of embodied difference - is to deny its creative function in our lives. It is worth quoting Lorde at length here:

Difference must be not merely tolerated, but seen as a fund of necessary polarities between which our creativity can spark like a dialectic. Only then does the necessity for interdependency become unthreatening. Only within that interdependency of different strengths, acknowledged and equal, can the power to seek new ways of being in the world generate, as well as the courage and sustenance to act where there are no charters.

Within the interdependence of mutual (nondominant) differences lies that security which enables us to descend into the chaos of knowledge and return with true visions of our future, along with the concomitant power to effect those changes which can bring that future into being. Difference is that raw and powerful connection from which our personal power is forged. ${ }^{22}$

For Lorde, difference is not something to be feared. Rather, it is a creative space that allows and enables the emergence of new ways of being, doing, and thinking. If the master's tools of biblical studies have been forged in a worldview where difference is something to be charted so that people can be separated, distanced, and then justifiably

${ }^{21}$ See note 2 and discussion above.

${ }^{22}$ Lorde, 'Master's Tools', 111. See also the essays in Rudolph P. Byrd, Johnnetta Betsch Cole, and Beverly Guy-Sheftall, eds, I Am Your Sister: Collected and Unpublished Writings of Audre Lorde (Oxford and New York: Oxford University Press, 2011), esp. 201-30. Lorde's thinking about difference was essential to her understanding of issues of gender, race, sexuality, and equality. 
subjugated, we need to re-examine them to see if they need to be transformed or jettisoned entirely for a new future to take place, and to focus our energies on new tools (or existing tools from other disciplines) that might take their place.

If we take Lorde's theorizing of difference as a starting point, our very model of knowing changes from one of mastery to one of dependence, from subject-object relation to an intersubjective 'leaning against' one another. In Quijano's terms, 'knowledge' no longer consists in the relationship of subject to object, knower to known, but is rather 'an intersubjective relation for the purpose of something, not a relation between an isolated subjectivity, and that something. ${ }^{23}$ That is, knowledge is no longer something any one person (or scholar) possesses or masters, but an intersubjective seeing/doing together. We become readers and thinkers who depend on each other. The master and his tools have always been premised on the refusal to acknowledge this interdependence. He speaks, rather, the language of control, of domination, of grasping things and people, of necessary disparity. To dismantle this house, or even to abandon it, we must at least begin here.

I have no uniform or universal (!) solution, but I would like to suggest that we think about what it might mean to take this interdependence seriously, both on a personal as well as institutional level, in the way we read the Bible or other sacred texts, or even approach religions as a whole. What, for example, happens to the study of religions when we begin our study of 'religion' not with text or gaze, but with people - that is, if we take as our starting point not a 'sacred text' historically conceived and analysed from the safety of ivory towers and tenured professorships, but conversation and engagement with the living practitioners of the traditions before us? Whom do our mechanisms and institutions of knowledge production include or exclude from the conversation? How might we approach our syllabi, fieldwork, or research papers differently? Beneath all these questions lurks the issue of power: The creative appreciation of difference, and the mutual learning from our differences, cannot take place while certain perspectives and positions hold defining and determinative power, but only when, as Lorde's analogy suggests, the tools of the master are replaced - or, to lean on a biblical metaphor, refashioned into ploughshares and pruning hooks.

If modern biblical scholarship emerged as a way of mending fracture, of managing difference by creating consensus using tools of objectivity, can we reimagine a biblical scholarship that handles difference in wholly new ways, not bound to relations of mastery of tools but rather to interdependent, human relationships? In her critique of the 'master's house' of white feminism, Lorde remarked that its dismantling 'is only threatening to those women who still define the master's house as their only source of support' - that is, those whose livelihoods are dependent on the very structure of domination. Perhaps, then, a good place to start would be for each of us to very honestly consider how our lives are invested in the master's stance towards difference. What if at the heart of our failure as a guild is not the want of tools but want of a generous spirit of interdependence, where difference is not something we fear but rather something we honour for its creative and generative powers?

${ }^{23}$ Quijano, 'Coloniality and Modernity/Rationality', 173. 


\section{References}

Byrd, Rudolph P., Johnnetta Betsch Cole, and Beverly Guy-Sheftall, eds. I Am Your Sister: Collected and Unpublished Writings of Audre Lorde. Oxford and New York: Oxford University Press, 2011.

Crossley, James G. Jesus in an Age of Terror: Scholarly Projects for a New American Century. London and Oakville: Routledge, 2008.

Fabian, Johannes. Time and the Other: How Anthropology Makes its Object. New York and Chichester, UK: Columbia University Press, 1983.

Galbraith, Deane. 'The Perpetuation of Racial Assumptions in Biblical Studies'. In History, Politics and the Bible from the Iron Age to the Media Age, edited by James G. Crossley and Jim West, 116-34. Library of Hebrew Bible/Old Testament Studies 651. London: Bloomsbury T\&T Clark, 2017.

Hurtado, Larry W. 'Fashions, Fallacies and Future Prospects in New Testament Studies'. JSNT 36, no. 4 (2014): 299-324.

Jaumann, Herbert. Critica: Untersuchungen zur Geschichte der Literaturkritik zwischen Quintilian und Thomasius. Leiden, New York and Köln: Brill, 1995.

Legaspi, Michael C. The Death of Scripture and the Rise of Biblical Studies. Oxford Studies in Historical Theology. Oxford: Oxford University Press, 2010.

Lorde, Audre. 'The Master's Tools Will Never Dismantle the Master's House'. In Sister Outsider: Essays and Speeches, 110-13. Berkeley: Crossing Press, 1984.

Michaelis, John David. Commentaries on the Laws of Moses. Volume 1, Article 3, translated by Alexander Smith, 9-13. London and Edinburgh: F. C. and J. Rivington, 1814.

Quijano, Aníbal. 'Coloniality and Modernity/Rationality'. Cultural Studies 21, no. 2 (2007): 168-78.

Sandford, Michael. 'On the Past and Future of New Testament Studies: A Response to Larry Hurtado'. Relegere: Studies in Religion and Reception 4, no. 2 (2015): 229-40.

Sheehan, Jonathan. The Enlightenment Bible: Translation, Scholarship, Culture. Princeton, NJ: Princeton University Press, 2007.

Society of Biblical Literature. Society Report, November 2015. Available online: https:// www.sbl-site.org/assets/pdfs/SR2015_online.pdf (accessed 5 April 2017).

Society of Biblical Literature's Committee on Underrepresented Racial/Ethnic Minorities in the Profession. '25 Years and Counting! Reflecting on the Past and Future of SBL's Committee on Underrepresented Racial/Ethnic Minorities in the Profession', 2016. Available online: https://www.sbl-site.org/assets/pdfs/CUREMP_25th_Anniv.Society_ Report_final.pdf (accessed 5 April 2017). 



\section{Index of Ancient Sources}

\begin{tabular}{|c|c|}
\hline OLD TESTAMENT AND SEPTUAGINT & $27-29 \quad 212$ \\
\hline Genesis & Testament of Issachar \\
\hline $1.1176,177$ & $5.2 \quad 212$ \\
\hline $2-3 \quad 162-3$ & $7.6 \quad 212$ \\
\hline $1084,86,87,88$ & \\
\hline 1184,88 & DEAD SEA SCROLLS \\
\hline $11.1-9 \quad 84$ & \\
\hline $47 \quad 69$ & $1.1-3 \quad 211$ \\
\hline Leviticus & $9-10 \quad 211$ \\
\hline $19.17-18 \quad 214$ & \\
\hline $19.18 \quad 211-12,214$ & NEW TESTAMENT \\
\hline $19.34 \quad 211$ & Matthew \\
\hline 2 Kings & $6.9-13 \quad 186$ \\
\hline 1210 & $8.21-22 \quad 138-9$ \\
\hline $1.1-3 \quad 210$ & $10.5 \quad 209$ \\
\hline 2.1-2 210 & $12.46-50 \quad 188$ \\
\hline $10-14 \quad 210$ & $15.21-28 \quad 179$ \\
\hline $17.6 \quad 87$ & \\
\hline 18.1187 & $\begin{array}{ll}\text { Mark } \\
3.31-35 & 188\end{array}$ \\
\hline Isaiah & $5 \quad 179$ \\
\hline 13.17-18 87 & Luke \\
\hline 21287 & 3.5204 \\
\hline $40.4 \quad 204$ & $4.16-30 \quad 204-5$ \\
\hline Jeremiah & $4.18-20 \quad 205,216$ \\
\hline $13.23 \quad 86$ & $4.24-27 \quad 216$ \\
\hline & $4.25-27 \quad 210$ \\
\hline Tobit & $7.36-50 \quad 213$ \\
\hline $4.17 \quad 211$ & $8.19-21 \quad 188$ \\
\hline Sirach & 9210 \\
\hline $28.4 \quad 211$ & $9.51-10.24 \quad 209,210$ \\
\hline & $9.51-56 \quad 209$ \\
\hline 2 Maccabees & $9.54-55 \quad 210$ \\
\hline $4.36 \quad 63$ & $9.58-10.24 \quad 210$ \\
\hline 4 Maccabees & $9.58-62 \quad 210$ \\
\hline $7.6,22 \quad 61$ & $9.59-60 \quad 138-9$ \\
\hline & $10 \quad 213-14$ \\
\hline OLD TESTAMENT PSEUDEPIGRAPHA & $10.1-24 \quad 210$ \\
\hline & $10.7 \quad 210$ \\
\hline Joseph and Aseneth & $10.8 \quad 210$ \\
\hline 4.961 & $10.25-31 \quad 202$ \\
\hline $8.5-8 \quad 61$ & \\
\hline
\end{tabular}


10.25-37 204, 208, 209, 210

$10.27 \quad 211$

$10.28 \quad 211$

$10.30 \quad 213,214$

$10.34 \quad 213$

$10.36 \quad 208$

12.13-15 213

16.19-31 204, 207

17.11-19 209

$17.18 \quad 212$

17.20-12 213

18.18-23 213

John

4.4-40 209

Acts

$1.8 \quad 209$

2.8-11 188

$8 \quad 214$

8.4-25 209

$13.9 \quad 38$

$14.1 \quad 63$

$15.3 \quad 209$

$18.4 \quad 63$

$19.10 \quad 63$

28.25-28 214

Romans

$1.7 \quad 92$

$1.16 \quad 63$

3.963

$3.22 \quad 93$

8.192

10.1293

$11.26 \quad 108$

11.29108

$12.10 \quad 62$

\section{Corinthians}

1.292

$1.22 \quad 63$

6.292

$10.32 \quad 92$

$11.16 \quad 92$

$11.22 \quad 92$

$12.13 \quad 63$

$15.9 \quad 92$

$15.23 \quad 92$

2 Corinthians

1.192

5.1793
Galatians

$1.13 \quad 92$

$3.28 \quad 93$

$4.10 \quad 64$

$5.24 \quad 92$

6.1593

Colossians

$2.16 \quad 64$

1 Peter

$1.1,17 \quad 68$

$2.9 \quad 68$

2.9-10 92

$2.11 \quad 68$

Revelation

2-3 208

$7.9 \quad 208$
$7.9-17$

7.9-17 204, 207

7.13-17 207

EARLY CHRISTIAN LITERATURE

Athenagoras

Leg. $1 \quad 67$

Clement of Alexandria

Protr.

$11.112 \quad 63$

Stromata

$5.14 .98 \quad 70$

6.5.41 101

Eusebius

Hist. eccl.

$4.26 .5 \quad 62$

Letter to Diognetus

162

$1.160,61,63$

1.261

$2.161,63$

$2.7 \quad 63$
3.1

$3.161,63$

$3.361,64$

$4.161,63$

4.561

$4.661,63$

$5.160,65$

$5.560,65-66$

5.11-17 61

$6.4 \quad 61$ 


\begin{tabular}{|c|c|}
\hline $6.5 \quad 61$ & $2.282-4 \quad 64$ \\
\hline 6.961 & $2.289 \quad 48$ \\
\hline 7.163 & $2.293-4 \quad 68$ \\
\hline $11.1 \quad 61$ & \\
\hline $12.1 \quad 61$ & War \\
\hline $12.8 \quad 61$ & $\begin{array}{ll}1.17 & 63 \\
1.94 & 63\end{array}$ \\
\hline Origen & $7.100-111$ \\
\hline Contra Celsum & Philo \\
\hline $5.35 \quad 67$ & Agr. \\
\hline $8.55 \quad 101$ & $64-5 \quad 69$ \\
\hline $\begin{array}{l}\text { Tertullian } \\
\text { Nat. }\end{array}$ & $\begin{array}{l}\text { Legat. } \\
19469\end{array}$ \\
\hline $1.20 \quad 101$ & \\
\hline $1.8 \quad 60$ & Vit. Mos. \\
\hline Scorp. & $2.51 \quad 69$ \\
\hline $10 \quad 60$ & GRECO-ROMAN LITERATURE \\
\hline JEWISH LITERATURE & Apollonius of Tyana \\
\hline Josephus & Epist. \\
\hline Antiquities of the Jews & 7166 \\
\hline $4.134-8 \quad 67$ & Arrian \\
\hline $16.160-78 \quad 67$ & Anab. 7.26.2 40 \\
\hline $18.257 \quad 63$ & Cassius Dio \\
\hline $\begin{array}{ll}20.17-96 & 9,50-2 \\
20.34-35 & 50\end{array}$ & $68.32 \quad 63$ \\
\hline $20.263 \quad 66$ & Roman History \\
\hline Apion & $37.16-17 \quad 67$ \\
\hline $1.6-56 \quad 48$ & Cicero \\
\hline $1.60 \quad 48$ & Flac. \\
\hline 1.7263 & $67 \quad 64$ \\
\hline 1.10348 & \\
\hline 1.13248 & Nat. $d$. \\
\hline $1.174 \quad 48$ & $2.154 \quad 39$ \\
\hline $1.179 \quad 47$ & Dionysius of Halicarnassus \\
\hline $1.180 \quad 47$ & Ant. rom. \\
\hline $1.210 \quad 48$ & $11.16,18 \quad 69$ \\
\hline 1.21248 & Epictetus \\
\hline $1.224 \quad 48$ & Diatr. \\
\hline $1.319 \quad 48$ & $2.10 .3 \quad 69$ \\
\hline $2.30 \quad 46$ & $4.1 .70-71 \quad 68$ \\
\hline $2.37 \quad 46$ & \\
\hline $2.38 \quad 46$ & Galen \\
\hline $2.165 \quad 48$ & De santitate 6.5170 \\
\hline $2.193-98 \quad 48$ & Herodotus \\
\hline $2.210 \quad 47$ & $\begin{array}{ll}1.57 .3 \quad 27\end{array}$ \\
\hline $2.261 \quad 47$ & $1.135 \quad 28$ \\
\hline $2.277 \quad 48$ & $1.146 \quad 28$ \\
\hline
\end{tabular}


$1.171 \quad 28$

$1.171 .2 \quad 27$

$2.42 \quad 40$

2.49-50 28

$2.51 \quad 27$

2.51.1-2 27

$2.109 \quad 28$

$2.156 \quad 40$

$2.171 .3 \quad 27$

$4.189 \quad 28$

$5.37 \quad 28$
5.49

$5.49 \quad 30$

$6.1 \quad 28$

$7.62 \quad 28$

Livy

39.8-18 24

Hist

39.13.14 60

Lucian

Peregrinus

2368

$33 \quad 68$

Scyth. 366

Ovid

Fast

2.683-4 69

Pliny

Ep.

$10.9660,64,101$

Nat.

2961
Plutarch

Alex.

$76 \quad 40$

Cam.

1.267

Per.

20.165

Publ.

$6.6 \quad 67$

Strabo

Geogr.

1.2.34 66

Suetonius

Nero

$\begin{array}{ll}16 & 101\end{array}$

16.260

Tacitus

Ann.

$15.44 \quad 64,101$

Hist.

5.5.2 64,67

Thucydides

$1.4 \quad 27$

$\begin{array}{ll}2.39 & 29\end{array}$

$2.41 \quad 29$

Vergil

Aen.

$8.321 \quad 61$ 


\section{Index of Modern Authors}

Abesamis, Carlos H. 14, 192, 194

Adamson, Fiona B 126

Ahmed, Sara. 4 n.16, 12, 13, 150 n.6, $151,159,160,164$

Al-Afghani, Jamal al-Din 117

Alexander, Michelle 215 n.53

Anderson, Victor 161

Andrade, Nathanael 26

Anidjar, Gil 158 n.31

Appasamy, Aiyadurai Jesudasen $157 \mathrm{n} .28$

Arendt, Hanna $\quad 22,97 \mathrm{nn} .21,141$

Arnal, William 134, 142

Back, Les 150 n.6

Bailey, Randall C. 203

Baldwin, James 163,164

Bangstad, Sindre 120 n.34, 123

Barclay, John M. G. 9, 15

Barreto, Eric D. 188 n.19

Bartels, Adolf 99

Barth, Fredrik 49, 106

Benedict XVI $186 \mathrm{n} .15$

Berg, Hallgrim 123

Bernasconi, Robert 152, 153 n.16

Bird, Michael F. 131, 137

Blount, Brian K. 203

Bohak, Gideon 37

Bohannan, Laura $\quad 13,168-71,173,180$

Böhm, Martina $\quad 45,212 \mathrm{nn} .44$

Boon, Jessica A. 188 n.23

Bormann, Lukas $\quad 106,107,108$

Bourdieu, Pierre 81,151

Breivik, Anders Behring 11, 12, 113, $119,121-3,126$

Brett, Mark G. 4 n.17

Brodkin, Karen 158 n.31

Brown, Michael Joseph 203 n.6

Brubaker, Rogers 4 n.13, 4 n.17, 5 n.19, 6 n. 28,16 n. 35
Buell, Denise Kimber 3, 4 n.16, 10, 12, 13, 16, 17, 30, 50 n.15, 69, 149 n.2, $157 \mathrm{nn} .28$

Byron, Gay L. 149 n.2, 154, 159

Calano, Mark Joseph 187 n.16

Carroll, Robert P. 24

Carter, J. Kameron 153 n.17, 161

Cartledge, Paul 23

Casey, Maurice 132

Cave, Sydney 156,157 n.28

Chamberlain, M. E. $\quad 98,100,132$

Clark, Elizabeth A. 156

Clarysse, Willy 33

Cohen, Shaye J. D. 16, 49, 50, 50 nn.15, $53,54,55,104$ n.49

Collins, Patricia Hill 215 n.53

Comaroff, Jean 26, 173 nn.25

Comaroff, John $\quad 26,173$ nn.25

Conradie, Ernst 185

Constantino, Letizia R. 184 n.4

Constantino, Renato $184 \mathrm{n} .4$

Crossley, James G. 12, 16, 223

Curtis, Mark 135

Doke, C. 172

Driver, Samuel Rolles 10,75-89

Dube, Musa W. 13, 17

DuBois, W. E. B. 202, 202 n.3, 217

Dunkley, Charles 75

Dunn, James D. G. $\quad 12,130,135$, 136 n.32, 137 n.39, 138, 142

Dyer, Richard. 17 n.37

Eckhardt, Benedikt 107 n.64

Ehrensperger, Kathy $3,10-11,16$, 103 n. 47

Eliav-Feldon 149 n.2

Enriquez, Virgilio G. 187

Esler, Philip F. 50 n.15 
Fabian, Johannes 223-4

Fein, Helen 120

Finkelstein, Norman 134

Fowler, Richard 26

Fraser, Peter Marshall $\quad$ 25, 26, 37

Fredriksen, Paula. 7

Frye, Matthew Jacobson 158 n.31

Galbraith, Deane 223-4

Gerdmar, Anders 97 n.21

Gilman, Sander 157 n.30

Gilroy, Paul 85

Goldberg, David Theo 136, 139, 142-3

Gourgues, Michel 212

Graham, Helen R. 55 n.35, 192

Green, Joel B. 37, 209 n.23, 211 nn.35

Grundmann, Walter 99-100, 132

Hall, Edith 23

Hall, Jonathan M. 23, 24, 25, 28, 29

Harnack, Adolf von 11, 95, 100, 101

Harrison, Peter 153 n.17

Hengel, Martin 138, 139

Herder, Johann Gottfried $11,95,96,97$, 98, 99

Heschel, Susannah 99 n.31

Hickman, Jared 153 n.17

Hidalgo, Jacqueline M. 154, 163 n.48

Horrell, David G. 149 n.1

Hutchinson, John 5-6, 48 n.7, 56

Ibita, Ma. Marilou S. $\quad$ 13-14, 17

Isaac, Benjamin 103 n.48

Jennings, Willie James. 153 n.17

Johnson, Luke Timothy 37, 140, 141 n. 57, 209, $211 \mathrm{nn} .36$

Johnson, Sylvester A. 105,157 n.30

Jones, Steve 4

Judge, Edwin. A. 92 n.1

Käsemann, Ernst 132

Keane, Augustus Henry $\quad 85,88$

Kelley, Shawn 113 n.2, 136 n.32

Kidd, Colin 153 n.17

King, Martin Luther, Jr. $\quad$ 14, 202, 204, 217

Kraus, Wolfgang 99 n.31

LaGarde, Paul 97, 98 n.26

Legaspi, Michael C. 221, 222
Lessing, Gotthold Ephraim 96

Levine, Amy-Jill 189

Lieu, Judith M. 9, 10, 15

Lincoln, Bruce 153 n.17

Lindsey, Hal 135

Lischer, Richard 204

Lorde, Audre $14,15,17,192,197,219$, 220, 221, 227, 227 n.22, 228

McCoskey, Denise Eileen 4 n.16, 149 n.2

Malette, Karla 114, 126

Malkin, I. 106

Malkin, Irad 106

Mason, S. 56 n.37

Meer, Nasar 2

Meier, John P 134

Mgadla, Part Themba 174

Michaelis, John David 223

Mitchell, Claire 1

Moffat, Robert 13, 25, 168, 172, 173 n.24, 174,175 n. $31,176,177,178,179,180$

Morgan, Catherine 23

Morgan, Teresa $8-9,15$

Moxnes, Halvor $3,11,12,16$

Nongbri, Brent $\quad 7,51$ n.17

Noss, Phillip A. 180, 181

Novick, Peter 134

Öhler, Markus $\quad$ 105, 106

Olender, Maurice 153 n.17

Paganini, Mario $\quad 37,40$

Patel, Vimal 153 n.16

Peppard, Michael 36

Perkinson, James 153 n.17

Powery, Emerson 17 n.38, 203 n.8

Priest, Robert D. 120 n.38

Priester, Karin 104

Quijano, Aníbal 225, 228

Rajak, Tessa 37

Renan, Ernest $\quad 11,12,99,113-21,126$

Rodinson, Maxime 119 n.31

Roediger, David R. 158 n.31

Roth, Jonathan P. 104 n.49

Said, Edward W. $\quad 37,83,114,120$ nn.35

Sanders, E. P. $12,130,131$ 
Sandford, C. Waldergrave 77

Sandford, Michael 226 n.20

Sayce, Archibald Henry $\quad 80,81,84$, 87,88

Schermerhorn, Richard A. 5, 6

Schofield, Malcolm 39

Schüssler Fiorenza, Elisabeth 163 n.48

Schwartz, Daniel R. 36, 37, 48 n.6, 53 n. 24,54 n. 30,55 nn.33

Schwartz, Seth $51,51 \mathrm{n} .18$

Sechrest, Love L. 5 n.22, 14, 16-17, 208 n. 20

Sedley, David 39

Sheehan, Jonathan 221

Smith, Anthony D. 5-6, 48 n.7, 56

Smith, Jonathan Z. 7

Smith, Mitzi 203 n.6

Smith, Wilfred Cantwell 7

Snodgrass, Klyne 210 n.27, 212 n.44, 213 n. 47

Spencer, F. Scott 213 n.46, 214 n.49

Stanley, Christopher D. 98, 105

Stavrianopoulou, Eftychia 31

Stegemann, Wolfgang 105

Storm, Ingrid 2 n.6

Stowers, Stanley 98, 105

Streeter, Burnett Hillman 157 n.28

Strootman, Rolf 32

Sugirtharajah, R. S. 193 n.42
Tannehill, Robert C. 209 n.23, 210 n.29

Thiessen, Matthew 52 n.19

Thompson, Dorothy J. 33

Todorov, Tzvetas 115 n.11

Treitschke, Heinrich von 99 n.32, 100

Tuor-Kurth, Christina 105

Tylor, Edward 85

Vermes, Géza $\quad 133,135,136$

Viswanathan, Gauri 157 n.30

Volz, Stephen C. 174

Ware, Vron 150 n.6

Watson, Francis B. 137

Weber, Gregor 5

Weber, Max 5 n.20

Webster, Phillip 159, 160

Wimbush, Vincent 163 n.48, 203

Wolter, Michael 105

Woolf, Greg 41

Wright, N. T. $12,130-2,135,137$, 138-42, 141 n.57, 142

Yamada, Frank 162, 163

Yancy, George 150, 161

Young, Stephen L. 138

Yoyotte, J. 35

Žižek, Slavoj 136, 142 


\section{Index of Subjects}

Africa $1,82,85,86,122,150,172$, 174,207

African-American hermeneutics/biblical interpretation $14,16-17,17$ n.38, $157,202-4,215-17$

Alexander the Great $8,29-30,32,39$, 107 n. 64

Alexandria $33-4,37,40,46,52,63$, $69-70,160$

American colonization 188

American politics 132, 135, 215

America/United States/US 12, 14, 16, 76, $82,85-6,120$ n.40, 123, 129, 134, $135,142,150,152,153$ n.18, 154-5, $158,162,163,164,205,206-7,208$, 214-16, 220

analogy, in biblical interpretation 14,17 , $78,95,103,106,114-15,118,160$, $202-5,207-8,212-16,228$

ancestry $30,51,56,62,161$

ancestor figures and $13,27,48$, 52 n. $20,88,164,179$

DNA-based tests $4-5$

shared descent and $48-50,52-3,55$

anti-racism. See racism and anti-racism

anti-Semitism/antisemitism 1-2, 14, 54-5, 98 n.24, 99-100, 113, 114, 120, 120 n. $38,124-5,127,134,142,189$

Arab(s) 11, 33-4, 37, 47, 66, 114, $116-19,121,135,223$

Aryan Jesus 99, 132

ascribed identity $49,60117-18,125$

Asia 28 n.22, 47, 65, 82, 84-5, 122, 189, 191, 194

Asian Americans 155, 215

Asian hermeneutics/biblical interpretation 155,193 n.42

assigned identity $8-9,32-4$

Australia 14, 85-6, 150, 191, 195

Batswana people $13,168,171-81$

Belgium 14, 195 belonging 52,53 n.22, 59, 63, 68, 105-7, $157,159-61,184,197$

biblical criticism $\quad 75,77,83-9,203$

biblical studies $114,153-6,163,181$, 220 n. 5

Christian identity in 13

European origins of modern

discipline $3,10,220-7$

methodology (dominant) 15, 17, 115, $127,184-6,193$

Black(s) 3, 14, 16, 202, 205-7, 209, 215

Black Lives Matter campaign 1 , 208 n. 20

as racialized identity $1,10,85,150-1$ body

Christian 66, 68, 85, 159-61

habituated 151-2, 156, 159

Botswana 168 n.2, 175 n.31

Britain/British 12, 76-7, 79-81, 95, 97 n.22, $117,130-1,135,142,150,155,172$

British politics 131,134

Catholic/Catholicism 13, 158, 161, $184,186-7$

Filipino 13-14, 183-97

identity $13,184,193,195,197$

schools 14,195

Christianoi (Xpıбıаvoi) 92, 95, 101-2

Church Congress meetings $10,75-8$

Church of England (Anglican

Church) $10,77-8$

The Church of England Pulpit and

Ecclesiastical Review 75

citizen/citizenship $8,24,26-7,31-3$, $37,39,46,65-6,68-9,71,107,153$

n. $18,157,171,214$ n. $50,215,220$

civil rights $122,157,203,206,208$

Clement of Alexandria 13, 39, 159

code-switching 8-9,34-8, 41

colonialism 150, 157, 172, 173 n.25, 224

cultural 13

European 3 
colonization 187,223

American 188

Spanish 184,188

contextual reading (of Bible) 203, 226

cosmopolitanism 9, 39

cultural complexity $12,16,40,127-8$

cultural hybridity 36

customs. See way of life

Darwinian evolution 78

dialogical method/approach $14,17,183$, 193, 195, 197

Dialogue School 14, 195

diversity $17-18,41,59,88,95-6,106$, $108,128,130,155,164,195,220$

Egypt/Egyptian 24-6, 28-9, 33-7, 40-1, $46-7,49,52$ n.20, 55, 69-70, 82, 86, 188,206

essentialism/essentialist $\quad 118-20$, $125,140-2$

ethnic fluidity $8-9,15-16,50$ n.15, 61, 122, 159, 185

ethnic hybridity 36

ethnicity(ies) passim

and code-switching $\quad 34-8$

concepts and theories $2-7,10,23,25$, 27-8, 96, 103, 105, 121, 149, 171,

193 n. $42,222,227-8$

in culture, philosophy, and religion $38-41$

fluidity of $8-9,15-16$

multiple $8-9,35-7$

ethno-nationalism 122

ethnos (है $\theta$ voc) 24 n. $4,25,48,51,52$ n. $21,56,66,67,92,95,103,106-7$, $109,159,161,190$

Eurocentrism $3,15,17,171,203,226-7$

Europe $3-4,10,12,15,17,84,86-7$, $115-23,125-6,143,150,155-7$, $189,220-2,224-5$

European

civilization $115-18,121$

colonialism 3,7

ideals 11

identities 11

Reformation 15, 221, 225

traditions of biblical scholarship $\quad 10-12$

Western context $78,82-3,88$

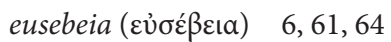

evolution

cultural 223

Darwinian 78

human 84

far-right politics 121

feminism/feminist 151, 154, 163 n.48, $164,219,226,228$

fictive kinship $\quad 5,186-7$

Filipino Catholics. See under Catholic, Filipino

First World War 99, 141

genos ( $\gamma \varepsilon ́ v o \varsigma) / g e n u s \quad 10,25,41,48,50$, 60-2, 69-70, 92, 95, 101-3, 106, $109,159,161,190$

Germany/German 1, 3, 12, 76-7, 79, 81, $82,98,156,180$

National Socialism in 11,99

New Testament interpretation $\quad 104-8$

Protestantism 102

scholarship $\quad 16,94-5,100,109,134$

'Volk' 96

Greek identity/Greekness 26 n.13, 28, $31,35,37,38$ n. $65,66,69$

Hellenism/Hellenistic 8-9, 26-41, 49-50, 65, 69, 133, 141

hermeneutics $17,86,88,94,183$, 189-97, 202-3

Higher Criticism 10, 75-82, 88, 156

Historical Criticism/historical-critical method $17,161,224,226-7$

Historical Jesus $115,127,132-5,142$

Holocaust 12, 127, 134, 189

hybridity $36,41,122$

identity(ies)

accretive $8,15,29,35,37$

Catholic/Catholicism 13, 184, 193, 195, 197

Christian, in biblical studies 13

construction of $1,8,12,133$, $140-2,149$

essentializing of $11-12,16,126$, $133,141-3$

Greek 26 n.13, 28, 31, 35, 37, 38 n.65, 66,69

Jewish 1, 12, 27, 94, 100, 127, 131-4, 140-2, 188-90, 211 


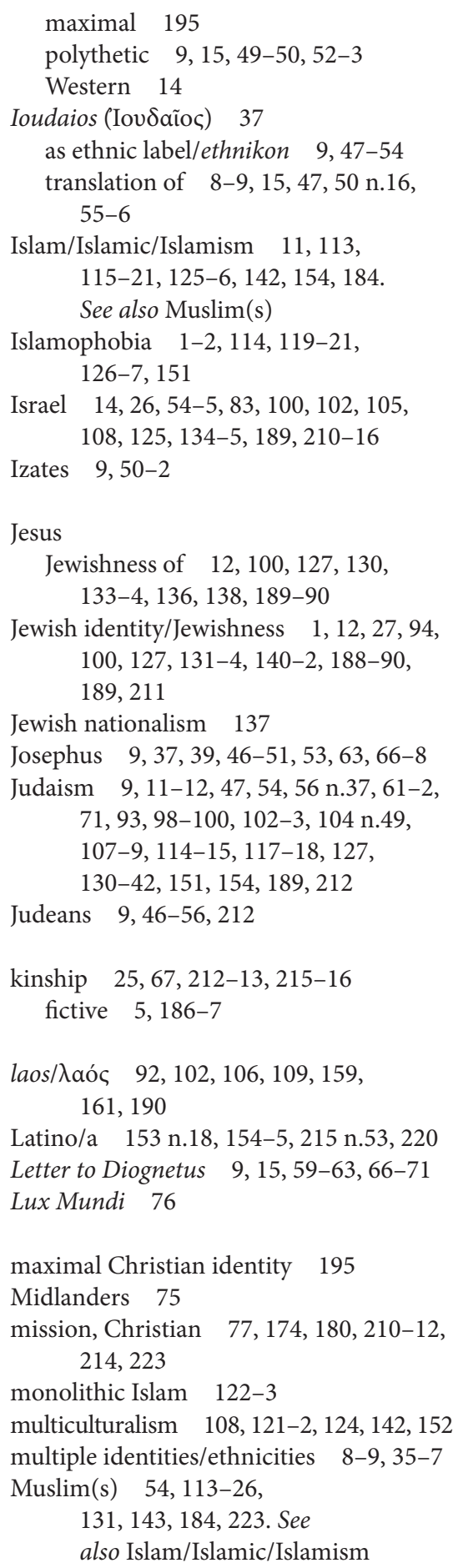

maximal 195

polythetic $9,15,49-50,52-3$

Western 14

udaios (Iov反aĩos) 37

as ethnic label/ethnikon 9, 47-54

ranslation of $8-9,15,47,50$ n.16, $55-6$

115-21, 125-6, 142, 154, 184.

$126-7,151$

Israel $14,26,54-5,83,100,102,105$, $108,125,134-5,189,210-16$

Izates $9,50-2$

Jesus

wishness of $12,100,127,130$, identity/Jewishness $1,12,27,94$ $100,127,131-4,140-2,188-90$, 189,211

Jewish nationalism 137

Josephus $9,37,39,46-51,53,63,66-8$ 71, 93, 98-100, 102-3, 104 n.49, $107-9,114-15,117-18,127$, $130-42,151,154,189,212$

Judeans 9, 46-56, 212

kinship $\quad 25,67,212-13,215-16$

fictive $5,186-7$ 161,190

Latino/a 153 n.18, 154-5, 215 n.53, 220

Letter to Diognetus 9, 15, 59-63, 66-71

Lux Mundi 76

maximal Christian identity 195

Midlanders 75 214,223

monolithic Islam 122-3

multiculturalism $\quad 108,121-2,124,142,152$

multiple identities/ethnicities $\quad 8-9,35-7$

131, 143, 184, 223. See

also Islam/Islamic/Islamism

and Breivik, Anders Behring 119-21

image of contemporary 114-15

Norwegian anti-Muslim positions 123-4

objections to Renan 117

parallels between Jews and 118-19

narrative criticism $\quad 14,196$

nation $7,48,51-2,66-8,87,94,97$, $101,124,127,131-2,136,142-3$, 206-8, 216

nation(s) 7, 48-9, 51-2, 60-1, 66-8, 67, $82,84,86,87,94,97,101,116,121$, $124,127,131-2,136,142-3,178$, 186, 206-8, 216

nationalism 97 n.21, 131-2, 136, 138,141

ethno- 122

Jewish 137

National Socialism See Germany, National Socialism in

Nazi/Nazism 1, 99-100, 121-2, 132-3, 142

neoliberalism 12, 132, 136-8

New Perspective on Paul 12, 130-2, 136-8, 142, 156

Nigeria $13,168,172$

Norway/Norwegian $11,113,119-26$

oral tradition/culture $\quad 179-80$

Orientalism/Orientalist $10,79-80,82-3$, 86, 113-14

Pasyon 13, 188-90

Philippines 13-14, 183-5, 188-97

physiognomy $86-8,160$

polythetic identity $9,15,49-50,52-3$

postmodernism $132,134,136,138,142$

poverty $122,204-8,216$

Protestantism 1, 2 n.6, 15, 98, 102, 137, $139,157,161,225$

race passim anthropology of 83-5 concepts and theories 2-7 hierarchy of 84-6 ideologies of $8,10,12$ post-racial views of 131-3 racial differences and 84-9 
racism and anti-racism $2-4,16,89$, 98-100, 103-4, 114, 121-2, 151-2, $161,171,203-5,208$

Rasse/race 3, 11, 16, 94-5, 97, 102-3

Reformation. See European

Reich 96, 103

Second German 97-8, 99 n.32, 100

Third Reich 93, 95, 97

religion passim

concepts and theories $\quad 2-7$

ideologies of 8,10

post-racial myth of 138

Roman Empire $\quad 26,37,65,96,149$

science $3,10,23,38,81-3,87,119,222$

Islamic $11,115-18,121$

progress in 85,117

Western $78-9,83,86,88$

Second World War 12, 122, 124, 127, $132,141,162-3,205,215$

secularism $116-17,137-8$

Setswana

Bible 13, 168, 171-5, 177-81

language 168 n.2, 175-8

shared descent. See ancestry

Shoah. See Holocaust

social practice. See way of life

Society of Biblical Literature 153, 155, 163 n. 48,191 n. $33,197,220$

Spanish colonization 184,188

status $17,40,53,81,102,107$ n.64, 150, 160, 162, 187 n.16, 212 n.14, 214 n. $50,215,221$

legal $8,37-8$

Macedonian 33,35

$\operatorname{tax} 32-4,37$ stereotypes $11-12,63,104,113,119-20$, $123,125,128,130,215$ n.53

syncretism/syncretist $28,40-1$

territory $6,8,23-4,27-8,30,37,47-8$, $52-3,55,141,209-11$

theosebeia $(\theta \varepsilon$ coбé $\beta \varepsilon เ \alpha) \quad 61-3,65,71$

translation

of Bible/biblical 13, 17, 168, 171-5, $174,177-8,180-1$

Volksgeist 95, 97

Volk/völkisch 11, 94-103

way of life $6,10,71,137$

Western identity 14

Western science See science, Western

white/whiteness 2 n.6, 15-17, 121-2, 124, 149-55, 157-64, 176, 205, 207, 209, 215, 219-20, 224, 226, 228

bifurcation of 3

Caucasian 85

exploitation of black Africans by 1

humanity $86-7$

notion of $12-13$

racial and religious assumptions of 8

supremacy 89

unarticulated 150

womanist interpretation 203, 208 n. 20

World War One. See First World War

World War Two. See Second World War

xenophobia $103-4,124,215$ 
